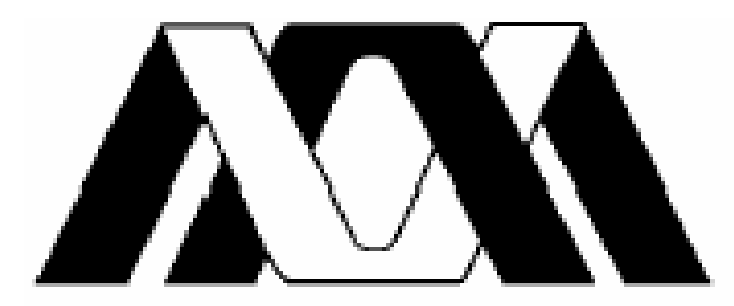

Casa abierta al tiempo

UNIVERSDAD AUTONOMA METROPOLITANA

UNDAD IZTAPALAPA

DIVISIÓN DE CIENCIAS BIOLÓGICAS Y DE LA SALUD

\title{
ELIMINACIÓN SIMULTÁNEA DE AMONIO Y 2-CLOROFENOL: ANÁLISIS CINÉTICO Y MOLECULAR
}

\author{
TESIS \\ QUE PARA OBTENER EL GRADO DE \\ DOCTOR EN BIOTECNOLOCIA
}

PRESENTA:

M. en B. MIGUEL ÁNGEL MARTÍNEZ JARDINES

DIRECTORA:
Dra. FLOR DE MARIA CUERV

9 DE OCTUBRE DE 2020 
Esta tesis se llevó a cabo en el Laboratorio de Fisiología Microbiana W-004 del Departamento de Biotecnología de la Universidad Autónoma Metropolitana unidad Iztapalapa, gracias al apoyo otorgado por el Consejo Nacional de Ciencia y Tecnología con el proyecto CB-2015-01-255740, la Universidad Autónoma Metropolitana y el Consejo de la División de Ciencias Biológicas y de la Salud de la UAM-Iztapalapa.

El Doctorado en Biotecnología de la Universidad Autónoma Metropolitana unidad Iztapalapa está inscrita en el marco del Padrón Posgrado de Excelencia del Consejo Nacional de Ciencia y Tecnología. 
Iztapalapa, CDMX. a 9 de octubre de 2020

El H. Jurado designado por la División de Ciencias Biológicas y de la Salud de la Universidad Autónoma Metropolitana unidad Iztapalapa

\title{
ELIMINACIÓN SIMULTÁNEA DE AMONIO Y 2-CLOROFENOL: ANÁLISIS CINÉTICO Y MOLECULAR
}

\section{M. en B. Miguel Ángel Martínez Jardines}

\author{
Comité tutorial \\ Dra. Flor de María Cuervo López \\ Directora, UAM-Iztapalapa \\ Dra. Anne Claire Texier \\ Asesor, UAM-Iztapalapa \\ Dr. Sergio Martínez Hernández \\ Asesor, Universidad Veracruzana
}

\author{
H. Jurado \\ Presidenta: Dra. Anne Claire Texier \\ Secretario: Dr. Sergio Martínez Hernández \\ Vocal: Dr. Guillermo Quijano Govantes \\ Vocal: $\quad$ Dr. Elie Girgis El Kassis
}




\section{AGRADECIMIENTOS}

Agradezco a la Dra. Flor de María Cuervo López por la dirección, asesoría y revisión de este trabajo. Después de varios años de arduo trabajo solo me queda dar infinitas gracias por su profesionalismo, paciencia, dedicación, consejos y el tiempo invertido en mi formación.

A la Dra. Anne Claire Texier y al Dr. Sergio Martínez Hernández por su asesoría, colaboración a este trabajo, sus sugerencias, disposición, críticas constructivas y el tiempo invertido en la revisión de la tesis.

Al jurado que revisó esta tesis por sus comentarios y sugerencias.

Por último, unas líneas no serían suficientes para mencionar a todas las personas que han aportado, ayudado y colaborado en este trabajo directa o indirectamente, para no dejar a nadie fuera solo me queda dar un agradecimiento general, creo que cada una de las personas conoce en que forma estuvo presente conmigo durante esta travesía de investigación. 


\title{
DEDICATORIA
}

\begin{abstract}
A mi familia.
Quienes siempre estuvieron y han estado con todo su amor, cariño, apoyo, compresión y confianza.
\end{abstract}

Gracias por creer en mí una vez más.

"No me atrevo a pensar en el futuro, el pasado aún está ocurriendo" John Grisham, 1998. Causa justa. 


\section{Índice General}

1. INTRODUCCIÓN 2

1.1. Panorama ambiental 2

1.2. Ciclo del nitrógeno 8

1.3. Oxidación anaerobia de amonio (Anaerobic ammonium oxidation, ANAMMOX) 9

1.4. Oxidación de amonio por arqueas $\quad 10$

1.5. Desnitrificación 11

1.6. Nitrificación 12

1.6.1. Microorganismos de la nitrificación $\quad 14$

1.6.2. Aspectos bioquímicos de la nitrificación $\quad 18$

1.6.3. Factores que afectan la nitrificación 22

1.7. 2-Clorofenol 26

1.8. Nitrificación y 2-clorofenol 29

1.9. Nitrificación en reactores de lotes secuenciados (SBR) 31

1.10. Enzima amonio monooxigenasa (AMO) 34

1.11. Cometabolismo 38

1.12. Técnicas moleculares en procesos biológicos 40

1.12.1. Dinámica poblacional, índices ecológicos y secuenciación 40

REFERENCIAS 46

2. JUSTIFICACIÓN 60

3. HIPÓTESIS $\quad 61$

4. OBJETIVOS 63

$\begin{array}{lll}\text { 4.1. General } & 63\end{array}$

$\begin{array}{ll}\text { 4.2. Particulares } & 63\end{array}$

5. METODOLOGÍA 65

5.1. Fuente de inóculo $\quad 66$

5.2. Ensayos abióticos y de adsorción 66 
5.3. Evaluación de la actividad nitrificante con diferentes concentraciones de amonio de un lodo previamente expuesto a 2-clorofenol

5.4. Ensayos en SBR nitrificantes: efecto de la concentración inicial de amonio en el consumo de 2-clorofenol

5.5. Participación de la enzima AMO en el consumo de 2-clorofenol

5.6. Variables de respuesta para evaluar el proceso nitrificante, consumo de 2clorofenol y análisis estadístico

5.7. Métodos moleculares

5.7.1. Extracción de ADN del lodo

5.7.2. Amplificación de ADN y separación por DGGE 74

5.7.3. Índices ecológicos $\quad 75$

5.7.4. Secuenciación 76

5.8. Técnicas analíticas $\quad 77$

5.8.1. Cuantificación de amonio 77

5.8.2. Cuantificación de nitrito y nitrato 78

5.8.3. Cuantificación de 2-clorofenol $\quad 79$

5.8.4. Cuantificación de proteína microbiana 80

REFERENCIAS $\quad 82$

6. RESULTADOS 84

6.1. Ensayos de control abiótico y de adsorción 84

6.2. Fuente de inóculo: verificación de la capacidad nitrificante del lodo 85

6.3. Evaluación de la actividad nitrificante con diferentes concentraciones de amonio de un lodo previamente expuesto a 2-CF 86

6.4. Evaluación del proceso nitrificante en presencia de 2-CF y diferentes concentraciones iniciales de amonio en el reactor SBR 89

6.5. Participación de la enzima AMO en el consumo de 2-CF 103

6.6. Extracción, amplificación y purificación de ADN de los lodos nitrificantes en presencia de 2-CF y diferentes concentraciones iniciales de amonio en el reactor SBR 109

6.7. Dinámica poblacional del lodo nitrificante en presencia de 2-CF y diferentes concentraciones iniciales de amonio en el reactor SBR. 
6.8. Relación de la respuesta fisiológica y cinética del lodo nitrificante con su dinámica poblacional.

7. CONCLUSIONES 143

8. RECOMENDACIONES 148

$\begin{array}{ll}\text { REFERENCIAS } & 149\end{array}$

9. ANEXOS 155

9.1. Artículo publicado 155

9.2. Trabajos presentados en eventos nacionales e internacionales 164 


\section{Índice de Figuras}

Figura 1. Diagrama de flujo de la eliminación de iones de amonio de las aguas residuales. Modificado de Gupta y col. (2015).

Figura 2. Principales procesos involucrados en el ciclo global del nitrógeno (N). GarcíaVelázquez y Gallardo, 2017.

Figura 3. Ruta global del catabolismo desnitrificante (González-Blanco, 2015). 12

Figura 4. Ruta global del catabolismo nitrificante (González-Blanco, 2015).

Figura 5. Arboles de guía de ARN ribosómico $16 \mathrm{~S}$ para los grupos $\beta$-proteobacteria de bacterias AOB basados en secuencias de alta calidad (> 1,200 pb) de aislamientos (Norton, 2011). 15

Figura 6. Árbol filogenético, basado en secuencias del gen 16S rRNA, que muestra las afiliaciones filogenéticas de NOB actualmente conocidas a bacterias oxidantes de amonio y no nitrificantes. Los nombres de las bacterias nitrito oxidantes están en negrita. Los números de acceso a la base de datos están indicados para todas las secuencias del gen 16S rRNA. Las barras de escala indican un cambio estimado de 0.1 (árbol grande) o 0.01 (recuadro) por nucleótido (Daims y col., 2011).

Figura 7. Esquema del metabolismo de la nitrificación. (a) Paso 1 por AOB del género Nitrosomonas. (b). Paso 2 por NOB del género Nitrobacter. Modificado de Costa y col. (2006).

Figura 8. a) Ruta de degradación aerobia. (1) Fenol hidroxilasa, (2) Catecol 2,3-dioxigenasa (Farrell y Quilty,1999). b) Vía de biodegradación de 2-CF en gránulos aerobios en un SBR (Mondal y Sabir, 2011). 28

Figura 9. Etapas de un ciclo de operación de un reactor de lotes secuenciados (SBR).

Figura 10. Reacciones catalizadas por la enzima amonio monooxigenasa (AMO) que incluyen oxidación y deshidrogenación (Sayavedra-Soto y Arp, 2011).

Figura 11. Diagrama de flujo de la metodología empleada en este trabajo.

Figura 12. Ejemplo de una curva de calibración para la cuantificación de amonio.

Figura 13. Ejemplos de curvas de calibración para la cuantificación de nitrito y nitrato por electroforesis capilar.

Figura 14. Ejemplo de curva de calibración de 2-clorofenol por HPLC.

Figura 15. Ejemplo de curva de calibración para la cuantificación de proteína microbiana por el método de Lowry modificado.

Figura 16. Ensayos abióticos y de adsorción con $100 \mathrm{mg}$ de $\mathrm{N}^{-N_{4}}{ }^{+} / \mathrm{L}$ y $20 \mathrm{mg}$ de C-2-CF/L: Reactores SBR sin biomasa y con oxígeno $(\square)$, Lote con ATU sin biomasa y sin oxígeno $(\triangle)$ y Lote de adsorción con biomasa estéril y sin oxígeno $(\diamond)$.

Figura 17. Perfil nitrificante en el ciclo 25 de operación en el reactor SBR en presencia de amonio y 2 -CF. Amonio $(\triangle)$, Nitrito $(\square)$, Nitrato $(\diamond)$ y $2-C F(\times)$. 
Figura 18. Perfiles de la nitrificación con diferentes concentraciones iniciales de amonio en los ensayos en lote: 100 (a), 300 (b) y 500 (c) mg de N-NH${ }_{4}^{+} / \mathrm{L}$. Amonio ( $\triangle$ ), Nitrito ( $\square$ ) y Nitrato $(\diamond)$.

Figura 19. Perfil del proceso nitrificante en el reactor SBR en presencia de 2-CF (60 mg C/L) y 100 (ciclo 1) (a), 200 (ciclo 4) (b), 300 (ciclo 7) (c), 400 (ciclo 10) (d) y 500 (ciclo 13) (e) mg $\mathrm{N}-\mathrm{NH}_{4}{ }^{+} / \mathrm{L}$. Amonio $(\triangle)$, Nitrito $(\square)$, Nitrato $(\diamond)$ y 2-CF $(\times)$.

Figura 20. Variables de respuesta del lodo nitrificante en el reactor SBR a lo largo de los ciclos de operación con 2-CF a diferentes concentraciones iniciales de amonio. Eficiencias de consumo de amonio $(\diamond)(\mathrm{a})$, rendimientos de producción de nitrato $(\bigcirc)(\mathrm{b})$, Eficiencias de consumo de 2-CF $(\triangle)(\mathrm{c})$, Concentración de amonio $(-)$.

Figura 21. Fase lag de consumo de Amonio, 2-CF (a) y producción de Nitrato (b) del lodo nitrificante en el reactor SBR en presencia de 2-CF y 100 (ciclo 1), 200 (ciclo 2, 3 y 4), 300 (ciclo 5,6 y 7), 400 (ciclo 8,9 y 10) y 500 (ciclo 11,12 y 13) $\mathrm{mg} \mathrm{N}^{-\mathrm{NH}_{4}}+\mathrm{L}$.

Figura 22. Variables de respuesta del lodo nitrificante en el reactor SBR a lo largo de los ciclos de operación con 2-CF a diferentes concentraciones iniciales de amonio. Velocidades específicas de consumo de amonio (a) $(\triangle), 2-\mathrm{CF}$ (b) ( $\square$ ) y producción de nitrato (c) ( $\diamond)$. Concentración inicial de amonio (-).

Figura 23. Perfil de correlación de la velocidad específica de consumo de amonio ( $\mathrm{qN}^{-\mathrm{NH}_{4}}{ }^{+}$) con la velocidad específica de consumo de 2-CF (qC-2-CF).

Figura 24. Perfiles de los ensayos en lote previos a la inoculación de los SBR: Nitrificación de referencia (a), Nitrificación con ATU (b), Nitrificación con 2-CF (c) y Nitrificación, 2-CF y $\operatorname{ATU}(\mathrm{d})$. Amonio $(\triangle)$, Nitrito $(\square)$, Nitrato $(\diamond)$ y $2-\mathrm{CF}(\times)$.

Figura 25. Perfiles de los ensayos en lote posteriores a la experimentación en los SBR: Nitrificación de referencia (a), Nitrificación con ATU (b), Nitrificación con 2-CF (c) y Nitrificación, 2-CF y ATU (d). Amonio $(\triangle)$, Nitrito $(\square)$, Nitrato $(\diamond)$ y 2-CF $(\times)$.

Figura 26. Extracción de ADN de los lodos nitrificantes a lo largo de los ciclos de operación con $60 \mathrm{mg}$ de $\mathrm{C}-2-\mathrm{CF} / \mathrm{L}$ y con diferentes concentraciones iniciales de amonio. E: Escalera. 110

Figura 27. Amplificación y purificación de ADN de los lodos nitrificantes a lo largo de los ciclos de operación con $60 \mathrm{mg}$ de C-2-CF/L y con diferentes concentraciones iniciales de amonio. E: escalera.

Figura 28. Análisis DGGE de las regiones V6 - V8 de 16S rDNA del lodo nitrificante a lo largo de los ciclos de operación con $60 \mathrm{mg}$ de $\mathrm{C}-2-\mathrm{CF} / \mathrm{L}$ y con diferentes concentraciones iniciales de amonio. Carril 1 con $100 \mathrm{mg}$ de $\mathrm{N}_{-} \mathrm{NH}_{4}{ }^{+} / \mathrm{L}$ (ciclo 1 de operación), carril 2, 3 y 4 con $200 \mathrm{mg}$ de $\mathrm{N}-\mathrm{NH}_{4}{ }^{+} / \mathrm{L}$ (ciclo 2, 3 y 4 de operación respectivamente), carril 5, 6 y 7 con $300 \mathrm{mg} \mathrm{de} \mathrm{N-NH}{ }_{4}^{+} / \mathrm{L}$ (ciclo 5, 6 y 7 de operación respectivamente), carril 8, 9 y 10 con $400 \mathrm{mg}$ de $\mathrm{N}_{-} \mathrm{NH}_{4}{ }^{+} / \mathrm{L}$ (ciclo 8, 9 y 10 de operación respectivamente), carril 11, 12 y 13 con $500 \mathrm{mg} \mathrm{de} \mathrm{N}_{-\mathrm{NH}_{4}}{ }^{+} / \mathrm{L}$ (ciclo 11 , 12 y 13 de operación respectivamente). Las bandas cortadas y secuenciadas se indican en el DGGE.

111 
Figura 29. Mapa de calor generado a partir de las intensidades de banda del gel de DGGE del lodo nitrificante a lo largo de los ciclos de operación con $60 \mathrm{mg}$ de C-2-CF/L y con diferentes concentraciones iniciales de amonio. El color blanco indica ausencia o no detección de la especie y el color negro indica la mayor proporción de individuos encontrada. Las bandas secuenciadas se indican en la figura (primera columna).

112

Figura 30. Análisis de frecuencia de aparición de las especies del lodo nitrificante a lo largo de los ciclos de operación con $60 \mathrm{mg}$ de C-2-CF/L y con diferentes concentraciones iniciales de amonio. Las bandas secuenciadas se indican en la figura.

114

Figura 31. El árbol filogenético se generó con base en el método de neighbor-joining y modelo de sustitución Jukes-Cantor de las secuencias de 16s rARN-DGGE y secuencias relacionadas de la base de datos estándar del GenBank del NCBI de lodo nitrificante en el reactor SBR en presencia de 2-CF. La barra representa la sustitución de 5 nucleótidos por 100 nucleótidos. La robustez nodal del árbol se evaluó utilizando 1000 réplicas de arranque. El número de acceso de NCBI GenBank para cada bacteria se muestra entre paréntesis.

118

Figura 32. El árbol filogenético se generó con base en el método de neighbor-joining y modelo de sustitución Jukes-Cantor de las secuencias de 16S rARN-DGGE y secuencias relacionadas de la base de datos del 16s rRNA de bacterias del GenBank del NCBI de lodo nitrificante en el reactor SBR en presencia de 2-CF. La barra representa la sustitución de 5 nucleótidos por 100 nucleótidos. La robustez nodal del árbol se evaluó utilizando 1000 réplicas de arranque. El número de acceso de NCBI GenBank para cada bacteria se muestra entre paréntesis.

120

Figura 33. Mapa de calor de las intensidades de banda de las 20 secuencias obtenidas a partir del DGGE con su especie relacionada a lo largo de los ciclos de operación con 60 mg de C-2$\mathrm{CF} / \mathrm{L}$ y con diferentes concentraciones iniciales de amonio del reactor SBR.

125

Figura 34. Perfiles de correlación de los índices ecológicos: S con la concentración de amonio (a) y los ciclos de operación (b). J con los ciclos de operación (c) y la concentración de amonio (d).

128

Figura 35. Perfiles de correlación del índice ecológico $\mathrm{S}$ con las variables de respuesta fisiológicas $\left(\mathrm{EN}_{-} \mathrm{NH}_{4}{ }^{+}\right.$(a) y $\mathrm{YN}_{-} \mathrm{NO}_{3}{ }^{-}$(b)) y cinéticas $\left(\mathrm{qN}^{-} \mathrm{NH}_{4}{ }^{+}\right.$(c) y $\mathrm{qN}^{-N_{3}}{ }^{-}$(d)) del lodo nitrificante.

Figura 36. Perfiles de correlación del índice ecológico $\mathrm{J}$ con las variables de respuesta fisiológicas $\left(\mathrm{EN}^{-\mathrm{NH}_{4}}{ }^{+}\right.$(a) y $\mathrm{YN}^{-\mathrm{NO}_{3}}{ }^{-}$(b)) y cinéticas $\left(\mathrm{qN}-\mathrm{NH}_{4}{ }^{+}\right.$(c) y $\mathrm{qN}^{-\mathrm{NO}_{3}}{ }^{-}$(d)) del lodo nitrificante.

Figura 37. Perfiles de correlación de los índices ecológicos: J con el consumo de 2-CF (a) y la velocidad específica del consumo de $2-\mathrm{CF}$ (c). S con el consumo de $2-\mathrm{CF}$ (b) y la velocidad específica del consumo de 2-CF (d).

Figura 38. Perfiles de correlación de la intensidad de banda de las especies obtenidas a partir de la secuenciación del DGGE con el aumento en la concentración de amonio (a, acidobacteria y $\mathrm{b}$, deinococcus-thermus) y los ciclos de operación (c, $\beta$-proteobacteria y d, $\gamma$-proteobacteria). 
Figura 39. Perfiles de correlación de la intensidad de banda de Nitrosomonas oligotropha con el consumo de amonio (a), la velocidad específica del consumo de amonio (b) y la velocidad específica del consumo de 2-CF (c).

Figura 40. Perfiles de correlación de la intensidad de banda de diferentes especies heterotróficas $(\gamma$-proteobacteria-azul, a, acidobacteria-rojo, b y deinococcus-thermus-amarillo, c y d) con la velocidad específica de consumo de $2-\mathrm{CF}$. 


\section{Índice de Tablas}

Tabla 1. Reacciones y valores de $\Delta \mathrm{G}^{\circ}$, de amonio y nitrito oxidación en el proceso nitrificante (Texier y col., 2012).

Tabla 2. Propiedades fisicoquímicas del 2-CF. Handbook of Environmental Data on Organic Chemicals Index Merk (1996).

Tabla 3. Composición del medio de cultivo utilizado para los reactores de lotes secuenciados.

Tabla 4. Composición del medio de cultivo utilizado para los ensayos en lote.

Tabla 5. Concentraciones de $\mathrm{NH}_{4}{ }^{+}$evaluadas en los reactores SBR.

Tabla 6. Parámetros matemáticos del modelo de Gompertz.

Tabla 7. Promedios de coeficientes de determinación y pendientes con su respectivo coeficiente de variación correspondientes a las curvas de calibración realizadas para los diferentes métodos analíticos.

Tabla 8. Variables de respuesta del lodo nitrificante en presencia de amonio y 2-CF en diferentes ciclos de operación en el reactor SBR.

Tabla 9. Variables de respuesta en los ensayos en lote a diferentes concentraciones iniciales de amonio.

Tabla 10. Balance de materia del lodo nitrificante en el reactor SBR a lo largo de los ciclos de operación con 2-CF a diferentes concentraciones iniciales de amonio.

Tabla 11. Variables de respuesta en los ensayos en lote nitrificantes en presencia y ausencia de aliltiourea.

Tabla 12. Índices ecológicos obtenidos a partir del gel de DGGE del lodo nitrificante a lo largo de los ciclos de operación con $60 \mathrm{mg}$ de C-2-CF/L y con diferentes concentraciones iniciales de amonio: Índices de riqueza de especies (S), diversidad estructural (H) y equitatividad (J) de la comunidad microbiana nitrificante.

Tabla 13. Identificación de secuencias de nucleótidos analizadas a partir de bandas DGGE del lodo nitrificante a lo largo de los ciclos de operación con $60 \mathrm{mg}$ de C-2-CF/L y con diferentes concentraciones iniciales de amonio utilizando la base de datos estándar del NCBI.

Tabla 14. Identificación de secuencias de nucleótidos analizadas a partir de bandas DGGE del lodo nitrificante a lo largo de los ciclos de operación con $60 \mathrm{mg}$ de C-2-CF/L y con diferentes concentraciones iniciales de amonio, utilizando la base del 16s rRNA de bacterias del GenBank del NCBI. 
Tabla 15. Matriz de correlaciones de las variables de respuesta cinéticas y fisiológicas del proceso respiratorio nitrificante y los índices ecológicos del lodo. En color verde se indican las correlaciones significativas y en color rojo las que no lo son.

Tabla 16. Matriz de correlaciones de las intensidades de banda de las especies de los 4 grupos bacterianos obtenidas a partir de la secuenciación del DGGE (acidobacteria-rojo, $\beta$ proteobacteria-verde, deinococcus-thermus-amarillo y $\gamma$-proteobacteria-azul) con la concentración de amonio y el número de ciclos de operación del lodo nitrificante. 134

Tabla 17. Matriz de correlaciones de las intensidades de banda de las especies de bacterias AOB con las variables de respuesta del consumo de amonio y 2-CF.

Tabla 18. Matriz de correlaciones de la velocidad específica de consumo de 2-CF y las intensidades de banda de diferentes especies heterotróficas obtenidas a partir de la secuenciación del DGGE (acidobacteria-rojo, Deinococcus-thermus-amarillo y $\gamma$-proteobacteria-azul).

139 


\section{Resumen}

El consumo simultáneo de amonio y 2-clorofenol (2-CF) por un lodo nitrificante se evaluó en dos reactores SBR alimentados con $60 \mathrm{mg}$ C-2-CF/L y diferentes concentraciones iniciales de amonio. Se llevó a cabo el análisis fisiológico, cinético y molecular, así como su posible relación a través de 13 ciclos de operación: un ciclo con 100, tres ciclos con 200, tres ciclos con 300, tres ciclos con 400 y tres ciclos con $500 \mathrm{mg} \mathrm{N}-\mathrm{NH}_{4}{ }^{+} / \mathrm{L}$. El comportamiento fisiológico y cinético de los lodos se evaluó mediante la eficiencia de consumo de amonio (EN-

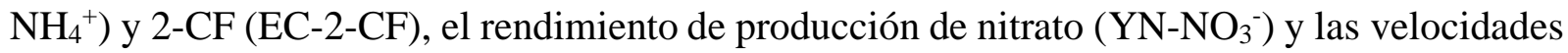
específicas de consumo de amonio $\left(\mathrm{qN}-\mathrm{NH}_{4}{ }^{+}\right)$y 2-CF $(\mathrm{qC}-2-\mathrm{CF})$ y producción de nitrato (qN$\mathrm{NO}_{3}{ }^{-}$). La dinámica poblacional y el análisis molecular del lodo nitrificante se determinó mediante un DGGE del ADN de bacterias al final de cada ciclo de operación. Se calcularon los índices ecológicos de riqueza de especies $(\mathrm{S})$ y equitatividad $(\mathrm{J})$, también se secuenciaron las bandas más representativas del DGGE. Por último, se llevaron a cabo diferentes correlaciones entre las variables de respuesta fisiológicas y cinéticas nitrificantes con la respuesta molecular. A lo largo de los ciclos de operación e independientemente del aumento en la concentración de amonio, el lodo presentó una nitrificación completa en 14 días de cultivo, obteniéndose EN$\mathrm{NH}_{4}{ }^{+}$cercanas al $99 \%$ y $\mathrm{YN}_{-\mathrm{NO}_{3}}{ }^{-}$entre 0.93 y $0.99{\mathrm{~g} \mathrm{~N}-\mathrm{NO}_{3}}^{-} / \mathrm{g} \mathrm{N}^{-\mathrm{NH}_{4}}{ }^{+}$consumido. Asimismo, el lodo fue capaz de consumir completamente el 2-CF en 7 días con EC-2-CF del 100\%. El aumento en la concentración de amonio a lo largo de los ciclos provocó un incremento en las

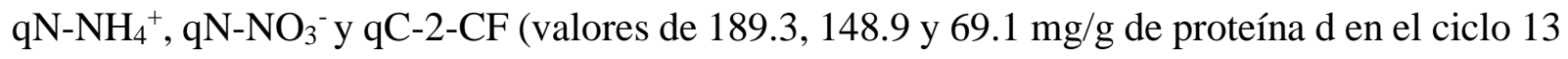
respectivamente) de hasta 5.1, 5.2 y 3.1 veces respectivamente en el ciclo 13 de operación con respecto al ciclo 1 . Se determinó que existe una relación directa y significativa entre las qN$\mathrm{NH}_{4}{ }^{+}$y qC-2-CF con un coeficiente de correlación de 0.83 entre ambas velocidades, mostrando el consumo cometabólico de 2-CF. En ensayos en lote utilizando aliltiourea como inhibidor específico de la enzima amonio monooxigenasa (AMO), se encontró que, con el lodo inoculado a los reactores, la qC-2-CF disminuyó 34.2×4.7\%, mostrando la participación de la AMO en el consumo del 2-CF. Cuando se realizó la misma prueba con el lodo proveniente de los reactores SBR después de 13 ciclos de operación, se observó una mayor participación de la actividad amonio oxidante con una disminución del $52.3 \pm 7.7 \%$ en la qC-2-CF. 
A lo largo de la experimentación y de acuerdo al DGGE, se presentaron cambios en el índice $S$, con una tendencia a la disminución. Se inició con un índice J de 0.89 y terminó en 0.99. La comunidad bacteriana tuvo una tendencia a la homogeneidad y podría estar asociada a la estabilidad del proceso nitrificante. Las especies encontradas se agruparon como $\beta$ proteobacteria $(45 \%)$, acidobacteria $(30 \%), \gamma$-proteobacteria $(10 \%)$ y deinococcus-thermus (15\%). El consumo simultáneo de amonio y 2-CF se podría atribuir a la detección y permanencia de especies de bacterias amonio oxidantes (AOB). La nitrificación completa, se podría atribuir a la presencia de especies de bacterias nitrito oxidantes (NOB) y el consumo de 2-CF a bacterias heterotróficas de los grupos Acidobacteria, $\gamma$-proteobacteria y deinococcus-thermus. La disminución en $\mathrm{S}$ y la tendencia a la homogeneidad $(\mathrm{J}=0.99)$ se puede asociar con la concentración de amonio y los ciclos de operación ( $\mathrm{r}$ de -0.56 y -0.61 y de 0.82 y 0.89 respectivamente). Por otro lado, la comunidad homogénea (J) se asocia con la respuesta fisiológica y cinética del proceso nitrificante $(r>0.60)$. Además, la disminución en $\mathrm{S}$ y la tendencia a la homogeneidad se asocia con la qC-2-CF, pero no con la EC-2-CF (r de -0.65 y 0.85 ; r de -0.45 y 0.28 respectivamente). En el mismo sentido, al relacionar la intensidad de banda de las especies obtenidas del DGGE (interpretada como la proporción de especies presentes) con la respuesta nitrificante, se estableció que el aumento en la proporción de individuos de las diferentes especies obtenidas del DGGE del lodo nitrificante se asocian con la concentración de amonio y los ciclos de operación. Se determinó que el aumento en la proporción de individuos de especies de $\mathrm{AOB}$ se asocian con la $\mathrm{EN}-\mathrm{NH}_{4}{ }^{+}$, con el incremento de la qN-NH${ }_{4}{ }^{+}$y qC-2-CF. Se estableció que el aumento en la proporción de individuos de especies heterotróficas se asocia con el incremento de la qC-2-CF. De acuerdo a estos resultados, Al final de la experimentación con $60 \mathrm{mg}$ C-2-CF/L y una concentración de $500 \mathrm{mg}$ de $\mathrm{N}-\mathrm{NH}_{4}{ }^{+} / \mathrm{L}$, se obtuvo una comunidad bacteriana homogénea con el aumento en proporción de individuos de algunas especies, que contribuyeron a un proceso fisiológicamente estable con q altas y un consumo cometabólico de 2-CF por la enzima AMO. El uso de sistemas SBR con lodos nitrificantes puede ser una buena alternativa para aumentar el consumo cometabólico de compuestos recalcitrantes como el 2-CF y tratar efluentes contaminados con altas concentraciones de amonio. 


\begin{abstract}
Simultaneous ammonium and 2-chlorophenol (2-CP) consumption by a nitrifying sludge was evaluated in two SBR reactors fed with $60 \mathrm{mg} 2-\mathrm{CP}-\mathrm{C} / \mathrm{L}$ and different initial concentrations of ammonium. The physiological, kinetic and molecular analysis was carried out, as well as their possible relationship through 13 operating cycles: one with 100, three with 200 , three with 300 , three with 400 and three cycles with $500 \mathrm{mg} \mathrm{NH}_{4}{ }^{+}-\mathrm{N} / \mathrm{L}$. The physiological behavior of the sludge was assessed using the ammonium $\left(\mathrm{ENH}_{4}{ }^{+}-\mathrm{N}\right)$ and 2-CF $(\mathrm{E} 2-\mathrm{CP}-\mathrm{C})$ consumption efficiencies and the nitrate production yield $\left(\mathrm{YNO}_{3}^{-}-\mathrm{N}\right)$ whereas the kinetic behavior was evaluated by the specific rates of ammonium $\left(\mathrm{qNH}_{4}{ }^{+}-\mathrm{N}\right)$ and 2-CF (q2-CP-C) consumption and nitrate generation $\left(\mathrm{qNO}_{3}^{-}-\mathrm{N}\right)$. The molecular and population dynamic analysis of the nitrifying sludge were determined by means a DGGE of the DNA of bacteria at the end of each operation cycle. An ecological index of species richness (S) and evenness (J) were calculated. Likewise, the most representative DGGE bands were sequenced. Finally, different correlations were conducted between the nitrifying behavior and the molecular response. Throughout the operation cycles and regardless to the increase in the ammonium concentration, the sludge presented a complete nitrification in 14 days of culture, obtaining $\mathrm{ENH}_{4}{ }^{+}-\mathrm{N}$ close to $99 \%$ and $\mathrm{YNO}_{3}{ }^{-}-\mathrm{N}$ between 0.93 and $0.99 \mathrm{~g} \mathrm{NO}_{3}{ }^{-} \mathrm{N} / \mathrm{g} \mathrm{NH}_{4}{ }^{+}-\mathrm{N}$ consumed. Likewise, the sludge was able to fully consume the 2-CP in 7 days with E2-CP-C of $100 \%$. The increase in the ammonium concentration throughout the operating cycles provoked in cycle 13 of operation a respectively increase in $\mathrm{qNH}_{4}{ }^{+}-\mathrm{N}, \mathrm{qNO}_{3}{ }^{-}-\mathrm{N}$ and q2-CP-C (values of $189.3,148.9$ and $69.1 \mathrm{mg} / \mathrm{g}$ of protein d in cycle 13 respectively) of up to 5.1, 5.2 and 3.1 times regarding to cycle 1 . A direct and significant relationship between the $\mathrm{qNH}_{4}{ }^{+}-\mathrm{N}$ and $\mathrm{q} 2-\mathrm{CP}-\mathrm{C}$ with a correlation coefficient of 0.83 was determined, showing effect of the increase in ammonium concentration on the cometabolic 2-CP consumption. Batch assays conducted with the sludge inoculated into the reactors in presence of allylthiourea as specific inhibitor of the ammonium monooxygenase enzyme (AMO), resulted in a decrease of $34.2 \pm 4.7 \%$ in q2-CP-C, evidenced the participation of the $\mathrm{AMO}$ in the consumption of 2-CP. When these assays were carried out with the sludge obtained after 13 operating cycles in the SBR reactors, a higher participation of the AMO in 2-CP consumption was noticed with a decrease of $52.3 \pm 7.7 \%$ in $\mathrm{q} 2-\mathrm{CP}-\mathrm{C}$.
\end{abstract}


According to experimentation, changes in the $\mathrm{S}$ index were observed with a decreasing tendency. The bacterial community showed a tendency to homogeneity as an initial $\mathbf{J}$ index of 0.89 was calculated whereas a $\mathrm{J}$ value of 0.99 was determined at the end of experimentation. This behavior might be associated with the stability of the nitrifying process. The identified species were grouped as $\beta$-proteobacteria (45\%), acidobacteria (30\%), $\gamma$-proteobacteria (10\%) and deinococcus-thermus (15\%). The simultaneous consumption of ammonium and 2-CP could be attributed to the detection and permanence of species of ammonium oxidizing bacteria (AOB). Complete nitrification could be attributed to the presence of a NOB specie and 2-CP consumption to the presence of heterotrophic bacteria of Acidobacteria group, $\gamma$-proteobacteria and deinococcus-thermus group. The decrease in $\mathrm{S}$ and the tendency to homogeneity $(\mathrm{J}=0.99)$ was associated with the ammonium concentration increase and the operating cycles ( $\mathrm{r}$ of -0.56 and -0.61 and of 0.82 and 0.89 respectively). On the other hand, homogeneous community (J) was associated with the physiological and kinetic response of the nitrifying process $(r>0.60)$. Furthermore, the decrease in $\mathrm{S}$ and the tendency to homogeneity were only associated with q2$\mathrm{CP}-\mathrm{C}$ ( $\mathrm{r}$ of -0.65 and $0.85 ; \mathrm{r}$ of -0.45 and 0.28 respectively). In the same sense, when relating the band intensity of the species obtained of DGGE (interpreted as the proportion of species present) with the nitrifying response, it was established that the increase in the proportion of individuals of the different species obtained from DGGE of nitrifying sludge was associated with ammonium concentration and operating cycles. It was established that the increase in the proportion of individuals of AOB species were associated with $\mathrm{ENH}_{4}{ }^{+}-\mathrm{N}$ values higher than $99 \%$; with the increase in $\mathrm{qNH}_{4}{ }^{+}-\mathrm{N}$ and the increase of q2-CP-C. It was established that the increase in the proportion of individuals of heterotrophic species were associated with the increase in q2-CP-C. According to these results, at the end of the experimentation with $60 \mathrm{mg}$ of 2-CP-C/L and $500 \mathrm{mg}$ of $\mathrm{NH}_{4}{ }^{+}-\mathrm{N} / \mathrm{L}$, a homogeneous bacterial community was obtained. Under these conditions an increase in proportion of individuals of some species might contribute achieve a physiologically stable nitrifying process with high $\mathrm{q}$ and a cometabolic 2-CP consumption enhanced by the AMO enzyme. The use of nitrifying SBR systems could be considered as a suitable alternative for increasing the cometabolic consumption of recalcitrant compounds such as 2-CP besides treating effluents highly contaminated with ammonium. 


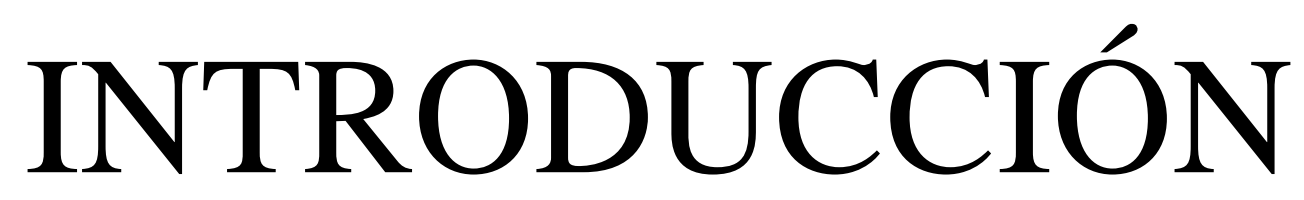




\section{INTRODUCCIÓN}

\subsection{Panorama ambiental}

Los recursos hídricos en México, como en todo el mundo, se encuentran bajo una creciente presión. La urbanización, el crecimiento demográfico y el incremento en el consumo de agua doméstico, en la agricultura y la industria, han aumentado considerablemente el uso frecuente del agua. A pesar de esta situación, los diferentes sectores involucrados como los usuarios del agua, siguen satisfaciendo sus necesidades sin tener en cuenta el impacto sobre el medio ambiente (SEMARNAT, 2018).

En México, la Comisión Nacional del Agua (CONAGUA) y los Organismos de Cuenca tienen el compromiso y la facultad de regular y administrar la cantidad de agua que se extrae de los acuíferos del país, con el fin de evitar su contaminación y sobreexplotación. Los organismos operadores censados, con autoridad para suministrar y extraer el agua en los municipios y entidades, reportaron al 2017 que cerca del 61\% del agua para uso consuntivo provenía de 3314 mantos superficiales (lagos, ríos, ojos de agua, manantiales, presas) y el resto de 12551 mantos del subsuelo (ríos subterráneos y otros acuíferos). En el año 2016, el volumen total de agua extraída del ambiente fue de $216593 \mathrm{hm}^{3}$ de agua, considerando el volumen de extracción de fuentes superficiales (82\%), fuentes del subsuelo (16\%) y pluviales (2\%) (SEMARNAT, 2018). El consumo de agua que las personas generalmente utilizan en un país depende no sólo de las necesidades esenciales y de cuánta agua se dispone para el uso, sino también del grado de urbanización y del nivel de desarrollo económico. Mundialmente, de las tres categorías del uso de agua dulce: doméstico (personal, familiar y municipal), agricultura e industria es la agricultura la que domina. De acuerdo a cifras de la Secretaría de Medio Ambiente y Recursos Naturales (SEMARNAT, 2018), casi el 76\% del agua que se consume en México es para fines agrícolas, $4.7 \%$ para energía eléctrica (excluyendo hidroeléctricas), $14.4 \%$ abastecimiento público y $4.9 \%$ para la industria autoabastecida, es decir, la industria en México consume relativamente poco conforme a los estándares internacionales.

Por otro lado, las aguas residuales generadas durante las actividades productivas contienen desechos diversos, que, al ser descargados directamente en los cuerpos de agua, 
representan las fuentes de contaminación. Esto se traduce en la desaparición de la vegetación natural, así como en la muerte de peces y demás especies acuáticas. Asimismo, limita el uso del recurso para el riego o la pesca y la agricultura; el consumo (agua potable) y recreación de contacto. Las descargas de aguas residuales pueden ser municipales y no municipales. Las municipales se generan en los núcleos de población y son colectadas en los sistemas de alcantarillado urbanos y rurales; a las generadas por otros usos, como puede ser la industria autoabastecida y que se descargan directamente a cuerpos de agua nacionales sin ser colectadas por sistemas de alcantarillado, se les denomina no municipales. Durante el año 2017, se trataron $135.6 \mathrm{~m}$ 3/s de aguas residuales en 2526 plantas en operación a lo largo del país, es decir el 63\% de los $215.2 \mathrm{~m} 3 / \mathrm{s}$ recolectados a través de los sistemas de alcantarillado. En el caso de aguas residuales industriales se trataron, en 3025 plantas en operación a escala nacional, $83.7 \mathrm{~m} / \mathrm{s} \mathrm{de}$ $\operatorname{los} 218.1 \mathrm{~m}$ /s generados (SEMARNAT, 2018). Por otro lado, las plantas potabilizadoras, que mejoran la calidad del agua de las fuentes superficiales o subterráneas para adecuarlas al consumo humano, en el 2017 produjeron un caudal potabilizado de $100.1 \mathrm{~m}^{3} / \mathrm{s}$ mediante 932 plantas potabilizadoras en operación (SEMARNAT, 2018). En resumen, la falta de coordinación entre autoridades y usuarios, aunado a la falta de un correcto reúso y tratamiento de las aguas residuales producidas; llevan a la sobre explotación del recurso, la degradación de los suelos, la contaminación de ecosistemas y a un impacto negativo sobre la seguridad alimentaria. Ante esta problemática, el saneamiento de las aguas residuales adquiere más importancia para asegurar su recolección, tratamiento, conducción y adecuada disposición en los cuerpos receptores, en condiciones que no afecten la salud de la población y al medio ambiente.

La composición de los efluentes contaminantes industriales varía con el tipo de industria y con el tipo de proceso que se lleva a cabo. Dentro de las sustancias disueltas hay elementos orgánicos que pueden ser biodegradables o no, y/o elementos inorgánicos nitrogenados como el amonio $\left(\mathrm{NH}_{4}^{+}\right)$, nitrato $\left(\mathrm{NO}_{3}{ }^{-}\right)$o nitrito $\left(\mathrm{NO}_{2}{ }^{-}\right)$(Camargo y Alonso, 2006). Estos compuestos pueden repercutir en la salud de muchos seres vivos. Debido a las actividades humanas, la cantidad de $\mathrm{NH}_{4}{ }^{+}$en las aguas residuales cada vez es mayor (Mcclelland y col., 1998; Breemen, 2002). En ecosistemas acuáticos, el $\mathrm{NH}_{4}{ }^{+}$es uno de los causantes de la eutroficación, que trae como consecuencia la muerte de organismos por asfixia (Smith, 2003; Conley y col., 2009). 
Además, la contaminación por nitrógeno inorgánico podría inducir efectos perjudiciales sobre la salud humana. Genera malestares como dolor de cabeza e incluso desmayos, irritación de ojos, nariz y garganta. Asimismo, su presencia en el agua impide consumirla (Camargo y Alonso, 2007). Particularmente, los efluentes de la industria química, refinería del petróleo, textil, tenerías, procesadoras de alimentos y papel, producción de látex, manufactureras de explosivos y plaguicidas, entre otras, contienen concentraciones altas de compuestos nitrogenados (Lens y Kuenen, 2001). Olmos y col. (2004) por ejemplo, encontraron concentraciones de $710 \pm 590 \mathrm{mg} \mathrm{N}-\mathrm{NH}_{4}+/ \mathrm{L}$, en los efluentes de la refinería de Tula, México. Existen normas que establecen los límites permisibles de contaminantes en las descargas de aguas residuales, con el fin de proteger, conservar y mejorar la calidad de las aguas y bienes nacionales. La NOM-001-ECOL-1996, NOM-003-ECOL-1997 y NOM-127-SSA11994 publicadas en el Diario Oficial de la Federación indican niveles máximos permisibles entre 10 y $15 \mathrm{mg}$ de nitrógeno total/L para descargas en aguas y bienes nacionales, así como 0.5, 0.05 y $10 \mathrm{mg} \mathrm{N} / \mathrm{L}$ de nitrógeno amoniacal, nitritos y nitratos respectivamente para uso y consumo humano. Como se ha mencionado anteriormente, las concentraciones de $\mathrm{N}_{-} \mathrm{NH}_{4}{ }^{+}$de los efluentes de algunas refinerías de México, sobrepasan los límites establecidos, por consiguiente, es necesario aplicar estrategias para reducir la contaminación por nitrógeno.

Además del $\mathrm{NH}_{4}^{+}$, los compuestos fenólicos pueden estar presentes en los efluentes industriales en concentraciones altas. Dentro de los compuestos fenólicos, los halogenados, en particular los clorados como el 2-clorofenol (2-CF), se encuentran contaminando suelos y acuíferos, debido a su uso generalizado como parte estructural de pesticidas y preservadores en la industria de la madera (Puhakka y Melin, 1996; Czaplicka, 2004). Aunque actualmente su uso para este fin está prohibido en casi todo el mundo, en muchos países madereros, los problemas de contaminación por clorofenoles persisten debido a su alta vida media en el ambiente (Czaplicka, 2004). El 2-CF también se utiliza en las industrias petroquímicas, textiles y de papel (Kostyal y col., 1997). Es un compuesto soluble en agua $\left(2.8 \mathrm{~g} / 100 \mathrm{~mL} \mathrm{de} \mathrm{H}_{2} \mathrm{O}\right)$ (Solomons, 2000), por lo que puede migrar fácilmente y contaminar el medio acuoso. La Agencia para el registro de sustancias tóxicas y enfermedades (ATSDR, por sus siglas en inglés) ha considerado la eliminación de 2-CF como una preocupación prioritaria debido a su toxicidad 
y persistencia en el medio ambiente (ATSDR, 2015). Los clorofenoles y el 2-CF podrían llegar a ser mutagénicos y cancerígenos, por lo que su impacto ambiental en el aire, el agua y el suelo es significativo (Armenante y col., 1999; Majumder y Gupta, 2007). Por consiguiente, el 2-CF es un compuesto persistente en el suelo y agua, el cual podría llegar a diferentes lugares en donde hay altas concentraciones de amonio o bien a plantas de tratamiento de aguas residuales en donde se llevan a cabo diferentes procesos biológicos como la nitrificación y por lo tanto la presencia de este tipo de compuestos recalcitrantes podría tener efectos negativos sobre los procesos respiratorios.

A fin de proteger la salud pública, algunas instituciones o agencias elaboran regulaciones y recomendaciones para la presencia de sustancias tóxicas en agua. Entre las agencias federales se encuentran la Agencia de Protección del Medio Ambiente de EE. UU. (EPA, por sus siglas en inglés), la Administración de Seguridad y Salud Ocupacional (OSHA, por sus siglas en inglés) y la Administración de Drogas y Alimentos de EE. UU. (FDA, por sus siglas en inglés). Por ejemplo, la presencia de clorofenoles en el agua, aún a concentraciones bajas le imparten un olor y sabor desagradable. Para evitar esto, estas instituciones recomiendan que las concentraciones de diferentes clorofenoles no sean mayores de $0.1 \mu \mathrm{g} / \mathrm{L}$ para los monoclorofenoles, $0.3 \mu \mathrm{g} / \mathrm{L}$ para los 2,4-diclorofenoles y $1 \mu \mathrm{g} / \mathrm{L}$ para el 2,4,5-triclorofenol y el 2,3,4,6-tetraclorofenol. En el caso del 2-CF, la concentración en la que se puede percibir el sabor en el agua para beber es de $40 \mu \mathrm{g} / \mathrm{L}$ (ATSDR, 2016). En México de acuerdo a la CONAGUA (2007) los umbrales para el 2-CF, 2,4-diclorofenol y 2,4,6-triclorofenol son de 0.1, 0.3 y 0.2 $\mu \mathrm{g} / \mathrm{L}$ para el sabor y de 10, 40 y $300 \mu \mathrm{g} / \mathrm{L}$ para el olor respectivamente, además la regulación para los clorofenoles limita el contenido a $300 \mu \mathrm{g} / \mathrm{L}$ para compuestos fenólicos en agua para uso y consumo humano (CONAGUA, 2007; NOM-127-SSA1-1994). Aunque en México en comparación con otras instituciones de EE. UU. no hay una regulación estricta para el 2-CF, los límites permisibles para compuestos fenólicos son bajos, puesto que los umbrales de detección de los clorofenoles para sabor y olor se dan en concentraciones pequeñas.

De acuerdo con lo anterior, la necesidad de cumplir con las regulaciones ambientales y de implementar sistemas de tratamiento que permitan eliminar tanto al $\mathrm{NH}_{4}{ }^{+}$como al 2-CF de los efluentes municipales y/o industriales, va en aumento. En la actualidad para eliminar el $\mathrm{NH}_{4}{ }^{+}$ 
de las aguas residuales se han desarrollado una amplia gama de tecnologías utilizando métodos físico-químicos y/o biológicos, que suelen ser combinados o acoplados entre sí en trenes de tratamiento. Existen diferentes tratamientos para eliminar el $\mathrm{NH}_{4}{ }^{+}$del agua residual, los más estudiados en los años 1979-2015 se observan en la Figura 1.

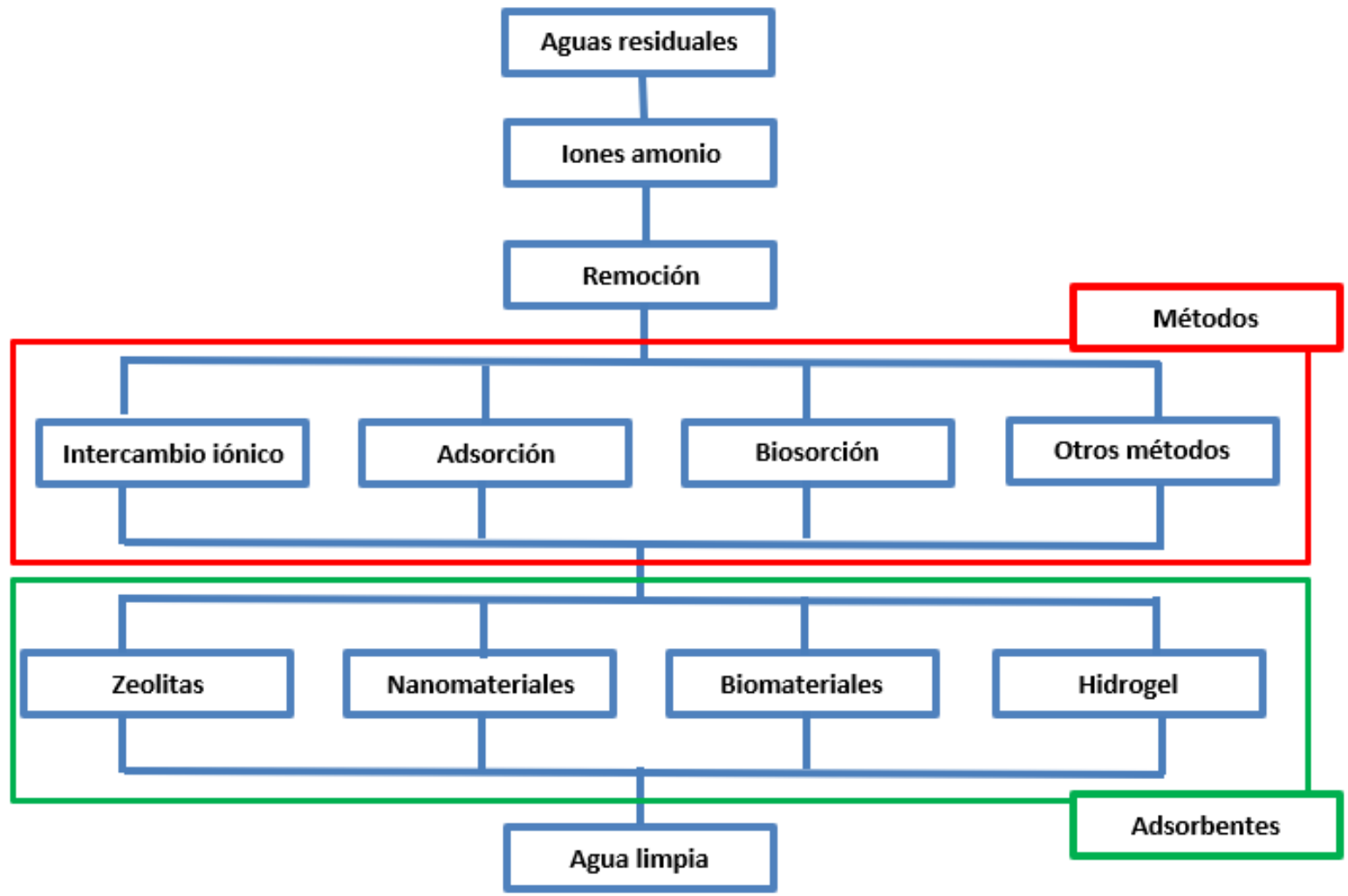

Figura 1. Diagrama de flujo de la eliminación de iones de amonio de las aguas residuales. Modificado de Gupta y col. (2015).

El intercambio iónico se ha utilizado para la eliminación de $\mathrm{NH}_{4}{ }^{+}$de las aguas residuales debido a sus propiedades únicas, tales como alta capacidad de tratamiento, alta eficiencia de eliminación, bajo costo y cinética rápida (Cooney col., 1999; Kang y col., 2004). Uno de los compuestos más utilizados como intercambiador de iones para la eliminación de $\mathrm{NH}_{4}{ }^{+}$son las zeolitas. Las zeolitas son aluminosilicatos altamente porosos con diferentes estructuras de cavidades que consisten en un marco tridimensional y una red con carga negativa (Bekkum y col., 1991). La carga negativa se equilibra con cationes que son intercambiables con ciertos 
cationes en solución. La alta capacidad de intercambio iónico, las áreas de superficie específicas relativamente altas y lo más importante, precios relativamente bajos, hacen que las zeolitas sean adsorbentes atractivos en la eliminación de $\mathrm{NH}_{4}{ }^{+}$(Gupta y col., 2015). La adsorción también es un método efectivo y económico para la eliminación de $\mathrm{NH}_{4}{ }^{+}$(Moradi, 2011). El proceso de adsorción ofrece flexibilidad en diseño y operación; de hecho, produce efluentes tratados de alta calidad en muchos casos. Además, dado que la adsorción a veces es reversible, los adsorbentes pueden regenerarse mediante una desorción adecuada (Gupta y col., 2015). Existen diferentes trabajos sobre la adsorción de iones de $\mathrm{NH}_{4}{ }^{+}$por materiales biológicos adsorbentes, por ejemplo, se han utilizado lodos granulares aerobios (Yu y col. 2014), lodos activados, gránulos anammox (Bassin y col., 2011) o lodos municipales (Ismail y col., 2010) así como residuos lignocelulósicos, cáscara de camarones, krill, calamar, cangrejo, etc. y biomasa de algas (Gupta y col., 2015). Las principales ventajas de la biosorción son su alta efectividad para disminuir los iones y el uso de biosorbentes. Los procesos de biosorción son particularmente adecuados para tratar aguas residuales con $\mathrm{NH}_{4}{ }^{+}$diluido. Otros métodos de eliminación fisicoquímica de amoníaco incluyen: volatilización, aireación difusa, oxidación del aire húmedo, ozonización (Gupta y col., 2015). Aunque todas las técnicas anteriores pueden emplearse para el tratamiento de aguas residuales con $\mathrm{NH}_{4}{ }^{+}$, es importante mencionar que la selección de las técnicas de tratamiento y del adsorbente adecuados depende de la concentración inicial del contaminante, de la inversión de capital y del costo operativo, flexibilidad y fiabilidad de la planta e impacto ambiental, así como del uso de agentes químicos, los cuales pueden causar una grave contaminación secundaria. Aunado a esto, hay que considerar que cuando se trata de una gran cantidad de aguas residuales que contienen concentraciones bajas de $\mathrm{NH}_{4}{ }^{+}$, estos métodos resultan costosos, por lo que no se pueden utilizar a gran escala (Gupta y col., 2015). De manera general, los tratamientos fisicoquímicos para eliminar $\mathrm{NH}_{4}{ }^{+}$del agua son efectivos y rápidos, sin embargo, generan costos elevados de inversión y operación, además; presentan el grave inconveniente de trasladar el problema ambiental de un lugar a otro.

Tomando en cuenta lo anterior, los procesos biológicos, tienen una gran ventaja. Por ejemplo, mediante la nitrificación, definida como un proceso respiratorio aerobio donde el $\mathrm{NH}_{4}{ }^{+}$ es secuencialmente oxidado a $\mathrm{NO}_{2}{ }^{-}$y posteriormente a $\mathrm{NO}_{3}{ }^{-}$(Prosser, 1990; Bernet y Spérandio, 
2009) y, posteriormente, mediante la desnitrificación, un proceso anóxico donde el $\mathrm{NO}_{3}{ }^{-}$se reduce hasta nitrógeno molecular $\left(\mathrm{N}_{2}\right)$ (Madigan y col., 2015; Wang y Chu, 2016), es posible eliminar completamente los contaminantes nitrogenados y convertirlos en compuestos inocuos. Asimismo, mediante la desnitrificación, también es posible oxidar simultáneamente materia orgánica de tipo fenólica hasta $\mathrm{CO}_{2}$ (Hernández 2005; Hernández y col., 2008).

\subsection{Ciclo del nitrógeno}

El $\mathrm{N}_{2}$ constituye el 78\% de la atmósfera (Mikhail y Sverjensky 2014). Esta riqueza posibilita tanto la fijación biológica como la fijación industrial (Vitousek y col., 1997). Existen otras formas nitrogenadas, como $\mathrm{NH}_{4}{ }^{+}, \mathrm{NO}_{2}{ }^{-}, \mathrm{NO}_{3}{ }^{-}$y $\mathrm{N}_{2} \mathrm{O}$, que pueden estar disueltas en agua o en forma gaseosa. Su alta movilidad, acumulación y capacidad de atravesar las fronteras de un ecosistema, así como la baja tasa de fijación biológica son las principales fuentes de la alteración del ciclo del nitrógeno. Mediante el proceso de Haber-Bosch (proceso en el cual a altas temperaturas y alta presión combinan el hidrógeno y el nitrógeno (del ambiente) para la producción de amoniaco), la industria química contribuye a la fijación de unos 120 Tg de N/año, a los que hay que añadir otros $60 \mathrm{Tg}$ de N/año fijados en cultivos (fundamentalmente leguminosas de interés agrícola) y $30 \mathrm{Tg}$ de N/año procedente de la quema de combustibles fósiles (Vitousek y col., 1997). En conjunto estas tres actividades dan como resultado la fijación antrópica. Los compuestos nitrogenados pueden tener múltiples efectos a su paso por los distintos ecosistemas, produciendo acidificación, eutrofización, alteración del albedo y generación de ozono troposférico, entre otros efectos, lo que puede contribuir de forma sustancial al cambio climático global (Figura 2) (García-Velázquez y Gallardo, 2017). La fijación biológica natural la conllevan los procesos biológicos de la nitrificación, desnitrificación (Wrage y col., 2001), amonio oxidación por arqueas (You y col., 2009), amonificación (que reduce el $\mathrm{NO}_{3}{ }^{-}$y $\mathrm{NO}_{2}{ }^{-}$a $\mathrm{NH}_{4}{ }^{+}$) y el de anammox (oxidación de $\mathrm{NH}_{4}{ }^{+}$en ambientes anaerobios) (Yoon y col., 2015; Xi y col., 2016), que en su conjunto suponen unas entradas de $\mathrm{N}$ por fijación biológica natural estimada en $198 \mathrm{Tg}$ de N/año, a lo que habría que añadir 5 Tg de N/año más de fijación abiótica producida en tormentas eléctricas (Fowler y col. 
2013). De acuerdo a lo anterior, el ciclo del nitrógeno se ha ido afectando por la fijación antrópica con $210 \mathrm{Tg}$ de $\mathrm{N}$ al año y que a su vez ya supera la fijación biológica natural de 203 $\mathrm{Tg}$ de N/año, por consiguiente, se requiere mantener una recirculación eficiente del ciclo del nitrógeno. Una alternativa para esto es seguir implementando los procesos biológicos que involucran a la nitrificación y desnitrificación.

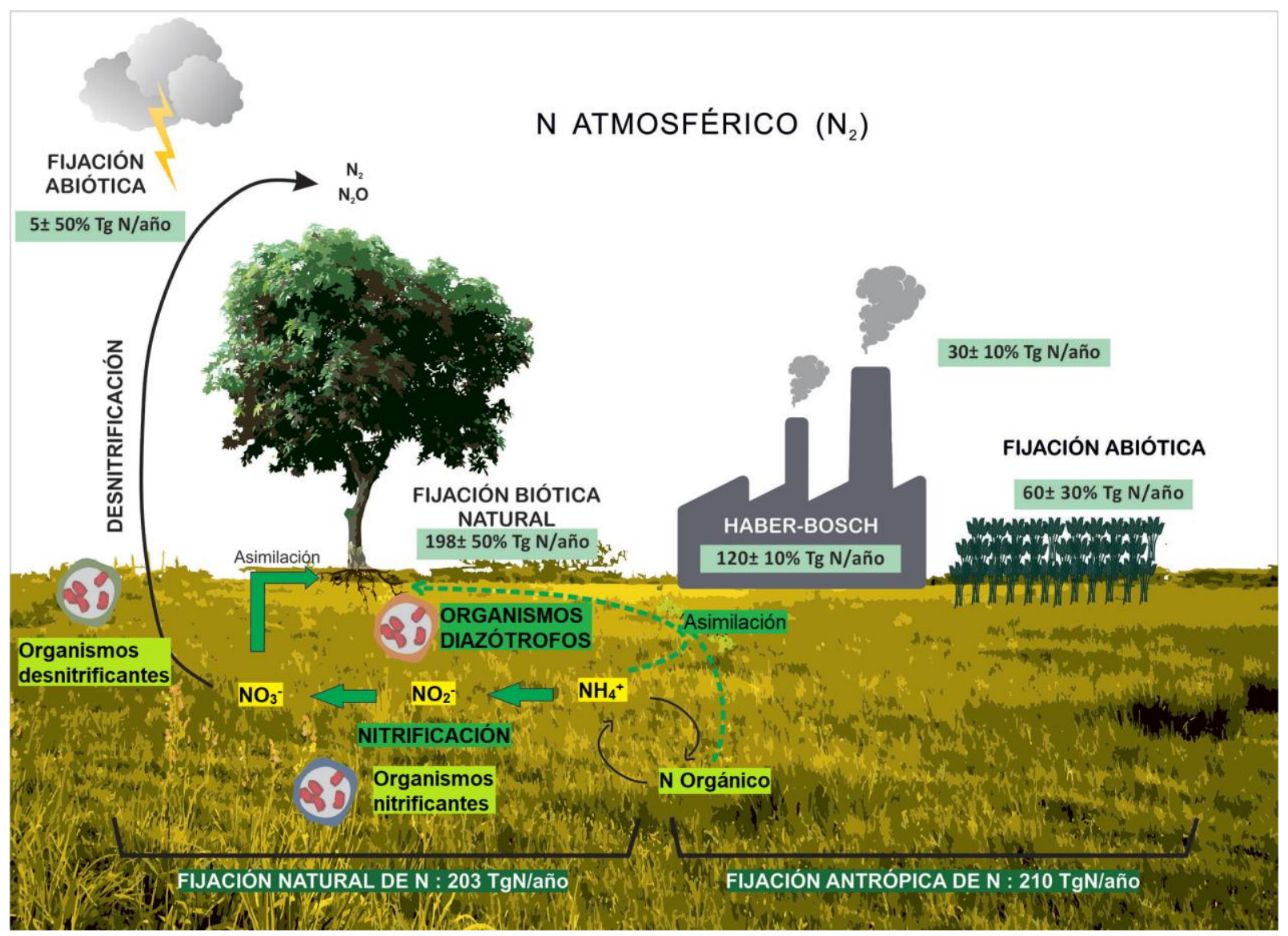

Figura 2. Principales procesos involucrados en el ciclo global del nitrógeno (N). García-Velázquez y Gallardo, 2017.

\subsection{Oxidación anaerobia de amonio (Anaerobic ammonium oxidation, ANAMMOX)}

La oxidación anaerobia de amonio (ANAMMOX), se descubrió por primera vez en 1995 en un reactor de lecho fluidizado desnitrificante, en el cual, en condiciones anóxicas, el amonio fue oxidado por la bacteria autotrófica denominada Anammox a $\mathrm{N}_{2}$ utilizando nitrito como 
aceptor final de electrones (Jin y col., 2012). En ensayos por lotes con exceso de hidroxilamina y amonio, se observó una acumulación transitoria de hidracina por la enzima hidracina hidrolasa, lo que sugiere que la hidracina es el intermediario de este paso final, indicando que la oxidación de hidracina a $\mathrm{N}_{2}$ genera los electrones para la reducción inicial de nitrito a hidroxilamina (Jetten y col., 2001). El proceso anammox ha sido planteado como una alternativa de la tecnología tradicional de nitrificación-desnitrificación para la eliminación biológica de nitrógeno (Van Hulle y col., 2010). Se ha reportado que las bacterias Anammox existen en varios sistemas naturales y artificiales, así como en zonas con baja disponibilidad de oxígeno, nitrito y nitrato (Rysgaard y col., 2004), incluidos los sistemas de tratamiento de aguas residuales, ecosistemas marinos, ecosistemas de agua dulce y ecosistemas terrestres (Jetten y col., 2001; Dalsgaard y col., 2005; Kuenen, 2008). Las fuentes de bacterias Anammox son, por lo tanto, fáciles de encontrar. Se han identificado cinco géneros bacterianos Brocadiales en el orden Planctomycetales: Candidatus Brocadia, Candidatus Kuenenia, Candidatus Jettenia, Candidatus Scalindua y Candidatus Anammoxoglobus (Oshiki y col., 2011; Jin y col., 2012).

\subsection{Oxidación de amonio por arqueas}

Recientemente se ha reportado el papel de las arqueas en los ciclos biogeoquímicos, así como su diversidad fisiológica. Anteriormente sólo se había descrito la distribución de arqueas metanogénicas, pero la existencia de arqueas oxidantes de amoníaco (AOA) y su contribución al ciclo del nitrógeno es de gran importancia (Andrade Ochoa y col., 2015). La existencia de AOA se reportó mediante el cultivo de una cepa marina quimiolitoautotrófica que usaba amoníaco como única fuente de energía y producía nitrito (Leininge y col., 2006). Las AOA contienen los genes que codifican las subunidades $a m o A, a m o B$ y $а m o C$ parecidas a las de las bacterias amonio oxidantes (Zhang y col., 20120). Además, las AOA parecen ser el grupo arqueal dominante en los suelos (que generalmente comprende de 1 a $5 \%$ de todos los procariotas), en ambientes marinos (el 20 a $40 \%$ de todos los bacterioplanctons marinos) y parecen ser una importante población oxidante de amoníaco en hábitats geotérmicos (Stahl y de la Torre, 2012). También se han encontrado en biorreactores de plantas de tratamiento de aguas residuales (Park y col., 2006). Inicialmente se clasificaron en un grupo Crenarchaeota mesófilo 
dentro de un nuevo filo arqueal ahora conocido como Thaumarchaeota, que no solo contiene todas las AOA conocidas sino también varios grupos ambientales (Pester y col., 2011). Recientemente, de acuerdo a las secuencias de genes de la subunidad amoA disponibles, las AOA se encuentran en cinco grupos principales: grupo Nitrosopumilis, Nitrososphaera, Nitrosocaldus, Nitrosotalea y grupo hermano Nitrososphaera (recientemente reconocido) (Hatzenpichler, 2012; Pester y col., 2012: Gao y col., 2013).

\subsection{Desnitrificación}

La desnitrificación biológica es un proceso anóxico que se lleva a cabo mediante microorganismos que utilizan $\mathrm{NO}_{3}{ }^{-} \mathrm{NO}_{2}{ }^{-}$como aceptor de electrones, los cuales se reducen a compuestos nitrogenados gaseosos, principalmente a $\mathrm{N}_{2}$, y utilizan sustancias orgánicas e inorgánicas como donador de electrones y fuente de energía para sostener el crecimiento microbiano (Madigan y col., 2015; Wang y Chu, 2016). Hay dos tipos de desnitrificación biológica, la organotrófica y la litotrófica. La desnitrificación autotrófica utiliza compuestos como el hidrógeno, hierro o azufre como fuente de energía y compuestos inorgánicos de carbono como dióxido de carbono y bicarbonato como fuente de carbono (Karanasios y col., 2010) mientras que los desnitrificantes organótrofos utilizan compuestos orgánicos de carbono como fuente de carbono y energía (Van Rijn y col., 2006). Tandukar y col. (2009) ha reportado que la desnitrificación con $\mathrm{NO}_{3}{ }^{-}$puede expresarse en términos generales por la siguiente reacción redox (Ecuación 1).

$$
2 \mathrm{NO}_{3}{ }^{-}+10 \mathrm{e}^{-}+12 \mathrm{H}^{+} \rightarrow \mathrm{N}_{2}+6 \mathrm{H}_{2} \mathrm{O} \quad \Delta \mathrm{G}^{\circ \prime}=-1120.5 \mathrm{~kJ} / \text { reacción } \quad \text { Ec. } 1
$$

No obstante, el proceso de reducción de $\mathrm{NO}_{3}{ }^{-}$hasta $\mathrm{N}_{2}$ ocurre en etapas sucesivas, catalizadas por sistemas enzimáticos diferentes, formando transitoriamente intermediarios como $\mathrm{NO}_{2}^{-}$, óxido nítrico (NO) y óxido nitroso $\left(\mathrm{N}_{2} \mathrm{O}\right)$, de acuerdo con las siguientes ecuaciones.

$$
\begin{array}{lll}
\mathrm{NO}_{3}{ }^{-}+2 \mathrm{e}^{-}+2 \mathrm{H}^{+} \rightarrow \mathrm{NO}_{2}{ }^{-}+\mathrm{H}_{2} \mathrm{O} & \Delta \mathrm{G}^{\circ \prime}=-163.2 \mathrm{~kJ} / \text { reacción } & \text { Ec. } 2 \\
\mathrm{NO}_{2}{ }^{-}+\mathrm{e}^{-}+2 \mathrm{H}^{+} \rightarrow \mathrm{NO}+\mathrm{H}_{2} \mathrm{O} & \Delta \mathrm{G}^{\circ \prime}=-73.2 \mathrm{~kJ} / \text { reacción } & \text { Ec. } 3
\end{array}
$$




$$
\begin{aligned}
& 2 \mathrm{NO}+2 \mathrm{e}^{-}+2 \mathrm{H}^{+} \rightarrow \mathrm{N}_{2} \mathrm{O}+\mathrm{H}_{2} \mathrm{O} \quad \Delta \mathrm{G}^{\circ \prime}=-306.2 \mathrm{~kJ} / \text { reacción } \quad \text { Ec. } 4 \\
& \mathrm{~N}_{2} \mathrm{O}+2 \mathrm{e}^{-}+2 \mathrm{H}^{+} \rightarrow \mathrm{N}_{2}+\mathrm{H}_{2} \mathrm{O} \quad \Delta \mathrm{G}^{\circ \prime}=-341.4 \mathrm{~kJ} / \text { reacción } \quad \text { Ec. } 5
\end{aligned}
$$

Cada paso del proceso es catalizado por una enzima: la nitrato reductasa (Nar), la cual cataliza la reducción del $\mathrm{NO}_{3}{ }^{-}$a $\mathrm{NO}_{2}{ }^{-}$; la nitrito reductasa (Nir) que reduce el $\mathrm{NO}_{2}{ }^{-}$a óxido nítrico; la óxido nítrico reductasa (Nor) que cataliza la reducción del óxido nítrico a óxido nitroso y finalmente la óxido nitroso reductasa (Nos), que reduce al óxido nitroso a $\mathrm{N}_{2}$. En cada uno de estos pasos enzimáticos se da la transferencia de electrones (Figura 3) (González-Blanco, 2015).

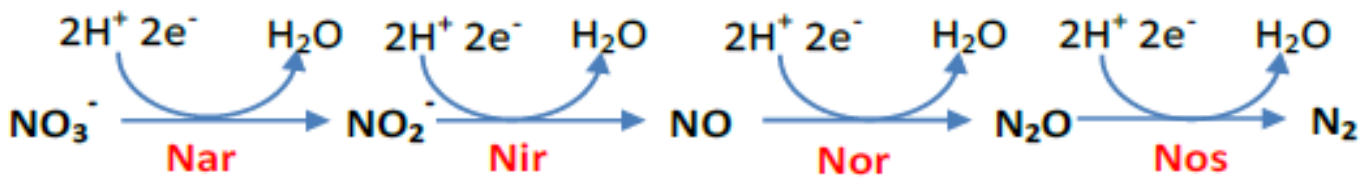

Figura 3. Ruta global del catabolismo desnitrificante (González-Blanco, 2015).

La reducción completa de $\mathrm{NO}_{3}{ }^{-}$a $\mathrm{N}_{2}$ se ha distinguido en diferentes especies de respiración facultativa, como Paracoccus denitrificans, Pseudomonas stutzery, Escherichia coli y Thiosphaera panthotropha (Baumann y col., 1996). Sin embargo, este proceso biológico es realizado por más de 50 géneros bacterianos desnitrificantes que pueden ser organótrofos, litoautótrofos y fotótrofos (Delwiche, 1982). Hay otras cepas identificadas con la capacidad metabólica para oxidar compuestos fenólicos acoplados a la reducción de $\mathrm{NO}_{3}{ }^{-}$, como Azoarcus sp., Thauera aromatica K172 y la cepa S100 (Anders y col., 1995; Shinoda y col., 2000).

\subsection{Nitrificación}

La nitrificación, que es la oxidación biológica del $\mathrm{NH}_{4}{ }^{+}$a $\mathrm{NO}_{3}{ }^{-}$a través de $\mathrm{NO}_{2}{ }^{-}$, se ha investigado ampliamente como un proceso fundamental en el primer paso de la eliminación de nitrógeno en el tratamiento biológico de aguas residuales, puesto que $\mathrm{el} \mathrm{NO}_{3}{ }^{-}$generado mediante la nitrificación es finalmente convertido a $\mathrm{N}_{2}$ a través de la desnitrificación (Gijs y Robertson, 1994; Texier y col., 2012). 
En el curso de su estudio sobre bacterias nitrificantes Winogradsky (1980) descubrió la quimioautotrofía bacteriana. Si bien el proceso de nitrificación en los suelos se conocía desde hacía algún tiempo, Winogradsky aisló tanto las bacterias amonio oxidantes como las bacterias nitrito oxidantes y demostró cuantitativamente que eran autótrofos. La nitrificación es un proceso respiratorio aerobio donde las bacterias nitrificantes utilizan $\mathrm{NH}_{4}{ }^{+} \mathrm{o} \mathrm{NO}_{2}{ }^{-}$como fuente de energía, dióxido de carbono como fuente de carbono y oxígeno molecular como aceptor final de electrones (Prosser, 1990). La nitrificación se realiza en dos etapas metabólicas sucesivas (Figura 4). En la primera etapa, el $\mathrm{NH}_{4}{ }^{+}$es oxidado a hidroxilamina $\left(\mathrm{NH}_{2} \mathrm{OH}\right)$ por la enzima amonio monooxigenasa (AMO) de las bacterias amonio oxidantes (AOB, por sus siglas en inglés) y la oxidación de la $\mathrm{NH}_{2} \mathrm{OH}$ a $\mathrm{NO}_{2}^{-}$se lleva a cabo por la actividad de la enzima hidroxilamina oxidorreductasa (HAO). Posteriormente en la segunda etapa, el $\mathrm{NO}_{2}{ }^{-}$es oxidado a $\mathrm{NO}_{3}{ }^{-}$por las bacterias nitrito oxidantes (NOB, por sus siglas en inglés) (Prosser, 1990; Bock y col., 1991). En la naturaleza, la nitrificación es un proceso que se lleva a cabo en conjunto con la desnitrificación, manteniendo una eficiente recirculación del nitrógeno, pero debido a la enorme generación de $\mathrm{NH}_{4}{ }^{+}$por el hombre, la velocidad de recirculación de este elemento puede verse disminuida y causar grandes problemas ambientales (Madigan y col., 2015).

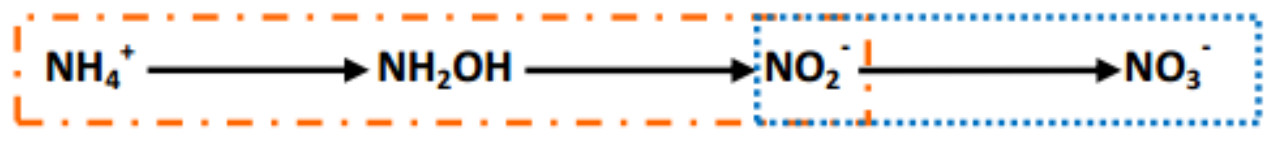

Etapa 1: Amonio oxidación

Etapa 2: Nitrito oxidación

Figura 4. Ruta global del catabolismo nitrificante (González-Blanco, 2015).

La energía libre estándar $\left(\Delta \mathrm{G}^{\mathrm{o}}\right)$ de la oxidación del $\mathrm{NH}_{4}{ }^{+}$a $\mathrm{NO}_{2}{ }^{-}$es $-275 \mathrm{~kJ} / \mathrm{mol}$, lo que indica que esta oxidación global es el paso donde las AOB pueden obtener energía (Tabla 1). El $\Delta \mathrm{G}^{\circ}$ para la oxidación de $\mathrm{NO}_{2}{ }^{-}$a $\mathrm{NO}_{3}{ }^{-}$es menor que para la oxidación de $\mathrm{NH}_{4}{ }^{+}$a $\mathrm{NO}_{2}{ }^{-}$y la consecuencia es un menor rendimiento de crecimiento de las NOB que de las AOB (Bernet y Spérandio, 2009). Debido a la baja disponibilidad de energía para la biosíntesis celular en el proceso respiratorio, el crecimiento de las bacterias nitrificantes es lento y escaso, incluso en condiciones óptimas. Por ejemplo, se han encontrado algunos valores de rendimiento de 
crecimiento de $0.08 \mathrm{~g}$ de células/g N-NH${ }_{4}{ }^{+}$para $\mathrm{AOB}$ y $0.05 \mathrm{~g}$ de células/g N-NO${ }_{2}^{-}$para $\mathrm{NOB}$, respectivamente (Wiesmann, 1994).

Tabla 1. Reacciones y valores de $\Delta \mathrm{G}^{\circ}$, de amonio y nitrito oxidación en el proceso nitrificante (Texier y col., 2012).

\begin{tabular}{lcr}
\hline Reacciones & Ecuaciones & $\Delta \mathrm{G}^{\circ 1}$ (kJ/reacción) \\
\hline Amonio oxidación & $\mathrm{NH}_{4}{ }^{+}+0.5 \mathrm{O}_{2} \rightarrow \mathrm{NH}_{2} \mathrm{OH}+\mathrm{H}^{+}$ & -8 \\
& $\mathrm{NH}_{2} \mathrm{OH}+\mathrm{O}_{2} \rightarrow \mathrm{NO}_{2}{ }^{-}+\mathrm{H}^{+}+\mathrm{H}_{2} \mathrm{O}$ & -267 \\
Reacción global de la amonio & $\mathrm{NH}_{4}{ }^{+}+1.5 \mathrm{O}_{2} \rightarrow \mathrm{NO}_{2}{ }^{-}+2 \mathrm{H}^{+}+\mathrm{H}_{2} \mathrm{O}$ & -275 \\
oxidación & & -74 \\
Nitrito oxidación & $\mathrm{NO}_{2}{ }^{-}+0.5 \mathrm{O}_{2} \rightarrow \mathrm{NO}_{3}^{-}$ & -349 \\
Reacción global de la & $\mathrm{NH}_{4}{ }^{-}+2 \mathrm{O}_{2} \rightarrow \mathrm{NO}_{3}{ }^{-}+2 \mathrm{H}^{+}+\mathrm{H}_{2} \mathrm{O}$ & \\
nitrificación & & \\
\hline
\end{tabular}

\subsubsection{Microorganismos de la nitrificación}

Delimitar un grupo taxonómico de bacterias como responsable de un proceso ambiental es a menudo un reto difícil de conseguir, sin embargo, el objetivo sigue siendo atractivo. Desde 1890 y hasta la década de 1980, las bacterias nitrificantes se agruparon en la familia Nitrobacteraceae, con distintos géneros de acuerdo a su función con respecto a su morfología celular y a la oxidación de $\mathrm{NH}_{4}{ }^{+}$o $\mathrm{NO}_{2}{ }^{-}$(Bock y col., 1986; Norton, 2011). Antiguamente algunas designaciones taxonómicas de las AOB quimilitótrofas se basaban en la forma celular y la disposición de las membranas citoplasmáticas, mientras que la taxonomía actual se basa en secuencias genómicas y ribosómicas comparativas (Norton, 2011). Las AOB terrestres generalmente están restringidas al grupo de las $\beta$-proteobacterias, mientras que los organismos marinos se encuentran tanto en las $\beta$-proteobacterias como en las $\gamma$-proteobacterias. La Figura 5 muestra un árbol guía de ARN ribosómico 16S para las designaciones de grupos de proteobacteria de $\mathrm{AOB}$. 


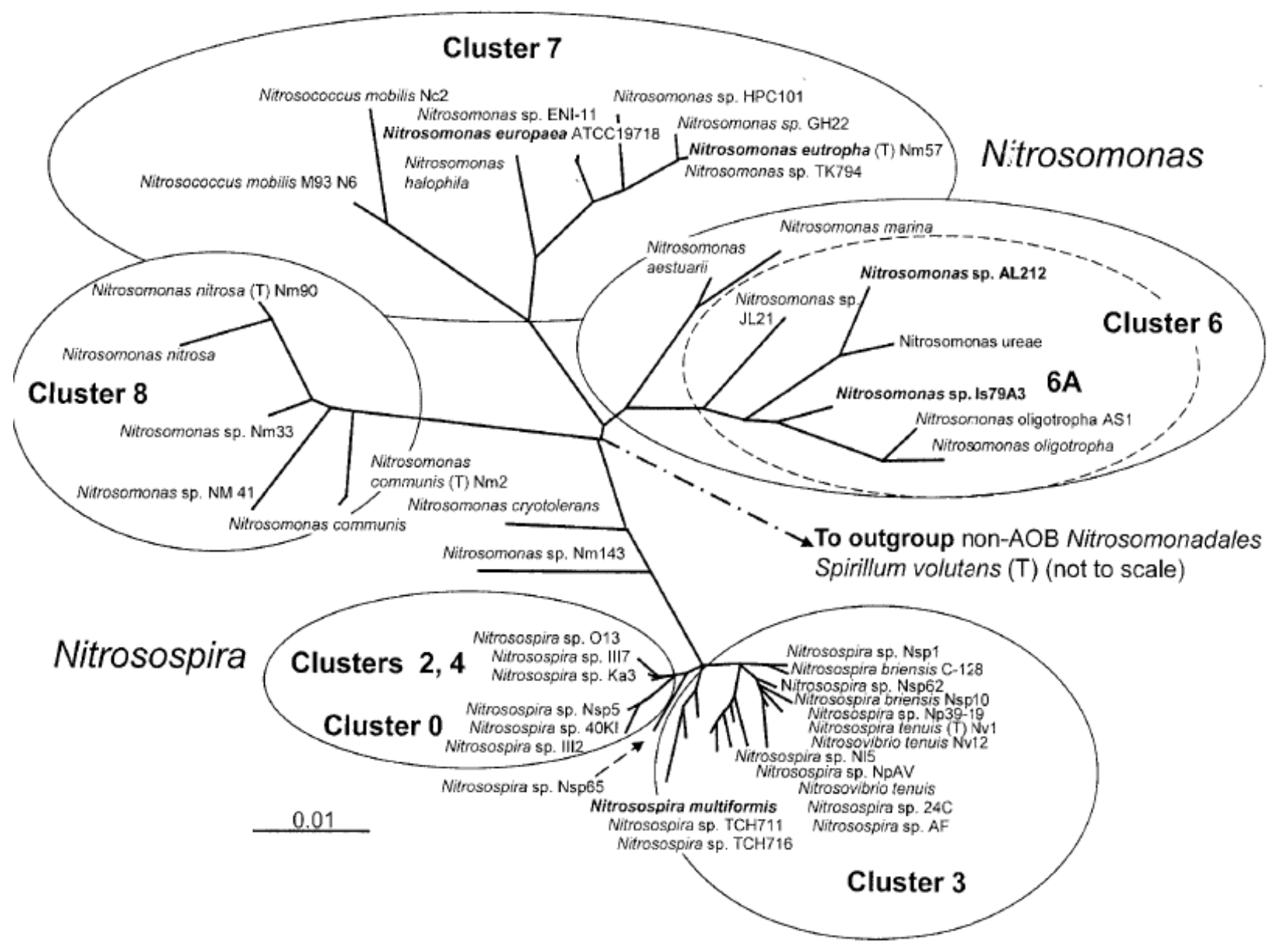

Figura 5. Arboles de guía de ARN ribosómico 16S para los grupos $\beta$-proteobacteria de bacterias AOB basados en secuencias de alta calidad (> 1,200 pb) de aislamientos (Norton, 2011).

Nitrosomonas y Nitrosospira son los géneros actualmente aceptados que comprenden las $\beta$-proteobacterias de AOB. Existen al menos seis líneas de descendencia dentro del género Nitrosomonas como se ha definido actualmente (Pommerening-Roser y col., 1996). Estos linajes se han definido por secuencias del gen 16S rRNA, secuencias del gen amoA y características ecofisiológicas (Purkhold y col., 2000; Koops y Pommerening-Roser, 2001). Dentro de Nitrosomonas, los linajes y/o especies generalmente se distribuyen en diferentes ambientes que incluyen la salinidad, la concentración de amoníaco y el pH (Figura 5). El clúster 6A representado por Nitrosomonas oligotropha y otras cepas sensibles al amoníaco se encuentran principalmente en aguas dulces, estuarios y en sistemas marinos. Los miembros del clúster 6B estrechamente relacionados, incluidos Nitrosomonas aestuarii y Nitrosomonas 
marina, tienen tolerancia a concentraciones de sales más altas, incluidos los sistemas marinos. El clúster 7 incluye a Nitrosomonas europaea, N. mobilis y Nitrosomonas eutropha, que son capaces de tolerar altas concentraciones de amoníaco. Cabe mencionar que este grupo ha sido aislado de una amplia variedad de ambientes, incluyendo aguas residuales, ambientes acuáticos y terrestres. El clúster 8 corresponde a Nitrosomonas communis y Nitrosomonas nitrosa los cuales tienen diversas características y fuentes ecofisiológicas, además los linajes representados por Nitrosomonas sp. la cepa NM 143 y N. cryotolerans son grupos marinos de ramificación profunda (Norton, 2011). Dentro de Nitrosospira los grupos basados en la filogenia de 16S rRNA son problemáticos de clasificar debido a los altos niveles generales de identidad del 16S rRNA (> 97\%) (Norton, 2011). Se puede lograr una resolución más fina dentro del grupo utilizando marcadores adicionales como la región 16S-23S rRNA (Aakra y col., 2001) o genes amoA de longitud completa (Norton y col., 2002).

Los grupos actuales representativos para Nitrosospira incluyen los clústeres 0, 2, 3 y 4 (Figura 5); el clúster 1 todavía no ha sido representado por cultivos puros. Los sistemas marinos y de agua dulce por lo regular tienen mezclas de los géneros de AOB presentes. La distribución de los grupos Nitrosospira está relacionada con rasgos ecofisiológicos que incluyen tolerancia al $\mathrm{pH}$, actividad de ureasa, $\mathrm{pH}$ óptimo para la ureólisis y tolerancia a sales (De Boer y Kowalchuk, 2001; Koops y Pommerening-Roser, 2001). Se han encontrado secuencias que se agrupan con el clúster 0 en suelos y ambientes de agua dulce, mientras que las secuencias del clúster 1 se recuperan predominantemente de aguas marinas o sedimentos. Los clústeres 2, 3 y 4 se encuentran en una variedad de entornos que incluyen suelos, agua dulce y sistemas marinos, las secuencias del clúster 2 a menudo son recuperadas de suelos ácidos (Kowalchuk y Stephen, 2001). Las secuencias del clúster 3 siguen siendo las más recuperadas de los ambientes terrestres, particularmente de los sistemas agrícolas, de pastizales o de césped (Kowalchuk y Stephen, 2001; Norton, 2008).

La actividad de las NOB está estrechamente relacionada con la actividad de las AOB, ya que éstas convierten el $\mathrm{NH}_{4}{ }^{+}$a $\mathrm{NO}_{2}^{-}$y suministran el sustrato que requieren las $\mathrm{NOB}$. En ausencia de $\mathrm{NOB}$, el $\mathrm{NO}_{2}{ }^{-}$se acumularía y finalmente alcanzaría concentraciones tóxicas para otros microorganismos en el medio ambiente. $\mathrm{El} \mathrm{NO}_{3}{ }^{-}$, producto de la oxidación de $\mathrm{NO}_{2}{ }^{-}$, no 
solo es una fuente principal de nitrógeno para otros microorganismos y plantas, sino que también sirve como aceptor de electrones en la respiración de $\mathrm{NO}_{3}{ }^{-}$en condiciones de oxígeno limitado. Las bacterias NOB tienen un papel clave ecológico, por lo que al igual que las bacterias amonio oxidantes, están ampliamente distribuidas en la naturaleza y se han adaptado a una gran variedad de condiciones ambientales (Daims y col., 2011). La Figura 6 muestra las posiciones filogenéticas de los principales linajes de NOB y sus afiliaciones a organismos relacionados con la oxidación de $\mathrm{NH}_{4}{ }^{+}$y organismos no nitrificantes.

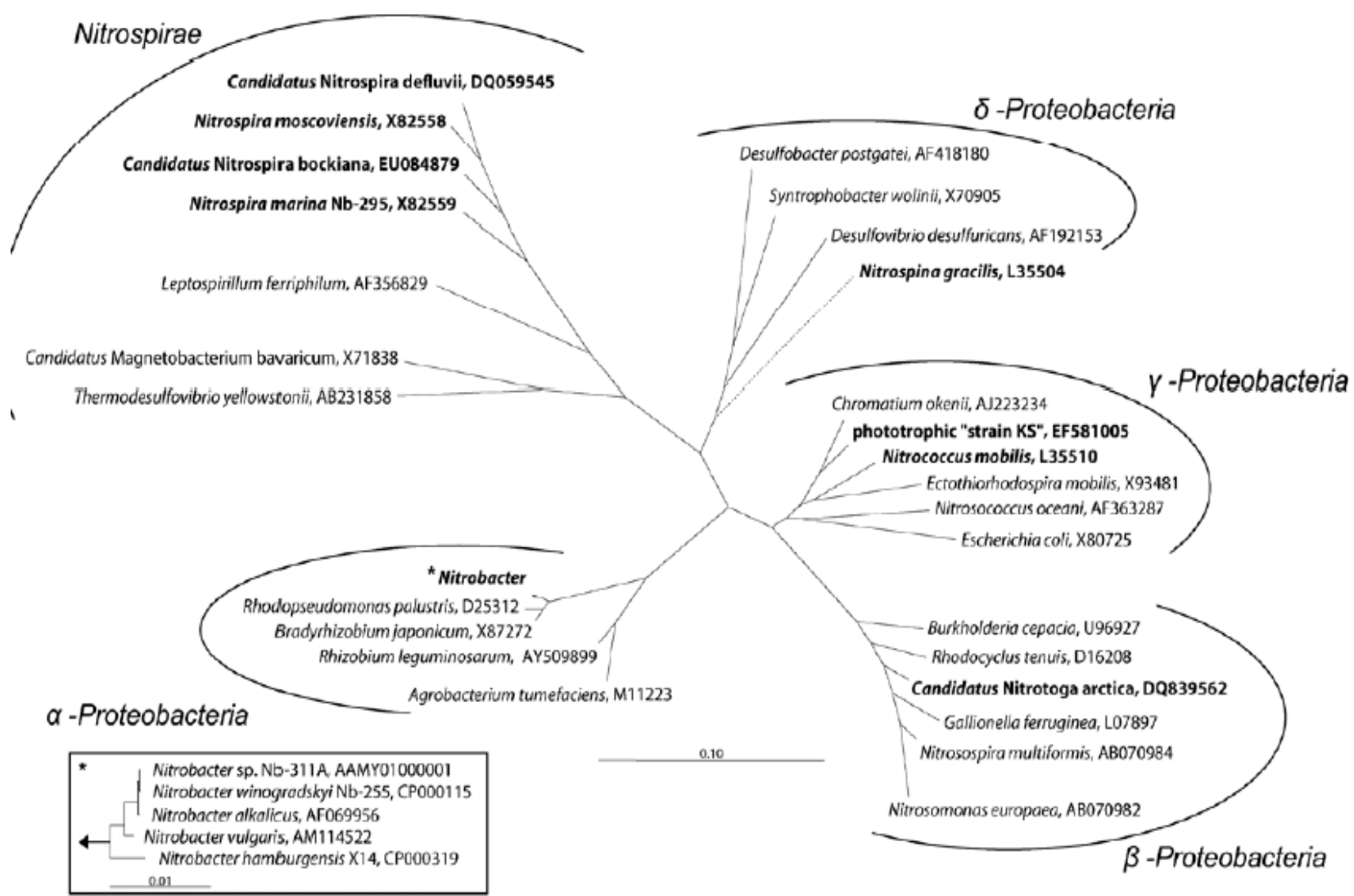

Figura 6. Árbol filogenético, basado en secuencias del gen 16S rRNA, que muestra las afiliaciones filogenéticas de NOB actualmente conocidas a bacterias oxidantes de amonio y no nitrificantes. Los nombres de las bacterias nitrito oxidantes están en negrita. Los números de acceso a la base de datos están indicados para todas las secuencias del gen 16S rRNA. Las barras de escala indican un cambio estimado de 0.1 (árbol grande) o 0.01 (recuadro) por nucleótido (Daims y col., 2011). 
Las bacterias NOB son filogenéticamente un grupo funcional relativamente heterogéneo. Hasta algunos años, se han descrito siete géneros de NOB quimiolitoautotróficas aerobias: Nitrobacter, Nitrococcus, Nitrotoga, Nitrospina, Candidatus Nitromaritima, Nitrolancea y el género Nitrospira (Daims y col., 2011; Feng y col., 2017). Los géneros más conocidos de NOB pertenecen a uno de los principales linajes en el phylum Proteobacteria. El género Nitrobacter es miembro de $\alpha$-proteobacteria (Woese y col., 1984; Stackebrandt y col., 1988), Nitrococcus es miembro de $\gamma$-proteobacteria (Teske y col., 1994) y el género Nitrotoga es miembro de las $\beta$ proteobacterias (Alawi y col., 2007). El género Nitrospina y Candidatus Nitromaritima son miembros de Nitrospinae (Teske y col., 1994; Ngugi y col., 2016). Nitrolancea es miembro de Chloroflexi (Feng y col., 2017). Finalmente, el género Nitrospira es un linaje importante del filo bacteriano Nitrospirae (Ehrich y col., 1995) y no está relacionado estrechamente con las proteobacterias. Este filo también incluye los dos géneros Leptospirillum (oxidantes de hierro quimio-quimioautotróficas aerobias) y Thermodesulfovibrio (reductores de sulfato anaerobios) (Ehrich y col., 1995).

\subsubsection{Aspectos bioquímicos de la nitrificación}

En condiciones aerobias el proceso amonio-oxidante se lleva a cabo por dos reacciones. En la primera de ellas, catalizada por la enzima $\mathrm{AMO}$, el $\mathrm{NH}_{3}$ es convertido a $\mathrm{NH}_{2} \mathrm{OH}$ (Ecuación 6, Figura7) (Castingnetti y Hollocher, 1985) y posteriormente, en una segunda reacción, ésta es convertida a $\mathrm{NO}_{2}{ }^{-}$mediante la acción de la enzima HAO (Ecuación 7, Figura 7) (Andersson y col., 1984; Costa y col., 2006).

$$
\begin{array}{ll}
\mathrm{NH}_{3}+\mathrm{O}_{2}+2 \mathrm{H}^{+}+2 e^{-} \stackrel{A M O}{\longrightarrow} \mathrm{NH}_{2} \mathrm{OH}+\mathrm{H}_{2} \mathrm{O} & \text { Ec. } 6 \\
\mathrm{NH}_{2} \mathrm{OH}+\mathrm{H}_{2} \mathrm{O} \stackrel{\mathrm{HAO}}{\longrightarrow} \mathrm{NO}_{2}^{-}+5 \mathrm{H}^{+}+4 e^{-} & \text {Ec. } 7
\end{array}
$$


(a) Paso 1: oxidación de amonio a nitrito

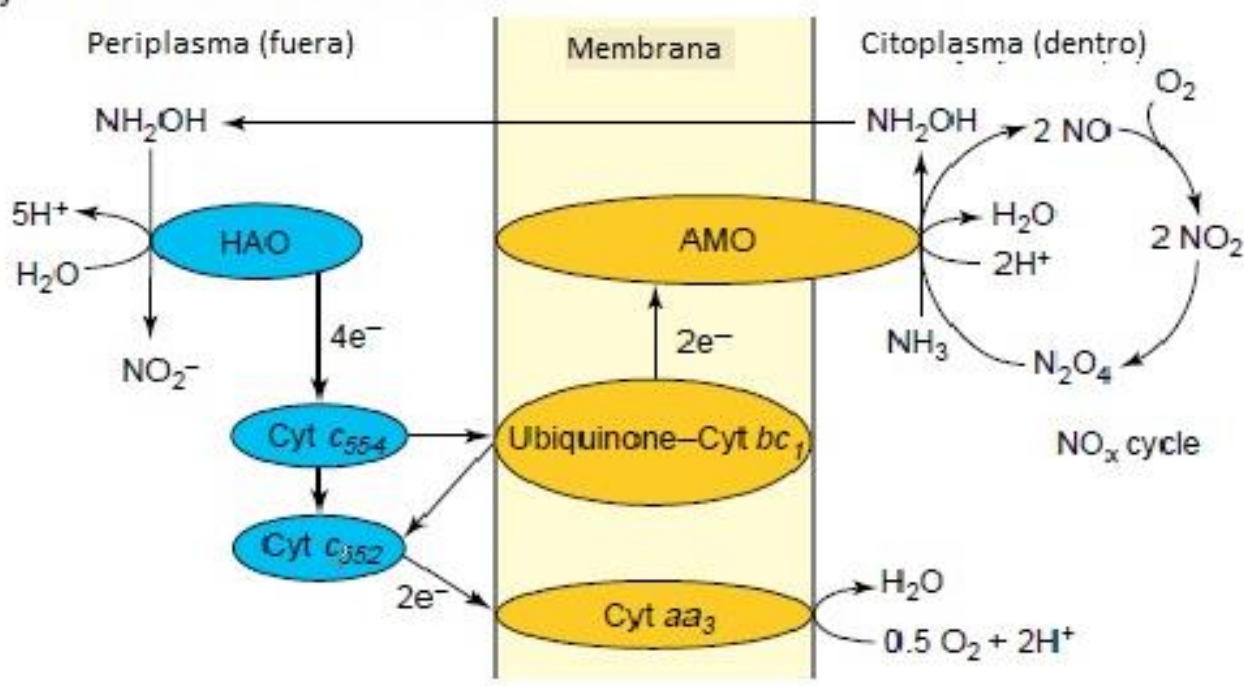

(b) Paso 2: oxidación de nitrito a nitrato

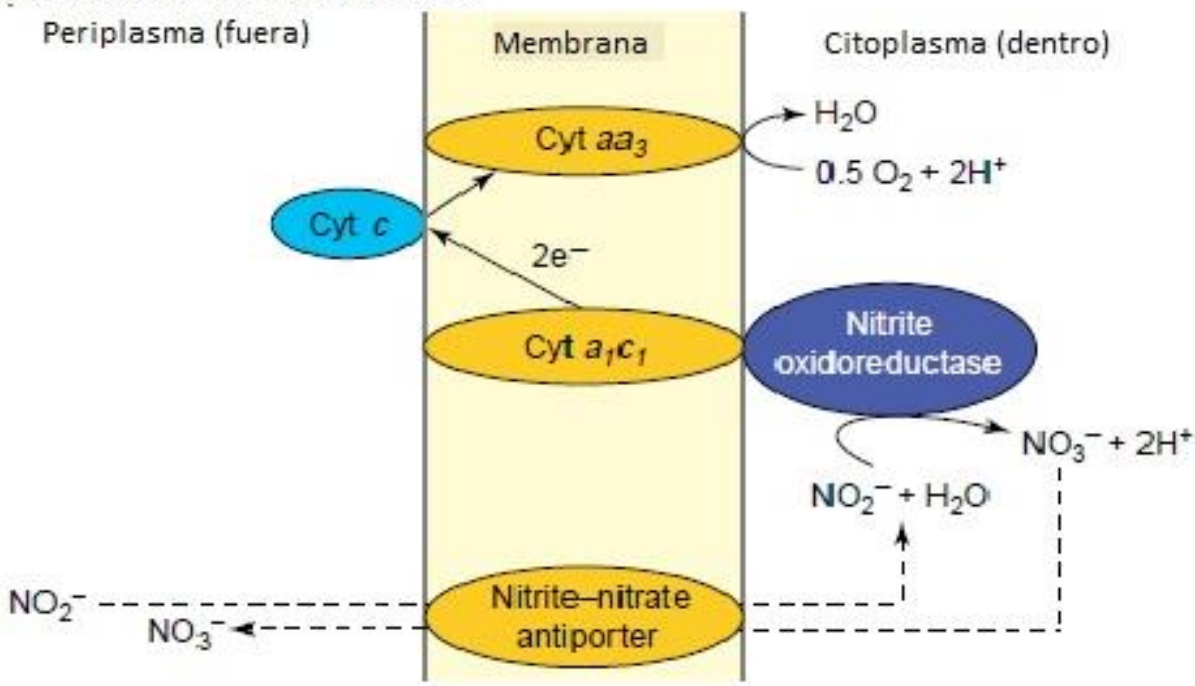

Figura 7. Esquema del metabolismo de la nitrificación. (a) Paso 1 por AOB del género Nitrosomonas. (b). Paso 2 por NOB del género Nitrobacter. Modificado de Costa y col. (2006).

Toda la energía requerida para el metabolismo de las AOB deriva de la oxidación de $\mathrm{NH}_{3}$ a $\mathrm{NO}_{2}-$ en un proceso de dos pasos. Las AOB primero usan la enzima AMO unida a la membrana citoplasmática para catalizar la oxidación de $\mathrm{NH}_{3}$ a $\mathrm{NH}_{2} \mathrm{OH}$ y luego, en el espacio periplásmico, usan la enzima $\mathrm{HAO}$ para catalizar la oxidación de $\mathrm{NH}_{2} \mathrm{OH}$ a $\mathrm{NO}_{2}{ }^{-}$. La oxidación de $\mathrm{NH}_{3}$ a $\mathrm{NH}_{2} \mathrm{OH}$ requiere $\mathrm{O}_{2}$, dos protones y dos electrones: un $\mathrm{O}$ se inserta al $\mathrm{NH}_{3}$ para formar 
$\mathrm{NH}_{2} \mathrm{OH}$, y el otro $\mathrm{O}$ se combina con los dos protones y dos electrones para formar $\mathrm{H}_{2} \mathrm{O}$ (Wood, 1986; Hooper y col., 1997).

La enzima AMO consta de tres subunidades: AmoA o a (27kDa), AmoB o b (38kDa), y AmoC o c (31.4 kDa). Las secuencias de aminoácidos de proteínas primarias de cada subunidad revelan varias hélices alfa que abarcan la membrana. Los estudios con acetileno como inactivador de la AMO llevaron a sugerir que la subunidad AmoA contiene el sitio catalítico para la oxidación del $\mathrm{NH}_{4}{ }^{+}$(Arp y col., 2002). Asimismo, se ha demostrado un papel importante del cobre en la catálisis, sugiriendo que el cobre es cofactor de la AMO (Ensign y col., 1993). Se ha reportado que la enzima AMO además de oxidar al $\mathrm{NH}_{4}{ }^{+}$tiene la capacidad para la cooxidación de numerosos compuestos orgánicos, incluyendo alifáticos recalcitrantes, aromáticos y moléculas halogenadas (Juliette y col, 1993; Keener y Arp, 1993, 1994; McCarty, 1999).

De la reacción de transformación de $\mathrm{NH}_{2} \mathrm{OH}$ en $\mathrm{NO}_{2}{ }^{-}$se liberan cuatro electrones y se canalizan a través del citocromo tetraheme $\mathrm{C}_{554}$ ubicado en el periplasma, y luego probablemente a través de un segundo citocromo unido a la membrana, el citocromo tetraheme $\mathrm{C}_{552}$. El citocromo $\mathrm{C}_{552}$ unido a la membrana sirve como una quinona reductasa (Hooper, 1989, Whittaker y col., 2000). Los electrones se reparten luego al nivel del grupo de ubiquinona periplásmico; dos electrones producidos en la segunda reacción se utilizan para compensar la entrada de electrones de la primera reacción y obtener una mayor oxidación de amoníaco por AMO, mientras que los otros dos se pasan a través de una cadena de transporte de electrones a la oxidasa terminal, generando así una fuerza motriz de protones para la generación de ATP y proporcionar un agente reductor para otros procesos celulares (por ejemplo la asimilación de nutrientes inorgánicos como el bicarbonato de sodio $\left.\left(\mathrm{NaHCO}_{3}\right)\right)($ Kowalchuk y Stephen, 2001; Sayavedra-Soto y Arp, 2011).

La HAO es una enzima cristalina que contiene complejos hemo en un estado $\alpha 3$ oligomérico. Cada una de sus tres subunidades contiene un hemo P460 de tipo C modificado, de alto giro y cinco coordenadas, que es el sitio catalítico. Este hemo P460 es exclusivo de la HAO. Siete hemos adicionales de tipo c en cada subunidad participan en la transferencia de electrones desde el sitio catalítico (Arciero y col., 1993). También se ha identificado un segundo 
cromóforo $\mathrm{P} 460$ en las AOB y reside en una pequeña proteína periplásmica soluble (Pearson y col., 2007). Este citocromo P460 tiene un solo hemo P460 de alto giro y cinco coordenadas por polipéptido de $18.8 \mathrm{kDa}$ y no tiene similitud estructural con HAO. El citocromo P460 se une a la $\mathrm{NH}_{2} \mathrm{OH}$, la hidracina y el cianuro en su forma férrica y al $\mathrm{CO}$ en su forma ferrosa y muestra una débil actividad de oxidación de hidroxilamina/citocromo c oxidorreductasa (Numata y col., 1990).

Se puede observar que el proceso de amonio-oxidación es de gran consumo de oxígeno: 1.5 mol de oxígeno por mol de amonio, lo que corresponde a $3.43 \mathrm{~g}$ de oxígeno por g de nitrógeno amoniacal (Bernet y Spérandio, 2009). La oxidación general de $\mathrm{NH}_{4}{ }^{+}$a $\mathrm{NO}_{2}{ }^{-}$con $\mathrm{O}_{2}$ como aceptor terminal de electrones resulta en la liberación de dos protones $\left(\mathrm{NH}_{4}{ }^{+}+1.5 \mathrm{O}_{2} \rightarrow\right.$ $\mathrm{NO}_{2}{ }^{-}+2 \mathrm{H}^{+}+\mathrm{H}_{2} \mathrm{O}$ ). Por lo tanto, la oxidación de amoníaco resulta en la acidificación del medio de crecimiento o del medio ambiente, y, por lo tanto, puede desplazar el equilibrio $\mathrm{NH}_{3} / \mathrm{NH}_{4}{ }^{+}$ hacia $\mathrm{NH}_{4}{ }^{+}$(pKa de 9.25 a $25^{\circ} \mathrm{C}$ ). Debido a que la AMO utiliza como sustrato $\mathrm{NH}_{3}$ y no $\mathrm{NH}_{4}{ }^{+}$, al bajar el pH, la concentración de $\mathrm{NH}_{3}$ que está disponible para el crecimiento también disminuye (Suzuki y col., 1974).

El último paso de la nitrificación se lleva a cabo por las NOB, que tienen como característica principal la capacidad de oxidar $\mathrm{NO}_{2}{ }^{-}$a $\mathrm{NO}_{3}{ }^{-}$y se cataliza por un complejo enzimático formado por la nitrito oxidorreductasa (NOR) (Ecuación 8), el citocromo C, una quinona y una deshidrogenasa dependiente de NADH (Figura 7). Se liberan dos electrones durante la oxidación de $\mathrm{NO}_{2}{ }^{-}$a $\mathrm{NO}_{3}{ }^{-}$, y el tercer átomo de $\mathrm{O}$ en la molécula del $\mathrm{NO}_{3}{ }^{-}$se deriva del $\mathrm{H}_{2} \mathrm{O}$ (Aleem y col., 1965; Aleem y Sewell, 1981). La enzima NOR está localizada en la membrana citoplasmática y se cree que es una proteína heterodimérica que consiste en una subunidad $\alpha$ grande, NorA (130 kDa) y una subunidad $\beta$ más pequeña, NorB (65 kDa) (Meincke y col., 1992).

$\mathrm{NO}_{2}^{-}+\mathrm{H}_{2} \mathrm{O} \stackrel{\mathrm{NOR}}{\longrightarrow} \mathrm{NO}_{3}^{-}+2 \mathrm{H}^{+}+2 e^{-} \quad$ Ec. 8 
Con estudios de espectroscopía de resonancia paramagnética electrónica, Meincke y col. (1992) propusieron que los centros de molibdeno, azufre y hierro se asocian como cofactores y están involucrados en la oxidación de $\mathrm{NO}_{2}{ }^{-}$a $\mathrm{NO}_{3}{ }^{-}$(Kruger y col., 1987; Meincke y col., 1992). Se ha sugerido que los electrones que se originan de la oxidación de $\mathrm{NO}_{2}{ }^{-}$por la $\mathrm{NOR}$ se liberan del componente hemo a1 de NOR, se transfieren a cyt c550 y posteriormente se transfieren a la citocromo oxidasa (Yamanaka y Fukumori, 1988). La oxidación de dos moléculas de $\mathrm{NO}_{2}{ }^{-}$ producen $4 \mathrm{H}^{+}$en el lado citoplasmático de la membrana, y la conversión de una molécula de $\mathrm{O}_{2}$ a 2 de $\mathrm{H}_{2} \mathrm{O}$ consume $4 \mathrm{H}^{+}$. Si esta combinación de actividades redox se produce en el mismo lado de la membrana citoplasmática, evitaría la formación de un gradiente de $\mathrm{H}^{+}$. Sin embargo, dado que ahora se acepta generalmente que se transfieren $4 \mathrm{H}^{+}$por recambio de citocromo oxidasa terminal convencional (Mathews y col., 2000), esto debería dar como resultado una transferencia neta de $2 \mathrm{H}^{+}$por mol de $\mathrm{NO}_{2}{ }^{-}$oxidado, un $\mathrm{H}^{+} / \mathrm{O}$ de 2 , y la generación de 1 ATP por $1.5 \mathrm{NO}_{2}^{-}$oxidado (suponiendo que $3 \mathrm{H}^{+}$se transloquen por ATP formado y que el $\mathrm{H}^{+}$gradiente no se disipa durante el flujo inverso de electrones).

\subsubsection{Factores que afectan la nitrificación}

Como cualquier proceso biológico, la nitrificación está condicionada al ambiente que la rodea. Se sabe que la eficacia de la transformación de $\mathrm{NH}_{4}{ }^{+}$a $\mathrm{NO}_{3}{ }^{-}$puede estar determinada, entre otros factores, por la temperatura, $\mathrm{pH}$, concentración de oxígeno y también por la forma y concentración del mismo sustrato $\left(\mathrm{NH}_{4}{ }^{+}\right.$y $\left.\mathrm{NO}_{2}^{-}\right)$o de materia orgánica.

Las tasas de crecimiento de las AOB y NOB se ven muy afectadas por la temperatura y el $\mathrm{pH}$. Se han reportado las condiciones óptimas de crecimiento para $\mathrm{AOB}$ de $25-30{ }^{\circ} \mathrm{C}$ a un $\mathrm{pH}$ de 7.5-8.0 y para NOB de $28-30{ }^{\circ} \mathrm{C}$ a un $\mathrm{pH}$ de 7.6-7.8. De manera general para obtener una nitrificación completa, así como un mejor desempeño en el crecimiento y actividad de las AOB y NOB, se utilizan intervalos de 25-30 ${ }^{\circ} \mathrm{C}$ y pH 7.5-8.0 (Bock y col., 1991; Gieseke y col., 2006; Texier y col., 2012). Por ejemplo, se ha evaluado el efecto de la temperatura y $\mathrm{pH}$ en un reactor alimentado con un lodo activado enriquecido nitrificante para obtener la velocidad de nitrificación máxima utilizando $3200 \mathrm{mg} / \mathrm{L}$ de sólidos suspendidos volátiles de licor mezclado 
(SSVLM). Se evaluaron tres valores de $\mathrm{pH}$ (7, 7.7 y 8.3) y diferentes temperaturas $(4,10,17$, 25 y $33{ }^{\circ} \mathrm{C}$ ). El mejor comportamiento nitrificante se obtuvo a un $\mathrm{pH}$ de 8.3 y una temperatura entre 25 y $33{ }^{\circ} \mathrm{C}$ (Shammas, 1986).

Se ha reportado que el $\mathrm{NH}_{3}$ (amoníaco libre) en lugar de $\mathrm{NH}_{4}{ }^{+}$(ion amonio) es el sustrato de Nitrosomonas y otras AOB aerobias quimiolitotróficas (Okabe y col., 2011). El pH es el parámetro clave que rige los equilibrios entre $\mathrm{NH}_{3} / \mathrm{NH}_{4}{ }^{+}$(pKa de 9.25 a $25{ }^{\circ} \mathrm{C}$ según Harris (2003) y $\mathrm{NO}_{2}{ }^{-} / \mathrm{HNO}_{2}$ (pKa de 3.34 a $25^{\circ} \mathrm{C}$ según Whitten y col. (2008)); las concentraciones de $\mathrm{NH}_{3}$ y $\mathrm{HNO}_{2}$ siendo más altas a $\mathrm{pH}$ más alcalino y más ácido, respectivamente. Además, la disponibilidad de $\mathrm{CO}_{2}$ necesaria para el crecimiento de AOB y $\mathrm{NOB}$ se ve afectada por el $\mathrm{pH}$, ya que se disuelve más fácilmente en agua a un pH más alto. Existe la hipótesis de que las formas no ionizadas de $\mathrm{NH}_{4}{ }^{+}$y de $\mathrm{NO}_{2}^{-}\left(\mathrm{NH}_{3}\right.$ y $\left.\mathrm{HNO}_{2}\right)$ inhiben a los organismos nitrificantes y se cree que podría tener un efecto en la actividad enzimática de las bacterias nitrificantes (Anthonisen y col., 1976; Peng y Zhu, 2006). Al respecto, Anthonisen y col. (1976) realizaron un diagrama para especificar la combinación de valores de $\mathrm{pH}$ y las concentraciones de $\mathrm{NH}_{4}{ }^{+}$y $\mathrm{NO}_{2}{ }^{-}$total para llevar a cabo una nitrificación estable en diferentes condiciones operacionales, los autores sugieren que las concentraciones iniciales de $\mathrm{NH}_{4}{ }^{+}$y $\mathrm{NO}_{2}{ }^{-}$son cruciales para identificar el nivel de inhibición sobre el rendimiento nitrificante. También se ha señalado que la inhibición por $\mathrm{NH}_{3}$ y $\mathrm{HNO}_{2}$ depende de la concentración celular, y que las NOB son más sensibles a esta inhibición que las AOB (Bernet y Spérandio, 2009). Considerando la disponibilidad de $\mathrm{CO}_{2}$ y $\mathrm{NH}_{3}$ y el posible efecto adverso de $\mathrm{NH}_{3}$ y $\mathrm{HNO}_{2}$, un $\mathrm{pH}$ alrededor de 7.5 sería el más favorable, especialmente para AOB (Okabe y col., 2011). La sensibilidad de las AOB al amoniaco también depende de la naturaleza fisiológica del lodo. Se ha encontrado que AOB presentes en lodos de depuración son más sensibles a una mayor concentración de $\mathrm{NH}_{4}{ }^{+}$, que un lodo encontrado en un reactor altamente enriquecido con mayores concentraciones o cargas de $\mathrm{NH}_{4}{ }^{+}$, el cual resulta más tolerante al $\mathrm{NH}_{4}{ }^{+}$(Suwa y col., 1994). El amoniaco libre inhibe no solo la amonio oxidación, sino que también la nitrito oxidación (Anthonisen y col., 1976), donde esta última resulta a menudo más sensible que la oxidación de $\mathrm{NH}_{4}{ }^{+}$, lo que da como resultado la acumulación de $\mathrm{NO}_{2}^{-}$. El $\mathrm{NO}_{2}^{-}$es otro de los inhibidores conocidos de la actividad de la AMO, pues inhibe la oxidación de amoníaco en presencia de $\mathrm{O}_{2}$ por un mecanismo aún desconocido (Stein y Arp, 
1998). Curiosamente, se ha reportado que el $\mathrm{NH}_{3}$ en sí y los alcanos cortos pueden proteger a la AMO de la inhibición del $\mathrm{NO}_{2}^{-}$(Sayavedra-Soto y Arp, 2011). Asimismo, altas concentraciones de $\mathrm{NO}_{2}{ }^{-}$pueden inhibir el proceso de nitrificación y eso podría estar relacionado principalmente con los valores de $\mathrm{pH}$ debido a la formación de $\mathrm{HNO}_{2}$. La nitrito oxidación es más sensible a la presencia de $\mathrm{NO}_{2}{ }^{-}$que el proceso amonio oxidante, por lo que se sugiere que la acumulación de $\mathrm{NO}_{2}{ }^{-}$en los sistemas nitrificantes debe controlarse a fin de evitar una mayor acumulación de $\mathrm{NO}_{2}^{-}$y una disminución en el rendimiento de producción de nitrato (YN-NO${ }^{-}$) (Silva y col., 2011; Texier y col., 2012). Algunos autores sugieren que el $\mathrm{NO}_{2}^{-}$se acumula cuando las AOB tienen mayor actividad o crecen más rápido que las NOB. Tal actividad desigual entre AOB y NOB se puede obtener en presencia de amoníaco libre a un pH más alto, así como a una temperatura más alta (Isaka y col., 2007; Volcke y col., 2006). Todo lo anterior indica que el control del pH es crucial para un buen desempeño de la nitrificación.

En el proceso respiratorio nitrificante, se utiliza oxígeno como aceptor final de electrones. Se asume generalmente que concentraciones de oxígeno superiores a $2 \mathrm{mg} / \mathrm{L}$ son adecuadas para realizar una nitrificación con éxito (Gerardi, 2002). De hecho, la nitrificación es muy sensible a concentraciones de oxígeno disuelto bajas. Las bacterias nitrificantes tienen una afinidad alta por él al presentar bajos valores de Ks entre 0.4 y 0.6 mg/L (Robinson y col., 2004). Las AOB y NOB pueden presentar afinidades diferentes por el oxígeno $\left(\mathrm{KO}_{2}\right)$ y las NOB son más sensibles a la limitación de $\mathrm{O}_{2}$ que las AOB (Laanbroek y Gerards, 1993). Por lo tanto, una concentración baja de oxígeno disuelto, alrededor de 0.2 a $0.5 \mathrm{mg} / \mathrm{L}$, es una condición posible para limitar la actividad nitrito-oxidante en los sistemas de nitrificación (Bernet y Sperandio, 2009). Por otra parte, la concentración de oxígeno disuelto en el medio es fundamental para la selección de microorganismos nitrificantes, ya que se ha reportado que al comparar la forma de aireación de dos reactores de lotes secuenciados (SBR) nitrificantes alimentados con lodos activados, un reactor en condiciones aerobias (aireación constante) y otro en condiciones aerobias/anóxicas (aireación intermitente), las comunidades AOB y NOB fueron diferentes. Los géneros Nitrosospira (AOB) y Nitrospira (NOB) se encontraron en mayor proporción en el reactor aireado constantemente que en el reactor aireado intermitentemente (Dytczak y col., 2008). 
Aunque las AOB presentan cierta capacidad para oxidar materia orgánica, también está bien documentada la alta sensibilidad de las bacterias nitrificantes a los efectos tóxicos o inhibitorios de los compuestos orgánicos (Schweighofer y col., 1996, Suárez-García y col., 2019). La mayoría de los estudios sobre los efectos de los compuestos orgánicos en la nitrificación han utilizado como inóculo cultivos axénicos o consorcios, como es el caso de los lodos activados. Algunos autores señalan que, debido a la baja velocidad de crecimiento de los microorganismos nitrificantes, su inhibición, aunque sea parcial, puede causar que, en sistemas de lodos activados, se detenga el proceso nitrificante (Bernet y Spérandio, 2009). Se ha mostrado que los efectos dependen principalmente de la concentración, estructura química y tipo de contaminante orgánico, así como también del tipo de cultivo (axénico o consorcio) y del origen de los lodos (Gómez y col., 2000; Zepeda y col., 2006). Desde la década de los 80, se ha estudiado el efecto de la materia orgánica sobre el proceso nitrificante, proponiéndose dos posturas. Una en la que se dice que la presencia de materia orgánica favorece el crecimiento de organismos heterotróficos sobre los organismos nitrificantes, propiciando una inhibición de la nitrificación, ya que se lleva a cabo una competencia por el $\mathrm{NH}_{4}{ }^{+}$y el oxígeno del medio (Digger y col., 1985; Michael y col., 1985; Hanaki y col., 1990). Así pues, se propone que la presencia de la materia orgánica ocasiona la disminución en la respuesta nitrificante (Eficiencias de consumo, rendimientos de producción y velocidades específicas de consumo o producción) al desviar el proceso respiratorio nitrificante a uno asimilativo. La otra postura propone un efecto directo sobre las enzimas nitrificantes (McCarty, 1999; Pérez-Alfaro, 2015), Algunos estudios han reportado que la enzima AMO puede oxidar diversos compuestos aromáticos y que la inhibición de la actividad de la AMO puede ser competitiva o no competitiva (Keener y Arp, 1993; McCarty, 1999). Además de algunos compuestos aromáticos otros inhibidores competitivos incluyen al metano, etileno y hasta el monóxido de carbono que compiten con el $\mathrm{NH}_{3}$ por el sitio activo de la AMO (Hooper y Terry, 1973; Keener y Arp, 1993). Los inhibidores no competitivos incluyen etano, cloroetano y a la tiourea (Sayavedra-Soto y Arp, 2011). Con respecto a la enzima HAO la información es aún muy escasa. Sin embargo, en la enzima NOR se ha reportado inhibición sobre su actividad por diferentes compuestos como la azida y clorato (Belser y Mays, 1980; Ginestet y col., 1998; Ali y col., 2013) 
Asimismo, se ha reportado que la exposición microbiana a compuestos fenólicos y clorofenólicos podría ocasionar varias alteraciones en la membrana celular, en sus mecanismos de transporte (Heipieper y col., 1992; Sikkema y col., 1995; Dercová y col., 2004), así como en el desacoplamiento de la fosforilación oxidativa (Bradberry y col., 2004). Como resultado, diferentes compuestos orgánicos podrían acumularse en la membrana microbiana cambiando su fluidez (Ramos y col., 2002; Segura y col., 2012). Para contrarrestar esta alteración de la membrana, algunos microorganismos son capaces de isomerizar los ácidos grasos insaturados cis en ácidos grasos insaturados trans, lo que resulta en una mayor densidad de las membranas bacterianas y, en consecuencia, en la adaptación celular a nuevas condiciones ambientales (Ramos y col., 2002; Segura y col., 2012). En general, la materia orgánica provoca efectos negativos sobre el proceso nitrificante, hace falta realizar más investigación que permita obtener mayor información sobre el tema, a fin de proponer alternativas para disminuir estos efectos y llevar a cabo una nitrificación completa y estable.

\subsection{2-Clorofenol}

El 2-clorofenol $\left(\mathrm{C}_{6} \mathrm{H}_{5} \mathrm{OCl}, o\right.$-Clorofenol, 2-cloro-1-hidroxibenceno, 2-CF) es un líquido desde incoloro a ámbar con un olor desagradable. El 2-CF es muy soluble en agua (28.5 g/L a $25^{\circ} \mathrm{C}$ y pH neutro) (Tabla 2). Esta característica implica peligro de movilización en suelos, contaminación de acuíferos y acumulación en ecosistemas acuáticos. De acuerdo con su coeficiente de partición octanol-agua $(\mathrm{Kow}=2.16)$, que es una medida de cómo una sustancia química puede distribuirse en dos solventes inmiscibles, agua (solvente polar) y octanol (solvente relativamente no polar, que representa a las grasas), el 2-CF puede fijarse con firmeza a materia orgánica, sedimentos y microorganismos (partes lipofílicas como membranas celulares). Debido a esto y considerando que la vía de exposición al 2-CF puede ser a través de la cadena alimenticia, este compuesto tiende a bioacumularse en la grasa corporal de los animales (Loehr y Krishnamoorthy, 1988). 
Tabla 2. Propiedades fisicoquímicas del 2-CF. Handbook of Environmental Data on Organic Chemicals Index Merk (1996).

\begin{tabular}{ll}
\hline Punto de fusión & $9.3^{\circ} \mathrm{C}$ \\
Punto de ebullición & $175{ }^{\circ} \mathrm{C}$ \\
Densidad relativa a $25{ }^{\circ} \mathrm{C}$ & 1.26 \\
Coeficiente de partición (Kow) & 2.16 \\
Constante de Henry a $20{ }^{\circ} \mathrm{C}$ & $1.31 \times 10^{-2} \mathrm{~atm} \mathrm{~L} / \mathrm{mol}$ \\
pKa a $25^{\circ} \mathrm{C}$ & 8.48 \\
Solubilidad en agua & $28.5 \mathrm{~g} / \mathrm{L}$ \\
Peso molecular & $128.56 \mathrm{~g} / \mathrm{mol}$ \\
Presión de vapor a $20^{\circ} \mathrm{C}$ & $2.9 \times 10^{-3} \mathrm{~atm}$ \\
\hline
\end{tabular}

El uso generalizado del 2-CF como parte estructural de pesticidas y conservantes en la industria de la madera, en las industrias petroquímica, textil y papelera, lo ha convertido en un contaminante de suelos y acuíferos (Puhakka y Melin, 1996; Czaplicka, 2004; Pera-Titus y col., 2004). Aunque su uso para estos propósitos está actualmente prohibido en la mayor parte del mundo, en muchos países productores de madera, los problemas de contaminación por 2-CF persisten debido a su larga vida media en el medio ambiente (Czaplicka, 2004). Del mismo modo, el 2-CF podría estar presente en el suelo y en las aguas residuales debido a la degradación incompleta de diferentes clorofenoles (Takeuchi y col., 2000) como el pentaclorofenol (Murthy y col., 1979). Al igual que otros clorofenoles, el 2-CF podría volverse tóxico, mutagénico y cancerígeno, por lo que su impacto ambiental en el aire, el agua y el suelo es significativo (Majumder y Gupta, 2007). La Agencia para el registro de sustancias tóxicas y enfermedades ha considerado la eliminación de 2-CF como una preocupación prioritaria (ATSDR, 2015). Finalmente, en los humanos, la exposición a los clorofenoles puede ocurrir por ingestión, inhalación o contacto dérmico en los lugares de trabajo donde se usa o produce. Se sabe que la mayor exposición ocupacional es la de los trabajadores de la industria de productos de madera (Badanthadka y Mehendale, 2014).

Los clorofenoles pueden degradarse por procesos biológicos. Durante la degradación microbiológica aerobia, el oxígeno sirve como aceptor de electrones. El paso inicial de la degradación aerobia de los monoclorofenoles es su transformación a clorocatecoles, que son los metabolitos centrales de la degradación aerobia de la mayoría de los clorofenoles. Farrell y Quilty (1999) propusieron una posible ruta de oxidación del 2-CF y sus isómeros, bajo condiciones aerobias (Figura 8a). Se observó la formación de catecoles, en específico el 3- 
clorocatecol. La ruptura del anillo aromático se puede producir mediante la vía orto o meta. La mayoría de la ruptura de los clorocatecoles se realiza por vía meta. Posteriormente, mediante una oxigenasa, se forma el ácido 5-cloroformil-2-hidroxi-penta-2,4-dienoico. Por otra parte, en un cultivo de gránulos aerobios, Mondal y Sabir (2011) propusieron que a diferencia de lo sugerido por Farrell y Quilty para la degradación de 2-CF en un reactor SBR, se siguió una ruta en la cual el principal intermediario de la biodegradación de 2-CF fue 3-clorocatecol, que luego de una ruptura orto modificada se transformó en ácido 2-cloro-hex-2,4-dieno-1,6-dioico conocido como ácido 2-cloromucónico (Figura 8b). Considerando que la nitrificación es un proceso aerobio, cabe la posibilidad de que la degradación de 2-CF bajo condiciones nitrificantes se presente mediante algunas de las rutas metabólicas propuestas por Farrell y Quilty (1999) y Mondal y Sabir (2011).
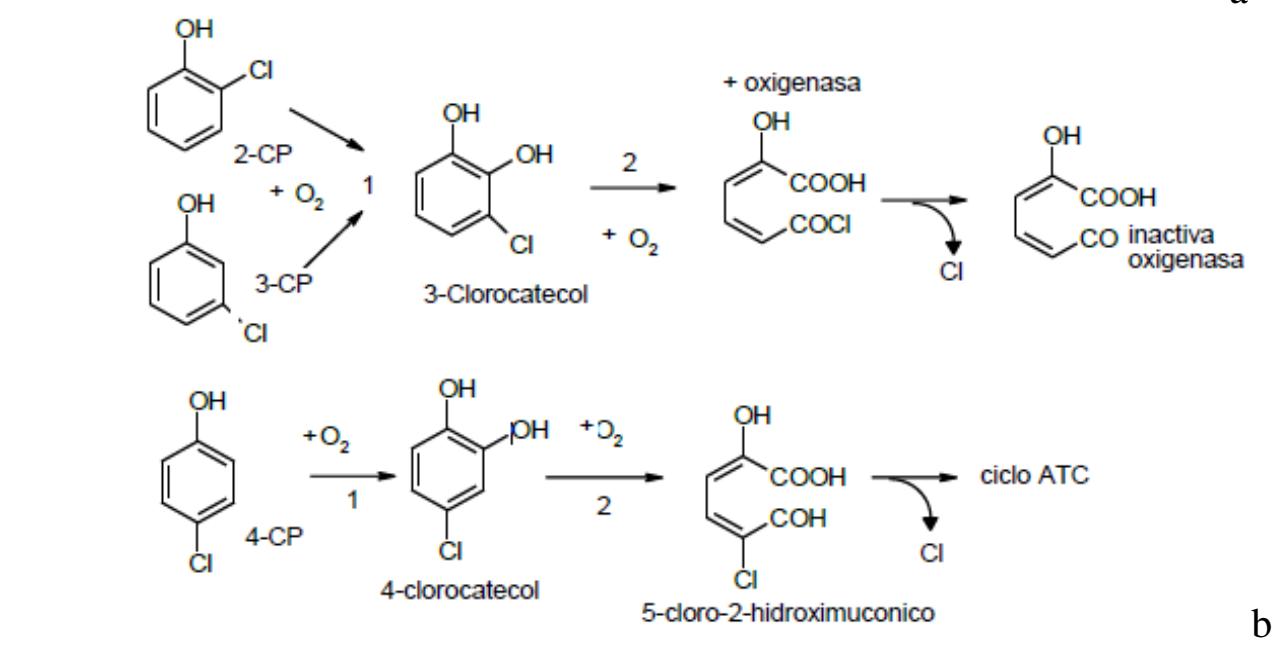

a

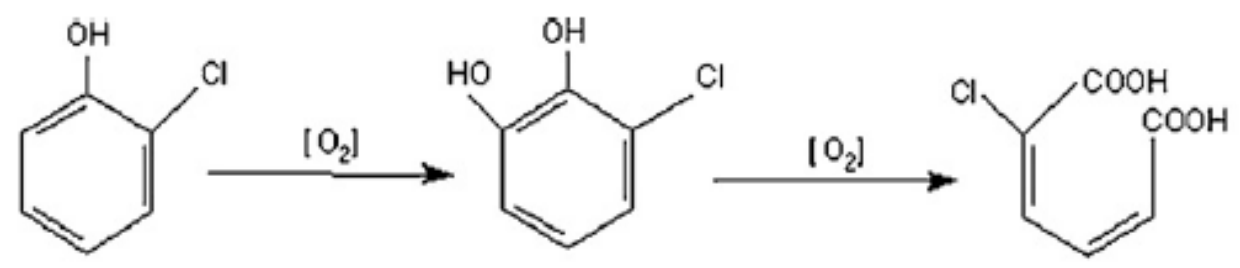

\section{2-clorofenol}

\section{3-clorocatecol Ácido 2-cloro-hex-2,4-dieno-1,6-dioico}

Figura 8. a) Ruta de degradación aerobia. (1) Fenol hidroxilasa, (2) Catecol 2,3-dioxigenasa (Farrell y Quilty,1999). b) Vía de biodegradación de 2-CF en gránulos aerobios en un SBR (Mondal y Sabir, 2011). 


\subsection{Nitrificación y 2-clorofenol}

Existen pocos trabajos en la literatura que abordan el efecto del 2-CF sobre el proceso nitrificante. Satoh y col. (2005), utilizando microelectrodos y una biopelícula nitrificante, reportan que la presencia de $10 \mathrm{mg}$ de C-2-CF/L inhibe la respiración aerobia y el consumo de $\mathrm{NH}_{4}{ }^{+}$. Inui y col. (2002), utilizando un cultivo de Nitrosomonas como biosensores para la presencia de clorofenoles en un sistema de tratamiento de aguas municipales, encuentran que con $0.9 \mathrm{mg} / \mathrm{L}$ de 2-CF, se inhibe en un $10 \%$ la velocidad de respiración nitrificante. Sin embargo, no hacen mención a la producción de $\mathrm{NO}_{2}{ }^{-} \mathrm{o} \mathrm{NO}_{3}{ }^{-} \mathrm{o}$ al destino del 2-CF. Pérez-Alfaro y col. (2013) encontraron que cuando $202 \pm 9.6 \mathrm{mg}$ de proteína microbiana/L de un lodo nitrificante fisiológicamente estable, que no ha tenido un contacto previo con 2-CF, se pone en presencia de concentraciones iniciales de 2.5 y hasta $10 \mathrm{mg}$ de $\mathrm{C}-2-\mathrm{CF} / \mathrm{L}$, no existe consumo de $\mathrm{NH}_{4}{ }^{+}$y por tanto no hay formación de $\mathrm{NO}_{2}^{-}$ni de $\mathrm{NO}_{3}{ }^{-}$, es decir, no se lleva a cabo la nitrificación, aunque sí fue posible eliminar las concentraciones de 2-CF, en 40 y 80 días de cultivo, respectivamente. Por otra parte, estudios en lote utilizando $200 \pm 20 \mathrm{mg}$ de proteína microbiana/L de un lodo nitrificante expuesto previamente a $5 \mathrm{mg}$ de 2-CF/L, indicaron que, aunque el 2-CF tiene efectos inhibitorios sobre el lodo nitrificante, donde el proceso de amonio oxidación fue más afectado que el de la nitrito oxidación, fue posible recuperar una parte de la actividad nitrificante del lodo (Martínez-Hernández y col., 2011).

Buitrón y col. (1998) mencionan que un inóculo con un contacto previo al 4-clorofenol (4-CF), presentó una velocidad específica de consumo mayor. También se ha reportado que el incremento en las velocidades específicas de consumo de 4-CF, dependerán del contacto previo que el lodo ha tenido a ciertos compuestos, en donde se ve una mejora del proceso cuando el lodo ha estado aclimatado a una gran diversidad de compuestos fenólicos (Moreno y Buitrón, 2004). Por otro lado, se encontró que la utilización de lodos metanogénicos con un contacto previo (80 días) al 2-CF, resultó en una reducción de 57\% en la fase de retardo para su consumo y en un incremento de $114 \%$ en la velocidad específica de su consumo (Beristain-Montiel y col., 2010). Posteriormente, utilizando un reactor anaerobio de lotes secuenciados, fue posible aumentar hasta en cinco veces la velocidad específica de consumo de 2-CF (qC-2-CF) (28 - 112 mg de C-2-CF/L) (Beristain-Montiel y col. 2011). Basu y col. (1996), reportan que después de 
200 días de cultivo y en contacto al 2-CF, la velocidad específica de consumo fue de $0.0019 \mathrm{mg}$ $\mathrm{C} / \mathrm{g} \mathrm{SSV} \cdot \mathrm{d}$, mayor a la obtenida con 80 días de cultivo. Por lo tanto, la utilización de los lodos con contacto previo al 2-CF podría ser una estrategia clave para mejorar la velocidad específica de consumo, como lo proponen Beristain-Montiel y col. (2010).

Pérez-Alfaro (2015) en un estudio en cultivos en lote, realizó ensayos cinéticos con un consorcio nitrificante $(213 \pm 10 \mathrm{mg}$ de proteína microbiana/L) expuesto a $5 \mathrm{mg}$ de C-2-CF/L y diferentes concentraciones de $\mathrm{NH}_{4}{ }^{+}\left(100,200,300\right.$ y $500 \mathrm{mg}$ de $\left.\mathrm{N}_{-} \mathrm{NH}_{4}{ }^{+} / \mathrm{L}\right)$ y con extractos libres de células $\left(110 \pm 9 \mathrm{mg}\right.$ de proteína del extracto/L) con $100 \mathrm{mg}$ de $\mathrm{N}-\mathrm{NH}_{4}{ }^{+} / \mathrm{L}$ y expuesto a $5 \mathrm{mg}$ de $\mathrm{C}-2-\mathrm{CF} / \mathrm{L}$. Los resultados con el consorcio nitrificante mostraron que con $100 \mathrm{mg}$ de $\mathrm{N}-\mathrm{NH}_{4}{ }^{+} / \mathrm{L}$, el 2-CF inhibió totalmente la actividad nitrificante ya que no se observó consumo de $\mathrm{NH}_{4}{ }^{+}$. El incremento de la concentración de $\mathrm{N}_{-} \mathrm{NH}_{4}{ }^{+}$de 200 y hasta $500 \mathrm{mg} / \mathrm{L}$ permitió observar actividad amonio y nitrito oxidante en presencia de $5 \mathrm{mg}$ de $\mathrm{C}-2-\mathrm{CF} / \mathrm{L}$. Los resultados obtenidos con extractos libres de células, indicaron que éstos mantuvieron el $80 \%$ de la actividad nitrificante respecto a las células completas y fueron capaces de consumir y oxidar $\mathrm{NH}_{4}{ }^{+}$ inmediatamente, aún en presencia de $5 \mathrm{mg}$ de C-2-CF/L. Asimismo, el extracto libre de células tuvo la capacidad de oxidar 2-CF. En general, la respuesta fisiológica y cinética obtenida en todos los ensayos realizados por el autor, sugieren que la presencia de 2-CF afecta de manera negativa el transporte de $\mathrm{NH}_{4}{ }^{+}$, debido probablemente a un daño en la membrana celular. Asimismo, el autor señala indicios claros de que el 2-CF también afecta a nivel enzimático la actividad amonio y nitrito oxidante. Por otra parte, con el consorcio nitrificante con la capacidad de consumir 2-CF, se evaluó fisiológica y cinéticamente con $200 \pm 3.1 \mathrm{mg}$ de proteína microbiana/L en cultivos en lote, la participación de las enzimas AMO y NOR en el consumo de este compuesto mediante inhibidores específicos de dichas enzimas (aliltiourea y clorato de sodio). Se encontró que al inhibir la actividad de la enzima AMO la qC-2-CF disminuye un $50 \%$, lo que muestra la participación de la AMO en el consumo de 2-CF. Al inhibir la actividad de la enzima NOR no se observó cambio significativo en la qC-2-CF, indicando que esta enzima nitrificante no estaría involucrada en el consumo del compuesto fenólico. En comparación con los ensayos con $100 \mathrm{mg}$ de N-NH${ }_{4}{ }^{+} / \mathrm{L}$, donde se requiere una fase de retardo de 18.5 días y de 35 días para consumir totalmente el 2-CF, cuando se realizó el ensayo con una concentración 
de $200 \mathrm{mg}$ de $\mathrm{N}-\mathrm{NH}_{4}{ }^{+} / \mathrm{L}$, la fase de retardo para el consumo de 2-CF disminuyó de 18.5 días a 5 horas. Cuando se utilizaron 300 y $500 \mathrm{mg}$ de $\mathrm{N}_{-} \mathrm{NH}_{4}{ }^{+} / \mathrm{L}$ la fase de retardo desapareció. Los resultados también mostraron que con $500 \mathrm{mg}$ de $\mathrm{N}_{-} \mathrm{NH}_{4}+/ \mathrm{L}$, la velocidad de consumo de 2-CF se incrementó 1.4 veces en comparación con el ensayo con $200 \mathrm{mg}$ de $\mathrm{N}-\mathrm{NH}_{4}^{+} / \mathrm{L}$. Dichos resultados mostraron que, al aumentar la concentración de $\mathrm{NH}_{4}^{+}$, se favoreció el consumo de 2CF, sugiriendo que dicho consumo podría darse por cometabolismo (Pérez-Alfaro, 2015). En resumen, el 2-CF tiene efectos negativos sobre los microorganismos nitrificantes, y aunque con el aumento en la concentración de $\mathrm{NH}_{4}{ }^{+}$se han reportado disminuciones en las fases de retardo para el consumo de concentraciones bajas de 2-CF (5 mg de C-2-CF/L), no se ha reportado una nitrificación completa y estable. En este sentido es de gran interés evaluar la adición de concentraciones crecientes de $\mathrm{NH}_{4}{ }^{+}$y la utilización de lodos expuestos previamente al 2-CF con el fin de disminuir el efecto inhibitorio del 2-CF sobre el proceso nitrificante y sus tiempos de consumo, así como favorecer el consumo del compuesto aromático por la enzima AMO.

\subsection{Nitrificación en reactores de lotes secuenciados (SBR)}

Para llevar a cabo la nitrificación se han utilizado configuraciones de reactores nitrificantes diferentes, por ejemplo, reactores de tanque agitado, filtros percoladores, discos rotatorios, filtros sumergidos y reactores de lecho fluidizado (Martínez, 2003). Cada una de estas configuraciones de reactores tiene sus ventajas y desventajas para tratar ciertos tipos de aguas residuales con $\mathrm{NH}_{4}{ }^{+}$como contaminante. No obstante, otro de los reactores nitrificantes utilizados es el SBR (Texier y Gómez., 2004). Este tipo de reactores tiene un sistema de trabajo por etapas, dividido en cuatro fases (Figura 9): llenado, reacción biológica, sedimentación y drenado (Lloyd y Ketchum, 1997). Es fácil de operar y la calidad del efluente se puede regular controlando los tiempos de retención, reacción y sedimentación (Lee y Jong 1999; Alemayehu y col., 2001). Una de las características principales de este tipo de reactor, es que los procesos biológicos tienden a alcanzar una etapa de adaptación y estabilización, pues se ha observado que los tiempos de reacción disminuyen conforme transcurre el número de ciclos (Texier y Gómez, 2007). Se ha propuesto que, en estos reactores, ocurre una selección de especies microbianas capaces de adaptarse a ambientes diversos, por lo que pueden mantener su actividad 
aun cuando haya cambios en el influente (Irvine y col., 1997; Ketchum, 1997). Así, al incrementarse el número de ciclos, las velocidades específicas de consumo y producción aumentan hasta llegar a un punto en el cual no sufren cambios significativos, es decir, se puede llegar a un estado estacionario (Moreno-Andrade y Buitrón, 2004). Entre las ventajas principales de este tipo de reactores sobre los sistemas aireados tradicionales de lodos activados se encuentran: el ahorro en espacio y mantenimiento, eficiencias de eliminación de materia orgánica biodegradable y nutrientes altas, fácil automatización, flexibilidad de operación y costos de inversión menores (Fernández-Polanco y col., 1993; Torrijos y Moletta, 1997; Wilderer y col., 2001). Como se ha mencionado el 2-CF es un compuesto recalcitrante y podría llegar a diferentes lugares donde hay altas concentraciones de amonio, además ambos compuestos podrían estar en coexistencia en diferentes efluentes industriales madereros, textiles, agrícolas, papeleras, petroquímicas, productores de plaguicidas y pesticidas, entre otros. Los reactores SBR son una alternativa para utilizarse en plantas de tratamiento de aguas residuales de diferentes industrias contaminadas con amonio y 2-CF y favorecer la biodegradación de ambos compuestos.
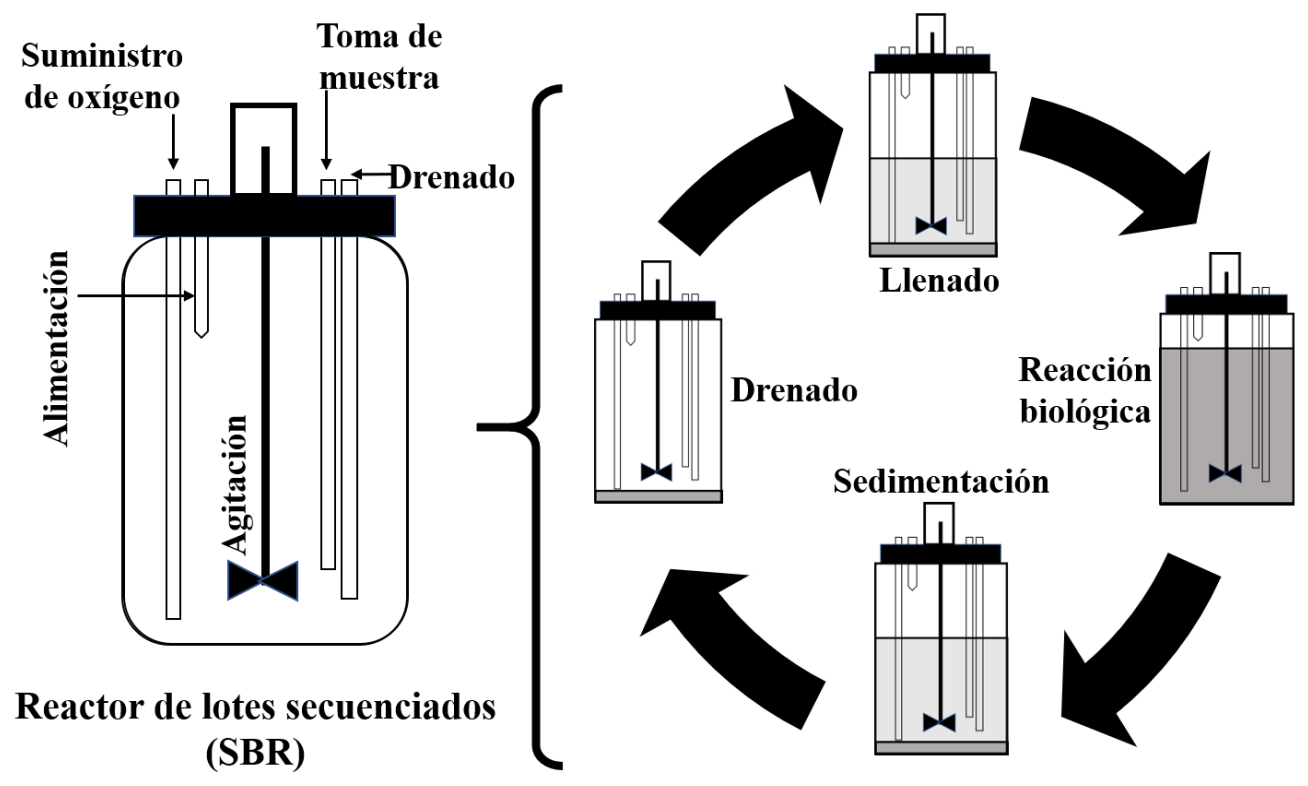

Etapas del ciclo de operación

Figura 9. Etapas de un ciclo de operación de un reactor de lotes secuenciados (SBR). 
Hay varios trabajos que reportan el uso de reactores SBR para tratar aguas sintéticas con $\mathrm{NH}_{4}{ }^{+}$y algunos compuestos aromáticos mediante la nitrificación, reportándose algunos efectos de la materia orgánica sobre el proceso respiratorio. Por ejemplo, la eficiencia de consumo de amonio $\left(\mathrm{EN}^{-\mathrm{NH}_{4}}{ }^{+}\right)$y el $\mathrm{YN}^{-N_{3}}{ }^{-}$no se afectan en presencia de hasta $30 \mathrm{mg}$ de $\mathrm{C}-\mathrm{fenol} / \mathrm{L}$, mientras que al adicionar $100 \mathrm{mg}$ de C-fenol/L, ambos parámetros cayeron en un 13\% (PérezAlfaro, 2007). Sin embargo, bajo estas condiciones y después de 244 ciclos de operación, se observó un aumento en las velocidades específicas de consumo de amonio ( $\mathrm{qN} \mathrm{NH}_{4}{ }^{+}$), fenol y producción de $\mathrm{NO}_{3}{ }^{-}$. Asimismo, se ha reportado que el efecto inhibitorio del $p$-cresol (25 mg/L) sobre la nitrificación, puede ser disminuido después de 30 ciclos de operación en un reactor de lotes secuenciados, mostrando que la $\mathrm{EN}-\mathrm{NH}_{4}{ }^{+}$y el $\mathrm{YN}-\mathrm{NO}_{3}{ }^{-}$no son afectados y las velocidades específicas de consumo de $p$-cresol incrementaron (Texier y Gómez, 2007).

Martínez-Jardines y col. (2019), reportan con un proceso nitrificante utilizando lodos expuestos previamente a compuestos fenólicos (2-CF y $p$-cresol) y con reactores de lotes secuenciados (SBR), que la adición de $20 \mathrm{mg}$ de C-2-CF/L provocó un efecto inhibitorio sobre el proceso nitrificante, pues se observó una disminución significativa del $98 \%$ en las $\mathrm{qN}^{-\mathrm{NH}_{4}}{ }^{+}$ y producción de $\mathrm{NO}_{3}{ }^{-}\left(\mathrm{qN}^{-\mathrm{NO}_{3}}{ }^{-}\right)$con respecto a un control. Sin embargo, la inhibición del proceso nitrificante disminuyó a través de los ciclos de operación, observando consumo de 2-

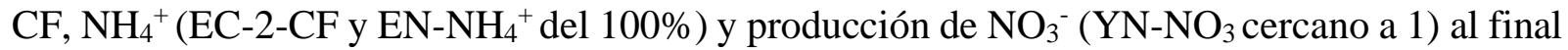
del estudio. Los autores proponen que este comportamiento puede estar asociado con la exposición previa de los lodos a compuestos fenólicos y a la utilización de los sistemas SBR, sin embargo, es necesario hacer más investigación al respecto. En un trabajo hecho por Martínez-Jardines (2015), se evaluó en términos metabólico y cinéticos un proceso nitrificante en presencia de diferentes concentraciones de 2-CF (mg C/L: 20, 40 y 60) en reactores SBR. Se realizaron 7 ciclos de operación de 30 días cada uno en presencia de las diferentes concentraciones de 2-CF (mg C/L): dos ciclos con 20, dos ciclos con 40 y tres ciclos con 60. Los valores obtenidos de $\mathrm{EN}_{-} \mathrm{NH}_{4}{ }^{+}$y $\mathrm{YN}_{-} \mathrm{NO}_{3}{ }^{-}$indicaron un efecto negativo de la adición e incremento del 2-CF en la actividad amonio oxidante del lodo del SBR1 (expuesto previamente a solo 2-CF) en los ciclos 3 y 5, mientras que un efecto negativo sobre la nitrito oxidación del lodo del SBR2 (expuesto previamente a p-cresol) se observó en los mismos ciclos. Sin embargo, 
al final del ciclo 7, ambos lodos recuperaron su actividad metabólica y se obtuvo un proceso nitrificante completo, estable y eficiente $\left(\mathrm{EN}_{-} \mathrm{NH}_{4}{ }^{+}=99.2 \pm 0.6 \%, \mathrm{YN}^{-\mathrm{NO}_{3}}{ }^{-}=0.96 \pm 0.03 \mathrm{mg}\right.$ de $\mathrm{N}$ producido/mg de $\mathrm{N}$ consumido). En ambos lodos, la adición de 2-CF provocó un efecto inhibitorio sobre el proceso nitrificante, pues las velocidades específicas disminuyeron de acuerdo a un control sin el compuesto clorado, sin embargo, el efecto inhibitorio sobre la cinética amonio y nitrito oxidante de ambos lodos disminuyó a lo largo de los ciclos de operación. Ambos lodos fueron capaces de consumir completamente desde 20 hasta $60 \mathrm{mg}$ de C-2-CF/L. Los autores encontraron que la utilización de sistemas SBR y el uso de lodos con exposición previa al 2-CF, permitieron obtener procesos nitrificantes metabólicamente estables y cinéticamente adaptados, así como una eliminación simultánea de $\mathrm{NH}_{4}{ }^{+}$y de hasta $60 \mathrm{mg} \mathrm{C}$ 2-CF/L. Todos estos resultados indican que el proceso nitrificante sigue presentando una inhibición por el 2-CF y que bajo estas condiciones se requieren tiempos largos para eliminarlo completamente. Una alternativa para disminuir los tiempos de consumo del compuesto aromático, así como su efecto inhibitorio sobre la nitrificación, podría ser el uso de sistemas SBR en los que se incremente la concentración inicial de $\mathrm{NH}_{4}^{+}$, con el fin de favorecer la eliminación de $\mathrm{NH}_{4}{ }^{+}$y promover la del 2-CF, ya que se observó previamente que la enzima AMO puede estar involucrada en el consumo cometabólico del 2-CF.

\subsection{Enzima amonio monooxigenasa (AMO)}

Como se ha mencionado anteriormente, la AMO es una enzima localizada en la membrana citoplasmática que cataliza la oxidación de $\mathrm{NH}_{3}$ a $\mathrm{NH}_{2} \mathrm{OH}$. Aún no se conoce tanto sobre los detalles de la estructura y mecanismo catalítico de esta enzima, ya que, hasta el momento, no se ha purificado en su totalidad con actividad, puesto que se ha reportado que la AMO pierde fácilmente su actividad tras la ruptura celular (Suzuki y col., 1981; Ensign y col., 1993; Sayavedra-Soto y Arp, 2011). Algunos autores han logrado obtener extractos celulares con actividad cuando se adiciona albúmina de suero animal, espermina o $\mathrm{Mg}^{2+}$ como agentes estabilizantes (Ensign y col., 1993), sin embargo, la actividad se pierde fácilmente después de pocas horas de almacenamiento. En otros trabajos se encontró que la adición de fracciones que 
contienen HAO o citocromos solubles daba como resultado la recuperación parcial de la actividad de la AMO (Suzuki y Kwok, 1981; Suzuki y col., 1981). Por otra parte, Pérez-Alfaro (2015) obtuvo un extracto libre de células que conservó actividad nitrificante durante 24 horas sin la necesidad de adicionar un agente estabilizante externo. Con este extracto fue posible observar la oxidación de $\mathrm{NH}_{4}{ }^{+}$en pocas horas.

Se sabe que la enzima AMO está relacionada evolutivamente con la enzima metano monooxigenasa particulada (pMMO), y es estructural y catalíticamente similar a ella, por lo que mucha de la información sobre la AMO se ha obtenido al compararla con la pMMO. Sin embargo, los estudios de la estructura de la pMMO están actualmente más avanzados que los de la AMO (Holmes y col., 1995; Sayavedra-Soto y Arp, 2011) por lo que es necesario realizar más investigación al respecto. Aunque todavía no hay evidencia de los sitios de unión para los cofactores metálicos en la AMO, el análisis de la estructura cristalina de la pMMO de $M$. capsulatus ha brindado por analogía algunas posibilidades acerca de los sitios de unión en la AMO (Hakemian y Rosenzweig, 2007). Por ejemplo, en cuanto a la pMMO, la presencia de $\mathrm{Cu}$ y probablemente Fe es necesaria para la catálisis (Hakemian y Rosenzweig, 2007). Al respecto, algunos autores han inferido supuestos sitios de unión a metales en la subunidad AmoB, donde un centro de cobre dinuclear y un centro de cobre mononuclear actuarían como sitios de unión, en AmoC y AmoA en los que un centro de metal mononuclear, Zn durante la cristalización y $\mathrm{Cu}$ o $\mathrm{Fe}$ in vivo, funcionarían como sitios de unión (Hakemian y Rosenzweig, 2007). Finalmente, se ha encontrado que entre las diversas AOB en las que se han secuenciado los nucleótidos de genes para la AMO, los supuestos aminoácidos de unión a metales están altamente conservados (Sayavedra-Soto y Arp, 2011).

La enzima AMO está codificada a partir de un grupo de genes ( $a m o C A B)$ presentes en una o tres copias en los genomas de diferentes bacterias AOB (Arp y col., 2007). Las tres subunidades de la AMO, alfa $(A m o A)$, beta $(A m o B)$ y gamma $(A m o C)$ están codificadas por este único grupo de genes $(a m o C A B)$ y por dos genes amoC adicionales localizados en otros loci genómicos (las copias AmoC comparten identidades de secuencia de aminoácidos de 99.6 a

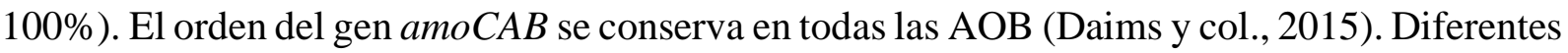
mecanismos reguladores pueden estar presentes dependiendo de las condiciones ambientales. 
Con base en las secuencias de genes $16 \mathrm{~S}$ rARN y del gen amoA, se sabe que éste último codifica la subunidad A de la enzima AMO, la cual cataliza el primer paso de la oxidación del $\mathrm{NH}_{4}{ }^{+}$y es una herramienta molecular capaz de distinguir poblaciones nitrificantes muy cercanas entre sí (Sayavedra-Soto y Arp, 2011). De acuerdo con la base de datos del Centro Nacional de Información Biotecnológica (NCBI por sus siglas en inglés), la alineación de los aminoácidos codificados para la AMO da como resultado coincidencias significativas solo con la AMO de otras $\mathrm{AOB}(>\quad 85 \%$ de identidades) y con la pMMO de los metanótrofos [Methylosinustrichosporium con $>80 \%$ de identidades, y con la mayor parte de la divergencia que ocurre en el extremo N] (Hakemian y Rosenzweig, 2007). Se ha reportado que en $N$. europaea hay dos copias del grupo de genes amoCAB en el que sus secuencias de ADN difieren en la subunidad amoA por un solo nucleótido, lo que da como resultado un solo cambio de aminoácidos en la enzima (Hommes y col., 1998). Del mismo modo, en los genomas de otras AOB que tienen múltiples copias del gen $a m o A$, todas las copias son casi idénticas dentro de un organismo. En N. europaea, ambas copias de la AMO son funcionales y cada una es suficiente para el crecimiento, aunque se ha reportado evidencia de regulación diferencial de las dos copias (Hommes y col., 1998; Stein y col., 2000). Por otro lado, en estudios mutacionales, la inactivación de una de las copias (amoAl) desaceleró el crecimiento en aproximadamente un $25 \%$, mientras que la inactivación de la otra (amoA2) no tuvo un efecto negativo sobre el crecimiento. Asimismo, si las células mutantes se expusieron a un medio fresco, la cepa de $N$. europaea que carecía de las copias amoAl o amoB1 respondía más lentamente al crecimiento que la cepa mutante que carecía de las copias amoA2 o amoB2 (Stein y col., 2000). En $N$. europaea, la actividad de la AMO está regulada por el amoníaco en tres niveles: transcripcional, traduccional y postraduccional (Sayavedra-Soto y col., 1996; Stein y col., 1997; Geets y col., 2006).

Una característica general del grupo de enzimas monooxigenasas es el amplio rango de sustratos que pueden utilizar (Gunsalus y col., 1975). La enzima AMO encaja bien en este grupo y no es la excepción, ya que se ha demostrado que más de 40 compuestos pueden ser sustratos de esta enzima (Hooper y col., 1997). Ejemplos de éstos se muestran en la Figura 10, donde se muestra que la enzima AMO puede catalizar la oxidación de diversos alcanos, alquenos, 
hidrocarburos aromáticos y éteres, todo mediante la inserción de un átomo de $\mathrm{O}$ en las moléculas (Vannelli y Hooper, 1992; Keener y Arp, 1994). Una característica común de todos los sustratos de la $\mathrm{AMO}$ es que en su mayoría no tienen carga y son de baja polaridad, lo que sugiere la existencia de un sitio activo de unión al sustrato hidrófobo (Arp y Stein, 2003).

\section{OXIDACIÓN}

Sustrato natural:

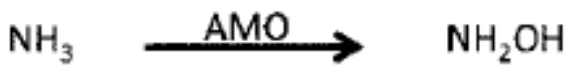

Alcanos a alcoholes:

$\mathrm{CH}_{3}-\mathrm{CH}_{3} \stackrel{\mathrm{AMO}}{\longrightarrow} \mathrm{CH}_{3}-\mathrm{CH}_{2}-\mathrm{OH}$

Alquenos a epóxidos:

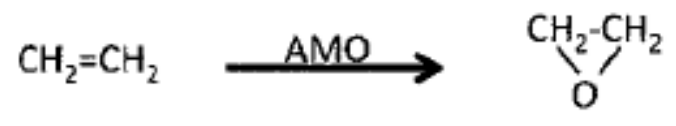

Hidrocarburos

aromáticos a alcoholes:

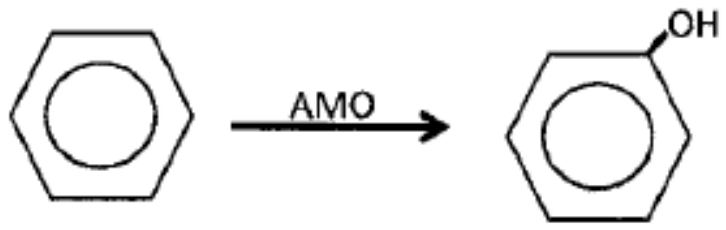

Deshalogenación de hidrocarburos a aldehídos:

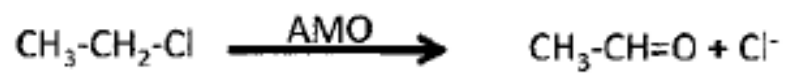

\section{DESHIDROGENACIÓN}

Etilbenceno a estireno:

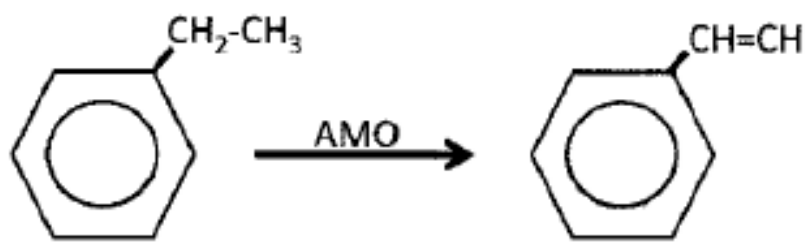

Figura 10. Reacciones catalizadas por la enzima amonio monooxigenasa (AMO) que incluyen oxidación y deshidrogenación (Sayavedra-Soto y Arp, 2011). 
Una amplia gama de microorganismos que expresan la actividad de la oxigenasa y usan $\mathrm{NH}_{4}{ }^{+}$como fuente de energía pueden oxidar solventes clorados (Arciero y col., 1989; Vannelli y col., 1990). Se sabe que microorganismos como las AOB también tienen la capacidad de oxidar diversos compuestos orgánicos clorados, incluidos los compuestos alifáticos clorados como el dicloroetileno (DCE), tricloroetileno (TCE) e incluso cloroformo (CF) (Ely y col., 1997), lo que se ha asociado con la afinidad de la enzima AMO por estos compuestos; así como compuestos aromáticos tales como benceno, etilbenceno, clorobenceno, tolueno, $p$-cresol y $p$ xileno (Keener y Arp, 1994; McCarty, 1999; Arp y Stein, 2003). La capacidad de la enzima AMO para oxidar compuestos alifáticos halogenados y no halogenados, así como aromáticos

tales como bromuro de metilo, 1,2-dicloropropano, 1,2-dibromo-3-cloropropano, tricloroetileno, etano, cloropropano, tolueno, benceno y fenol, ha sido mostrada en cultivos axénicos de Nitrosomonas europaea (Alvarez-Cohen y Speitel, 2001; Hyman y col., 1995; Keener y Arp, 1994). También se ha reportado la oxidación de fenol, benceno y 2-CF asociada con la oxidación de $\mathrm{NH}_{4}{ }^{+}$por lodos nitrificantes (Zepeda y col., 2003; Silva y col., 2011; Martínez-Jardines y col., 2019), aunque la participación de la enzima AMO en el consumo de estos compuestos no fue confirmada por los autores. Aunque se tiene información sobre la participación de la enzima AMO en el consumo de diferentes compuestos, se desconoce el papel que juega en la oxidación de compuestos aromáticos clorados como el 2-CF. Generar información al respecto nos permitirá conocer el comportamiento de las bacterias AOB en presencia de compuestos recalcitrantes como el 2-CF y su posible consumo mediante la acción de la enzima AMO.

\subsection{Cometabolismo}

El cometabolismo microbiano es parte fundamental de la eliminación biológica de compuestos tóxicos en el ambiente, puesto que mediante él se pueden obtener tasas de degradación altas y una acumulación baja de subproductos (Jesus y col., 2016). Se sabe que varios microorganismos pueden degradar por cometabolismo diferentes compuestos orgánicos recalcitrantes, como compuestos aromáticos y halogenados (Liu y col., 1991; Hao y col., 2002). 
El cometabolismo se ha definido como la capacidad de los microorganismos para transformar un sustrato que no se usa como soporte de crecimiento en la presencia obligatoria de un sustrato de crecimiento o un compuesto fácilmente transformable o biodegradable en condiciones aerobias o anaerobias. El sustrato que no se utiliza como soporte de crecimiento no es compatible con el crecimiento microbiano, y no produce carbono ni beneficio energético para las células (Dalton y Stirling, 1982; Arp y col., 2001; Jesus y col., 2016). Por ejemplo, en condiciones aerobias, algunas cepas de Pseudomonas putida tienen la capacidad de biodegradar compuestos fenólicos clorados como 2-CF y 4-CF en presencia de fenol como sustrato de crecimiento (Kai-Chee y Tingting, 2006). Asimismo, se ha informado sobre la biodegradación cometabólica de 3-clorofenol (3-CF) (Chiavola y col., 2004) y 4-CF (Monsalvo y col., 2009) en sistemas SBR inoculados con lodo activado donde se añadió fenol como sustrato de crecimiento. Las bacterias amonio oxidantes como Nitrosomonas europaea son capaces de biodegradar cometabólicamente diferentes compuestos orgánicos clorados como el DCE, el TCE, el CF y el dicloroetano (DE) utilizando $\mathrm{NH}_{4}{ }^{+}$como principal fuente de energía (Ely y col., 1997). También hay información que indica que los consorcios nitrificantes son candidatos para realizar el consumo biológico de compuestos orgánicos recalcitrantes mediante cometabolismo (Tran y col., 2013). Kocamemi y Çeçen (2010) reportaron resultados sobre la eliminación cometabólica de TCE con un consorcio nitrificante cuando aumenta la concentración de $\mathrm{NH}_{4}{ }^{+}$, una mayor tasa específica de consumo de TCE fue obtenida.

Se ha reportado que muchas de las reacciones cometabólicas son llevadas a cabo por enzimas oxigenasas, como metano monooxigenasa, tolueno mono y dioxigenasa, bifeniloxigenasa y la enzima AMO (Furukawa, 2000; Hazen, 2010). De hecho, se sabe que las enzimas oxigenasas son capaces de oxidar un sustrato que no proporciona carbono ni fuente de energía durante el cometabolismo aerobio (Jesus y col., 2016). Es por esto que se ha sugerido que la enzima AMO puede desempeñar un papel importante en la biodegradación cometabólica de varios contaminantes orgánicos, ya que, en condiciones de nitrificación y altas tasas de carga de $\mathrm{NH}_{4}{ }^{+}$, se ha observado una mayor biodegradación de compuestos orgánicos (Tran y col., 2013). Asimismo, se ha mostrado que, en cultivos nitrificantes en lote, un aumento en la concentración de $\mathrm{NH}_{4}{ }^{+}$mejoró la eficiencia y la qC-2-CF, sugiriendo que la eliminación del 
compuesto aromático podría darse por cometabolismo (Pérez-Alfaro, 2015). Sin embargo, la participación de la enzima AMO no ha sido aclarada o evidenciada en todos los casos, por lo que resulta importante realizar investigación sobre la mejora del consumo cometabólico de clorofenoles por los consorcios nitrificantes mediante la adición de concentraciones crecientes de $\mathrm{NH}_{4}{ }^{+}$. De hecho, en los efluentes industriales y municipales, el consumo cometabólico de 2CF podría sostenerse bajo condiciones nitrificantes por la alta presencia de $\mathrm{NH}_{4}{ }^{+}$que éstos contienen, ya que podría estar actuando como sustrato primario o de crecimiento. Por lo tanto, se requiere generar información que permita entender el papel de los consorcios nitrificantes expuestos previamente a compuestos fenólicos cuando se incrementa la concentración inicial de $\mathrm{NH}_{4}{ }^{+}$en reactores SBR, así como su comportamiento cinético y fisiológico durante la degradación cometabólica de 2-CF.

\subsection{Técnicas moleculares en procesos biológicos}

\subsubsection{Dinámica poblacional, índices ecológicos y secuenciación}

En una comunidad microbiana la dinámica de las poblaciones que la conforman podría utilizarse para relacionar el comportamiento fisiológico $\left(\mathrm{EN}-\mathrm{NH}_{4}{ }^{+}\right.$y $\left.\mathrm{YN}^{-\mathrm{NO}_{3}}{ }^{-}\right)$y cinético $(\mathrm{qN}-$ $\mathrm{NH}_{4}{ }^{+}$o $\mathrm{qN}^{-\mathrm{NO}_{3}}{ }^{-}$) con la composición microbiana (número y especies presentes), es decir, evaluar si un ecosistema funcionalmente estable implica necesariamente una comunidad constante, o si cambios ambientales, entre ellos el tipo y concentración de nutrientes, pueden determinar el tipo de poblaciones presentes en un consorcio, o en dado caso, si los cambios ambientales sólo modifican el metabolismo de la población microbiana. Asimismo, es necesario mejorar el entendimiento de los roles y diversidad de las poblaciones presentes en los sistemas bacterianos de biorremediación, puesto que, al entender mejor el comportamiento y funcionamiento de los consorcios microbianos en los procesos biológicos bajo ciertas condiciones operativas, se podrían obtener sistemas depuradores más estables con mayor capacidad de producción, así como tiempos más prolongados de funcionamiento. Además de caracterizar y cuantificar las poblaciones microbianas en un sistema biológico, la importancia 
de estudiar la dinámica de las poblaciones a lo largo del tiempo, podría permitir entender mejor cómo se llevan a cabo los procesos biológicos en reactores.

Existen técnicas microbiológicas convencionales basadas en el aislamiento de cultivos puros y análisis morfológicos, metabólicos, bioquímicos y genéticos, que han proporcionado información sobre la biodiversidad de las comunidades microbianas presentes en sistemas naturales e ingenieriles. Sin embargo, estas técnicas presentan algunos inconvenientes, tales como un conocimiento incompleto sobre las necesidades fisiológicas (nutricionales y fisicoquímicas) y las relaciones simbióticas dentro de la comunidad y a lo largo del tiempo (Belser, 1979; Grunditz y Dalhammar, 2001). Una alternativa para generar mayor información al respecto es el uso de técnicas moleculares. Los avances en las técnicas moleculares pueden proporcionar herramientas para seguir la estructura y dinámica de una comunidad en el tiempo, así como caracterizar y cuantificar microorganismos en muestras particulares o bajo ciertas condiciones ambientales u operativas. En la literatura, existe información que puede ayudar a entender el comportamiento de las bacterias nitrificantes en los sistemas de tratamiento de aguas residuales, por ejemplo cuando se cambia la fuente de nitrógeno de $\mathrm{NH}_{4}{ }^{+}$a $\mathrm{NO}_{2}^{-}$(VázquezPadín y col., 2009), cuando son aireados constante e intermitentemente (Dytczak y col. 2008) o bien a lo largo del tiempo (Feng y col., 2007), pero al día de hoy, todavía hay pocos trabajos que buscan asociar el comportamiento fisiológico y cinético con la comunidad microbiana. Al respecto, Lydmark y col. (2007) observaron que, en una planta piloto de tratamiento de aguas residuales, las qN-NH${ }_{4}^{+}$se relacionan con la cantidad de bacterias amonio oxidantes que están presentes. Al comparar diferentes tanques de reacción, encontraron que en cada uno de ellos las poblaciones microbianas estuvieron presentes en diferentes proporciones, de forma que el tanque que tenía mayor presencia de $\mathrm{AOB}$, fue en el que se obtuvieron las $\mathrm{qN}^{-\mathrm{NH}_{4}}{ }^{+}$mayores. En otro trabajo realizado en un SBR inoculado con gránulos aerobios con actividad nitrificante, se dio seguimiento a bacterias amonio oxidantes ( $\alpha$ y $\beta$-proteobacterias) y bacterias nitrito oxidantes (Nitrospira). En este estudio, se observó un cambio en las poblaciones bacterianas en el transcurso del tiempo, ya que, al arranque del reactor, la biodiversidad de $\alpha$-proteobacterias era mayor que la de $\beta$-proteobacterias y al final del estudio, la proporción de Nitrospira disminuyó (Feng y col., 2007). Es importante señalar que, en la mayoría de los trabajos, no se 
reporta el comportamiento fisiológico y/o cinético del proceso biológico, quedando en duda si la nitrificación se llevó a cabo y si se realizó de forma estable. Asimismo, también es notorio que en los trabajos donde se realizan estudios de biología molecular, sólo se da información que refleja el cambio en las comunidades microbianas al modificar las condiciones ambientales o al aumentar o disminuir las cargas de sustrato. Por consiguiente, es necesario incluir variables de respuesta que permitan evaluar, entender y asociar el comportamiento fisiológico y cinético nitrificante con su dinámica poblacional.

La posibilidad de identificar poblaciones de microorganismos específicas en su hábitat natural sin la necesidad de aislarlos está revolucionando la ecología microbiana y ha dado lugar a nuevas aplicaciones en numerosos campos de investigación. El uso de herramientas moleculares para el estudio de la dinámica poblacional de cultivos tiene la finalidad de identificar los cambios poblacionales que pueden ocurrir (Godon y col., 1997; Sekiguchi y col., 1998). Una variedad de métodos se ha desarrollado para tratar de entender la diversidad y abundancia de microorganismos o secuencias genéticas de interés. El uso de las técnicas de separación de ADN por electroforesis en gel con gradientes desnaturalizantes (DGGE por sus siglas en inglés) ofrece la posibilidad de analizar géneros bacterianos específicos, dentro de comunidades complejas. Esta técnica permite la separación de bandas de ADN de igual tamaño (masa molecular) pero con diferente información de secuencia, de forma que bandas con desigual tamaño e intensidad representan diferentes proporciones de individuos de una especie. Idealmente, el perfil electroforético (definido por el número de bandas) reflejará la abundancia relativa de miembros diferentes de una comunidad microbiana (Muyzer y col., 1993; Felske y col., 1997). Esta técnica ya se ha aplicado para determinar la filogenia de los miembros de una comunidad microbiana (Ferris y col., 1996; Watanabe y col., 2000). Con respecto al 2-CF, se ha reportado en reactores por lotes secuenciados anaerobios (ASBR por sus siglas en inglés) la dinámica de la comunidad microbiana involucrada en la degradación anaerobia de diferentes concentraciones de 2-CF (Beristain-Montiel y col., 2015). Los autores determinaron por DGGE que el número de especies presentes en el reactor ASBR mostró una tendencia al aumento a lo largo de los ciclos de operación junto con el incremento de la concentración del compuesto fenólico de 42 a 140 mg de C-2-CF/L, lo que indicó una mayor diversidad bacteriana. Cabe 
mencionar que existe poca información en la literatura sobre el comportamiento del proceso nitrificante y la dinámica poblacional del consorcio en presencia de 2-CF. Proporcionar información a través de estudios fisiológicos y la evaluación de la dinámica poblacional abriría la posibilidad de una mejor comprensión del papel de los microorganismos cuando están en presencia de compuestos recalcitrantes o inhibitorios.

Cuando se estudia la dinámica de poblaciones, los índices ecológicos, como la riqueza de secuencias (S), el índice de diversidad de Shannon-Weaver $(\mathrm{H})$ y el índice de equidad (J), son utilizados para la interpretación de los patrones de bandas obtenidos a partir de un DGGE. El valor del índice $\mathrm{S}$ representa el número de especies, el de $\mathrm{H}$ indica la distribución y variación genética dentro de las poblaciones y entre ellas y el de J representa la distribución de la abundancia de las poblaciones. Estos índices permiten analizar de manera cuantitativa los patrones de bandas y comparar entre diferentes tratamientos operativos o condiciones empleadas dentro de un consorcio microbiano. Los índices ecológicos podrían ayudar a determinar si los cambios en la respuesta fisiológica y/o cinética del proceso biológico podrían estar o no asociados con los cambios del medio ambiente y en la comunidad microbiana. Por ejemplo, Martínez-Hernández y col. (2009), utilizó un reactor UASB para realizar un proceso desnitrificante en el que evaluó diferentes cargas de acetato para promover la mineralización de tolueno. Los autores encontraron que, de acuerdo a los índices ecológicos calculados, la mejora de eficiencias, rendimientos y velocidades específicas del proceso desnitrificante no estuvo claramente relacionada con los cambios en la composición de la comunidad microbiana. Por otra parte, en un proceso sulfato reductor se estudió la relación entre los cambios del metabolismo microbiano y la dinámica de la población (García-Saucedo y col., 2015). Los autores encontraron que, a pesar del aumento de la tasa de carga de sulfato y lactato, no se observaron cambios en los índices ecológicos S, H y J, mientras que se observaron cambios metabólicos en el proceso respiratorio. Los resultados sugieren que el proceso se vio más afectado por las condiciones de operación que por los cambios microbianos. En un trabajo reciente (Bejarano-Ortiz y col., 2020), se realizó un estudio cinético en un reactor SBR inoculado con un lodo nitrificante y alimentado con diferentes concentraciones iniciales de sulfuro (2.5-20 mg de S-HS/L). Los resultados mostraron que el índice S disminuyó con el 
aumento en la concentración de sulfuro a lo largo de los ciclos de operación del SBR, el índice J se mantuvo entre 0.97 y 0.99 hasta $10.0 \mathrm{mg}$ de S-HS-/L y la actividad nitrificante fue completa y estable con valores altos de $\mathrm{EN}-\mathrm{NH}_{4}{ }^{+}$y $\mathrm{YN}_{-N_{3}}{ }^{-}$, pero a concentraciones más altas de sulfuro de 15 y $20 \mathrm{mg}$ de $\mathrm{S}-\mathrm{HS} / \mathrm{L}$ el índice J cayó a 0.33 y 0.40 respectivamente, indicando que ocurrieron cambios en la comunidad bacteriana con una disminución significativa en la uniformidad del lodo. Asimismo, cuando el índice J decayó, la inhibición de sulfuro en la nitrificación disminuyó, el lodo nitrificante mostró una mayor tolerancia a concentraciones altas de sulfuro, así como una adaptación metabólica para realizar la nitrificación y oxidar el sulfuro a lo largo de los ciclos de operación en el SBR, por lo que fue posible asociar estas respuestas con una menor riqueza y uniformidad de la comunidad bacteriana. Cabe mencionar- que, en los procesos biológicos, tanto la dinámica poblacional como el comportamiento metabólico se llevan a cabo simultáneamente, por consiguiente, el uso de métodos de biología molecular como herramientas para estimar los índices ecológicos, podría ser una estrategia más completa para estudiar los consorcios microbianos y su posible relación. Los trabajos anteriores encontraron que podría haber o no relación de los índices ecológicos de la comunidad con su respuesta respiratoria. Por otra parte, un análisis estadístico sería de utilidad para corroborar con más claridad los resultados, por lo tanto, sería de gran interés obtener evidencia para establecer si los perfiles fisiológicos y cinéticos están asociados con cambios microbianos o condiciones ambientales de acuerdo a un análisis estadístico de correlaciones.

Además de conocer la dinámica de poblaciones e índices ecológicos en un sistema dado, la secuenciación de bandas de un DGGE es una herramienta de mucha utilidad para conocer las especies presentes y que podrían estar involucradas en los procesos biológicos de un consorcio microbiano. La secuenciación de ácidos nucleicos es un método para determinar el orden exacto de nucleótidos presentes en una molécula de ADN o ARN dada, lo que permite identificar microorganismos de interés (Sanger y col., 1977). El método utilizado es conocido como secuenciación de primera generación, método de terminación de cadena o secuenciación Sanger. Fue desarrollado en 1975 por Edward Sanger (Sanger y col., 1977) y a pesar de que se han desarrollado técnicas de nueva generación para la secuenciación de ADN, ésta sigue siendo utilizada arduamente (Ansorge, 2009). Como un ejemplo de la aplicación de la técnica de 
DGGE, se puede citar al trabajo realizado por Pérez-Alfaro y col. (2015), donde evaluaron en ensayos en lote, el uso de dos lodos nitrificantes en presencia de 2-CF, uno aclimatado a $p$-cresol y el otro no aclimatado a $p$-cresol. Los autores reportaron que el cultivo no aclimatado no presentó capacidad para consumir $\mathrm{NH}_{4}{ }^{+}$ni 2-CF, mientras que el cultivo aclimatado mostró capacidad metabólica para nitrificar y mineralizar el 2-CF. El análisis del DGGE mostró cambios en la estructura de la comunidad microbiana, lo que indica que la diversidad microbiana se debió al proceso de aclimatación, sin embargo, dado que no realizaron secuenciación, no es posible conocer los microorganismos involucrados en los procesos ni identificar las bacterias que podrían ser las responsables de llevar a cabo el proceso nitrificante, así como el consumo de 2-CF. Por otra parte, existen trabajos utilizando DGGE y secuenciación. Por ejemplo, en un reactor por lotes de biopelícula nitrificante, el DGGE demostró que la diversidad estructural de la comunidad bacteriana aumentó durante el período de formación de biopelícula. Se mantuvieron dos bandas relacionadas con Nitrosomonas que presentaron una mayor intensidad durante todo el proceso, sugiriendo que el proceso nitrificante se podría asociar a ellas (Wang y col., 2014). Además, se han identificado diferentes bacterias nitrificantes por secuenciación en diferentes procesos, por ejemplo, en lodos activados para el tratamiento de aguas residuales (Limpiyakorn y col., 2004) y en lodos nitrificantes para la eliminación de $\mathrm{NH}_{4}{ }^{+}$y de bisfenol A (Zielinska y col., 2014) o p-cresol (Silva y col., 2014).

Por último, a la fecha no existen trabajos en sistemas dinámicos como el SBR, donde se reporte el efecto del incremento de la concentración de $\mathrm{NH}_{4}{ }^{+}$sobre el proceso nitrificante y/o sobre la dinámica poblacional en presencia de 2-CF. De esta manera, la evaluación de la respuesta fisiológica y cinética del proceso respiratorio, el consumo de 2-CF y su relación con la dinámica poblacional a lo largo de los ciclos de operación, abriría la posibilidad de entender el papel de los microorganismos presentes en el proceso nitrificante. 


\section{REFERENCIAS}

1 Aakra, A., Utåker, J. B., Pommerening-Röser, A., Koops, H. P. and Nes, I. F. (2001). Detailed phylogeny of ammonia-oxidizing bacteria determined by rDNA sequences and DNA homology values. International journal of systematic and evolutionary microbiology. 51(6), 2021-2030.

2 Agency for toxic substances and disease registry (ATSDR) (2015). www.atsdr.cdc.gov/spl/resources/2015_atsdr_substance_priority_list.html.

3 Agency for toxic substances and disease registry (ATSDR) (2016). https://www.atsdr.cdc.gov/es/phs/es_phs107.html.

4 Alawi, M., Lipski, A., Sanders, T. and Spieck, E. (2007). Cultivation of a novel cold-adapted nitrite oxidizing betaproteobacterium from the Siberian Arctic. The ISME journal. 1(3), 256-264.

5 Aleem, M.I.H. and Sewell, D.L. (1981). Mechanism of nitrite oxidation and oxidoreductase systems in Nitrobacter agilis. Current Microbiology. 5, 267-272.

6 Aleem, M.I.H., Hoch, G.E. and Varner J.E. (1965). Water as the source of oxidizing and reducing power in bacterial chemosynthesis. Proceedings of the National Academy of Sciences of the United States of America. 5, 869-873.

7 Alemayehu, M., Kumar, P. and Kumar A. (2001). Use of sequencing batch reactor for biological denitrification of high nitrate-containing water. Journal of Environmental Engineering. 127(3), 273-278.

8 Ali, T. U., Kim, M. and Kim, D. J. (2013). Selective inhibition of ammonia oxidation and nitrite oxidation linked to $\mathrm{N} 2 \mathrm{O}$ emission with activated sludge and enriched nitrifiers. Journal of microbiology and biotechnology. 23(5), 719-723.

9 Alvarez-Cohen, L. and Speitel, G.E., (2001). Kinetics of aerobic cometabolism of chlorinated solvents. Biodegradation. 12, 105-126.

10 Anders, H.J., Kaetzke, A., Kampfer, P., Ludwig, W. and Fuchs, G. (1995). Taxonomic position of aromaticdegrading denitrifying pseudomonas strains K 172 and KB 740 and their description as new members of the genera Thauera, as Thaueraaromatica sp. nov., and Azoarcus, as Azoarcusevansii sp. nov., respectively, members of the beta subclass of the Proteobacteria. International Journal of Systematic Bacteriology, 45,327-333.

11 Andersson, R.K., Rent, T.A., Lipscomb, J.D., Hooper, A.B. and Münck, E. (1984). Mössbauer EPR and Optical Studies of the P460 Center of Hydroxylamine Oxidoreductase from Nitrosomonas. Journal of Biological Chemistry. 259, 6833-6840.

12 Ansorge, W. J. (2009). Next-generation DNA sequencing techniques. New Biotechnology. 25(4), 195203.

13 Anthonisen, A.C., Loehr, R.C., Prakasom, T.B.S. and y Srinath E.G. (1976). Inhibition of nitrification by ammonia and nitrous acid. Journal of Water Pollution Control Federation. 48(5), 835-851.

14 Arciero, D., Vannelli, T., Logan, M. and Hooper, A.B. (1989). Degradation of trichloroethylene by ammonia-oxidizing bacterium Nitrosomonas europaea. Biochemical and biophysical research communications. 159(2), 640-643.

15 Arciero, D.M., Hooper, A.B., Cai, M. and Timkovich, R. (1993). Evidence for the structure of the active site heme P460 in hidroxylamina oxidoreductase of Nitrosomonas. Biochemistry. 32, 9370-9378.

16 Armenante, P.M., Kafkewitz, D., Lewandowski, G.A. and Jou C.J. (1999). Anaerobic-aerobic treatment of halogenated phenolic compounds. Water Research. 33, 681-692.

17 Arp, D., Sayavedra-Soto, L.A. and Hommes, N.G. (2002). Molecular biology and biochemistry of ammonia oxidation by Nitrosomonas europaea. Archives ofMicrobiology. 178, 250-258. 
18 Arp, D.J., and Stein, L.Y. (2003). Metabolism of inorganic N compounds by ammonia-oxidizing bacteria. Critical Reviews in Biochemistry and Molecular Biology. 38(6), 471-495.

19 Arp, D.J., Chain, P.S. and Klotz, M.G. (2007). The impact of genome analyses on our understanding of ammonia-oxidizing bacteria. Annual Review of Microbiology. 61,503-528.

20 Arp, D.J., Yeager, C.M., Hyman, M.R., (2001). Molecular and cellular fundamentals of aerobic cometabolism of trichloroethylene. Biodegradation. 12, 81-103.

21 Badanthadka, M. and Mehendale, H.M. (2014). Chlorophenols. Encyclopedia of Toxicology, 896-899.

22 Bassin, J.P., Pronk, M., Kraan, R., Kleerebezem, R. and Van Loosdrecht, M.C.M. (2011). Ammonium adsorption in aerobic granular sludge, activated sludge and anammox granules. Water Research. 45(16), 5257-5265.

23 Basu, S.K., Oleszkiewicsz, J.A. and Sparling, R. (1996). Dehalogenation of 2-Chlorophenol in anaerobic batch cultures. Elsevier Science. 30, 315-322.

24 Baumann, B., Snozzi, M., Zehnder, A., Roelof, J. and van der Meer, JR. (1996) Dynamics of denitrification activity of Paracoccus denitrificans in continuous culture during aerobic anaerobic changes. Journal of Bacteriology. 178, 4367-4374.

25 Bejarano-Ortiz, D., Martínez-Jardines, M., Cuervo-López, F. and Texier, A-C. (2020). Biological ammonium and sulfide oxidation in a nitrifying sequencing batch reactor: Kinetic and microbial population dynamics assessments. Chemosphere, 253, 126637.

26 Bekkum, H.V., Jansen, J.C. and Flanigen, E.M. (1991). Introduction to zeolite science and practice. Studies in Surface catalysis, Elsevier, Amsterdam, Vol. 58.

27 Belser, L.W. (1979). Population ecology of nitrifying bacteria. Annual reviews in microbiology. 33(1), 309-333.

28 Beristain-Montiel, L., Gómez, J., Monroy, O., Cuervo-López, F. and Ramírez-Vives, F. (2011). Biodegradation of 2-chlorophenol (2CP) in an anaerobic sequencing batch reactor (ASBR). Water Science and technology. 65(10), 1721-1728.

29 Beristain-Montiel, L., Gómez-Hernández, J., Monroy-Hermosillo, O., Cuervo-López, F. and RamírezVives, F. (2010). Methanization and mineralization of 2-chlorophenol by anaerobic digestion. Water Science and technology.62(8), 1791-1798.

30 Beristain-Montiel, L., Martínez-Hernández, S., Cuervo-López, F., Ramírez-Vives, F. (2015). Dynamics of a microbial community exposed to several concentrations of 2-chlorophenol in an anaerobic sequencing batch reactor. Environmental Technology. 36(14), 1776-1784.

31 Bernet, N. and Spérandio, M. (2009). Principles of nitrifying processes. En: Environmental technologies to treat nitrogen pollution. 1ra edición. Editorial: IWA Publishing, London. pp. 23-39.

32 Bock, E., Koops, H.P. and Harms, H. (1986). Cell biology of nitrifying bacteria, p. 17-38. In J. I. Prosser (ed.), Nitrification. IRL Press, Oxford, United Kingdom.

33 Bock, E., Koops, H.P., Harms, H. and Ahlers, B. (1991). The biochemistry of nitrifying microorganism, in variations in Autotrophic life, Bock E (Ed) (academic Press London). 171-200.

34 Bradberry, S.M, Proudfoot, A.L. and Vale, J.A. (2004). Poisoning due to chlorophenoxy herbicides. Toxicological Reviews.23, 65-73.

35 Breemen, N.V. (2002). Nitrogen cycle: Natural organic tendency. Nature. 415, 381-382.

36 Buitrón, G., Gonzalez, A. and Lopen-Marın, L.M. (1998). Biodegradation of phenolic compounds by an acclimated activated sludge and isolated bacteria. Water Science Technology. 37,371-378. 
37 Camargo, J.A and Alonso, A. (2007). Contaminación por nitrógeno inorgánico en los ecosistemas acuáticos: problemas medio ambientales, criterios de calidad del agua, e implicaciones del cambio climático. Ecosistemas. 16(2), 98-110.

38 Camargo, J.A. and Alonso, A. (2006). Ecological and toxicological effects of inorganic nitrogen pollution in aquatic ecosystems: A global assessment. Environment international. 32, 831-849.

39 Castingnetti, D. and Hollocher, T.C. (1985). Heterotrophic nitrification among Denitrifiers. Applied and Environmental Microbiology. 6, 229-231.

40 Chiavola, A., Baciocchi, R., Irvine, R.L., Gavasci, R. and Sirini, P., (2004). Aerobic biodegradation of 3chlorophenol in a sequencing batch reactor: effect of cometabolism. Water Science and Technology. 50(10), 235-242.

41 CONAGUA. (2007). Manual de Agua Potable, Alcantarillado y Saneamiento. http://www.conagua.gob.mx/CONAGUA07/Publicaciones/Publicaciones/Libros/11DisenoDePlantasPot abilizadorasTipoDeTecnologiaSimplificada.pdf.

42 Conley, DJ., Paerl, HW., Howarth, R., Boesch, D., Seitzinger, S., Havens, K., Lancelot, C. and Likens, G. (2009). Controlling Eutrophication: Nitrogen and Phosphorus. Science. 323, 1014-1015.

43 Cooney, E.L., Booker, N.A., Shallcross, D.C. and Stevens, G.W. (1999). Ammonia removal from wastewaters using natural Australian zeolite. I. Characterization of the zeolite. Separation Science and Technology. 34(12), 2307-2327.

44 Costa, E., Pérez, J. and Kreft, J. (2006). Why is metabolic labour divided in nitrification? Trends in Microbiology. 14(5), 213-219.

45 Cuervo-López, F., Martínez-Hernández, S., Texier, AC. and Gómez, J. (2009). Denitrification for Wastewater Treatment. In: Francisco J. Cervantes. J. Environmental Technologies to Treat Nitrogen Pollution: Principles and Engineering. London: IWA Publication; pp. 41-65.

46 Czaplicka, M., (2004). Sources and transformations of chlorophenols in the natural environment. Sci. Total Environ. 322, 21-39.

47 Daims, H., Lebedeva, E. V., Pjevac, P., Han, P., Herbold, C., Albertsen, M. and Kirkegaard, R. H. (2015). Complete nitrificationbyNitrospira bacteria. Nature. 528, 504-509.

48 Daims, H., Lücker, S., Paslier, D. and Wagner, M. (2011). Diversity, environmental genomics, and ecophysiology of nitrite-oxidizing bacteria. Nitrification, Edited by Bess B. Ward, Daniel J. Arp, and Martin G. Klotz @ ASM Press, Washington, DC p 295-322.

49 Dalsgaard, T., Thamdrup, B. and Canfield, D.E. (2005). Anaerobic ammonium oxidation (anammox) in the marine environment. Research in microbiology. 156(4), 457-464.

50 Dalton, H. and Stirling, D.I. (1982). Co-metabolism. Philosophical Transactions of the Royal Society of London. B, Biological Sciences. 297(1088), 481-496.

51 De Boer, W. and Kowalchuk, G.A. (2001). Nitrification in acid soils: micro-organisms and mechanisms. Soil Biol. Biochem. 33,853-866.

52 Delwiche, C.C. (1982). Denitrification, Nitrification and Atmospheric Nitrous Oxide. edition F, editor. New York, USA: John Wiley \&Sons, Inc.

53 Dercová, K., Čertík, M., Mal'ová, A. and Sejáková, Z. (2004). Effect of chlorophenols on the membrane lipids of bacterial cells. International biodeterioration and biodegradation, 54(4), 251-254.

54 Digger, G.T., Robbins, M.H. and Marshall, B.R. (1985). The design of selector to control low F/M filamentous bulking. Journal. Pollution Control Federation. 57, 2220-2226.

55 Dytczak, M., Londry, K. and Oleszkiewicz, J. (2008). Activated sludge operational regime has significant impact on the type of nitrifying community and its nitrification rates. Water research. 42, 2320-2328. 

chemolithoautotrophic, nitrite-oxidizing bacterium, Nitrospira moscoviensis sp. nov. and its phylogenetic relationship. Archives of Microbiology. 164(1), 16-23.

57 Ely, R.L., Williamson, K.J., Hyman, M.R., Arp, D.J., (1997). Cometabolism of chlorinated solvents by nitrifying bacteria: kinetics, substrate, interactions, toxicity effects, and bacterial response. Biotechnology. Bioengineering. 54, 520-534.

58 Ensign, S. A., Hyman, M. R. and Arp, D. J. (1993). In vitro activation of ammonia monooxygenase from Nitrosomonas europaea by copper. Journal of bacteriology, 175(7), 1971-1980.

59 Erosa de la Vega, G. and Nevárez Moorillón, G. V. (2015). Amonio-oxidasas bacterianas y arqueales involucradas en el ciclo del nitrógeno. Terra Latinoamericana. 33(3), 233-245.

60 Farrell, A. and Quilty, B. (1999). Degradation of mono-chorophenols by mixed microbial community via a meta-cleavage pathway. Biodegradation. 10, 353-362.

61 Felske, A., Rheims, H., Woltering, A., Stackebrandt, E. and Akkermans, A.D.L. (1997). Ribosome analysis reveals prominent activity of an uncultured member of the class Actinobacteria in glass lands soils. Microbiology. 143, 2983-2989.

62 Feng, W., Si-qing, X., Yi, L., Xue-song, C., Jun, Z., (2007). Community analysis of ammonia and nitrite oxidizers in start-up of aerobic granular sludge reactor. Journal of Environmental Sciences 19, 996-1002.

63 Feng, Y., Lu, X., Al-Hazmi, H. and Mąkinia, J. (2017). An overview of the strategies for the deammonification process start-up and recovery after accidental operational failures. Reviews in Environmental Science and Bio/Technology. 16(3), 541-568.

64 Fernández-Polanco, F., García, P.A., Rodríguez, P., Bueno, J.M., Real, J.F. and Acítores, M. (1993). Sistemas combinados aerobios anaerobios: aplicación a aguas urbanas, en Depuración Anaerobia de Aguas Residuales. Valladolid, 26-28 de mayo.

65 Ferris, M.J., Muyzer, G. and Ward, D.M., (1996). Denaturing gradient gel electrophoresis profiles of 16S rRNA-defined populations inhabiting a hot spring microbial mat community. Applied and Environmental Microbiology. 62, 340-346.

66 Fowler, D., Coyle, M., Skiba, U., Sutton, M.A., Cape, J.N., Reis, S., Sheppard, L.J. and Vitousek, P. (2013). The global nitrogen cycle in the Twenty first century. Philosophical Transactions of the Royal Society B: Biological Sciences. 368(1621), 20130164.

67 Furukawa, K.(2000). Engineering dioxygenases for efficient degradation of environmental pollutants. Current Opinion Biotechnology. 11(3), 244-249.

68 Gao, J. F., Luo, X., Wu, G. X., Li, T. and Peng, Y. Z. (2013). Quantitative analyses of the composition and abundance of ammonia-oxidizing archaea and ammonia-oxidizing bacteria in eight full-scale biological wastewater treatment plants. Bioresource technology. 138, 285-296.

69 García-Saucedo, C., Fernández, F., Cuervo-López, F. and Gómez, J. (2015). Effect of sulfate and lactate loading rates on the respiration process and microbial population changes measured by ecological índices. Water Science and Technology. 71(1), 97-104.

70 García-Velázquez, L. and Gallardo, A. (2017). The global nitrogen cycle. A perspective for the terrestrial ecologist. Ecosistemas. 26(1), 4-6.

71 Geets, J., Boon, N. and Verstraete, W. (2006). Strategies of aerobic ammonia-oxidizing bacteria for coping with nutrient and oxygen fluctuations. FEMS Microbiology Ecology. 58,1-13.

72 Gerardi, M.H. (2002). Nitrification and Denitrification in the Activated Sludge Process. Editorial: WileyInterscience, John Wiley \& Sons, Inc., New York. 
73 Gieseke, A., Tarre, S., Green M. and Beer, D. (2006). Nitrification in a biofilm at low pH values: Role of in situ microenvironments and acid tolerance. Applied and Environmental Microbiology. 72(6), 42834292.

74 Gijs, J. and Robertson, L. (1994). Combined nitrification-denitrification processes. FEMS Microbiology Reviews. 15(2-3): 109-117.

75 Ginestet, P., Audic, J. M., Urbain, V. and Block, J. C. (1998). Estimation of nitrifying bacterial activities by measuring oxygen uptake in the presence of the metabolic inhibitors allylthiourea and azide. Applied and Environmental Microbiology, .64(6), 2266-2268.

76 Godon, J.J., Zumstein, E., Dabert, P., Habouzit, F. and Moletta, R. (1997). Microbial 16S rDNA diversity in an anaerobic digester. Applied and Environmental Microbiology. 63, 2802-2813.

77 Gómez, J., Mendez, J.R. and Lema, J.M. (2000). Kinetic study of addition of volatile organic compounds to a nitrifying sludge. Applied Biochemistry and Biotechnology. 88, 1-12.

78 González-Blanco, G. (2015). Caracterización cinética de la eliminación simultánea de $p$-cresol y amonio por un lodo desnitrificante. Tesis de doctorado. Universidad Autónoma Metropolitana-Iztapalapa

79 Grunditz, C. and Dalhammar, G. (2001). Development of nitrification inhibition assays using pure cultures of Nitrosomonas and Nitrobacter. Water research. 35(2), 433-440.

80 Gunsalus, I.C., Pederson, T.C. and Sligar, S.G. (1975). Oxygenase-Catalyzed Biological Hydroxylations. Annual Review of Biochemistry.44, 377-407.

81 Gupta, V.K. Sadegh, H., Yari, M., Shahryari, R., Maazinejad, B. and Chahardori, B. (2015). Removal of ammonium ions from wastewater A short review in development of efficient methods. Global Journal of Environmental Science and Managemant. 1(2), 149-158.

82 Hakemian, A.S. and Rosenzweig, A.C. (2007). The biochemistry of methane oxidation. Annual Review of Biochemistry. 76,223-241.

83 Hanaki, K., Wantawin, C. and Ohgaki, S. (1990). Effects of the activity of heterotrophs on nitrification in a suspended-growth reactor. Water Research. 24(3), 289-296.

84 Hao, O.J., Kim, H.M., Seagren, A.E. and Kim, H. (2002). Kinetics of phenol and chlorophenol utilization by Acinetobacter species. Chemosphere. 46 (6), 797-807.

85 Hatzenpichler, R. (2012). Diversity, physiology, and niche differentiation of ammonia-oxidizing archaea. Applied and environmental microbiology. 78(21), 7501-7510.

86 Hazen, T.C. (2010). Cometabolic bioremediation. In: Timmis, K.N. (Ed.), Handbook of Hydrocarbon and Lipid Microbiology. Springer-Verlag Berlin Heidelberg, pp. 2505-2514.

87 Heipieper, H.J., Diefenbach, R. and Keweloh, H. (1992). Conversion of cis unsaturated fatty acids to trans, a possible mechanism for the protection of phenol-degrading Pseudomonas putida P8 from substrate toxicity. Applied and Environmental Microbiology. 58(6), 1847-1852.

88 Hernández, L. (2005). Estudio del proceso respiratorio y estructura de un lodo desnitrificante en presencia de acetato y tolueno en un SBR. Tesis de maestría UAM-Iztapalapa.

89 Hernández, L., Buitron, G., Gómez, J. and Cuervo-Lopez F.M. (2008). Denitrification of toluen and slugde settleability. Proceedings of 4th IWA Specialized Conference on Sequencing Batch Reactor Technology SBR. S. Michele a Ripa, Rome, Italy. 69-72.

90 Hoffman, R.V. (2004). Acidity and Basicity, In: Organic Chemistry: An intermediate text, (Second Ed.), 55, ISBN 0-471-45024-3, John Wiley and Sons, Inc, publication, New Jersey, USA.

91 Holmes, A., Costello, A. Lidstrom, M. and Murrell, J. (1995). Evidence that particulate methane monooxygenase and ammonia monooxygenase may be evolutionarily related. FEMS Microbiology Letters. 132(3), 203-208. 
92 Hommes, N.G., Sayavedra-Soto, L.A. and Arp, D.J. (1998). Mutagenesis and expression of amo, which codes for ammonia monooxygenase in Nitrosomonas europaea. Journal of Bacteriology. 180, 3353-3359.

93 Hooper, A.B. (1989). Biochemistry of the nitrifying lithoautotrophic bacteria, p. 239-281. In H. G. Schlegel and B. Bowien (ed.), Autotrophic Bacteria. Science Tech Publishers, Madison. WI.

94 Hooper, A.B. and Terry, K.R. (1973). Specific inhibitors of ammonia oxidation in Nitrosomonas. Journal of Bacterioloy. 115, 480-485.

95 Hooper, A.B., Vannelli T., Bergmann D.J. and Arciero D.M. (1997). Enzymology of the oxidation of ammonia to nitrite by bacteria. Antonie van Leeuwenhoeck. 71, 59-67.

96 Hyman, M.R., Russell, S.A., Ely, R.L., Williamson, K.J. and Arp, D.J. (1995). Inhibition, inactivation, and recovery of ammonia-oxidizing activity in cometabolism of trichloroethylene by Nitrosomonas europaea. Applied and Environmental Microbiology. 61(4), 1480-1487.

97 Inui, T., Tanaka, Y., Okayasu, Y. and Tanaka, H. (2002). Application of toxicity monitor using nitrifying bacteria biosensor to sewerage systems. Water Science and technology. 45, 271-278.

98 Irvine, R., Wilderer, P. and Flemming, H. (1997). Controlled unsteady state processes and technologies an overview. Water Science and technology. 35(1), 1-10.

99 Isaka, K., S. Yoshie, T. Sumino, Y. Inamori, and S. Tsuneda. (2007). Nitrification of landfill leachate using immobilized nitrifying bacteria at low temperatures. Biochemical Engineering Journal. 37,49-55.

100 Ismail, Z.Z., Tezel, U. and Pavlostathis, S.G. (2010). Sorption of quaternary ammonium compounds to municipal sludge. Water Research. 44(7), 2303-2313.

101 Jesus, J., Frascari, D., Pozdniakovac, T. and Dankoa, A. (2016). Kinetics of aerobic cometabolic biodegradation of chlorinated and brominated aliphatic hydrocarbons: a review. Journal of Hazardous Materials. 309, 37-52.

102 Jetten, M.S., Wagner, M., Fuerst, J., van Loosdrecht, M., Kuenen, G. and Strous, M. (2001). Microbiology and application of the anaerobic ammonium oxidation ('anammox') process. Current opinion in biotechnology. 12(3), 283-288.

103 Jin, R.C., Yang, G.F., Yu, J.J. and Zheng, P. (2012). The inhibition of the Anammox process: a review. Chemical engineering journal. 197, 67-79.

104 Juliette, L.Y., Hyman, M.R. and Arp, D.J. (1993). Inhibition of ammonia oxidation in Nitrosomonas europaea by sulfur compounds: thioethers are oxidized to sulfoxides by ammonia monooxygenase. Applied and Environmental Microbiology. 59(11), 3718-3727.

105 Kai-Chee, L., Tingting, W., (2006). Cometabolic transformation of 2-chlorophenol and 4-chlorophenol in the presence of phenol by Pseudomonas putida. The Canadian Journal of Chemical Engineering. 84 (3), 356-367.

106 Kang, S.Y., Lee, J.U., Moon, S.H. and Kim, K.W. (2004). Competitive adsorption characteristics of $\mathrm{Co}_{2}^{+}$, $\mathrm{Ni}_{2}{ }^{+}$, and $\mathrm{Cr}_{3}{ }^{+}$by IRN-77 cation exchange resin in synthesized wastewater. Chemosphere. 56(2), 141-147.

107 Karanasios, K.A., Vasiliadou, I.A., Pavlou, S. and Vayenas, D.V. (2010). Hydrogenotrophic denitrification of potable water: a review. Journal of Hazardous Materials. 180 (1-3), $20-37$.

108 Keener, W. and Arp, D.J., (1994). Transformation of aromatics compounds by Nitrosomonas europaea. Applied and Environmenta lMicrobiology. 60, 1914-1920.

109 Keener, W.K. and Arp, D.J. (1993). Kinetic studies of ammonia monooxygenase inhibition in Nitrosomonas europaea by hydrocarbons and halogenated hydrocarbons in a optimizer whole-cell assay. Applied and Environmental Microbiology. 59(68), 2501-2510.

110 Ketchum, J. (1997). Design and Physical Features of Sequencing Batch Reactors. Water Science and technology. 35(1), 11-18. 
111 Kocamemi, B. and Çeçen, A. F. (2010). Biological removal of the xenobiotic trichloroethylene (TCE) through cometabolism in nitrifying systems. Bioresource Technology.101, 430-433.

112 Koops, H.P. and Pommerening-Roser, A. (2001). Distribution and ecophysiology of the nitrifying bacteria emphasizing cultured species. FEMS Microbiology Ecology. 37, 1-9.

113 Kostyal, E., Nurmiaho-Lassila, L.E., Puhakka, J.A. and Salkinoja-Salonen, M. (1997). Nitrification, denitrification, and dechlorination in bleached kraft pulp mill wastewater, Applied Microbiology and Biotechnology. 47, 734-741.

114 Kowalchuk, G.A. and Stephen, J.R. (2001). Ammonia-oxidizing bacteria: A model for molecular microbial ecology. Annual Review of Microbiology. 55, 485-529

115 Kruger, B., Meyer, O., Nagel, A., Andreesen, J.R., Meincke, M., Bock, E., Blamle, S. and Zumft. W.G. (1987). Evidence for the presence of bactopterin in the eubacterial molybdoenzymes nicotinic acid dehydrogenase, nitrite oxidoreductase and respiratory nitrate reductase. FEMS Microbiology Letters. $48,225-227$.

116 Kuenen, J.G. (2008). Anammox bacteria: from discovery to application. Nature Reviews Microbiology. 6(4), 320-326.

117 Laanbroek, H.J. and Gerards, S. (1993). Competition for limiting amounts of oxygen between Nitrosomonas europaea and Nitrobacter winogradskyi grown in mixed continuous cultures. Archives of Microbiology.159, 453-459.

118 Lee, D. and Jong, M.P. (1999). Neural network mideling for on-line estimation of nutrient dyminamics in a sequentially-opeated batch reactor. Journal of Biotechnology. 75, 29-239.

119 Leininger, S., Urich, T., Schloter, M., Schwark, L., Qi, J., Nicol, G. W. and Schleper, C. (2006). Archaea predominate among ammonia-oxidizing prokaryotes in soils. Nature. 442(7104), 806-809.

120 Lens, P. and Kuenen, J. (2001). The biological sulfur cycle: novel opportunities for environmental biotechnology. Water Science and technology. 44(8), 57-66.

121 Limpiyakorn, T., Shinohara, Y., Kurisu, F. and Yagi, O. (2004). Distribution of ammonia oxidizing bacteria in sewage activated sludge: analysis based on $16 \mathrm{~S}$ rDNA sequence. Water Science and technology. 50 (8), 9-14.

122 Liu, D., Maguire, R.J., Pacepavicius, G. and Dutka, B.J., (1991). Biodegradation of recalcitrant chlorophenols by cometabolism. Environmental Toxicology. 6, 85-95.

123 Lloyd, H. and Ketchum, Jr. (1997). Design and physical features of sequencing batch reactors. Water Science and technology. 35(1), 11-18.

124 Loehr R.C. and Krishnamoorthy R. (1998). Terrestrial bioaccumulation potential of phenolic compounds. Hazardous Waste and Hazardous Materials. 5,2-9.

125 Lydmark, P., Almstrand, R., Samuelsson, K., Mattsson, A., Sörensson, F., Lindgren, P. and Hermansson, M. (2007). Effects of environmental conditions on the nitrifying population dynamics in a pilot wastewater treatment plant. Environmental Microbiology. 9(9),2220-2233.

126 Madigan, M.T., Martinko, J.M., Bender, K.S., Buckley, D.H. and Stahl, D.A. (2015) Brock Biología de los microorganismos 14 ed., Pearson Prentice Hall, Pearson Education S.A.

127 Majumder, P.S. and Gupta, S. K. (2007). Removal of chlorophenols in sequential anaerobic-aerobic reactors. Bioresource Technology. 98,118-129.

128 Martínez, F. (2003). Sedimentabilidad de un lodo nitrificante en dos tipos de reactores y en presencia de material orgánica. Tesis de doctorado. Universidad Autónoma Metropolitana-Iztapalapa. 
129 Martínez-Hernández, S., Olguín, E., Gómez, J. and Cuervo-López, F. (2009). Acetate Enhances the Specific Consumption Rate of Toluene Under Denitrifying Conditions. Archives Environmental Contamination and Toxicology. 57,679-687

130 Martínez-Hernández, S., Texier, A-C., Cuervo-López, F. and Gomez, J. (2011). 2-Chlorophenol and its effect on the nitrifying sludge. Journal Hazardous Materials. 185, 1592-1595.

131 Martínez-Jardines, M. (2015). Evaluación de la inhibición de la nitrificación en presencia de 2-clorofenol y la dinámica poblacional del consorcio nitrificante. Tesis de maestría. Universidad Autónoma Metropolitana Iztapalapa.

132 Martínez-Jardines, M., Perez-Alfaro, E., González-Robles, R.O., Texier, A.-C. and Cuervo-López, F., (2019). Decrease of inhibitory effect of 2-chlorophenol on nitrification in sequencing batch reactors. Environmental Technology.

133 Mathews, C.K., Van Holde, K.E. and Ahern, K.G. (2000). Biochemistry, 3rd ed. Benjamin Cummings, San Francisco, CA.

134 McCarty, G.W. (1999). Modes of action of nitrification inhibitors. Biology and Fertility of Soils. 29(1), $1-9$.

135 Mcclelland, J.W. and Valiela, I. (1998). Linking nitrogen in estuarine producers to land-derived sources. American Society of Limnology and Oceanography. 43(4),577-585.

136 Meincke, M., Bock, E., Kastrau, D. and Kroneck. P.M.H. (1992). Nitrite oxidoreductase from Nitrobacter hamburgensis: redox centers and their catalytic role. Archives of Microbiology. 158,127-131.

137 Michael, G.R., Shimitzu, G.P. and Jenkins, D. (1985) The growth physiology of the flamentous organism type $021 \mathrm{~N}$ and its significance activated sludge bulking. Journal. Water Pollution Control Federation. $57,1152-1162$.

138 Mikhail, S. and Sverjensky, D.A. (2014). Nitrogen speciation in upper mantle fluids and the origin of Earth's nitrogen-rich atmosphere. NatureGeoscience.7, 816-819.

139 Mondal, P.K. and Sabir, S. (2011). Bioremediation of 2-chlorophenol containing wastewater by aerobic granules-kinetics and toxicity. Journal of hazardous materials. 190(1-3), 222-228.

140 Monsalvo, V.M., Mohedano, A.F., Casas, J.A. and Rodríguez, J.J. (2009). Cometabolic biodegradation of 4-chlorophenol by sequencing batch reactors at different temperatures. Bioresource Technology. 100 (20), 4572-4578.

141 Moradi, O. (2011). The removal of ions by functionalized carbon nanotube: equilibrium, isotherms and thermodynamic studies. Chemical and biochemical engineering quarterly. 25(2), 229-240.

142 Moreno, G. and Buitrón, G. (2004). Influence of the origin of the inoculum and the acclimation strategy on the degradation of 4-chlorophenol. Bioresource Technology. 94, 215-218.

143 Moreno-Andrade, I. and Buitrón, G. (2004). Evolución de la actividad de los microrganismos en los procesos de aclimatación y des aclimatación al 4-clorofenol. XIV Congreso Nacional de la FederacionMexicana de Ingenieria Sanitaria y Ciencias Ambientales AC, Mazatlán, Sinaloa.

144 Murthy, N.B., Kaufman, D.D. and Fries, G.F. (1979). Degradation of pentachlorophenol (PCP) in aerobic and anaerobic soil. Journal of Environmental Science \& Health Part B.14,1-14.

145 Muyzer, G., De Waal E.C. and Uitterlinden, A.G. (1993). Profiling of complex microbial populations by denaturing gradient gel electrophoresis analysis of polymerase chain reaction-amplified genes coding for 16S rRNA. Applied and Environmental Microbiology. 59, 695-700.

146 Ngugi, D. K., Blom, J., Stepanauskas, R. and Stingl, U. (2016). Diversification and niche adaptations of Nitrospina-like bacteria in the polyextreme interfaces of Red Sea brines. The ISME journal. 10(6), 13831399. 
147 Ni, B., Pan, Y., Guo, J., Virdis, B., Hu, S., Chen, X., and Yuan, Z. (2017). Denitrification Processes for Wastewater Treatment Denitrification Processes for Wastewater Treatment. In: I. Moura, J. J. G. Moura, S. R. Pauleta, and L. B. Maia, eds. Metalloenzymes in Denitrification: Applications and Environmental Impacts. The Royal Society of Chemistry. pp. 368-418.

148 Norton, J. (2008). Nitrification in agricultural soils, In J. S. Schepers and W. R. Raun (ed.), Nitrogen in Agricultural Systems. American Society of Agronomy, Inc.; Crop Science Society of America, Inc.; Soil Science Society of America, Inc., Madison, WI.pp. 173-199.

149 Norton, J. (2011). Diversity and environmental distribution of AOB. Nitrification, Edited by Bess B. Ward, Daniel J. Arp, and Martin G. Klotz @ 2011 ASM Press, Washington, DC pp 39-55.

150 Norton, J. Alzerreca, J.J., Suwa. and. Klotz, M.G. (2002). Diversity of ammonia monooxygenase operon in autotrophic ammonia-oxidizing bacteria. Archives of Microbiology. 177,139-149.

151 Numata, M., Saito, T., Yamazaki, T., Fukumori, Y. and Yamanaka, T. (1990). Cytochrome P-460 of Nitrosomonas eropaea: further purification and further characterization. Journal of Biochemical. 108, 1016-1021.

152 Okabe, S., Aoi, Y., Satoh, H. and Suwa, Y. (2011). Nitrification in wastewater treatment En: Nitrification, Edited by Bess B. Ward, Daniel J. Arp, and Martin G. Klotz () 2011 ASM Press, Washington, DC pp. 405-433.

153 Olmos, A., Olguin, P., Fajardo, C., Razo, E. and Monroy, O. (2004). Physicochemical characterization of spent caustic from the OXIMER process and sour waters from mexican oil refineries. Energy and Fuels. $18,302-304$.

154 Oshiki, M., Shimokawa, M., Fujii, N., Satoh, H. and Okabe, S. (2011). Physiological characteristics of the anaerobic ammonium-oxidizing bacterium 'Candidatus Brocadia sinica'. Microbiology, 157(6), 17061713.

155 Park, H. D., Wells, G. F., Bae, H., Criddle, C. S. and Francis, C. A. (2006). Occurrence of ammoniaoxidizing archaea in wastewater treatment plant bioreactors. Applied and environmental microbiology, 72(8), 5643-5647.

156 Pearson, A.R, Elmore, B.O., Yang, C., Ferrara, J.D., Hooper, A.B. and Wilmot, C.M. (2007). The crystal structure of cytochrome P460 of Nitrosomonas europaea reveals a novel cytochrome fold and hemeprotein cross-link. Biochemistry. 46, 8340-8349.

157 Peng, Y. and Zhu, G. (2006). Biological nitrogen removal with nitrification and denitrification via nitrite pathway. AppliedMicrobiology and Biotechnology. 75, 15-26.

158 Pera-Titus, M., García-Molina, V., Baños, M. A., Giménez, J. and Esplugas, S. (2004). Degradation of chlorophenols by means of advanced oxidation processes: a general review. Applied Catalysis B: Environmental. 47(4), 219-256.

159 Pérez-Alfaro, J. E., González-Blanco, G., Sierra-Palacios, E., Marcial-Quino, J. and Beristain-Cardoso, R. (2015). Acclimation of nitrifying biomass and its effect on 2-chlorophenol removal. Water Science and Technology. 71.2, 277-282.

160 Pérez-Alfaro, J.E., Buitrón, G., Gómez, J., Texier, A-C. and Cuervo-López, F.M. (2013). Kinetic and Physiological Evaluation of Ammonium and Nitrite Oxidation Processes in Presence of 2-Chlorophenol. Applied Biochemistry and Biotechnology. 169(3),990-1000.

161 Pérez-Alfaro. (2007). Evaluación del efecto del fenol en la nitrificación y sedimentabilidad de un lodo utilizando un reactor de lote secuenciado (SBR). Tesis de especialidad. Universidad Autónoma Metropolitana Iztapalapa.

162 Pérez-Alfaro. (2015). Efecto del 2-clorofenol sobre la nitrificación. Tesis de doctorado. Universidad Autónoma Metropolitana Iztapalapa. 
163 Pester, M., Rattei, T., Flechl, S., Gröngröft, A., Richter, A., Overmann, J. and Wagner, M. (2012). amoAbased consensus phylogeny of ammonia-oxidizing archaea and deep sequencing of amoA genes from soils of four different geographic regions. Environmental Microbiology. 14(2), 525-539.

164 Pommerening-Roser, A., Rath, G. and Koops, H.P. (1996). Phylogenetic diversity within the genus Nitrosomonas. Systematic and Applied Microbiology. 19,344-351.

165 Prosser, J.I. (1990). Autotrophic nitrification in bacteria. In Advances in microbial physiology (Vol. 30, pp. 125-181). Academic Press.

166 Puhakka, J.A. and Melin, E.S. (1996). Bioremediation of chlorinated phenols. In:Crawford, R.L., Crawford, D.L. (Eds.), Bioremediation: Principles and Applications. Cambridge Univ Pr, New York, pp. 254-297.

167 Purkhold, U., Pommerening-Röser, A., Juretschko, S., Schmid, M. C., Koops, H. P. and Wagner, M. (2000). Phylogeny of all recognized species of ammonia oxidizers based on comparative 16S rRNA and amoA sequence analysis: implications for molecular diversity surveys. Applied and Environmental Microbiology. 66(12), 5368-5382.

168 Ramos, J.L., Duque, E., Gallegos, M.T., Godoy, P., Ramos-González, M.I., Rojas, A. and Segura, A. (2002). Mechanisms of solvent tolerance in gram-negative bacteria. Annual Reviews in Microbiology. 56(1), 743-768.

169 Robinson, K.G., Sayler G.S. and Janalyn, J.R. (2004). Used of Novel Techniques to Quantify Phenotypes in Biological Treatment Process, IWA Publishing, Orlando, USA 2.11- 2.12.

170 Rysgaard, S., Glud, R.N., Risgaard-Petersen, N. and Dalsgaard, T. (2004). Denitrification and anammox activity in Arctic marine sediments. Limnology and Oceanography. 49(5), 1493-1502.

171 Sanger, F. Nicklen S, Coulson AR. (1977) DNA sequencing with chain-terminating inhibitors. Proc. Natl. Acad. Sci. U. S. A. 74, 5463-5467.

172 Satoh, H., Sasaki, Y., Nakamura, Y., Okabe, S. and Suzuki T. (2005). Use of microelectrodes to investigate the effects of 2-chlorophenol on microbial activities in biofilms. Wiley Interscience. 91, 133137.

173 Sayavedra-soto, L. and Arp, D. (2011). Ammonia-oxidizing bacteria: their biochemistry and molecular biology. En: Nitrification, Edited by Bess B. Ward, Daniel J. Arp, and Martin G. Klotz (C) 2011 ASM Press, Washington, DC pp. 11-37.

174 Sayavedra-Soto, L.A., Hommes, N.G., Russell, S.A. and Arp, D.J. (1996). Induction of ammonia monooxygenase and hydroxylamine oxidoreductase mRNAs by ammonium in Nitrosomonas europaea. Molecular Microbiology. 20(3), 541-548.

175 Schweighofer, P., Nowak, O., Svardal, K. and Kroiss H. (1996). Steps towards the upgrading of a municipal WWTP affected by nitrification inhibiting compounds-A case study. Water Science and Technology. 33(12), 39-46.

176 Segura, A., Molina, L., Fillet, S., Krell, T., Bernal, P., Muñoz-Rojas, J. and Ramos, J. L. (2012). Solvent tolerance in Gram-negative bacteria. Current opinion in biotechnology. 23(3), 415-421.

177 Sekiguchi, Y., Kamagata, Y., Syutsubo, K., Ohashi, A., Harada, H. and Nakamura, K. (1998). Phylogenetic diversity of mesophilic and thermophilic granular sludges determined by $16 \mathrm{~S}$ rRNA gene analysis. Microbiology. 144, 2655-2665.

178 SEMARNAT. (2018). Estadísticas del Agua en México, edición, México. http://sina.conagua.gob.mx/publicaciones/EAM_2018.pdf.

179 Shammas, N.K. (1986). Interactions of temperature, pH and biomass on the nitrification process. Journal. Water Pollution Control Federation. 58(1), 52-59. 
180 Shinoda, Y., Sakai, Y., Ue, M., Hiraishi, A. and Kato, N. (2000). Isolation and characterization of a new denitrifying spirillum capable of anaerobic degradation of phenol. Applied and Environmental Microbiology. 66,1286-1291.

181 Sikkema, J., Jam, B. and Poolman, B. (1995). Mechanisms of membrane toxicity of hydrocarbons. Microbial Reviews. 59(2), 201-222.

182 Silva, C.D., Beristain-Montiel, L., Cuervo-López F. and Texier, A-C. (2014). p-cresol mineralization and bacterial population dynamics in a nitrifying sequential batch reactor. Journal of Environmental Sciences. 26, 1885-1893.

183 Silva, C.D., Gomez, J., Beristain-Cardoso, R. (2011). Simultaneous removal of 2-chlorophenol, phenol, $p$-cresol and $p$-hydroxybenzaldehyde under nitrifying conditions: kinetic study. Bioresource Technology. 102(11), 6464-6468.

184 Smith, V.H. (2003). Eutrophication of Freshwater and Coastal Marine Ecosystems a Global Problem. Environmental Science and Pollution Research. 10(2), 126-139.

185 Solomons, T.W. and Graham. (2000). Química orgánica. Ed. Limusa-Wiley, México, pp.1124.

186 Stackebrandt, E., Murray, R.G.E. and Trüper, H.G. (1988). Proteobacteria classis nov., a name for the phylogenetic taxon that includes the "purple bacteria and their relatives". International Journal of Systematic and Evolutionary Microbiology. 38(3), 321-325.

187 Stahl, D.A. and de la Torre, J.R. (2012). Physiology and diversity of ammonia-oxidizing archaea. Annual review of microbiology. 66, 83-101.

188 Stein, L.Y., and Arp, D.J. (1998). Loss of ammonia monooxygenase activity in Nitrosomonas europaea upon exposure to nitrite. Applied of Environmental Microbiology. 64, 4098-4102.

189 Stein, L.Y., Arp, D.J. and Hyman, M.R. (1997). Regulation of the synthesis and activity of ammonia monooxygenase in Nitrosomonas europaea by altering $\mathrm{pH}$ to affect $\mathrm{NH}_{3}$ availability. Applied of Environmental Microbiology. 63,4588-4592.

190 Stein, L.Y., Sayavedra-Soto, L.A. Hommes, N.G. and Arp, D. J. (2000). Differential regulation of amoA and amoB gene copies in Nitrosomonas europaea. FEMS Microbiology Letters. 192, 163-168.

191 Suárez-García, L., Cuervo-López, F.M. and Texier, A.-C. (2019). Biological removal of mixtures of ammonium, phenol, cresol isomers, and sulfide in a sequencing batch reactor. Revista Mexicana de Ingeniería Química. 18(3), 1189-1202.

192 Suwa, Y., Imamura, Y., Suzuki, T., Tashiro, T. and Urushigawa. Y. (1994). Ammonia-oxidizing bacteria with different sensitivities to $\left(\mathrm{NH}_{4}\right)_{2} \mathrm{SO}_{4}$ in activated sludges. Water Research. 28, 1523-1532.

193 Suzuki, I. and Kwok, S.C. (1981). A partial resolution and reconstitution of the ammonia-oxidizing system of Nitrosomonas europaea: role of cytochrome c554. Canadian journal of biochemistry. 59(7), 484-488.

194 Suzuki, I., Dular, U. and Kwok, S. (1974). Ammonia or ammonium ion as substrate for oxidation by Nitrosomonas europea cells and extracts. Journal of Bacteriology. 120, 556-558.

195 Suzuki, I., Kwok, S.C., Dular, U. and Tsang. Y. (1981). Cell-free ammonia-oxidizing system of Nitrosomonas europaea: general conditions and properties. Canadian journal of biochemistry. 59, 477483.

196 Takeuchi, R., Suwa, Y. and Yamagishi, T. (2000). Anaerobic transformation of chlorophenols in methanogenic sludge unexposed to chlorophenols. Chemosphere. 41, 1457-1462.

197 Tandukar, M., Pavlostathis, S.G. and Cervantes, F.J. (2009). Autotrophic denitrification for the removal of nitrogenous and sulphurous contaminants from wastewaters. In: Cervantes FJ (Ed) Environmental technologies to treat nitrogen pollution: principles and engineering. IWA, London, pp. 324-377. 
198 Teske, A., Alm, E., Regan, J.M., Toze, S., Rittmann, B.E. and Stahl, D.A. (1994). Evolutionary relationships among ammonia-and nitrite-oxidizing bacteria. Journal of bacteriology. 176(21), 66236630 .

199 Texier, A-C, Zepeda, A., Gómez, J. and Cuervo-López, F. (2012). Simultaneous Elimination of Carbon and Nitrogen Compounds of Petrochemical Effluents by Nitrification and Denitrification, Petrochemicals, DrVivek Patel (Ed.).

200 Texier, A-C. and Gómez, J. (2004). Settleability and kinetics of a nitrifying sludge in a sequencing batch reactor. Canadian Journal of Microbiology. 50, 943-949.

201 Texier, A-C. and Gomez, J. (2007). Simultaneous nitrification and p-cresol oxidation in anitrifying sequencing batch reactor. Water research. 41, 315-322.

202 Torrijos, M. and Moletta, R. (1997). Winery Wastewater Depollution by Sequencing Batch Reactor. Water Science and technology. 35(1), 249-250.

203 Tran, N., Urase, T., Ngo, H., Hu, J. and Ong, S. (2013). Insight into metabolic and cometabolic activities of autotrophic and heterotrophic microorganisms in the biodegradation of emerging trace organic contaminants. Bioresource Technology. 146, 721-731.

204 Van Hulle, S.W., Vandeweyer, H.J., Meesschaert, B.D., Vanrolleghem, P.A., Dejans, P. and Dumoulin, A. (2010). Engineering aspects and practical application of autotrophic nitrogen removal from nitrogen rich streams. Chemical engineering journal. 162(1), 1-20.

205 Van Rijn, J., Tal, Y. and Schreier, H. J. (2006). Denitrification in recirculating systems: theory and applications. Aquacultural engineering. 34(3), 364-376.

206 Vannelli, T. and Hooper, A.B. (1992). Oxidation of nitrapyrin to 6-chloropicolinic acid by the ammoniaoxidizing bacterium Nitrosomonas europaea. Applied of Environmental Microbiology. 58, 2321-2325.

207 Vannelli, T., Logan, M., Arciero, D.M. and Hooper, A.B., (1990). Degradation of halogenated aliphatic compounds by the ammonia-oxidizing bacterium Nitrosomonas europaea. Applied of Environmental Microbiology. 56(4), 1169-1171.

208 Vázquez-Padín, J., Figueroa, A., Mosquera-Corral, Campos, J. and Menuez. R. (2009). Population dynamics of nitrite oxidizers in nitrifying granules. Water Science \& Technology. 60(10), 2529-2536.

209 Vitousek, P.M., Aber, J.D., Howarth, R.W., Likens, G.E., Matson, P.A., Schindler, D.W., Schlesinger, W.H. and Tilman, D.G. (1997). Human alteration of the global nitrogen cycle: Sources and consequences. Ecological Applications 7, 737-750.

210 Volcke, E.I., van Loosdrecht, M.C. and Vanrolleghem, P.A. (2006). Controlling the nitrite: ammonium ratio in a SHARON reactor in view of its coupling with an Anammox process. Water science and technology. 53(4-5), 45-54.

211 Wang, J. and Chu, L. (2016). Biological nitrate removal from water and wastewater by solid-phase denitrification process. Biotechnology Advances. 34, 1103-1112

212 Wang, J., Zhang C., Rong H. (2014). Analysis and succession of nitrifying bacteria community structure in sequencing biofilm batch reactor. Appl Microbiol Biotechnol. 98, 4581-4587.

213 Watanabe, K., Kodama, Y., Syutsubo, K. and Harayama, S. (2000). Molecular characterization of bacterial populations in petroleum-contaminated groundwater discharged from under-ground crude oil storage cavities. Applied and Environmental Microbiology. 66, 4803-4809.

214 Whittaker, M., Bergmann, D., Arciero, M. and Hooper, A.B. (2000). Electron transfer during the oxidation of ammonia by the chemolithotrophic bacterium Nitrosomonas europaea. Biochimica et Biophysica Acta (BBA)-Bioenergetics. 1459(2-3), 346-355. 
215 Whitten, K.W., Davis R.E., Peck M.L. and Stanley G.G. (2008). Química. 8va edición. Cenage Learning Editores S.A. Anexo A14.

216 Wiesmann, U. (1994). Biological nitrogen removal from wastewater. In: Advances in biochemical engineering/biotechnology, A. Fiechter, (Ed.), 113-154, Springer, Verlag, Berlin.

217 Wilderer, P.A., Irvine, R.L. and Goronszy, M.C. (Eds.). (2001). Sequencing batch reactor technology. IWA publishing.

218 Winogradsky, S. (1890). Recherches sur les organismes de la nitrification. Annales de l'Institut Pasteur. 5, 257-275.

219 Woese, C.R., Stackebrandt, E., Weisburg, W.G., Paster, B.J., Madigan, M.T., Fowler, V.J., Hahn, C.M., Blanz, P., Gupta, R., NealsonK.H. and Fox, G.E. (1984). The phylogeny of purple bacteria: the alpha subdivision. Systematic and applied microbiology. 5(3), 315-326.

220 Wood, P.M. (1986). Nitrification as a bacterial energy source, In J. I. Prosser (ed). Nitrification. IRI. Pres. Oxford, United Kingdom. pp. 39-62.

221 Wrage, N., Velthof, G.L., van Beusichem, M.L. and Oenema, O. (2001). Role of nitrifier denitrification in the production of nitrous oxide. SoilBiology and Biochemistry 33, 1723-1732.

222 Xi, D., Bai, R., Zhang, L. and Fang, Y. (2016). Contribution of Anammox to Nitrogen Removal in Two Temperate Forest Soils. Applied and Environmental Microbiology 82, 4602-4612.

223 Yamanaka, T. and Fukumori, Y. (1988). The nitrite oxidizing system of Nitrobacter winogradskyi. FEMS Microbiology Reviews. 4,259-270.

224 Yoon, S., Cruz-García, C., Sanford, R., Ritalahti, K.M. and Löffler, F.E. (2015). Denitrification versus respiratory ammonification: environmental controls of two competing dissimilatory NO 3-/NO 2reduction pathways in Shewanellaloihica strain PV-4. The ISME journal. 9(5), 1093-1104.

225 You, J., Das, A., Dolan, E. M. and Hu, Z. (2009). Ammonia-oxidizing archaea involved in nitrogen removal. Water research. 43(7), 1801-1809.

226 Yu, X., Wan, C., Lei, Z., Liu, X., Zhang, Y., Lee, D.J. and Tay, J.H. (2014). Adsorption of ammonium by aerobic granules under high ammonium levels. Journal of the Taiwan Institute of Chemical Engineers. 45(1), 202-206.

227 Zepeda, A., Texier, A.-C. and Gomez, J. (2003). Benzene transformation in nitrifying batch cultures. Biotechnology Progress. 19(3), 789-793.

228 Zepeda, A., Texier, A-C., Razo-Flores, E. and Gómez, J. (2006). Kinetic and metabolic study of benzene, toluene and m-xylene in nitrifying batch cultures. Water Research. 40, 1643-1649.

229 Zhang, L.M., Hu, H.W., Shen, J.P. and He, J.Z. (2012). Ammonia-oxidizing archaea have more important role than ammonia-oxidizing bacteria in ammonia oxidation of strongly acidic soils. The ISME journal. 6(5), 1032-1045.

230 Zielinska, M., Cydzik-Kwiatkowska, A., Bernat, K., Bułkowska, K. and Wojnowska-Baryła, I. (2014). Removal of bisphenol A (BPA) in a nitrifying system with immobilized biomass. Bioresource Technology. 171, 305-313. 


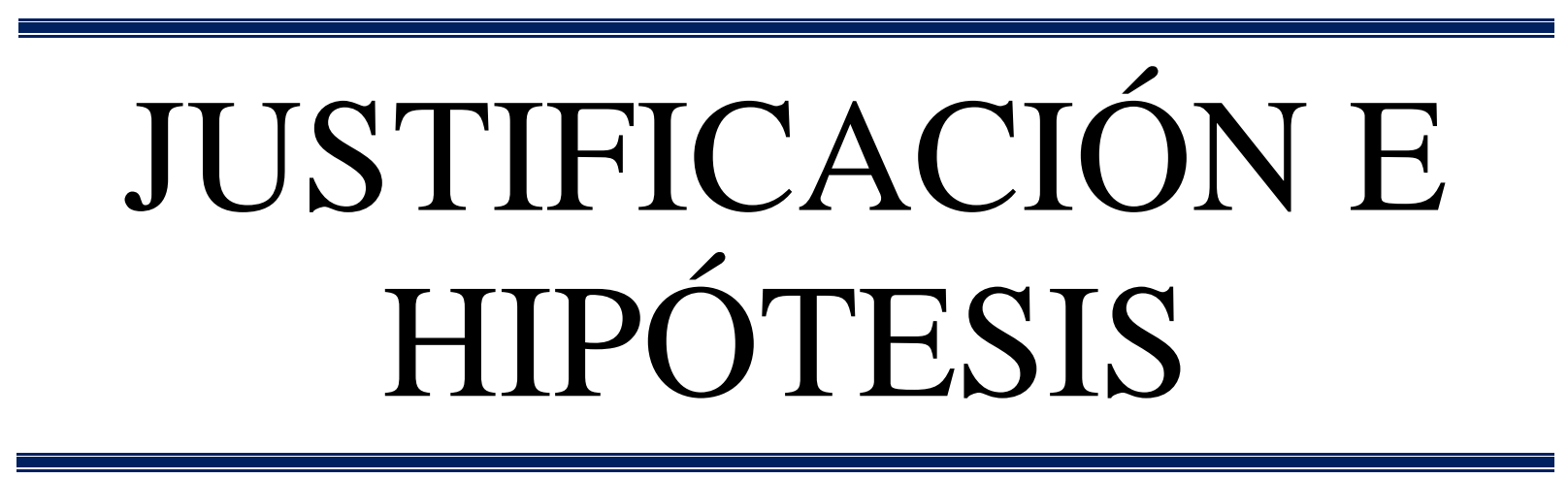




\section{JUSTIFICACIÓN}

Las actividades que realiza el humano en lo cotidiano generan tanto efluentes municipales como industriales dando como resultado aguas residuales contaminadas por compuestos fenólicos y compuestos nitrogenados que contienen altas concentraciones de $\mathrm{NH}_{4}{ }^{+}$. El 2-CF es un compuesto persistente en el suelo y agua, el cual podría llegar a diferentes lugares en donde hay amonio o bien a plantas de tratamiento de aguas residuales en donde se llevan a cabo diferentes procesos biológicos como la nitrificación, además ambos compuestos podrían estar en coexistencia en diferentes efluentes industriales madereros, textiles, agrícolas, papeleras, petroquímicas, productores de plaguicidas y pesticidas, entre otros. Los procesos biológicos como la nitrificación han resultado ser una alternativa eficiente para tratar aguas residuales con $\mathrm{NH}_{4}{ }^{+}$, pero pueden sufrir efectos negativos por la presencia de compuestos recalcitrantes como el $2-\mathrm{CF}$.

Con el uso de reactores SBR y lodos con exposición previa al 2-CF, ha sido posible llevar a cabo una nitrificación completa y el consumo total de hasta $60 \mathrm{mg}$ C-2-CF/L utilizando ciclos de operación de 30 días, sin embargo, se sigue presentando una inhibición del proceso respiratorio por la presencia del compuesto clorado. Una posibilidad para disminuir los tiempos de consumo del 2-CF y su efecto inhibitorio sobre la nitrificación, a fin de favorecer la eliminación simultánea de ambos compuestos, podría ser, además de la utilización del sistema SBR, el incremento de la concentración de $\mathrm{NH}_{4}{ }^{+}$. En este sentido, se ha reportado que la enzima AMO de las bacterias AOB puede catalizar la oxidación de diversos compuestos asociada con la oxidación de $\mathrm{NH}_{4}{ }^{+}$. Se ha propuesto que en sistemas nitrificantes se puede observar consumo cometabólico de compuestos recalcitrantes, donde la enzima AMO, encargada de realizar la primera reacción de oxidación en el proceso nitrificante, podría participar en el consumo de 2CF y tener un papel decisivo en su cometabolismo. Sin embargo, el consumo cometabólico de 2-CF no ha sido verificado en lodos nitrificantes. En este sentido, el uso de lodos nitrificantes y altas concentraciones de amonio en reactores SBR puede ser una alternativa adecuada para favorecer el consumo cometabólico de compuestos recalcitrantes como el 2-CF, y por lo tanto ser una alternativa para tratar efluentes de aguas residuales altamente contaminadas con amonio. 
No se cuenta con información fisiológica ni cinética del proceso respiratorio bajo estas condiciones, por lo que es necesario generar información al respecto.

Por otro lado, es posible que la exposición constante del consorcio microbiano al 2-CF y a concentraciones altas de $\mathrm{NH}_{4}{ }^{+}$, traiga como consecuencia un cambio en la proporción de bacterias nitrificantes y heterotróficas presentes en el consorcio nitrificante. Las técnicas de biología molecular son útiles para determinar la dinámica poblacional de consorcios microbianos. Sin embargo, en reactores SBR no hay reportes en condiciones nitrificantes con altas concentraciones de $\mathrm{NH}_{4}{ }^{+}$y en presencia de 2-CF que relacionen la dinámica poblacional con la respuesta fisiológica y cinética. Falta generar información que permita entender el papel de los microorganismos presentes en el proceso nitrificante.

\section{HIPÓTESIS}

Con un lodo nitrificante estable con capacidad de consumir $\mathrm{NH}_{4}{ }^{+}$y $2-\mathrm{CF}$, el incremento de la concentración de $\mathrm{NH}_{4}{ }^{+}$mejorará el consumo de 2-CF, disminuirá su efecto inhibitorio sobre la actividad nitrificante y favorecerá la eliminación simultánea de ambos compuestos.

Será posible establecer en la comunidad bacteriana una relación entre el comportamiento fisiológico y cinético nitrificante, en presencia de 2-CF, con el comportamiento de la dinámica poblacional en términos de índices ecológicos. 


\section{OBJETIVOS}




\section{OBJETIVOS}

\subsection{General}

Evaluar y analizar cinética y molecularmente un lodo nitrificante en presencia de 2-CF y diferentes concentraciones de $\mathrm{NH}_{4}{ }^{+}$.

\subsection{Particulares}

Evaluar en ensayos en lote:

- La actividad nitrificante con concentraciones altas de $\mathrm{NH}_{4}{ }^{+}$.

- La participación de la enzima AMO en el consumo de 2-CF.

En un reactor SBR nitrificante, evaluar y analizar a lo largo de los ciclos de operación:

- El comportamiento fisiológico y cinético del proceso respiratorio en presencia de 2-CF y de diferentes concentraciones iniciales de $\mathrm{NH}_{4}{ }^{+}$.

- La dinámica poblacional del consorcio nitrificante.

- La relación entre la respuesta fisiológica y cinética del lodo nitrificante con su estructura en términos de dinámica poblacional. 


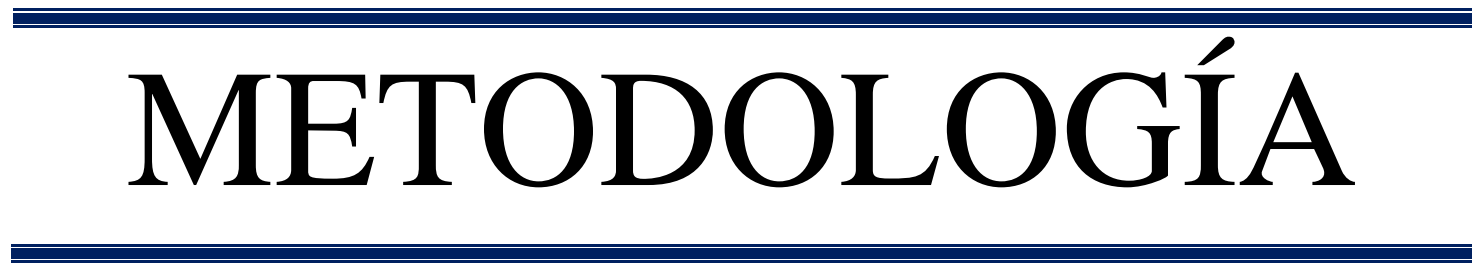




\section{METODOLOGÍA}

Se buscó evaluar en un reactor SBR inoculado con un consorcio nitrificante, el consumo cometabólico de 2-CF, cuando se adicionaron concentraciones iniciales crecientes de amonio como sustrato de crecimiento, evaluar en ensayos en lotes nitrificantes el consumo de amonio y 2-CF por la enzima AMO, y evaluar los cambios en la dinámica poblacional del lodo en el reactor SBR. Por lo tanto, se realizaron diferentes ensayos, primeramente, se evaluó la actividad nitrificante del lodo en ensayos en lote con diferentes concentraciones de amonio (100, $300 \mathrm{y}$ $500 \mathrm{mg}$ de $\mathrm{N}-\mathrm{NH}_{4}{ }^{+} / \mathrm{L}$ ), posteriormente en reactores de lotes secuenciados se evaluó a lo largo de los ciclos de operación, el efecto de las diferentes concentraciones iniciales de $\mathrm{NH}_{4}{ }^{+}(100-$ $500 \mathrm{mg}$ de $\mathrm{N}^{-N_{4}}{ }_{4}^{+} / \mathrm{L}$ ) sobre el consumo de $60 \mathrm{mg}$ de 2-CF/L y el proceso nitrificante. Posteriormente en ensayos en lote se evaluó la participación de la enzima AMO en el consumo de 2-CF. Estos ensayos se realizaron al comienzo de la experimentación con el lodo nitrificante utilizado como inóculo de los reactores SBR y con el lodo obtenido después de haber transcurrido 13 ciclos de operación en los reactores SBR. Por último, se determinó el efecto de la concentración inicial de $\mathrm{NH}_{4}{ }^{+}$sobre la dinámica poblacional nitrificante del lodo en el reactor SBR, así como la relación de los cambios en la dinámica poblacional con la respuesta fisiológica y cinética (Figura 11).

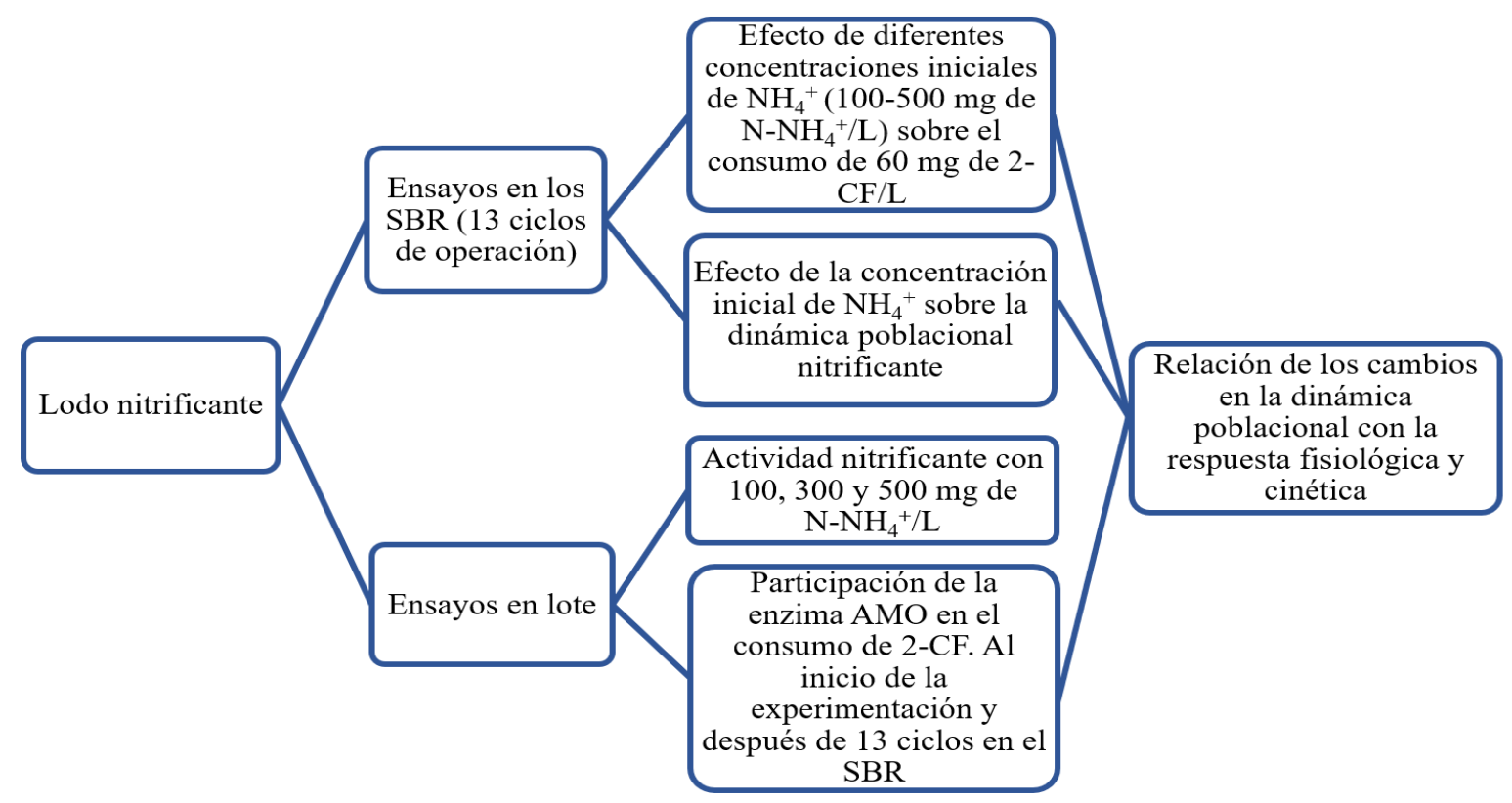

Figura 11. Diagrama de flujo de la metodología empleada en este trabajo. 


\subsection{Fuente de inóculo}

El inóculo utilizado en el presente trabajo se obtuvo de un reactor SBR alimentado durante 11 meses (19 ciclos de operación) con $\mathrm{NH}_{4}{ }^{+}\left(100 \mathrm{mg}\right.$ de $\left.\mathrm{N}-\mathrm{NH}_{4}{ }^{+} / \mathrm{L}\right)$ y $2-\mathrm{CF}(60 \mathrm{mg} \mathrm{C}-$ 2-CF/L) periodo durante el cual el lodo demostró la capacidad de consumir ambos compuestos. Con el agua residual sintética que contenía los medios A (50\% del volumen total como fuente de nitrógeno) y B (50\% del volumen total como fuente de carbono) descritos en la Tabla 3, se realizaron ensayos en el reactor SBR con este lodo nitrificante para verificar su actividad con

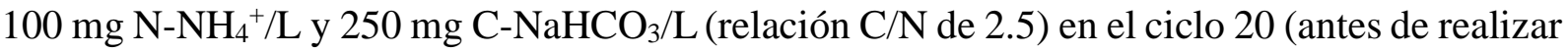
los ensayos en lote con diferentes concentraciones de amonio), 25 (antes de llevar a cabo los ensayos en lote para evaluar la participación de la enzima AMO en el consumo de 2-CF) y 32 de operación (antes de inocular los dos reactores SBR y evaluar el efecto de la concentración inicial de amonio en el consumo de 2-clorofenol). Se adicionó además $1 \mathrm{~mL}$ de una solución de $\mathrm{FeSO}_{4} \cdot 7 \mathrm{H}_{2} \mathrm{O}(5 \% \mathrm{v} / \mathrm{v})$. Una vez que se verificó que el lodo llevaba a cabo el proceso nitrificante de manera estable (con valores de $\mathrm{EN}-\mathrm{NH}_{4}{ }^{+}$y $\mathrm{YN}_{-\mathrm{NO}_{3}}{ }^{-}$altos), se utilizó como fuente de inóculo para llevar a cabo los ensayos en lote y en los reactores SBR que a continuación se describen.

Tabla 3. Composición del medio de cultivo utilizado para los reactores de lotes secuenciados.

\begin{tabular}{llll}
\hline Medio A & Concentración (g/L) & Medio B & Concentración (g/L) \\
\hline $\mathrm{NH}_{4} \mathrm{Cl}$ & 0.385 & $\mathrm{NaHCO}_{3}$ & 3.5 \\
$\left(\mathrm{NH}_{4}\right)_{2} \mathrm{SO}_{4}$ & 0.47 & $\mathrm{CaCl}_{2}$ & 0.02 \\
$\mathrm{KH}_{2} \mathrm{PO}_{4}$ & 0.56 & & \\
$\mathrm{MgSO}_{4}$ & 0.4 & & \\
$\mathrm{NaCl}$ & 0.4 & & \\
\hline
\end{tabular}

\subsection{Ensayos abióticos y de adsorción}

Se realizaron diferentes ensayos abióticos para medir la pérdida de 2-CF por volatilización o reacción química en ambos sistemas SBR durante un período de 6 días. Estos

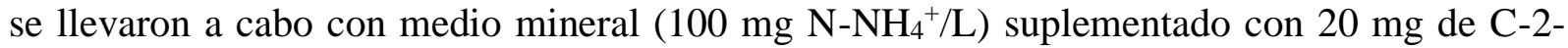


$\mathrm{CF} / \mathrm{L}$, en ausencia de lodo nitrificante y se airearon intermitentemente dos veces por día con $\mathrm{O}_{2}$ (99\% de pureza) con agitación a $250 \mathrm{rpm}$ y temperatura ambiente. La pérdida de 2-CF por reacción química o volatilización se estableció como la diferencia entre las concentraciones iniciales y finales de 2-CF detectadas en la fase líquida.

Aunados a los anteriores ensayos y con el fin de determinar la pérdida de 2-CF por adsorción, reacción química o volatilización, se realizaron en botellas serológicas de $100 \mathrm{~mL}$ de capacidad, ensayos abióticos con medio mineral (50 mL), $40 \mathrm{mg}$ de aliltiourea/L y $20 \mathrm{mg}$ de C2-CF/L, sin oxígeno y en ausencia de biomasa. La adsorción de 2-CF en el lodo nitrificante se determinó en botellas serológicas de $100 \mathrm{~mL}$ de capacidad, se colocó medio mineral $(70 \mathrm{~mL})$

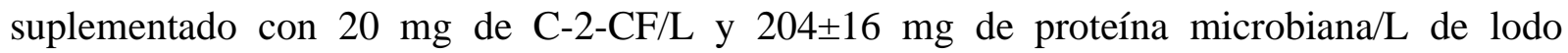
nitrificante esterilizado $\left(120{ }^{\circ} \mathrm{C}\right.$ durante $\left.15 \mathrm{~min}\right)$ y en ausencia de oxígeno. Las botellas de ambos ensayos se incubaron a $200 \mathrm{rpm}$ a $28{ }^{\circ} \mathrm{C}$ durante 6 días por duplicado. La pérdida de 2CF por adsorción, reacción química o volatilización se estableció como la diferencia entre las concentraciones iniciales y finales de 2-CF detectadas en la fase líquida.

\subsection{Evaluación de la actividad nitrificante con diferentes concentraciones de amonio de un lodo previamente expuesto a 2-clorofenol}

Como el lodo nitrificante a utilizar como inóculo había estado en constante contacto con 2-CF y durante periodos largos, en primer lugar, se evaluó en ensayos en lote su actividad nitrificante con diferentes concentraciones de amonio (100, 300 y $\left.500 \mathrm{mg} \mathrm{N}-\mathrm{NH}_{4}^{+} / \mathrm{L}\right)$ y en ausencia del compuesto clorado.

De acuerdo a la concentración de $\mathrm{NH}_{4}{ }^{+}$a evaluar $\left(100,300\right.$ y $\left.500 \mathrm{mg} \mathrm{N}-\mathrm{NH}_{4}{ }^{+} / \mathrm{L}\right)$ y a fin de asegurar que la unidad experimental contuviera el oxígeno necesario para llevar a cabo el proceso nitrificante, se utilizaron botellas serológicas de 160 o $500 \mathrm{~mL}$ con un volumen de operación de $100 \mathrm{~mL}$. Se adicionó en cada ensayo $5 \mathrm{~mL}$ del medio A, $5 \mathrm{~mL}$ del medio B (Tabla 4) y $0.5 \mathrm{~mL}$ de una solución de $\mathrm{FeSO}_{4} \cdot 7 \mathrm{H}_{2} \mathrm{O}(5 \% \mathrm{v} / \mathrm{v})$. A cada botella se le inyectó oxígeno puro (99\% de pureza) durante $2 \mathrm{~min}$. Posteriormente, en cada botella se adicionaron como 
inóculo, entre 16 y $33 \mathrm{~mL}$ de lodo nitrificante dependiendo de la concentración de proteína microbiana en el reactor SBR (el lodo se lavó previamente con solución fisiológica que contenía $9 \mathrm{~g} / \mathrm{L}$ de $\mathrm{NaCl}$ ) para mantener una concentración inicial de proteína microbiana de $200 \pm 12$ mg/L. Se agregó agua destilada para completar $100 \mathrm{~mL}$ y tener una concentración inicial de 100 mg N-NH${ }_{4}^{+} / \mathrm{L}$ y $250 \mathrm{mg} \mathrm{C}-\mathrm{NaHCO}_{3} / \mathrm{L}$. Dependiendo de la concentración inicial de $\mathrm{NH}_{4}{ }^{+}$a evaluar, se adicionó el medio A y B respectivo para mantener una relación $\mathrm{C} / \mathrm{N}$ de 2.5. Las botellas se sellaron herméticamente con un tapón de goma y un anillo de aluminio y se saturó el espacio de cabeza (60 o $400 \mathrm{~mL}$ ) con oxígeno durante otros 2 min. Finalmente, cada botella se colocó en un agitador orbital a $200 \mathrm{rpm}$ dentro de una incubadora a temperatura controlada de $28{ }^{\circ} \mathrm{C}$. El pH inicial del medio fue de 8.2 \pm 0.6 . Se tomaron muestras independientes a diferentes tiempos durante 10 días del cultivo y se filtraron $(0.45 \mu \mathrm{m})$ para cuantificar $\mathrm{NH}_{4}{ }^{+}$, $\mathrm{NO}_{2}^{-}$y $\mathrm{NO}_{3}^{-}$. Todos los ensayos se realizaron por duplicado.

Tabla 4. Composición del medio de cultivo utilizado para los ensayos en lote.

\begin{tabular}{llll}
\hline \multicolumn{1}{c}{$\mathbf{A}$} & $\mathbf{( g / L )}$ & \multicolumn{1}{c}{$\mathbf{B}$} & $(\mathbf{g} / \mathbf{L})$ \\
\hline $\mathrm{NH}_{4} \mathrm{Cl}$ & 3.86 & $\mathrm{NaHCO}_{3}$ & 35 \\
$\left(\mathrm{NH}_{4}\right)_{2} \mathrm{SO}_{4}$ & 4.75 & $\mathrm{CaCl}_{2}$ & 0.2 \\
$\mathrm{KH}_{2} \mathrm{PO}_{4}$ & 5.6 & & \\
$\mathrm{MgSO}_{4}$ & 4 & & \\
$\mathrm{NaCl}$ & 4 & & \\
\hline
\end{tabular}

\subsection{Ensayos en SBR nitrificantes: efecto de la concentración inicial de amonio en el consumo de 2-clorofenol}

Se operaron dos reactores de lotes secuenciados (Applikon ADI 1012, Holland) de 10.5 $\mathrm{cm}$ de diámetro, $23.2 \mathrm{~cm}$ de altura, un agitador de paleta plana, $2 \mathrm{~L}$ de capacidad y $1.2 \mathrm{~L}$ de volumen de operación (SBR1 y SBR2) para evaluar a lo largo de los ciclos de operación, el efecto de las diferentes concentraciones iniciales de $\mathrm{NH}_{4}{ }^{+}$(Tabla 5) sobre el consumo de $60 \mathrm{mg}$ de 2-CF/L y el proceso nitrificante. 
Tabla 5. Concentraciones de $\mathrm{NH}_{4}{ }^{+}$evaluadas en los reactores SBR.

\begin{tabular}{cc}
\hline Concentración de $\mathbf{N H}_{4}{ }^{+}(\mathbf{m g ~ N} / \mathbf{L})$ & Número de ciclo \\
\hline 100 & 1 \\
200 & 2,3 y 4 \\
300 & 5,6 y 7 \\
400 & 8,9 y 10 \\
500 & 11,12 y 13 \\
\hline
\end{tabular}

Los reactores se alimentaron con el medio mineral mostrado en la Tabla 3. Además, se adicionó $1 \mathrm{~mL}$ de una solución de $\mathrm{FeSO}_{4} \cdot 7 \mathrm{H}_{2} \mathrm{O}(5 \% \mathrm{v} / \mathrm{v})$. Dependiendo de la concentración de $\mathrm{NH}_{4}{ }^{+}\left(\mathrm{NH}_{4} \mathrm{Cl}\right.$ y $\left.\left(\mathrm{NH}_{4}\right)_{2} \mathrm{SO}_{4}\right)$ alimentada, se adicionó la respectiva concentración de bicarbonato para mantener una relación $\mathrm{C} / \mathrm{N}$ de 2.5 en cada ensayo. La adición de $60 \mathrm{mg}$ de C-2-CF/L no se consideró en la relación C/N y no se agregó ninguna otra fuente adicional de carbono orgánico. Cada uno de los SBRs se inoculó con 354.7×9.9 mg de proteína microbiana como biomasa/L. Los reactores se mantuvieron herméticamente cerrados para evitar pérdidas del 2-CF por volatilización o arrastre y se airearon intermitentemente dos veces por día con $\mathrm{O}_{2}$ puro $(99 \%$ de

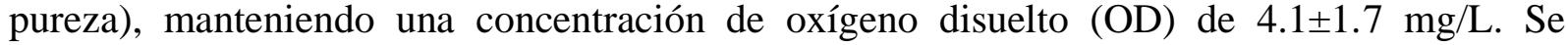
mantuvieron con agitación a $250 \mathrm{rpm}$ y a temperatura ambiente. El pH inicial del medio fue de 8.1 \pm 1.3 . Los ciclos de operación fueron divididos en las siguientes fases: llenado $=0.02 \mathrm{~d}$; tiempo de reacción $=14-21 \mathrm{~d}$; sedimentación de lodos $=0.02 \mathrm{~d}$, y drenado $=0.083 \mathrm{~d}$. Teniendo en cuenta que ambos lodos nitrificantes mostraron buenas propiedades de sedimentación con índices de volumen de lodo (SVI) inferiores a $24.7 \pm 3.5 \mathrm{~mL} / \mathrm{g}$, la relación de intercambio volumétrico de líquido se estableció en $83 \%$, y ambos reactores se purgaron periódicamente para mantener la concentración de biomasa constante.

A fin de obtener los perfiles cinéticos nitrificantes y del consumo de 2-CF en cada SBR, se tomaron muestras a diferentes ciclos de operación a lo largo del tiempo de reacción y se filtraron $(0.45 \mu \mathrm{m})$ para cuantificar $\mathrm{NH}_{4}{ }^{+}, \mathrm{NO}_{2}^{-}, \mathrm{NO}_{3}^{-}$y $2-\mathrm{CF}$. 


\subsection{Participación de la enzima AMO en el consumo de 2-clorofenol}

La participación de la enzima AMO en el consumo de 2-CF se evaluó en ensayos en lote. Se utilizaron botellas serológicas de $160 \mathrm{~mL}$ de capacidad y $100 \mathrm{~mL}$ de volumen de trabajo y bajo condiciones semejantes a las descritas en los ensayos de la sección 5.2. Estos ensayos se realizaron al comienzo de la experimentación con el lodo nitrificante utilizado como inóculo de los reactores SBR y con el lodo obtenido después de haber transcurrido 13 ciclos de operación en los reactores SBR. Las botellas se inocularon con $207.1 \pm 3.5 \mathrm{mg}$ de proteína microbiana/L nitrificante como biomasa. En todos los casos, se adicionó una concentración de $100 \mathrm{mg}$ de N$\mathrm{NH}_{4}{ }^{+} / \mathrm{L}$ y se mantuvo una relación $\mathrm{C} / \mathrm{N}$ de 2.5 (la adición de $5 \mathrm{mg}$ de C-2-CF/L no se consideró en la relación $\mathrm{C} / \mathrm{N}$ ). La composición del medio de cultivo fue la descrita en la tabla 4, además de $0.5 \mathrm{~mL}$ de una solución de $\mathrm{FeSO}_{4} \cdot 7 \mathrm{H}_{2} \mathrm{O}(5 \% \mathrm{v} / \mathrm{v})$. Bajo estas condiciones se realizaron cuatro ensayos: 1) Nitrificación de referencia, 2) Nitrificación en presencia de $40 \mathrm{mg}$ aliltiourea/L (ATU) como inhibidor específico de la AMO (Silva y col., 2009), 3) Nitrificación en presencia de $5 \mathrm{mg}$ de C-2-CF/L y 4) Nitrificación en presencia de $40 \mathrm{mg}$ de ATU/L y $5 \mathrm{mg}$ de C-2-CF/L. En cada caso, el medio se burbujeó durante 2 minutos con oxígeno ( $99 \%$ de pureza), las botellas se inocularon, se adicionó 2-CF y/o ATU de acuerdo a cada ensayo, se sellaron herméticamente con un tapón de goma y un anillo de aluminio y se saturó el espacio de cabeza durante 2 minutos

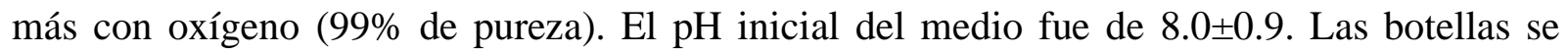
incubaron a $28^{\circ} \mathrm{C}$ y se mantuvieron agitadas a $200 \mathrm{rpm}$. Los ensayos se realizaron por duplicado, se tomaron muestras independientes a diferentes tiempos durante 15 días del cultivo y se filtraron $(0.45 \mu \mathrm{m})$ para cuantificar $\mathrm{NH}_{4}{ }^{+}, \mathrm{NO}_{2}{ }^{-}, \mathrm{NO}_{3}{ }^{-}$y $2-\mathrm{CF}$.

\subsection{Variables de respuesta para evaluar el proceso nitrificante, consumo de 2- clorofenol y análisis estadístico}

El comportamiento fisiológico y cinético del lodo nitrificante y el consumo de 2-CF en los ensayos en lote como en los reactores SBR se determinaron mediante diferentes variables de respuesta: Eficiencias de consumo de amonio $\left(\mathrm{EN}^{-\mathrm{NH}_{4}}{ }^{+}\right.$) (Ecuación 9) y 2-CF (EC-2-CF) (Ecuación 10), rendimientos de producción de nitrato $\left({\mathrm{YN}-\mathrm{NO}_{3}}^{-}\right)$(Ecuación 11), rendimientos 
de producción de biomasa (YBM) (Ecuación 12) que se determinó suponiendo que el 16\% de la proteína microbiana es nitrógeno (Bailey y Ollis 1986), balances de materia (Ecuación 13) y velocidades específicas de consumo de amonio $\left(\mathrm{qN}-\mathrm{NH}_{4}{ }^{+}\right)$o 2-CF (qC-2-CF) y producción de nitrato $\left(\mathrm{qN}-\mathrm{NO}_{3}^{-}\right)$.

Eficiencia de consumo de $\mathrm{N}-\mathrm{NH}_{4}^{+}$.

$$
E N-N H_{4}^{+}=\frac{m g \text { de } N-N H_{4}^{+} \frac{\text { entrada }}{L}-m g \text { de } N-N H_{4}^{+} \frac{\text { salida }}{L}}{m g \text { de } N-N H_{4}^{+} \frac{\text { entrada }}{L}} * 100 \quad \text { Ec. } 9
$$

Eficiencia de consumo del 2-CF.

$$
\mathrm{EC}-2-\mathrm{CF}=\frac{\mathrm{mg} \mathrm{de} \mathrm{C}-2-\mathrm{CF} \frac{\text { entrada }}{\mathrm{L}}-\mathrm{mg} \text { de } \mathrm{C}-2-\mathrm{CF} \frac{\text { salida }}{\mathrm{L}}}{\mathrm{mg} \mathrm{de} \mathrm{C}-2-\mathrm{CF} \frac{\text { entrada }}{\mathrm{L}}} * 100 \quad \text { Ec. } 10
$$

Rendimiento de producción de $\mathrm{N}-\mathrm{NO}_{3}{ }^{-}$.

$$
Y N-\mathrm{NO}_{3}^{-}=\frac{m g \text { de } \mathrm{N}-\mathrm{NO}_{3}^{-} \frac{\text { producido }}{L}}{m g \text { de } N-\mathrm{NH}_{4}^{+} \frac{\text { consumido }}{L}} \quad \text { Ec. } 11
$$

Rendimiento de producción de biomasa.

$$
Y B M=\frac{m g \text { de } N-\text { Biomasa } \frac{\text { producida }}{L}}{m g \text { de } N-N_{4}^{+} \frac{\text { consumido }}{L}}
$$

Balances de materia.

$$
\left[\mathrm{N}-\mathrm{NH}_{4}{ }^{+} \text {entrada }\right]=\left[\mathrm{N}-\mathrm{NH}_{4}{ }^{+} \text {salida }\right]+\left[\mathrm{N}-\mathrm{NO}_{2}{ }^{-}\right]+\left[\mathrm{N}-\mathrm{NO}_{3}{ }^{-}\right]+[\mathrm{N} \text {-biomasa }] \text { Ec. } 13
$$


Las velocidades específicas para el consumo de sustratos (qN-NH$\left.{ }_{4}^{+}, \mathrm{qC}-2-\mathrm{CF}\right)$ o la generación de productos $\left(\mathrm{qN}^{-\mathrm{NO}_{3}}{ }^{-}\right)$se calcularon utilizando el modelo ajustado de Gompertz (Zwietering y col., 1990), en donde la concentración de $\mathrm{NH}_{4}^{+}$o 2-CF consumido, o $\mathrm{NO}_{3}{ }^{-}$ producido $Y(\mathrm{t})[\mathrm{mg} / \mathrm{L}]$, en el tiempo $t(\mathrm{~d})$, puede expresarse como una función del tiempo. La Tabla 6 muestra el modelo de Gompertz y sus tres parámetros matemáticos $(A, B$ y $C)$ que conducen a la determinación de las velocidades volumétricas máximas (Vmax) y las fases lag (ג). Para realizar el ajuste, se calculó el incremento en la concentración de $\mathrm{NH}_{4}^{+}$y 2-CF consumidos [mg/L] a lo largo del tiempo de experimentación con respecto a las concentraciones iniciales de $\mathrm{N}-\mathrm{NH}_{4}{ }^{+}$o C-2-CF respectivamente. En este sentido y según el modelo de Gompertz, $Y(\mathrm{t})$ representa el incremento de $\mathrm{N}-\mathrm{NH}_{4}{ }^{+}$o $\mathrm{C}-2-\mathrm{CF}$ consumido $[\mathrm{mg} / \mathrm{L}], A$ es la concentración máxima de $\mathrm{N}-\mathrm{NH}_{4}{ }^{+}$o $\mathrm{C}-2-\mathrm{CF}$ consumido [mg/L] cuando el tiempo tiende al infinito, $C$ es el tiempo de inflexión [d], mientras que $B$ es la velocidad volumétrica de consumo de $\mathrm{NH}_{4}{ }^{+}$o 2$\mathrm{CF}\left[\mathrm{mg} / \mathrm{L} \mathrm{d}\right.$ y y $t$ es el tiempo [d]. Cuando se ajusta el desempeño de la producción de $\mathrm{NO}_{3}{ }^{-}$a lo largo del tiempo, $Y(\mathrm{t})$ representa la concentración de $\mathrm{N}-\mathrm{NO}_{3}{ }^{-}$producida $[\mathrm{mg} / \mathrm{L}], A$ es la concentración máxima de $\mathrm{N}_{-} \mathrm{NO}_{3}{ }^{-}$producido $[\mathrm{mg} \mathrm{N} / \mathrm{L}$ ] cuando el tiempo tiende al infinito, $C$ es el tiempo de inflexión [d], mientras que $B$ es la velocidad volumétrica de producción de $\mathrm{NO}_{3}{ }^{-}$ [mg/L d] y $t$ es el tiempo [d]. Los tres coeficientes de regresión $A, B$ y $C$ del modelo ajustado de Gompertz, se calcularon mediante el paquete estadístico NCSS (Hintze, 2001). De acuerdo con las ecuaciones de la Tabla 6, se calcularon las velocidades volumétricas máximas (Vmax) de consumo de $\mathrm{NH}_{4}{ }^{+}$o 2-CF y producción de $\mathrm{NO}_{3}{ }^{-}$, así como la fase lag $(\lambda)$ necesaria para el consumo de $\mathrm{NH}_{4}^{+}$o 2-CF. Por último, se calcularon las velocidades específicas (qN-NH${ }_{4}^{+}, \mathrm{qC}$ 2-CF, $\mathrm{qN}^{-\mathrm{NO}_{3}}{ }^{-}$) dividiendo Vmax entre la concentración de proteína microbiana determinada en los SBRs o ensayos en lote. La significancia del modelo y los valores de $r^{2}\left(r^{2}>0.98\right)$ se utilizaron como criterio de ajuste. 
Tabla 6. Parámetros matemáticos del modelo de Gompertz.

\begin{tabular}{|c|c|}
\hline Parámetros & \\
\hline Modelo de Gompertz y sus tres parámetros & $Y(t)=A \exp (-\exp (-B((t)-C)))$ \\
\hline $\begin{array}{l}\text { Concentración máxima de sustrato consumido o } \\
\text { producto formado }[\mathrm{mg} / \mathrm{L}]\end{array}$ & $A$ \\
\hline $\begin{array}{l}\text { Velocidad volumétrica de sustrato o producto }[\mathrm{mg} / \mathrm{L} \\
\text { d] }\end{array}$ & $B$ \\
\hline Punto de inflexión de la curva (d) & $C$ \\
\hline $\begin{array}{l}\text { Velocidad volumétrica máxima de consumo o } \\
\text { producción }(\operatorname{Vmax},[\mathrm{mg} / \mathrm{L} \mathrm{d}])\end{array}$ & $V \max =\frac{A B}{\exp }$ \\
\hline Velocidad específica $(q[\mathrm{mg} / \mathrm{g}$ proteína d] $)$ & $q=\frac{V \max }{\text { Concentración de proteína }}$ \\
\hline Fase lag $(\lambda,[d])$ & $\lambda=\frac{\mathrm{BC}-1}{\mathrm{~B}}$ \\
\hline
\end{tabular}

Finalmente, las qC-2-CF obtenidas en los ensayos en lote en presencia y ausencia del inhibidor ATU, se compararon entre sí utilizando las pruebas estadísticas de homogeneidad de coeficientes en modelos de regresión (Martínez y Castillo, 1987) mediante el paquete estadístico NCSS. Donde la hipótesis nula (Ho) se refiere a que las pendientes de los perfiles de consumo de 2-CF en presencia de ATU es igual al perfil con 2-CF (Ecuación 14) y la hipótesis alternativa (Ha) es que las pendientes son diferentes (Ecuación 15). Sustituyendo los valores de $B$ y $S$ de los respectivos ensayos en la ecuación 16 se obtuvieron valores de $t$ que fueron comparados con la $\mathrm{t}$ de tablas, que indica que un valor por encima de $\mathrm{t}=2.0687$ ( $\alpha=0.025)$ rechaza la hipótesis nula.

$$
H o: \beta o=\beta o^{\prime}
$$

Ec. 14 


$$
\begin{aligned}
& H a: \beta o \neq \beta o^{\prime} \\
& t=\frac{B-B^{\prime}}{\sqrt{S^{2+} S^{2 \prime}}}
\end{aligned}
$$

\subsection{Métodos moleculares}

\subsubsection{Extracción de ADN del lodo}

Para determinar el efecto de la concentración inicial de $\mathrm{NH}_{4}{ }^{+}$sobre la dinámica poblacional nitrificante, se tomaron muestras de los lodos al final de cada ciclo de operación (13 ciclos) de cada SBR. Las muestras se centrifugaron a $5000 \mathrm{rpm}$ durante 10 min y los pellets se congelaron a $-20{ }^{\circ} \mathrm{C}$ hasta realizar la extracción de ADN.

El ADN se extrajo utilizando un kit de aislamiento de ADN UltraCleanTM del suelo (MO BIO Laboratories, Carlsbad, CA, EE.UU.), siguiendo las recomendaciones del fabricante. La efectividad de la extracción se verificó mediante electroforesis en un gel de agarosa al 1\% $(\mathrm{p} / \mathrm{v})$ a $85 \mathrm{~V}$ durante $50 \mathrm{~min}$. La cuantificación del ADN extraído y la pureza del mismo se determinaron en un espectrofotómetro para micromuestras (NanoDrop 2000, ThermoScientific) midiendo la absorbancia a $260 \mathrm{~nm}$ y la relación entre la absorbancia a 260 y a $280 \mathrm{~nm}$, respectivamente. El $\mathrm{ADN}$ se almacenó a $-20^{\circ} \mathrm{C}$ hasta su uso posterior.

\subsubsection{Amplificación de ADN y separación por DGGE}

Las regiones V6-V8 del gen 16S ADNr se amplificaron mediante el uso de los cebadores bacterianos 968F (5'-GAACGCGAAGAACCTTACC-3') con abrazadera y 1401R (5'CGGTGTGTACAAGACCC-3') (Silva y col., 2014). La abrazadera consistía en una secuencia de $40 \mathrm{pb}$ (5'-CGCCCGGGGCGCGCCCCGGGCGGGGCGGGGGCACGGGGGG-3'). La amplificación por la reacción en cadena de la polimerasa (PCR) se realizó en un termociclador 
T100 ${ }^{\mathrm{TM}}$ (Bio-Rad Laboratories) de la siguiente manera: desnaturalización previa a $94{ }^{\circ} \mathrm{C}$ durante 2 min; 30 ciclos: desnaturalización a $94{ }^{\circ} \mathrm{C}$ durante $45 \mathrm{~s}$, hibridación a $55^{\circ} \mathrm{C}$ durante $30 \mathrm{~s}$ y elongación a $72{ }^{\circ} \mathrm{C}$ durante $90 \mathrm{~s} \mathrm{y} \mathrm{por} \mathrm{último} \mathrm{una} \mathrm{post-elongación} \mathrm{a} 72{ }^{\circ} \mathrm{C}$ durante $10 \mathrm{~min}$ (Silva y col., 2014). La mezcla de reacción para la PCR consistió en ( $\mu \mathrm{L})$ : 0.7 de cada cebador $(20$ mmol/L), 25 de solución Master Mix que contenía una mezcla de nucleótidos (concentración final: $10 \mathrm{mM}$ por nucleótido), buffer de $\mathrm{pH}, \mathrm{MgCl}_{2}$ (concentración final: $25 \mathrm{mM}$ ) y ADN Taq polimerasa (concentración final: $5 \mathrm{u} / \mu \mathrm{L}$ ), 4 de $\mathrm{ADN}$ de lodo y 19.6 de agua estéril. El rendimiento y calidad de los productos de amplificación se verificaron por electroforesis en un gel de agarosa al 1.0\%, la separación se realizó a 85 V durante 45 minutos. Posteriormente se purificaron los fragmentos de ADN con Wizard® Genomic DNA Purification Kit (Promega. Madison, WI.EE.UU). De nueva cuenta se corrió un gel de agarosa con la misma metodología que se ha descrito anteriormente para verificar el rendimiento y calidad de los productos de la purificación. Los fragmentos purificados se guardaron en congelación a $-20{ }^{\circ} \mathrm{C}$ hasta su posterior uso. Los productos de amplificación purificados se separaron por DGGE en un sistema universal de detección de mutaciones DCode (Bio-Rad Laboratories) con TAE 0.5X a $60{ }^{\circ} \mathrm{C}$. Se usaron geles de poliacrilamida al $6 \%(\mathrm{p} / \mathrm{v})$ y los gradientes desnaturalizantes variaron del $30 \%$ al 60\% (la solución madre de desnaturalización al 100\% estaba hecha de $7 \mathrm{M}$ de urea y $40 \%$ de formamida). El gel se corrió durante 5 minutos a $200 \mathrm{~V}$ y luego durante 16 horas a 85 $\mathrm{V}$, de acuerdo con el procedimiento descrito por Silva y col. (2014). El gel DGGE se tiñó con nitrato de plata (Sanguinetti y col., 1994) y se fotografió en un MiniLumi (sistema DNR Bio Imaging).

\subsection{3. Índices ecológicos}

Los cambios en las comunidades bacterianas se analizaron mediante el índice de riqueza de especies (S) y el índice de uniformidad (J), calculados a partir de los perfiles de DGGE. Los cambios estructurales se analizaron mediante el índice $\mathrm{J}$ porque refleja una visión general del predominio de las especies dentro de una comunidad microbiana. El índice J se calculó como J $=\mathrm{H} / \mathrm{lnS}$. El término $\mathrm{H}$ se define como $\mathrm{H}=-\Sigma \mathrm{PilnPi}$, donde Pi es la abundancia relativa de las 
bandas en un carril y se calcula como $\mathrm{Pi}=\mathrm{ni} / \mathrm{N}$, ni es la intensidad de la banda para bandas individuales, y $\mathrm{N}$ es la suma de las intensidades de bandas en un carril. El índice de riqueza $\mathrm{S}$ representa el número total de bandas en un carril. Cada banda dentro de un perfil se consideró un fragmento de una población microbiana diferente, mientras que las bandas con posiciones de migración similares en diferentes perfiles se consideraron fragmentos de la misma población (Martínez-Hernández y col., 2009; Silva y col., 2014). La relación entre el área de superficie de una banda y la intensidad media de píxeles de esa área, se consideró como la intensidad de la banda y se calculó utilizando el programa de análisis de imágenes Imagen J (programa de análisis y procesamiento de imágenes de dominio público), desarrollado en los Institutos Nacionales de Salud. Aunado a esto, a partir de la imagen de DGGE, se realizó un análisis estadístico de frecuencias, así como un análisis de correlaciones de los índices ecológicos (S y J) con las variables de respuesta del lodo nitrificante (Eficiencias (EN-NH${ }_{4}^{+}, \mathrm{EC}-2-\mathrm{CF}$ ), rendimientos $\left(\mathrm{YN}^{-\mathrm{NO}_{3}}{ }^{-}\right)$y velocidades específicas $\left(\mathrm{qN}-\mathrm{NH}_{4}{ }^{+}, \mathrm{qC}-2-\mathrm{CF}, \mathrm{qN}-\mathrm{NO}_{3}{ }^{-}\right)$) mediante el programa NCSS (Hintze, 2001).

\subsubsection{Secuenciación}

Las bandas de interés del DGGE fueron cortadas y reamplificadas utilizando los mismos primers (968F sin abrazadera y 1401R) de acuerdo a lo descrito en la sección 5.7.2. de la metodología. Los productos de PCR se purificaron (gel Wizard ${ }^{\circledR}$ SV y sistema de limpieza de PCR, Promega) y se secuenciaron por Macrogen Inc. (Seúl, Corea del Sur) con el secuenciador de ADN ABI 3730xl (Applied Biosystems) usando Big-Dye Terminator V1.1 y 3.1. Las secuencias de ADN se alinearon y analizaron utilizando los programas ClustalX (Larkin y col., 2007), SeaView (Gouy y col., 2010) y (http://www.mbio.ncsu.edu/bioedit/bioedit.html). Las secuencias de los amplicones de las bandas cortadas del DGGE se verificaron y se examinaron para detectar quimeras potenciales utilizando Bellerophon (Huber y col., 2004), las cuales se excluyeron de los análisis futuros. Las afiliaciones filogenéticas de las secuencias parciales se estimaron utilizando el programa Basic Local Alignment Search Tool (BLAST por sus siglas en inglés) 
(http://blast.ncbi.nlm.nih.gov/Blast.cgi) (McGinnis y Madden, 2004). Los árboles filogénicos de las secuencias del gen 16S ADNr de los fragmentos de DGGE se construyeron utilizando el método de unión de vecinos (neighbor-joining) con el modelo de sustitución Jukes-Cantor y secuencias relacionadas de la base de datos del 16s ADNr de bacterias del GenBank del NCBI implementado en el software MEGAX (Kumar y col., 2018). La robustez nodal de la filogenia se evaluó mediante un análisis bootstrap con 1000 iteraciones.

\subsection{Técnicas analíticas}

Para verificar la reproducibilidad y linealidad de los métodos analíticos utilizados en este trabajo, se realizaron al menos tres curvas de calibración para cada técnica analítica. Las técnicas analíticas, el fundamento y ejemplos de las curvas de calibración que se emplearon en el desarrollo experimental de este trabajo se describen a continuación.

\subsubsection{Cuantificación de amonio}

El $\mathrm{NH}_{4}{ }^{+}$disuelto en solución acuosa se cuantificó mediante su conversión a amoniaco mediante un electrodo de ion selectivo (Phoenix electrode Co. Mod. NH331501). El principio del método se basa en desplazar el equilibrio del par $\mathrm{NH}_{4}{ }^{+} / \mathrm{NH}_{3}$ en solución acuosa mediante la alcalinización de las muestras. El electrodo selectivo cuenta con una membrana permeable al $\mathrm{NH}_{3}$. Por lo cual fue necesario alcalinizar las muestras de $25 \mathrm{~mL}$ con $\mathrm{NaOH} 10 \mathrm{~N}$, bajo agitación constante y temperatura ambiente. El electrodo estuvo acoplado a un potenciómetro portátil (DigiSense, Cole-Parmer) que permitió la lectura del potencial $(\mathrm{mV})$ cuando fue estable (aproximadamente 3 min después de adicionar el $\mathrm{NaOH}$ ). Siempre que fue analizada una muestra se construyó una curva de calibración de $\mathrm{N}-\mathrm{NH}_{4}{ }^{+}$en un intervalo de concentraciones adecuado para cada muestra (entre 0 y $500 \mathrm{mg} / \mathrm{L}$ ) (Figura 12). El valor del potencial es proporcional al logaritmo de la concentración, cuyo valor puede ser calculado directamente de la ecuación de la recta (Ec. 17). La ecuación (18) fue utilizada para calcular la concentración de $\mathrm{NH}_{4}{ }^{+}$en las muestras. 


$$
\begin{array}{ll}
\text { Potencial }=m \text { logaritmo }\left(\left[\mathrm{NH}_{4}^{+}\right]\right)+b & \text { Ec. } 17 \\
{\left[\mathrm{NH}_{4}^{+}\right]=\text {antilog }\left(\frac{\text { Potencial }-b}{m}\right)} & \text { Ec. } 18
\end{array}
$$

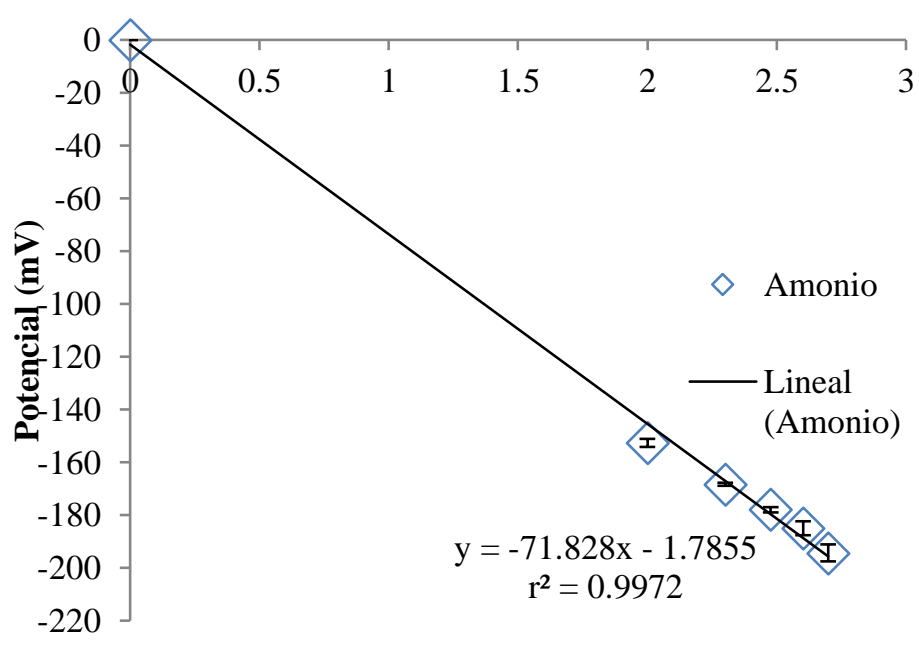

$\log (\mathbf{m g} / \mathrm{L})$

Figura 12. Ejemplo de una curva de calibración para la cuantificación de amonio.

\subsubsection{Cuantificación de nitrito y nitrato}

Estos compuestos se cuantificaron mediante electroforesis capilar, la cual se basa en la migración de los iones en solución bajo la influencia de un campo eléctrico, hacia el electrodo con la carga opuesta a ellos. La fuerza conductora de una partícula está relacionada con su carga y la intensidad del campo eléctrico aplicado, así como la composición del electrolito, el cual funciona como el medio de separación que proporciona una resistencia (Weinberger, 1993). El equipo utilizado fue un analizador capilar de iones (CIA) con un detector UV (arreglo de iodos) y se trabajó a una longitud de onda de $240 \mathrm{~nm}$. Las condiciones de operación fueron: voltaje de $12 \mathrm{KV}$, tiempo de corrida de 10 min y temperatura de $25^{\circ} \mathrm{C}$. El capilar utilizado tiene un recubrimiento de sílica fundida de $60 \mathrm{~cm}$ de largo y $75 \mu \mathrm{m}$ de diámetro interno. El electrolito se preparó tomando $5 \mathrm{~mL}$ de las siguientes soluciones: sulfato de sodio anhidro $(0.1 \mathrm{M})$, cloruro de sodio (10 mM) y CIA Pak OFM anion-BT (Waters), finalmente se llevó a un volumen de 50 
$\mathrm{mL}$ con agua desionizada. Las muestras fueron filtradas por una membrana de nylon $(0.45 \mu \mathrm{m})$ y se realizaron diluciones para que las muestras no superaran los $50 \mathrm{mg} \mathrm{N} / \mathrm{L}$ al momento de ser analizadas. Para comprobar la linealidad del método, se construyeron curvas de calibración. La Figura 13 es un ejemplo de éstas.

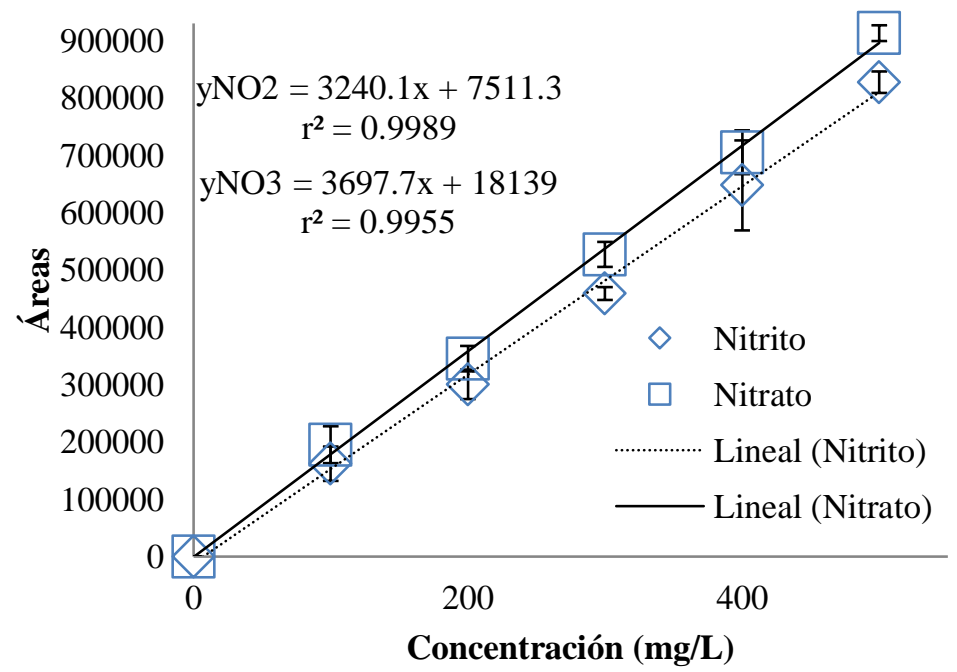

Figura 13. Ejemplos de curvas de calibración para la cuantificación de nitrito y nitrato por electroforesis capilar.

\subsubsection{Cuantificación de 2-clorofenol}

Se utilizó un cromatógrafo de líquidos (HPLC) Perkin-Elmer series 200, una columna Bondclone 10u C-18 (Phenomenex, 300 x $3.9 \mathrm{~mm}$ ). El equipo cuenta con un detector UV/VIS y la longitud de onda utilizada para la detección del 2-CF fue $274 \mathrm{~nm}$. La fase móvil fue una mezcla de acetonitrilo y agua (60:40 v/v) y se utilizó un flujo de $1.5 \mathrm{~mL} / \mathrm{min}$ y un tiempo de corrida de 4 min. La inyección de muestra se hace por un auto muestreador fijando el volumen de inyección en $20 \mu \mathrm{l}$. A partir de una solución madre se realizaron las soluciones estándar con 0, 10, 30, 50 y $70 \mathrm{mg} / \mathrm{L}$ de C-2-CF. Todas las diluciones se hicieron con agua desionizada y las soluciones fueron filtradas por una membrana de $0.45 \mu \mathrm{m}$ para finalmente colocar $2 \mathrm{~mL}$ de muestra en cada vial. La Figura 14 es un ejemplo de las curvas de calibración construidas para la técnica de cuantificación de 2-CF por HPLC. 


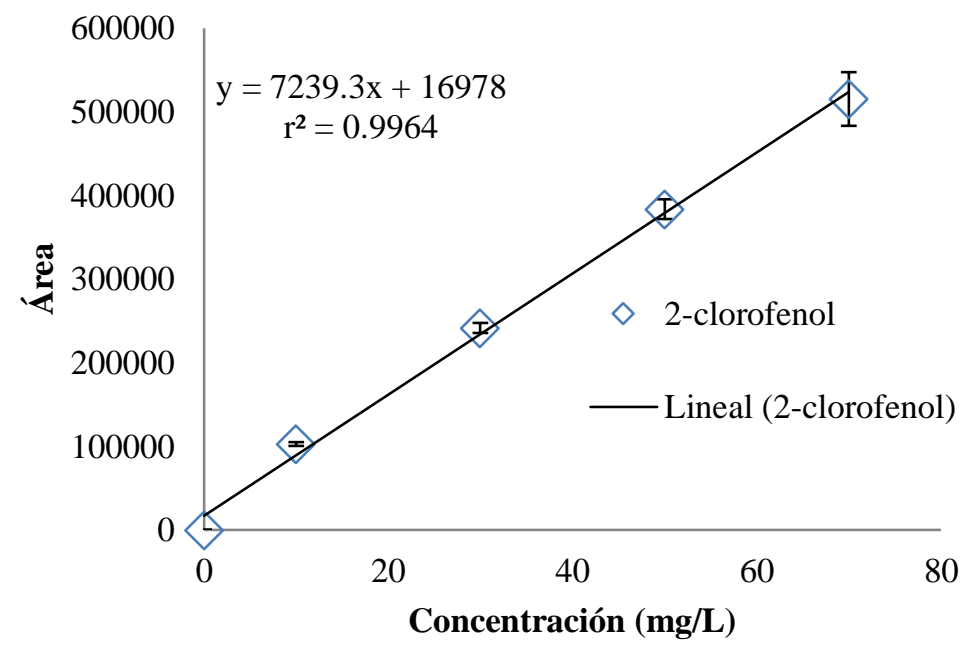

Figura 14. Ejemplo de curva de calibración de 2-clorofenol por HPLC.

\subsubsection{Cuantificación de proteína microbiana}

El método colorimétrico de Lowry y col. (1951) modificado (Martínez y col., 2004) fue utilizado para determinar la concentración de proteína microbiana tanto en el reactor de lotes secuenciados como en los ensayos en lote. El método se basa en la reacción realizada para formar un complejo Cu-proteína y la posterior reducción de este complejo por el reactivo de Folin-Ciocalteau, donde se obtiene un color azul en un ambiente alcalino ( $\mathrm{pH}$ de 10). El reactivo de Folin-Ciocalteau (Hycel) está formado por molibdato, fosfato y tungstato de sodio y produce un máximo de absorción a $750 \mathrm{~nm}$. Esta técnica requiere de proteínas que contengan péptidos con grupos fenólicos que puedan enlazarse con el $\mathrm{Cu}^{2+}$. Para cada serie de muestras analizadas, se preparó una curva de calibración de albúmina (Sigma, 96-99\%) de 0 a $300 \mathrm{mg} / \mathrm{L}$. Las muestras y los estándares recibieron el mismo tratamiento. Se tomó $1 \mathrm{~mL}$ de muestra y se colocó en tubos de ensaye con tapa de rosca de $10 \mathrm{~mL}$. Se adicionó $0.1 \mathrm{~mL}$ de $\mathrm{NaOH}(10 \mathrm{~N})$. Posterior a la agitación mediante un vortex, se calentaron los tubos por 20 min a $90^{\circ} \mathrm{C}$ en un baño seco. Se necesitaron tres soluciones: (a) $\mathrm{Na}_{2} \mathrm{CO}_{3} 0.19 \mathrm{M}$ en $\mathrm{NaOH} 0.1 \mathrm{~N}$, (b) $\mathrm{CuSO}_{4}$ al $1 \%$ y (c) tartrato de sodio y potasio al $2 \%$. Se preparó una solución con $(1 \mathrm{~mL}$ solución (b) $+1 \mathrm{~mL}$ de solución (c) $+48 \mathrm{~mL}$ de solución (a)) que fue posteriormente adicionada a cada tubo $(5 \mathrm{~mL})$. Se dejaron reposar los tubos por $30 \mathrm{~min}$ en la oscuridad. Posteriormente, se agregó $1 \mathrm{~mL}$ de reactivo de Folin-Ciocalteau, dejando reposar nuevamente en la oscuridad por $1 \mathrm{~h}$, para finalmente medir 
la absorbancia a $750 \mathrm{~nm}$ en un espectrofotómetro UV/VIS (Shimadzu, mod. UV-1601). Todos los ensayos se realizaron por triplicado. La Figura 15 muestra un ejemplo de las curvas de calibración utilizadas en esta técnica.

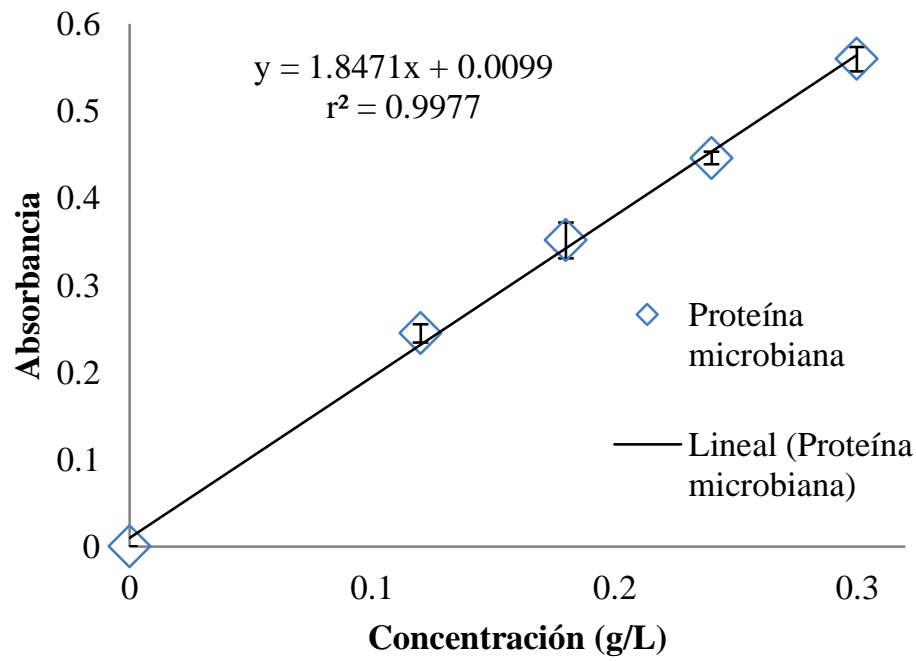

Figura 15. Ejemplo de curva de calibración para la cuantificación de proteína microbiana por el método de Lowry modificado.

En la Tabla 7 se muestran los coeficientes de determinación $\left(\mathrm{r}^{2}\right)$ y de variación $(\mathrm{CV})$ de las pendientes correspondientes a las curvas de calibración de los diferentes métodos analíticos. Todos los métodos presentaron un $\mathrm{CV}$ menor al 10\%, lo cual indicó una aceptable reproducibilidad, mientras que $\operatorname{los} \mathrm{r}^{2}$ fueron mayores a 0.992 , demostrando una respuesta lineal de los métodos.

Tabla 7. Promedios de coeficientes de determinación y pendientes con su respectivo coeficiente de variación correspondientes a las curvas de calibración realizadas para los diferentes métodos analíticos.

\begin{tabular}{lcccc}
\hline \multicolumn{1}{c}{ Análisis } & $\begin{array}{c}\text { Coeficiente de } \\
\text { determinación }\left(\mathbf{r}^{2}\right)\end{array}$ & $\begin{array}{c}\text { Coeficiente de } \\
\text { variación }(\mathbf{C V}, \boldsymbol{\%})\end{array}$ & Pendientes (m) & $\begin{array}{c}\text { Coeficiente de } \\
\text { variación }(\mathbf{C V}, \boldsymbol{\%})\end{array}$ \\
\hline $\mathrm{NH}_{4}{ }^{+}$(electrodo selectivo) & $0.996 \pm 0.001$ & $0.18 \%$ & $71.82 \pm 0.64$ & $0.90 \%$ \\
$\mathrm{NO}_{2}^{-}$(CIA) & $0.992 \pm 0.002$ & $0.23 \%$ & $1643.50 \pm 61.74$ & $3.75 \%$ \\
$\mathrm{NO}_{3}^{-}$(CIA) & $0.996 \pm 0.001$ & $0.18 \%$ & $1793.60 \pm 23.27$ & $1.29 \%$ \\
$2-\mathrm{CF}$ (HPLC) & $0.996 \pm 0.004$ & $0.48 \%$ & $7239.33 \pm 422.72$ & $5.8 \%$ \\
Proteína microbiana (Lowry) & $0.996 \pm 0.003$ & $0.39 \%$ & $1.84 \pm 0.02$ & $1.26 \%$ \\
\hline
\end{tabular}




\section{REFERENCIAS}

1. Bailey, J., Ollis, D., (1986). Biochemical engineering fundamentals. New York (NY): Chem Eng Educ.

2. Gouy, M., Guindon, S. and Gascuel, O. (2010). SeaView version 4: a multi platform graphical user interface for sequence alignment and phylogenetictree building. Mol. Biol. Evol. 27(2), 221-224.

3. Hintze, J., (2001). Number Cruncher Statistical System (NCSS).

4. Huber, T., Faulkner, G., Hugenholtz, P. and (2004). Bellerophon: a program to detect chimeric sequences in multiple sequence alignments. Bioinformatics. 20, 2317-2319.

5. Kumar, S., Stecher, G., Li, M., Knyaz, C. and Tamura, K., (2018). MEGA X: Molecular Evolutionary Genetics Analysis across computing platforms. Mol. Biol. Evol. 35, 1547-1549.

6. Larkin, M.A., Blackshields, G., Brown, N.P., Chenna, R., McGettigan, P.A., McWilliam, H., Valentin, F., Wallace, I.M., Wilm, A., Lopez, R., Thompson, J.D., Gibson, T.J. and Higgins, D.G. (2007). Clustal W and Clustal X version 2.0. Bioinformatics. 23, 2947-2948.

7. Lowry, O.H., Rosebrough, N.J., Farr, A.L. and Randall, R.J. (1951). Protein measurement with the folin phenol reagent. The Journal of Biological Chemistry. 193, 265-275.

8. Martínez, F., Lema, J., Méndez, R., Cuervo-López, F. and Gómez, J., (20049. Role of exopolymeric protein on the settleability of nitrifying sludges. Bioresour. Technol. 94, 43-48.

9. Martínez, G.A., Castillo, M.A., (1987). In: Teoría de la Regresión con aplicación agronómica. Colegio de Posgraduados, México, pp. 490.

10. Martínez-Hernández, S., Olguín, E., Gómez, J. and Cuervo-López, F. (2009). Acetate Enhances the Specific Consumption Rate of Toluene Under Denitrifying Conditions. Archives Environmental Contamination and Toxicology. 57, 679-687.

11. McGinnis, S. and Madden, T.L. (2004). BLAST: at the core of a powerful and diverse set of sequence analysis tools. Nucleic Acids Res. 32 (Suppl. 2). W20-W25.

12. Sanguinetti, C.J., Dias, E. and Simpson, A.J. (1994). Rapid silver staining and recovery of PCR products separated on polyacrylamide gels. Biotechniques. 17(5), 914-21.

13. Silva, C. D., Beristain-Montiel, L., Cuervo-López, F. and Texier A-C. (2014). p-cresol mineralization and bacterial population dynamics in a nitrifying sequential batch reactor. Journal of Environmental Sciences. 26, 1885-1893.

14. Silva, C.D., Gómez, J., Houbron, E., Cuervo-López, F. and Texier, A.-C. (2009). p-cresol biotransformation by a nitrifying consortium. Chemosphere. 75(10), 1387-1391.

15. Weinberger, R. (1993). Practical capillary electrophoresis. Academic Press, San Diego CA. pp 6-7.

16. Zwietering, M.H., Jongenburger, I., Rombouts, F.M. and Van't Riet, K., (1990). Modeling of the bacterial growth curve. Appliedand Environmental Microbiology. 56(6), 1875-1881. 


\section{RESULTADOS}




\section{RESULTADOS}

\subsection{Ensayos de control abiótico y de adsorción}

Los ensayos de control abióticos realizados tanto en lote como en los reactores SBR, con $100 \mathrm{mg}$ de $\mathrm{N}_{-} \mathrm{NH}_{4}{ }^{+} / \mathrm{L}$ y $20 \mathrm{mg}$ de C-2-CF/L en ausencia de biomasa, así como los de adsorción con biomasa estéril, mostraron que después de 144 h (6 días) de experimentación el 96.7 $\pm 3.2 \%$, $99 \pm 0.5 \%$ y $95.5 \pm 4.5 \%$ de $2-\mathrm{CF}$ se mantuvo en la fracción líquida de los cultivos respectivamente (Figura 16); por lo tanto, la pérdida de 2-CF por volatilización, reacción química o adsorción fue insignificante. Estos resultados coinciden con los reportados en sistemas SBR en condiciones similares por Martínez-Jardines y col. (2019), e indican que la disminución de 2-CF en los ensayos bióticos puede ser asociada con el consumo biológico realizado por el consorcio nitrificante.

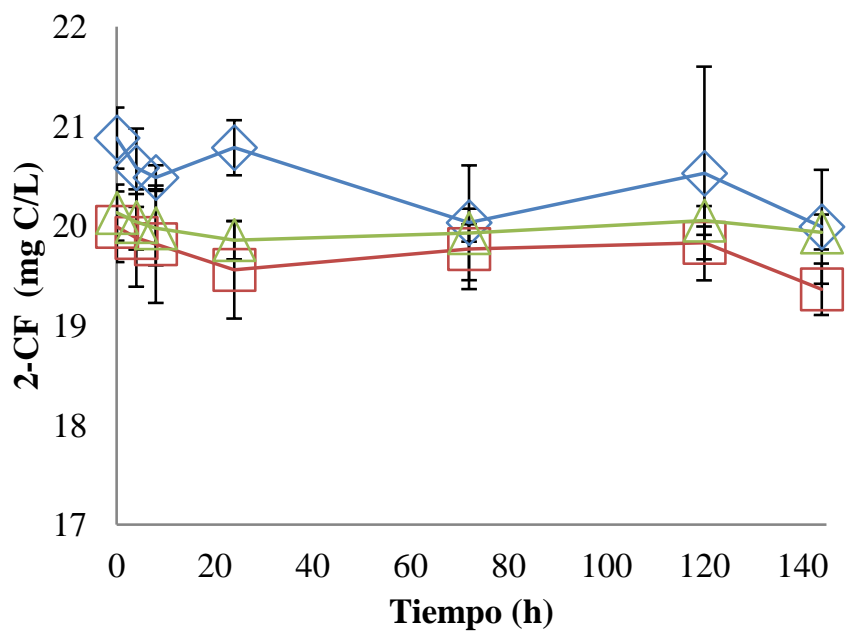

Figura 16. Ensayos abióticos y de adsorción con $100 \mathrm{mg}$ de N-NH${ }_{4}^{+} / \mathrm{L}$ y $20 \mathrm{mg}$ de C-2-CF/L: Reactores SBR sin biomasa y con oxígeno $(\square)$, Lote con ATU sin biomasa y sin oxígeno $(\triangle)$ y Lote de adsorción con biomasa estéril y $\sin$ oxígeno $(\diamond)$. 


\subsection{Fuente de inóculo: verificación de la capacidad nitrificante del lodo}

La capacidad nitrificante del lodo contenido en el reactor SBR se verificó en varios puntos, de acuerdo a lo indicado en la Sección 5 de la metodología: En el ciclo 20 de operación, antes de realizar los ensayos en lote con diferentes concentraciones de amonio para la evaluación de la actividad nitrificante del lodo previamente expuesto a 2-CF. En el ciclo 25 de operación, antes de llevar a cabo los ensayos en lote para evaluar la participación de la enzima AMO en el consumo de 2-CF y en el ciclo 32 de operación, antes de inocular los dos reactores SBR. Los perfiles nitrificantes obtenidos en los ciclos de operación antes mencionados tuvieron un comportamiento similar en términos de consumo de amonio, producción de nitrato y consumo de 2-CF. Un ejemplo del perfil nitrificante en el ciclo 25 de operación se presenta en la Figura 17, donde se muestra el consumo total del amonio alimentado en 11 días de reacción, la presencia transitoria de nitrito desde el inicio y hasta el día 8 de reacción, y la oxidación del amonio consumido a nitrato en 16 días de reacción. El 2-CF se consumió totalmente en 8 días.

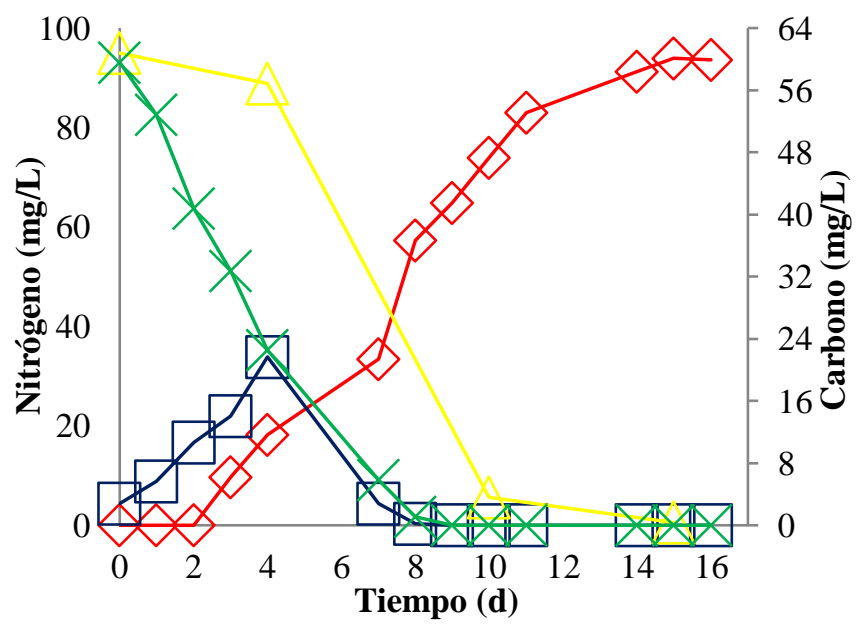

Figura 17. Perfil nitrificante en el ciclo 25 de operación en el reactor SBR en presencia de amonio y 2-CF. Amonio $(\triangle)$, Nitrito $(\square)$, Nitrato $(\diamond)$ y $2-\mathrm{CF}(\times)$. 
Las variables de respuesta del proceso nitrificante obtenidas bajo estas condiciones se presentan en la Tabla 8. Estos resultados comprueban que el lodo nitrificante mantuvo el proceso nitrificante de manera estable con la capacidad de consumir amonio y 2-CF con valores de EN$\mathrm{NH}_{4}{ }^{+}$y $\mathrm{YN}-\mathrm{NO}_{3}{ }^{-}$altos.

Tabla 8. Variables de respuesta del lodo nitrificante en presencia de amonio y 2-CF en diferentes ciclos de operación en el reactor SBR.

\begin{tabular}{|c|c|c|c|c|c|c|}
\hline Ciclo & EN-NH4${ }_{4}^{+}$ & $\mathrm{YN}-\mathrm{NO}_{3}^{-}$ & qN-NH ${ }_{4}^{+}$ & $\mathrm{qN}^{-\mathrm{NO}_{3}}{ }^{-}$ & qC-2-CF & Biomasa \\
\hline 19 & 99.51 & 0.98 & 24.54 & 12.89 & 9.48 & 1154 \\
\hline 25 & 99.43 & 0.99 & 19.82 & 9.68 & 10.07 & 1124 \\
\hline 32 & 99.63 & 0.99 & 11.17 & 70.56 & 17.14 & 656 \\
\hline
\end{tabular}

$\mathrm{EN}^{-N_{4}}{ }^{+}=$Porcentaje.

$\mathrm{YN}^{-\mathrm{NO}_{3}}{ }^{-}=\mathrm{mg}$ de $\mathrm{N}$ producto/mg de $\mathrm{N}$ consumido.

qN-NO${ }_{3}^{-}=\mathrm{mg}$ de producto formado/g proteína $\mathrm{d}$.

$\mathrm{qN}-\mathrm{NH}_{4}{ }^{+}, \mathrm{qC}-2-\mathrm{CF}=\mathrm{mg}$ sustrato consumido/g proteína $\mathrm{d}$.

Biomasa $=\mathrm{mg} / \mathrm{L}$.

\subsection{Evaluación de la actividad nitrificante con diferentes concentraciones de amonio de un lodo previamente expuesto a 2-CF}

Se realizaron ensayos en lote con 100, 300 y $500 \mathrm{mg}^{\mathrm{de}} \mathrm{N}-\mathrm{NH}_{4}{ }^{+} / \mathrm{L}$ utilizando el lodo que estuvo en periodos largos y en constante contacto con el 2-CF (60 mg de C-2-CF/L durante 11 meses), con la finalidad de evaluar la actividad nitrificante del lodo sin la adición de 2-CF. En todos los casos se mantuvo un $\mathrm{pH}$ inicial de $6.9 \pm 0.4$, una temperatura de $28^{\circ} \mathrm{C}$ y una concentración de $208.1 \pm 5.7 \mathrm{mg}$ de proteína microbiana/L. En la Figura 18 se muestran los perfiles nitrificantes encontrados en cada condición experimental. 

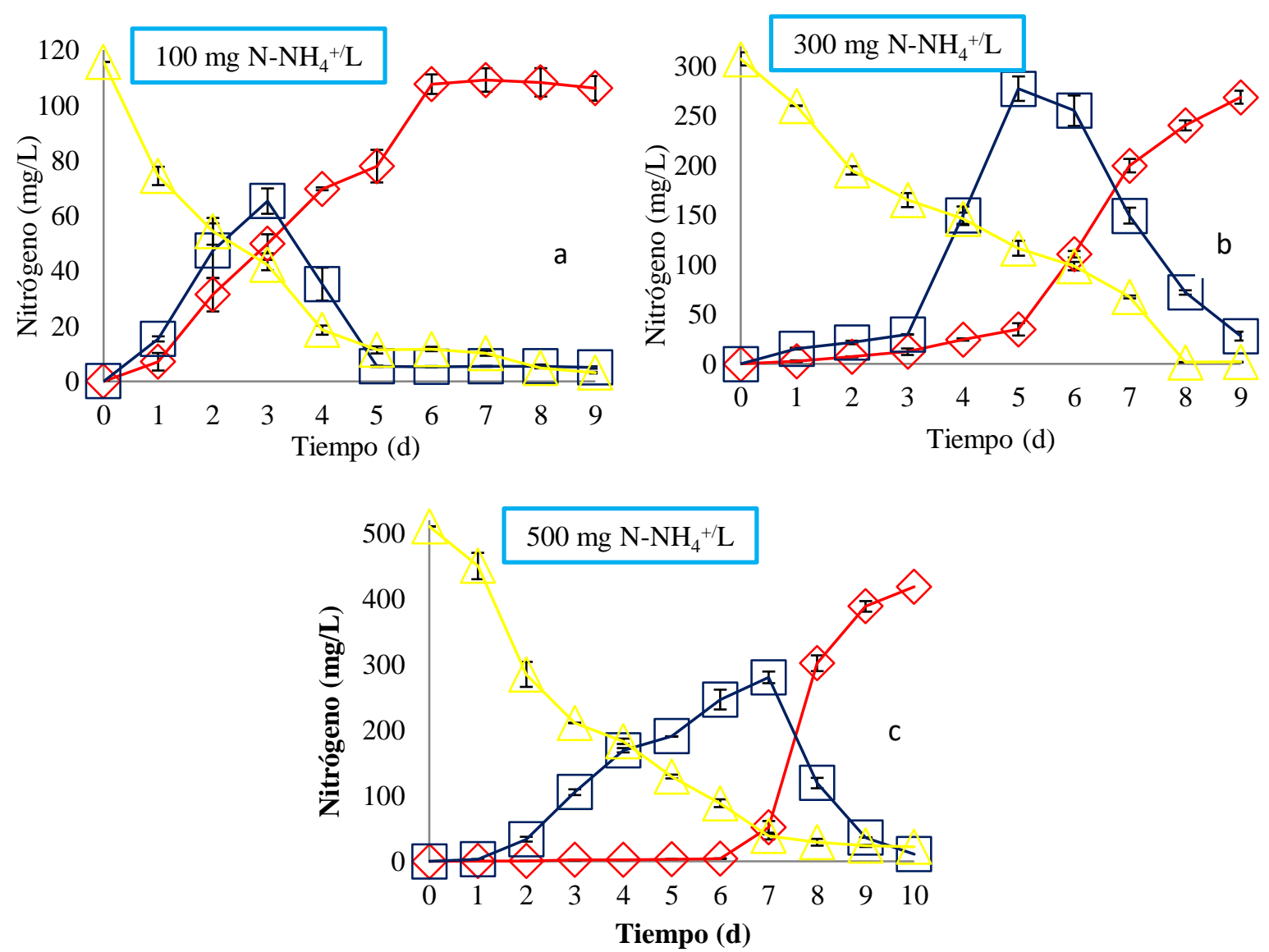

Figura 18. Perfiles de la nitrificación con diferentes concentraciones iniciales de amonio en los ensayos en lote: 100 (a), 300 (b) y 500 (c) mg de N-NH${ }_{4}^{+} / \mathrm{L}$. Amonio $(\triangle)$, Nitrito ( $\left.\square\right)$ y Nitrato $(\diamond)$.

En todos los casos se presentó un consumo de amonio entre los días 8 y 10 de cultivo y al final de cada ensayo, la concentración residual de éste fue mínima. En todos los casos se presentó una acumulación de nitrito transitoria muy notoria que prevalecía entre 2 y 5 días en el ensayo con $100 \mathrm{mg}$ de $\mathrm{N}^{-\mathrm{NH}_{4}}+\mathrm{L}$ y entre 5 y 9 días en los ensayos con 300 y $500 \mathrm{mg}$ de N$\mathrm{NH}_{4}{ }^{+} / \mathrm{L}$. La máxima producción de nitrato se alcanzó al final de todos los ensayos. En todos los casos se obtuvieron $\mathrm{EN}-\mathrm{NH}_{4}{ }^{+}$arriba del $95 \%$ y $\mathrm{YN}^{-\mathrm{NO}_{3}}{ }^{-}$mayores al 0.85 , lo que indica que se llevó a cabo una nitrificación completa (Tabla 9), sin embargo, los lodos nitrificantes requirieron de un mayor tiempo para lograrlo. Por ejemplo, en el ensayo con $100 \mathrm{mg}$ de $\mathrm{N}-\mathrm{NH}_{4}+/ \mathrm{L}$, se requirieron 5 días para obtener $97.2 \%$ de $\mathrm{EN}^{-\mathrm{NH}_{4}}{ }^{+}$y 6 días para su conversión a nitrato. Por otro lado, las qN- $\mathrm{NH}_{4}{ }^{+}$fueron incrementando de acuerdo al incremento en la concentración de amonio inicial, un comportamiento similar se presentó en las $\mathrm{qN}^{-\mathrm{NO}_{3}}$. Todos estos resultados 
indican que, bajo las condiciones operacionales establecidas, en ausencia del compuesto clorado e independientemente de la concentración inicial de amonio, los lodos nitrificantes tuvieron la capacidad metabólica para consumir y oxidar al amonio hasta nitrato.

Tabla 9. Variables de respuesta en los ensayos en lote a diferentes concentraciones iniciales de amonio.

\begin{tabular}{|c|c|c|c|c|c|c|}
\hline Ensayo & EN-NH ${ }_{4}^{+}$ & $\mathrm{YN}-\mathrm{NO}_{3}^{-}$ & $\mathrm{qN}-\mathrm{NH}_{4}{ }^{+}$ & $\mathrm{qN}-\mathrm{NO}_{3}^{-}$ & $q \mathrm{C}-2-\mathrm{CF}$ & Biomasa \\
\hline $\mathrm{NH}_{4}{ }^{+} 100$ & $97.2 \pm 0.2$ & $0.94 \pm 0.03$ & $142.5 \pm 5.4$ & $117.1 \pm 14.6$ & --- & $201.5 \pm 2.1$ \\
\hline $\mathrm{NH}_{4}+300$ & $99.3 \pm 0.1$ & $0.88 \pm 0.04$ & $179.6 \pm 3.0$ & $405.8 \pm 59.2$ & ---- & $211.4 \pm 1.4$ \\
\hline $\mathrm{NH}_{4}{ }^{+} 500$ & $95.6 \pm 0.5$ & $0.85 \pm 0.02$ & $476.9 \pm 17.1$ & $1338.6 \pm 141.4$ & ---- & $211.5 \pm 3.5$ \\
\hline
\end{tabular}

${\mathrm{EN}-\mathrm{NH}_{4}}^{+}=$Porcentaje.

${\mathrm{YN}-\mathrm{NO}_{3}}^{-}=\mathrm{mg}$ de $\mathrm{N}$ producto/mg de $\mathrm{N}$ consumido.

$\mathrm{qN}-\mathrm{NO}_{3}{ }^{-}=\mathrm{mg}$ de producto formado/g proteína $\mathrm{d}$.

$\mathrm{qN}-\mathrm{NH}_{4}{ }^{+}, \mathrm{qC}-2-\mathrm{CF}=\mathrm{mg}$ sustrato consumido/g proteína d.

Biomasa $=\mathrm{mg} / \mathrm{L}$.

En la literatura se reporta que en ensayos en lote utilizando lodos nitrificantes que no han sido expuestos a compuestos fenólicos y con una concentración inicial de 100 mg de N$\mathrm{NH}_{4}+/ \mathrm{L}$, los tiempos para observar el proceso nitrificante completo van desde 8 horas (MartínezHernández y col., 2011; Pérez-Alfaro y col., 2013) y hasta 24 horas (Bejarano-Ortiz y col., 2013). El mayor tiempo requerido en el presente trabajo para realizar la nitrificación en lote podría estar asociado al efecto del 2-CF sobre la membrana celular, ocasionando su ruptura o cambios en su configuración (Martínez-Jardines y col., 2019) y al tiempo requerido por los microorganismos para reparar los daños. Sin embargo, en comparación con lo reportado por Pérez-Alfaro y col. (2013), quienes realizaron un ensayo con $100 \mathrm{mg}$ de $\mathrm{N}_{-} \mathrm{NH}_{4}{ }^{+} / \mathrm{L}$ y un lodo nitrificante que estuvo en presencia de hasta $10 \mathrm{mg}$ de $\mathrm{C}-2-\mathrm{CF} / \mathrm{L}$, encontraron que después de 10 días de cultivo solo se consumió el $48 \%$ de amonio y se transformó totalmente a nitrito, es decir, ocurrió una nitrificación parcial. En contraste, en el presente estudio, se obtuvo en 7 días de cultivo, la oxidación mayoritaria a nitrato sin acumulación de nitrito. Asimismo, Pérez-Alfaro (2015) encontró en ensayos en lote con 300 y $500 \mathrm{mg}$ de $\mathrm{N}^{-\mathrm{NH}_{4}}+\mathrm{L}$, utilizando un lodo nitrificante sin contacto previo a ningún compuesto fenólico, $\mathrm{EN}-\mathrm{NH}_{4}{ }^{+}$del $60 \%$, en 2 días de cultivo. Mientras que los ensayos realizados en este trabajo con las concentraciones de $300 \mathrm{y}$ 500 arrojaron eficiencias de consumo de amonio de 37.5 y $44.2 \%$ respectivamente en 2 días y de 99.3 y $95.6 \%$ respectivamente en 9 días de cultivo. Es importante notar que, aunque se requieren tiempos largos de cultivo, el lodo nitrificante que ha sido expuesto a $60 \mathrm{mg} \mathrm{C}-2-\mathrm{CF} / \mathrm{L}$, 
es capaz de realizar el proceso nitrificante con concentraciones desde 100 y hasta $500 \mathrm{mg}$ de $\mathrm{N}$ $\mathrm{NH}_{4}{ }^{+} / \mathrm{L}$ de manera completa y en ausencia del compuesto clorado. Esta respuesta se puede atribuir a la adaptación microbiana que obtuvo el lodo nitrificante durante su cultivo en el reactor SBR en presencia de $\mathrm{NH}_{4}^{+}$y 2-CF.

\subsection{Evaluación del proceso nitrificante en presencia de 2-CF y diferentes concentraciones iniciales de amonio en el reactor SBR}

Para evaluar a lo largo de los ciclos de operación, el efecto de diferentes concentraciones iniciales de $\mathrm{NH}_{4}{ }^{+}$sobre el consumo de $60 \mathrm{mg}$ de $\mathrm{C}-2-\mathrm{CF} / \mathrm{L}$ y el proceso nitrificante, en el ciclo 32 de operación y de acuerdo a la sección de 5.4 de la metodología, el lodo nitrificante contenido en el reactor SBR se dividió en dos, a fin de instalar dos reactores SBR con una concentración de proteína microbiana de $354.7 \pm 9.9 \mathrm{mg} / \mathrm{L}$. Con estos dos reactores y de acuerdo a la sección 5.3 de la metodología, se llevaron a cabo 13 ciclos de operación. En la Figura 19 se muestran los perfiles nitrificantes cuando se adicionaron 100 (ciclo 1 de operación), 200 (ciclo 4 de operación), 300 (ciclo 7 de operación), 400 (ciclo 10 de operación) y $500 \mathrm{mg}$ de N-NH${ }_{4}^{+} / \mathrm{L}_{\text {(ciclo }}$ 13 de operación), manteniendo una concentración constante de 60 mg de C-2-CF/L. En un primer ciclo de operación se observa el consumo total de $100 \mathrm{mg}$ de $\mathrm{N}-\mathrm{NH}_{4}{ }^{+} / \mathrm{L}$ en 15 días de reacción, se detecta una concentración transitoria de nitrito que desaparece al final del cultivo y después de 18 días se obtiene la producción máxima de nitrato y una nitrificación completa, mientras que el 2-CF se consume totalmente en 15 días (Figura 19a). En el primer ciclo con el incremento de la concentración inicial de amonio a $200 \mathrm{mg} \mathrm{de} \mathrm{N}-\mathrm{NH}_{4}{ }^{+} / \mathrm{L}$ y en el tercer ciclo con la misma concentración (ciclo 4 de operación), la nitrificación se lleva a cabo completamente en 14 días y el 2-CF se consume en 8 días (Figura 19b). Con el incremento a $300 \mathrm{mg}$ de N$\mathrm{NH}_{4}{ }^{+} / \mathrm{L}$ en el ciclo 7 de operación, se observa una disminución en el tiempo requerido para llevar a cabo el proceso nitrificante, de forma que el consumo de amonio y la producción máxima de nitrato se obtuvieron en 11 y 14 días de cultivo, mientras que el consumo de 2-CF ocurrió en un tiempo menor a 7 días (Figura 19c). Aun con el aumento a 400 y $500 \mathrm{mg}$ de $\mathrm{N}_{-} \mathrm{NH}_{4}{ }^{+} / \mathrm{L}$ en $\operatorname{los}$ ciclos de operación 10 y 13 respectivamente, se observa un consumo total de amonio y una nitrificación completa, logrando al final del ciclo 13, consumir tanto el amonio como el 2-CF alimentados en un lapso entre 11 y menos de 7 días respectivamente (Figura 19d, Figura 19e). 

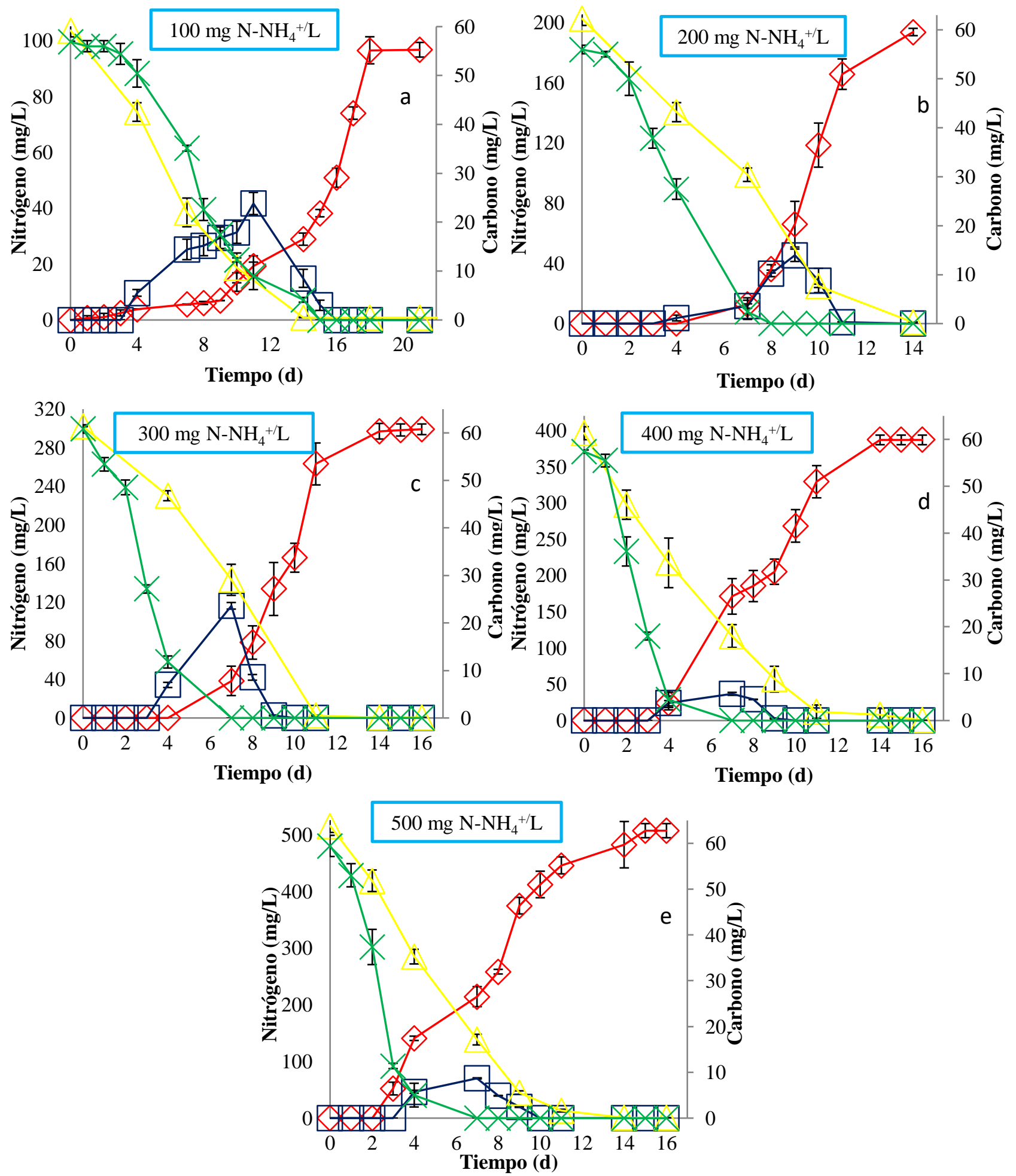

Figura 19. Perfil del proceso nitrificante en el reactor SBR en presencia de 2-CF (60 mg C/L) y 100 (ciclo 1) (a), 200 (ciclo 4) (b), 300 (ciclo 7) (c), 400 (ciclo 10) (d) y 500 (ciclo 13) (e) $\mathrm{mg} \mathrm{N}^{-\mathrm{NH}_{4}}{ }^{+} / \mathrm{L}$. Amonio ( $\triangle$ ), Nitrito ( $\square$ ), Nitrato $(\diamond)$ y $2-\mathrm{CF}(\times)$. 
Estos resultados indican que con el incremento en la concentración de amonio e independientemente de la presencia de $60 \mathrm{mg}$ de $\mathrm{C}-2-\mathrm{CF} / \mathrm{L}$, el lodo mantuvo su capacidad nitrificante y el proceso respiratorio se llevó a cabo de forma estable, puesto que durante todos los ciclos de operación la nitrificación se llevó a cabo completamente, resultando en $\mathrm{EN}^{-\mathrm{NH}_{4}}{ }^{+}$

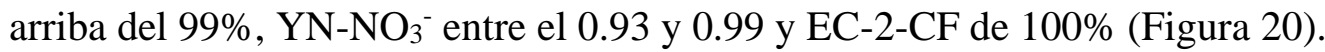

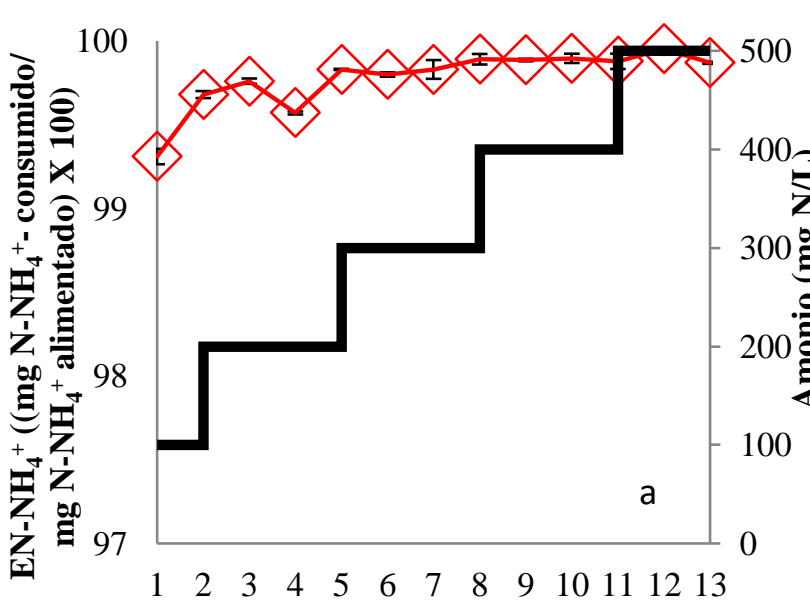

Ciclos

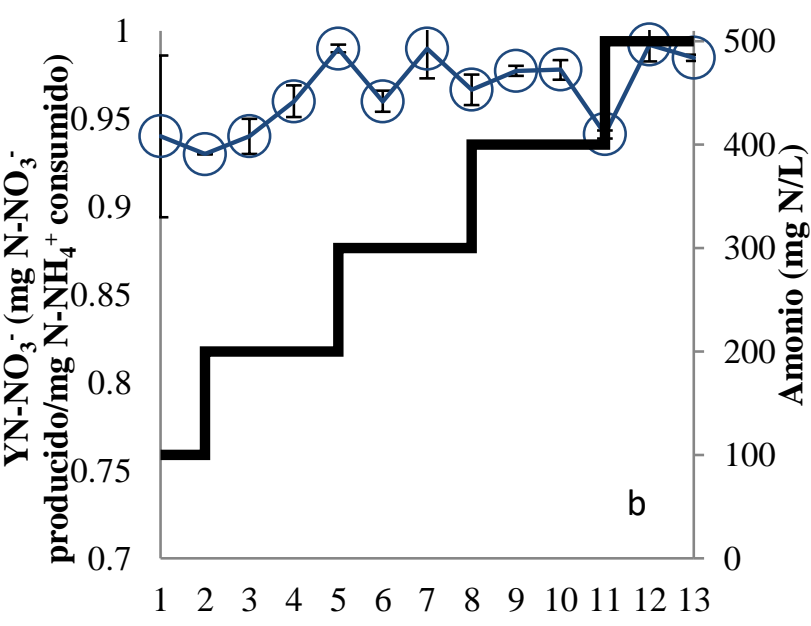

Ciclos

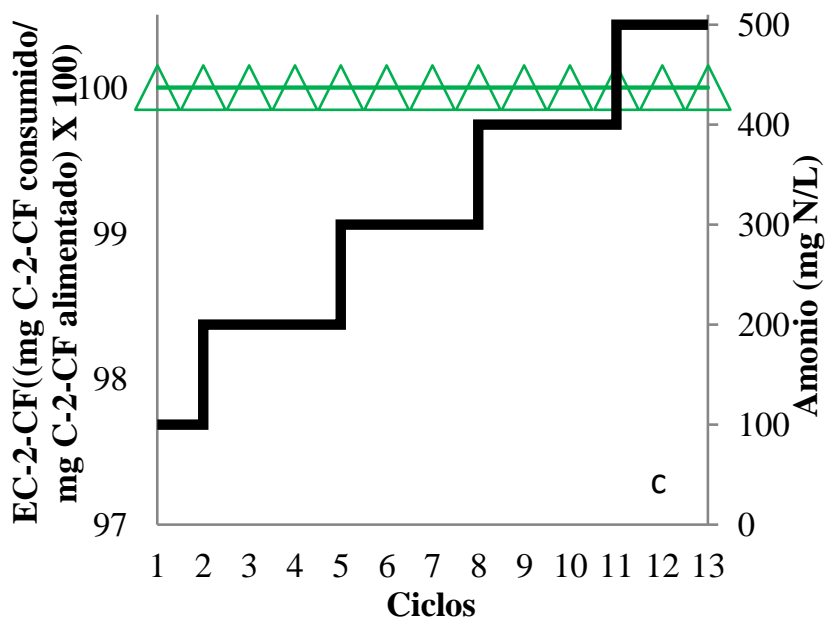

Figura 20. Variables de respuesta del lodo nitrificante en el reactor SBR a lo largo de los ciclos de operación con 2-CF a diferentes concentraciones iniciales de amonio. Eficiencias de consumo de amonio $(\diamond)(\mathrm{a})$, rendimientos de producción de nitrato $(\mathrm{O})(\mathrm{b})$, Eficiencias de consumo de 2-CF $(\triangle)(\mathrm{c})$, Concentración de amonio $(-)$. 
Cabe mencionar que a lo largo de los ciclos de operación en los reactores SBR, se detectó un intermediario carbonado no identificado del 2-CF que aparecía en los cromatogramas en un tiempo de retención de $1.58 \mathrm{~min}$. Al respecto, Pérez-Alfaro y col. (2013) reportaron que durante el consumo de 2-CF apareció un intermediario en un tiempo de retención similar de 1.6 min. Este intermediario podría ser el mismo reportado por los autores. Sin embargo, en este estudio no se realizaron más análisis para identificar el intermediario formado.

Se ha reportado que la concentración de amonio es crucial para inhibir a los organismos nitrificantes y se cree que podría tener un efecto en la actividad enzimática de las bacterias nitrificantes (Peng y Zhu, 2006), de forma que la posibilidad de que se produzca inhibición en la nitrificación por sustrato, aumenta cuanto mayor es la concentración de nitrógeno del agua residual industrial (Carrera, 2004). En este sentido hay reportes que indican que la inhibición del proceso amonio oxidante se da a partir de concentraciones de $150 \mathrm{mg}$ de $\mathrm{N}-\mathrm{NH}_{4}{ }^{+} / \mathrm{L}$ (Anthonisen y col., 1976). En el presente trabajo, aun con el aumento en la concentración inicial de amonio hasta $500 \mathrm{mg}$ de $\mathrm{N}-\mathrm{NH}_{4}{ }^{+} / \mathrm{L}$ y con $60 \mathrm{mg}$ de $\mathrm{C}-2-\mathrm{CF} / \mathrm{L}$, el lodo presentó una respuesta metabólica estable y eficiente con $\mathrm{EN}_{-} \mathrm{NH}_{4}{ }^{+}$y $\mathrm{YN}^{-\mathrm{NO}_{3}}{ }^{-}$altos que permitieron alcanzar un consumo simultáneo de $\mathrm{N}_{-} \mathrm{NH}_{4}{ }^{+}$y 2-CF. Estos resultados se pueden atribuir a la exposición previa del lodo nitrificante al 2-CF, así como a los cambios metabólicos adquiridos durante el transcurso de los ciclos de operación en los reactores SBR que resultaron en una adaptación metabólica de los lodos nitrificantes (Martínez-Jardines, 2015; Martínez-Jardines y col., 2019). En este sentido, se ha reportado previamente la capacidad de lodos nitrificantes para consumir simultáneamente en reactores SBR amonio y diferentes compuestos aromáticos, recalcitrantes, tóxicos o inhibidores tales como $m$-cresol (Zepeda y col., 2012), $o$-cresol y $p$-cresol (SalasCortés y col., 2017) y $50 \mathrm{mg}$ de $\mathrm{N}-\mathrm{NH}_{4}{ }^{+} / \mathrm{L}$, así como hasta $100 \mathrm{mg}$ de $\mathrm{N}-\mathrm{NH}_{4}{ }^{+} / \mathrm{L}$ junto con $p$ hidroxibenzaldehido (Téllez-Pérez y col., 2013), p-cresol (Silva y col., 2014) y 2-CF (MartínezJardines y col., 2019). Sin embargo, las concentraciones de amonio utilizadas en los trabajos mencionados no exceden los $100 \mathrm{mg}$ de $\mathrm{N}_{-} \mathrm{NH}_{4}{ }^{+} / \mathrm{L}$. Hasta donde sabemos, este es el primer informe donde el proceso nitrificante se evalúa cinética y fisiológicamente a lo largo de los ciclos de operación en reactores SBR alimentados con concentraciones crecientes de amonio (100-500 mg de N/L) y un compuesto recalcitrante como el 2-CF (60 mg de C-2-CF/L). 
El balance de materia obtenido a lo largo de los 13 ciclos de operación con amonio y 2CF se presenta en la Tabla 10. Se encontró que la mayor parte del amonio alimentado al inicio de la experimentación fue consumido y oxidado a nitrato y que no hubo acumulación de nitrito al final de los ciclos de operación.

Tabla 10. Balance de materia del lodo nitrificante en el reactor SBR a lo largo de los ciclos de operación con 2-CF a diferentes concentraciones iniciales de amonio.

\begin{tabular}{|c|c|c|c|c|c|c|c|c|}
\hline \multirow[b]{2}{*}{ Ciclo } & \multirow{2}{*}{$\begin{array}{c}\text { Concentración } \\
\text { de N-NH}{ }_{4}^{+} \\
(\mathrm{mg} / \mathrm{L})\end{array}$} & \multirow{2}{*}{ 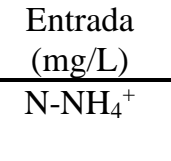 } & \multicolumn{6}{|c|}{ Salida (mg/L) } \\
\hline & & & ${\mathrm{N}-\mathrm{NH}_{4}}^{+}$ & ${\mathrm{N}-\mathrm{NO}_{2}}^{-}$ & $\mathrm{N}^{-\mathrm{NO}_{3}{ }^{-}}$ & N-Biomasa & YBM & $\begin{array}{l}\% \text { de } \mathrm{N} \\
\text { recuperado }\end{array}$ \\
\hline 1 & 100 & $103.6 \pm 2.3$ & $0.71 \pm 0.06$ & 0 & $96.7 \pm 2.6$ & $4.0 \pm 0.3$ & $0.039 \pm 0.002$ & $97.9 \pm 4.3$ \\
\hline 2 & 200 & $209.3 \pm 4.7$ & $0.66 \pm 0.05$ & 0 & $196.0 \pm 4.3$ & $10.9 \pm 0.6$ & $0.052 \pm 0.001$ & $99.2 \pm 0.1$ \\
\hline 3 & 200 & $199.6 \pm 9.0$ & $0.50 \pm 0.05$ & 0 & $187.3 \pm 6.2$ & $12.9 \pm 0.5$ & $0.065 \pm 0.002$ & $100.5 \pm 1.1$ \\
\hline 4 & 200 & $202.8 \pm 4.6$ & $0.85 \pm 0.04$ & 0 & $193.8 \pm 2.4$ & $12.7 \pm 1.4$ & $0.063 \pm 0.005$ & $102.3 \pm 0.3$ \\
\hline 5 & 300 & $307.1 \pm 6.9$ & $0.51 \pm 0.10$ & 0 & $303.7 \pm 6.2$ & $7.2 \pm 6.2$ & $0.023 \pm 0.019$ & $101.5 \pm 0.3$ \\
\hline 6 & 300 & $311.3 \pm 9.8$ & $0.74 \pm 0.04$ & 0 & $299.5 \pm 2.0$ & $5.9 \pm 0.9$ & $0.019 \pm 0.003$ & $98.1 \pm 0.9$ \\
\hline 7 & 300 & $302.4 \pm 7.9$ & $0.51 \pm 0.20$ & 0 & $299.1 \pm 5.5$ & $3.8 \pm 1.0$ & $0.012 \pm 0.003$ & $100.4 \pm 1.4$ \\
\hline 8 & 400 & $402.5 \pm 5.6$ & $0.43 \pm 0.10$ & 0 & $388.5 \pm 3.6$ & $6.3 \pm 1.0$ & $0.015 \pm 0.002$ & $98.2 \pm 0.6$ \\
\hline 9 & 400 & $408.9 \pm 9.2$ & $0.46 \pm 0.02$ & 0 & $399.2 \pm 7.8$ & $7.3 \pm 0.1$ & $0.018 \pm 0.001$ & $99.5 \pm 0.3$ \\
\hline 10 & 400 & $396.1 \pm 8.9$ & $0.40 \pm 0.10$ & 0 & $386.9 \pm 6.6$ & $4.2 \pm 0.8$ & $0.010 \pm 0.005$ & $98.8 \pm 0.4$ \\
\hline 11 & 500 & $506.8 \pm 11.5$ & $0.61 \pm 0.24$ & 0 & $476.3 \pm 9.4$ & $7.4 \pm 1.6$ & $0.014 \pm 0.002$ & $95.6 \pm 0.1$ \\
\hline 12 & 500 & $500.3 \pm 2.3$ & $0.23 \pm 0.03$ & 0 & $494.5 \pm 4.7$ & $3.3 \pm 1.2$ & $0.006 \pm 0.002$ & $99.9 \pm 0.7$ \\
\hline 13 & 500 & $515.5 \pm 11.7$ & $0.67 \pm 0.01$ & 0 & $506.9 \pm 12.4$ & $2.4 \pm 0.6$ & $0.004 \pm 0.001$ & $98.9 \pm 0.1$ \\
\hline
\end{tabular}

YBM: Rendimiento de producción de biomasa (mg de $\mathrm{N}$ de biomasa producido/mg $\mathrm{N}$ consumido).

En todos los ciclos la producción de N-biomasa generada fue baja, la cantidad más alta encontrada fue de $12.9 \pm 0.5 \mathrm{mg} / \mathrm{L}$, correspondiente a un YBM de $0.065 \pm 0.002 \mathrm{mg}$ de $\mathrm{N}$ biomasa/mg de $\mathrm{N}_{-} \mathrm{NH}_{4}{ }^{+}$consumido en el ciclo 3 de operación con $200 \mathrm{mg}$ de N-NH${ }_{4}{ }^{+} / \mathrm{L}$. Esto indica que bajo las condiciones experimentales establecidas y en presencia de concentraciones altas de amonio y hasta $60 \mathrm{mg}$ de $\mathrm{C}-2-\mathrm{CF} / \mathrm{L}$, se presentó un proceso completamente desasimilativo, puesto que el amonio consumido se utilizó como fuente de energía y se dirigió hacia el proceso catabólico. Estos resultados coinciden con lo mencionado por Wiesmann (1994), quien indica que el proceso nitrificante, sin presencia de algún tipo de materia orgánica es prácticamente catabólico, y encontró valores bajos en los rendimientos de crecimiento en 
bacterias amonio oxidantes y nitrito oxidantes de $0.08 \mathrm{~g}$ de células $/ \mathrm{g} \mathrm{N}^{-\mathrm{NH}_{4}}{ }^{+}$y $0.05 \mathrm{~g}$ de células $/ \mathrm{g} \mathrm{N}-\mathrm{NO}_{2}$ respectivamente. También son acordes con los YBM de 0.01 y de $0.07 \mathrm{mg}$ de $\mathrm{N}$-biomasa/mg de $\mathrm{N}^{-\mathrm{NH}_{4}}{ }^{+}$consumido reportados en un SBR nitrificante alimentado con $100 \mathrm{mg}$ de $\mathrm{N}-\mathrm{NH}_{4}{ }^{+} / \mathrm{L}$ y $20 \mathrm{mg}$ de C-2-CF/L (Martínez-Jardines y col., 2019) y con los YBM de 0.05 y de $0.08 \mathrm{mg}$ de N-biomasa/mg de $\mathrm{N}^{-\mathrm{NH}_{4}}{ }^{+}$consumido encontrados en un SBR alimentado con $100 \mathrm{mg}$ de $\mathrm{N}-\mathrm{NH}_{4}{ }^{+} / \mathrm{L} \mathrm{y} 60 \mathrm{mg}$ de C-2-CF/L (Martínez-Jardines, 2015).

Por otro lado, el ajuste de los datos experimentales generados con el modelo de Gompertz, permitió calcular la duración de la fase lag $(\lambda)$ que el lodo nitrificante requirió para iniciar el consumo de amonio, de 2-CF y la producción de nitrato a lo largo de los ciclos de operación en el reactor SBR. En la Figura 21 se presentan los diferentes valores de las fases lag que el lodo nitrificante requirió. En el ciclo adicionado con 100 mg N/L (ciclo 1 de operación), el valor de $\lambda$ para el consumo de amonio y de 2 -CF fueron de $1.7 \pm 0.4$ y $3.7 \pm 0.6$ días respectivamente. Se encontró que con el incremento en la concentración inicial de amonio a 200 mg de $\mathrm{N}-\mathrm{NH}_{4}{ }^{+} / \mathrm{L}$, se obtuvo un efecto positivo en las $\lambda$ para el consumo de amonio y 2-CF, al disminuir un $37.9 \%$ y un $34.4 \%$ respectivamente. En el ciclo 5, con el incremento en la concentración de amonio a $300 \mathrm{mg}$ de $\mathrm{N}_{-} \mathrm{NH}_{4}{ }^{+} / \mathrm{L}$, la $\lambda$ para el consumo de amonio incrementó a $3.7 \pm 0.7$ días y se obtuvo la menor $\lambda$ para el consumo de $2-\mathrm{CF}$ de $0.6 \pm 0.1$ días. Posteriormente a través de los ciclos de operación y con el aumento en la concentración de amonio en el ciclo 11 de operación a $500 \mathrm{mg}$ de $\mathrm{N}-\mathrm{NH}_{4}{ }^{+} / \mathrm{L}$, se presentó la menor $\lambda$ para el consumo de amonio de $0.16 \pm 0.1$ días y la $\lambda$ para el consumo de $2-\mathrm{CF}$ se mantuvo oscilando entre $1.0 \pm 0.1$ y $1.9 \pm 0.1$ días. Con la última concentración de amonio (500 mg N/L) en el ciclo 13, la $\lambda$ para iniciar el consumo de amonio y 2-CF disminuyeron un $54 \%$ y $64.8 \%$ respectivamente con respecto al ciclo 1 de operación, requiriéndose solamente de $0.8 \pm 0.1$ horas para iniciar el consumo de

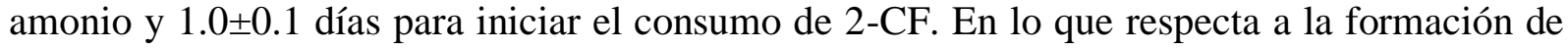
nitrato, durante el ciclo 1 y 2 de operación con 100 y $200 \mathrm{mg}$ N/L, se calcularon $\lambda$ para iniciar la producción de nitrato de $10.3 \pm 0.1$ días. Al incrementar la concentración inicial de amonio y a lo largo de los ciclos de operación, también se obtuvo una tendencia a la disminución en este parámetro, registrándose una $\lambda$ de $2.5 \pm 0.1$ días para la producción de nitrato en el último ciclo de operación con $500 \mathrm{mg} \mathrm{N}-\mathrm{NH}_{4}{ }^{+} / \mathrm{L}$, correspondiendo a una disminución del $76 \%$ con respecto 
al ciclo 1. El aumento en la concentración inicial de amonio y el transcurso de los ciclos de operación de los reactores SBR tuvieron efectos sobre las $\lambda$ de consumo de amonio, de 2-CF y formación de nitrato.
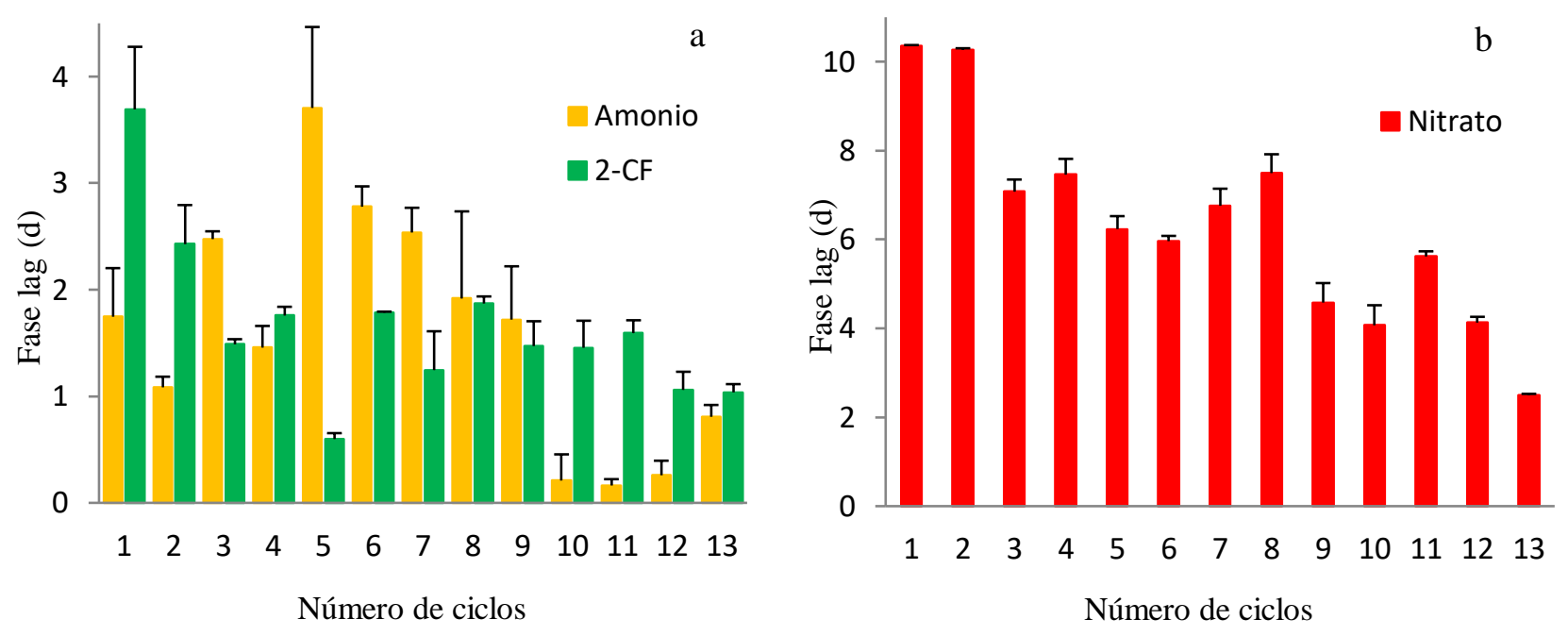

Figura 21. Fase lag de consumo de Amonio, 2-CF (a) y producción de Nitrato (b) del lodo nitrificante en el reactor SBR en presencia de 2-CF y 100 (ciclo 1), 200 (ciclo 2, 3 y 4), 300 (ciclo 5, 6 y 7), 400 (ciclo 8, 9 y 10) y 500 (ciclo 11,12 y 13) $\mathrm{mg} \mathrm{N}-\mathrm{NH}_{4}{ }^{+} / \mathrm{L}$.

Se ha reportado en ensayos en lotes nitrificantes sin previa exposición a compuestos fenólicos, valores de $\lambda$ que van desde 30 y hasta 80 días para consumir concentraciones menores de 2-CF (5-10 mg C-2-CF/L) (Martínez-Hernández y col., 2011; Pérez-Alfaro y col., 2013). En otro estudio utilizando reactores SBR nitrificantes, han reportado $\lambda$ para el consumo de $100 \mathrm{mg}$ de $\mathrm{N}-\mathrm{NH}_{4}{ }^{+} / \mathrm{L}$ de 19 días en presencia de $40 \mathrm{mg}$ de C-2-CF/L y de 9 días en presencia de $60 \mathrm{mg}$ de C-2-CF/L (Martínez-Jardines, 2015). Por otro lado, el mismo autor reportó $\lambda$ para iniciar la producción de nitrato de hasta 14 días después de 7 ciclos de operación. En contraste, en el presente estudio se ha disminuido significativamente el tiempo requerido para iniciar el consumo de amonio y 2-CF. La aclimatación previa y la exposición continua de lodos nitrificantes al 2-CF, el uso de sistemas SBR y el incremento en la concentración de amonio, promovieron la eliminación del compuesto recalcitrante, la disminución en el tiempo requerido para su biodegradación y la disminución de las fases lag para el consumo de sustratos y generación de productos. 
Además de la disminución en las $\lambda$ para la nitrificación y el consumo de 2-CF, el aumento de la concentración de amonio a lo largo de los ciclos de operación en el reactor SBR resultó tener un efecto importante sobre el comportamiento cinético del proceso nitrificante y del consumo del 2-CF, ya que se presentaron cambios en las velocidades específicas de consumo y de producción. Es importante mencionar que la concentración de biomasa en los reactores SBR se mantuvo constante en $365.8 \pm 10.9 \mathrm{mg} / \mathrm{L}$, lo que permite asociar los cambios en las velocidades específicas con cambios en la actividad enzimática y no con cambios en la concentración de biomasa.

En la Figura 22 se muestran las velocidades específicas del proceso respiratorio nitrificante obtenidas a lo largo de los ciclos de operación. En el ciclo 2 de operación y como resultado del primer incremento en la concentración de amonio a $200 \mathrm{mg}$ de $\mathrm{N}_{-} \mathrm{NH}_{4}{ }^{+} / \mathrm{L}$, la qN$\mathrm{NH}_{4}{ }^{+}$aumentó un $40 \%$ con respecto al ciclo 1 operado con $100 \mathrm{mg}$ de $\mathrm{N}_{-} \mathrm{NH}_{4}{ }^{+} / \mathrm{L}$ (Figura 22a). Después de tres ciclos de operación bajo estas condiciones, la qN-NH${ }_{4}{ }^{+}$incrementó un $18 \%$ en el ciclo 4. Este porcentaje de aumento se puede asociar con el efecto de la continua exposición al amonio durante estos tres ciclos de operación del reactor SBR. Con los subsecuentes aumentos en la concentración de amonio y a lo largo de la operación de los reactores SBR, la qN-NH${ }_{4}^{+}$se mantuvo incrementando. Con la concentración de $500 \mathrm{mg} \mathrm{N}-\mathrm{NH}_{4}{ }^{+} / \mathrm{L}$ adicionada en el último ciclo de operación, la qN-NH${ }_{4}^{+}$fue de $189.3 \pm 0.7$, lo que representa un incremento de 5.2 veces asociado al aumento de amonio con respecto al ciclo 1 y un aumento de $7 \%$ asociado al transcurso de tres ciclos de operación bajo esta concentración de amonio. La velocidad de producción de nitrato también estuvo en aumento. El mayor incremento se registró cuando se aumentó a $200 \mathrm{mg} \mathrm{N}-\mathrm{NH}_{4}{ }^{+} / \mathrm{L}$, puesto que la $\mathrm{qN}^{-\mathrm{NO}_{3}}{ }^{-}$tuvo un incremento de 2.8 veces en promedio. De hecho, independientemente de los posteriores incrementos en la concentración de amonio, la qN- $\mathrm{NO}_{3}{ }^{-}$se mantuvo oscilando a lo largo de los ciclos de operación (Figura 22c). 

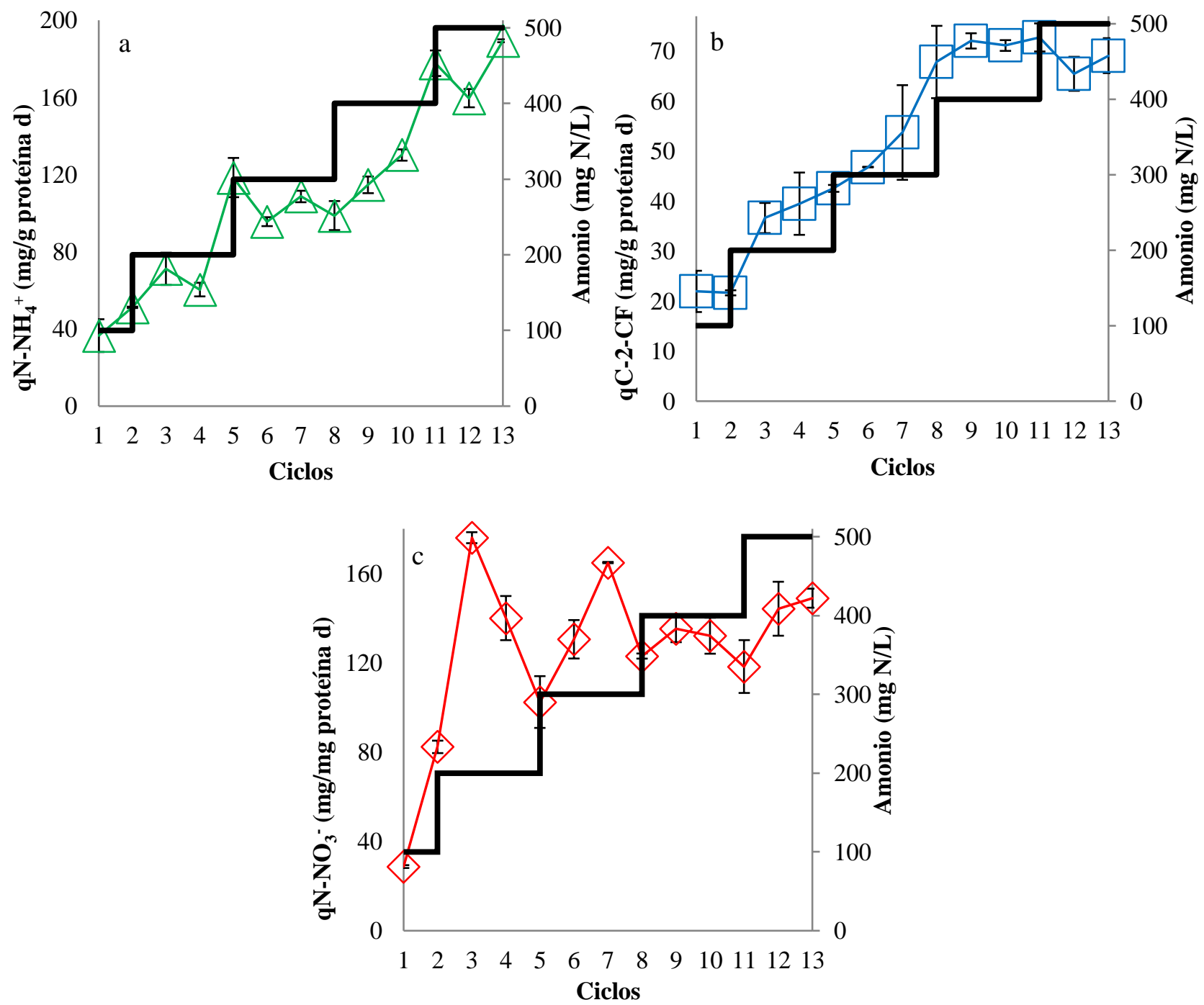

Figura 22. Variables de respuesta del lodo nitrificante en el reactor SBR a lo largo de los ciclos de operación con 2-CF a diferentes concentraciones iniciales de amonio. Velocidades específicas de consumo de amonio (a) $(\triangle)$, 2CF (b) $(\square)$ y producción de nitrato (c) $(\diamond)$. Concentración inicial de amonio (-).

Las diferentes concentraciones de amonio alimentadas también tuvieron un efecto en la velocidad de consumo del 2-CF. En la Figura 22b se presentan las qC-2-CF obtenidas bajo las condiciones nitrificantes impuestas en los SBR a lo largo de los ciclos de operación. Se encontró que con el incremento en la concentración de amonio a $200 \mathrm{mg}$ de $\mathrm{N}-\mathrm{NH}_{4}{ }^{+} / \mathrm{L}$ en el ciclo 2 de operación, la qC-2-CF se mantuvo en $21.7 \pm 0.5 \mathrm{mg}$ de C consumido/g proteína d, mientras que después de tres ciclos de operación con la misma concentración de amonio, la qC-2-CF incrementó un $82 \%$. Como resultado del aumento en la concentración de amonio a $400 \mathrm{mg} \mathrm{N} / \mathrm{L}$ 
en el ciclo 8 de operación, la qC-2-CF incrementó 3 veces con respecto al ciclo 1 y posteriormente se mantuvo oscilando y alcanzando el máximo valor de la qC-2-CF de 72.7 22.8 $\mathrm{mg}$ de $\mathrm{C}$ consumido/g proteína d. En resumen, como resultado del aumento en la concentración de amonio alimentada y del transcurso de los ciclos de operación en los reactores SBR, las qN$\mathrm{NH}_{4}{ }^{+}, \mathrm{qC}-2-\mathrm{CF}$ y qN-NO${ }_{3}{ }^{-}$tuvieron una tendencia al incremento. De esta forma, en el último ciclo de alimentación con $500 \mathrm{mg}$ de $\mathrm{N}_{-} \mathrm{NH}_{4}{ }^{+} / \mathrm{L}$, se obtuvieron incrementos de 5.1, 3.1 y 5.2 veces en las qN-NH${ }_{4}{ }^{+}, \mathrm{qC}-2-\mathrm{CF}$ y qN-NO${ }^{-}$respectivamente, en comparación con el ciclo 1 de operación.

Los incrementos en las velocidades específicas nitrificantes se podrían explicar considerando que la velocidad específica de consumo de sustrato es una variable de primer orden que depende de las condiciones ambientales del cultivo (Cuervo-López y col., 2009). De acuerdo con Cervantes y col. (2016) en condiciones nitrificantes bien definidas, el crecimiento microbiano es insignificante debido a la baja producción de energía. Por lo tanto, la cinética de los cultivos nitrificantes puede establecerse mediante la ecuación 17, donde qs es la velocidad específica de consumo de sustrato, para el presente caso, la velocidad específica de consumo de amonio; qp es la velocidad específica de formación del producto, es decir, la velocidad específica de producción de nitrato y $\mathrm{Yp}$ es el rendimiento de formación del producto (producción de nitrato). De este modo, los valores de qp están estrechamente relacionados con los valores de qs.

$q s=\frac{q p}{Y p} \quad$ Ec. 17

Asimismo, en términos de la ecuación de Monod y de acuerdo con la ecuación 18, los aumentos en la concentración de amonio (sustrato, S) se reflejarán en velocidades de consumo de amonio (qs) más altas.

$q s=\frac{q \max [S]}{(Y p(K s+[S]))} \quad$ Ec. 18

El aumento en la concentración de amonio, también podría resultar en la inducción de enzimas, particularmente en una mayor producción de la enzima AMO y/o en una mayor actividad de ésta, por lo que se podría promover el desarrollo o enriquecimiento de una 
comunidad microbiana AOB capaz de consumir mejor al amonio y al 2-CF (Martínez-Jardines y col., 2019).

Continuando con el comportamiento cinético, vale la pena recordar que existen datos sobre el efecto inhibitorio del 2-CF sobre el proceso nitrificante en ensayos en lote, cuando en presencia de $100 \mathrm{mg}$ de $\mathrm{N}-\mathrm{NH}_{4}{ }^{+} / \mathrm{L}$ y con $200 \mathrm{mg}$ de proteína microbiana/L de lodos sin contacto previo a materia orgánica, se adicionan desde 2.5 y hasta 10 mg C-2-CF/L (Martínez-Hernández y col., 2011; Pérez-Alfaro y col., 2013). También se ha encontrado que cuando en ensayos en lote se incrementa la concentración de amonio a 200 y hasta $500 \mathrm{mg} \mathrm{N} / \mathrm{L}$, es posible observar cierta actividad amonio y nitrito oxidante aún en presencia de $5 \mathrm{mg} \mathrm{C}-2-\mathrm{CF} / \mathrm{L}$ (Pérez-Alfaro, 2015). Con anterioridad se ha evidenciado en reactores SBR, el efecto inhibitorio de $60 \mathrm{mg}$ de C-2-CF/L sobre el proceso respiratorio del lodo nitrificante (358 mg de proteína microbiana/L) utilizado en este estudio, en donde las $\mathrm{qN}^{-\mathrm{NH}_{4}}{ }^{+}$y $\mathrm{qN}^{-\mathrm{NO}_{3}}{ }^{-}$disminuyeron un 98 y $65 \%$ respectivamente de acuerdo a un control sin el compuesto clorado (qN-NH${ }_{4}{ }^{+}$control de 980.5 $\mathrm{mg} / \mathrm{g}$ proteína d y qN-NO${ }_{3}{ }^{-}$control de $131.8 \mathrm{mg} / \mathrm{g}$ proteína d). De hecho, se observó un mayor efecto inhibitorio del 2-CF sobre la cinética del proceso amonio oxidante que sobre el proceso nitrito oxidante (Martínez-Jardines, 2015). Es importante señalar que en el presente estudio se siguió presentando la inhibición del 2-CF, puesto que en el ciclo 1 de operación las qN-NH${ }_{4}^{+}$y $\mathrm{qN}^{-\mathrm{NO}_{3}}{ }^{-}$fueron menores que las encontradas en el control sin 2-CF. Sin embargo, con el aumento en la concentración de amonio y el transcurso de los ciclos de operación, el efecto inhibitorio de este compuesto sobre la amonio oxidación disminuyó, puesto que en el ciclo 13 de operación con $500 \mathrm{mg}$ de $\mathrm{N}-\mathrm{NH}_{4}{ }^{+} / \mathrm{L}$, la qN-NH${ }_{4}^{+}$solo disminuyó un $80 \%$ con respecto a un control sin 2-CF. Asimismo, es interesante mencionar que el efecto inhibitorio del 2-CF sobre el proceso nitrito oxidante desapareció, puesto que al final del ciclo 13, la $\mathrm{qN}^{-\mathrm{NO}_{3}}{ }^{-}$fue similar a la del control sin el compuesto clorado (149 mg/g proteína d) (Figura 22). La disminución del efecto inhibitorio del 2-CF sobre el proceso nitrificante observado en este trabajo, así como el aumento en las q nitrificantes, se puede asociar a diversos factores. Por ejemplo, a la exposición previa del lodo al 2-CF y al establecimiento previo de un proceso respiratorio completo con capacidad de consumir simultáneamente amonio y 2-CF en el sistema SBR, que pudo haber resultado en una mayor tolerancia del lodo a compuestos tóxicos o inhibidores, que le permitió 
desarrollar una mejora cinética para el consumo de compuestos recalcitrantes. Sin embargo, no se puede descartar la capacidad del lodo nitrificante para reparar los posibles daños ocasionados por el 2-CF a la membrana celular, como la rigidez de las membranas o sus cambios estructurales (Sikkema y col., 1995; Segura y col., 2004; Bernal y col., 2007), y/o una mejora en el transporte de amonio o en sus mecanismos (Pérez-Alfaro, 2015). A este respecto, se ha reportado que el amonio es introducido a las células a través de transporte pasivo por medio de dos mecanismos diferentes que no requieren gasto energético. Uno de ellos es la difusión simple, en la cual el $\mathrm{NH}_{4}{ }^{+}$puede ser impulsado a favor de un gradiente de concentración o un gradiente de potencial eléctrico y se observa a altas concentraciones de amonio; el segundo mecanismo es la difusión facilitada mediante canales iónicos y permeasas o proteínas transportadoras (transportadores especiales de amonio) (Khademi y col., 2004; Zheng y col., 2004). A altas concentraciones de amoníaco/amonio, la penetración pasiva de $\mathrm{NH}_{3}$ por la membrana puede ser suficientemente efectiva, mientras que a bajas concentraciones es necesario un sistema diferente de transporte como los canales de amonio (Lin y col., 2006). De acuerdo a lo anterior, se puede sugerir que, en el presente trabajo, el transporte de amonio a través de la membrana celular podría haberse dado por difusión simple, ya que se utilizaron altas concentraciones de amonio que fueron de 100 a $500 \mathrm{mg}$ N/L. De esta forma, las concentraciones más altas de amonio provocaron un transporte de amonio más rápido y, por lo tanto, aumentos en los valores de qN$\mathrm{NH}_{4}{ }^{+}$como se ha propuesto en otros trabajos (Khademi y col., 2004; Zheng y col., 2004; PérezAlfaro, 2015). Por último, el uso de sistemas SBR también tuvo un papel importante, puesto que se ha indicado que en este tipo de reactores es posible seleccionar algunos tipos de microorganismos y promover una mejora en su actividad metabólica y cinética (Bassin y col., 2012; Fernandes y col., 2013). Por ejemplo, para el caso particular de la nitrificación, los trabajos reportados por Texier y Gómez $(2004,2007)$, muestran que las velocidades específicas de consumo de amonio y producción de nitrato incrementan al transcurso de los ciclos de operación. Asimismo, se ha reportado que al utilizar sistemas SBR nitrificantes, el efecto inhibitorio de $p$-hidroxibenzaldehido (Téllez-Pérez y col., 2013), p-cresol y sus intermediarios (Silva y col., 2014), m-cresol (Zepeda y col., 2012) y 2-CF (Martínez-Jardines y col, 2019) sobre la nitrificación disminuye. En resumen, los resultados cinéticos en el consumo de amonio y del 2-CF obtenidos en el presente estudio podrían estar asociados al efecto de la continua exposición 
al amonio y al transcurso de los ciclos de operación, sin embargo, habría que considerar también el papel del cometabolismo.

Algunos autores han abordado el concepto de cometabolismo como la transformación de un compuesto llamado cosustrato, en presencia obligada de un sustrato durante el crecimiento o por células en reposo en ausencia del sustrato de crecimiento (García-Rivero y Peralta-Pérez, 2008) o bien como la capacidad de los microorganismos para consumir sustratos que no son de crecimiento, típicamente en presencia de un sustrato de crecimiento (Tran y col., 2013). Estas definiciones no permiten diferenciar entre cooxidación y cometabolismo. Una definición que permitiría diferenciarlos es la siguiente: el cometabolismo es la capacidad de los microorganismos para transformar un sustrato que no se usa como soporte de crecimiento en la presencia obligatoria de un sustrato de crecimiento o un compuesto fácilmente transformable o biodegradable en condiciones aerobias o anaerobias; como su nombre indica, el sustrato que no se utiliza como soporte de crecimiento no es compatible con el crecimiento microbiano, y no produce carbono ni beneficio energético para las células (Dalton y Stirling, 1982; Arp y col., 2001; Jesus y col., 2016). Se han reportado varios trabajos donde un cultivo bacteriano en condiciones aerobias degrada cometabólicamente compuestos recalcitrantes como el 3,5diclorofenol (DCF), 3,4,5-triclorofenol (TCF), y 2,3,5,6-tetraclorofenol (TRCF) y utiliza pentaclorofenol (PCF) como sustrato de crecimiento (Liu y col., 1991). Asimismo, en sistemas SBR inoculados con lodos activados y alimentados con fenol como sustrato de crecimiento, se obtuvo la biotransformación cometabólica de 3-clorofenol (3-CF) (Chiavola y col., 2004) y 4CF (Monsalvo y col., 2009). Existe una gama muy amplia de compuestos recalcitrantes que se ha reportado se degradan por cometabolismo en condiciones aerobias utilizando como sustrato de crecimiento al amonio, tales como el dicloroetileno (DCE), TCE, dicloroetano (DE), cloroformo (CF), tricloroetano y cloroetano (Arp y col., 2001; Jesus y col., 2016). Kocamemi y Çeçen (2007), mencionan que, en condiciones nitrificantes, la concentración relativa de amonio es crucial para la degradación cometabólica de compuestos como el tricloroetileno, puesto que independientemente de la concentración inicial de éste, la qN-NH${ }_{4}^{+}$aumenta con el aumento en la concentración de amonio. En condiciones nitrificantes con cultivos axénicos de Nitrosomonas europaea, donde el amonio es el sustrato primario, se ha reportado el cometabolismo de 
compuestos como el TCE, DE y CF (Arciero y col., 1989; Ely y col., 1997; Alvarez-Cohen y Speitel 2001). Sin embargo, en todos estos trabajos solo se presenta el consumo de sustratos y los autores no presentan velocidades específicas de consumo de los compuestos recalcitrantes ni su asociación al consumo de los sustratos primarios. De hecho, las velocidades específicas de consumo pueden ser un criterio más para evaluar el comportamiento cometabólico en los sistemas biológicos. Al respecto, se ha mencionado que la relación entre las velocidades específicas de consumo de sustratos (primario y cosustrato) es una característica del cometabolismo (Kocamemi y Çeçen 2010). Estos autores han reportado que el rendimiento de la biotransformación de tricloroetileno (TCE) está fuertemente correlacionado con las concentraciones iniciales de este compuesto y las de $\mathrm{N}-\mathrm{NH}_{4}{ }^{+}$, de forma que las velocidades de consumo de ambos incrementan con el aumento en la concentración inicial de ambos compuestos. Asimismo, con un lodo activado con actividad nitrificante alimentado con concentraciones altas de amonio y una variedad de microcontaminantes, se ha reportado que mientras mayor sea la velocidad de consumo del sustrato primario por las bacterias, mayor será la velocidad para consumir los microcontaminantes (Fernandez-Fontaina y col., 2012).

En el presente trabajo, se encontró que existe una relación directa y significativa entre la velocidad específica de consumo de amonio y la velocidad específica de consumo de $2-\mathrm{CF}$ (Figura 23); de hecho, se determinó una correlación de Pearson (r) positiva de 0.83 entre ambas velocidades. El aumento correlacionado de ambas velocidades es un indicativo de que suceden fenómenos cometabólicos (Kocamemi y Çeçen 2010), donde el amonio puede estar actuando como sustrato para el crecimiento y mantenimiento de la célula, así como para la transformación biológica del 2-CF. Por tanto, considerando la correlación entre las velocidades de consumo de sustratos y de acuerdo con Kocamemi y Çeçen (2010), el valor significativo de la r (0.83) es una evidencia del consumo cometabólico de 2-CF en condiciones nitrificantes. Bajo las condiciones experimentales establecidas en el presente estudio, al aumentar la concentración de amonio se propiciaría un aumento en la actividad biológica de las bacterias AOB que producen más enzima AMO, no solo para la oxidación del amonio, sino también para la degradación cometabólica de diferentes compuestos recalcitrantes. Es importante mencionar que el modo de operación de los 
reactores SBR también promovió una adaptación metabólica y cinética de los lodos nitrificantes y que contribuye al incremento en las qC-2-CF y qN-NH${ }_{4}^{+}$a lo largo de los ciclos de operación.

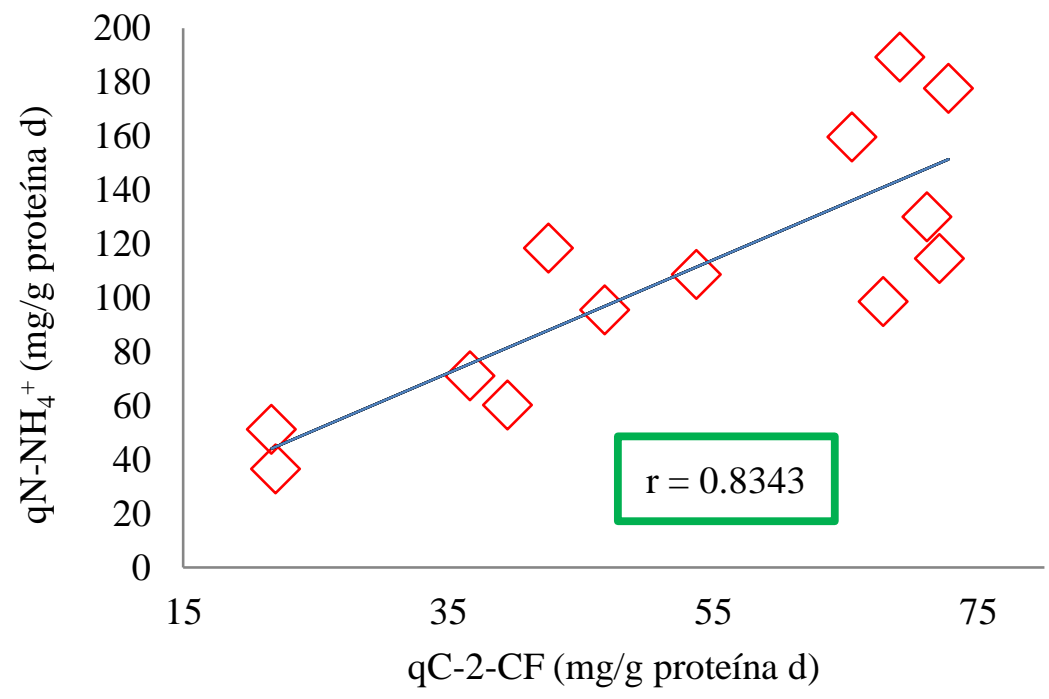

Figura 23. Perfil de correlación de la velocidad específica de consumo de amonio $\left(\mathrm{qN}-\mathrm{NH}_{4}{ }^{+}\right)$con la velocidad específica de consumo de 2-CF (qC-2-CF).

\subsection{Participación de la enzima AMO en el consumo de 2-CF}

Con el fin de determinar la participación de la enzima AMO en el consumo cometabólico de 2-CF, se realizaron ensayos en lote en botellas serológicas tanto al lodo nitrificante utilizado para inocular los reactores SBR como al lodo obtenido al final de los 13 ciclos de operación. De acuerdo con la metodología presentada, se realizaron cuatro tipos de ensayos: 1. Ensayos

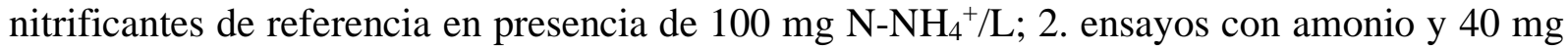
de aliltiourea/L (ATU) como inhibidor específico de la AMO (Silva y col., 2009); 3. ensayos con amonio y $5 \mathrm{mg}$ de C-2-CF/L y 4. ensayos con amonio, 2-CF y ATU. Los resultados obtenidos se presentan a continuación.

Los ensayos nitrificantes de referencia realizados con el lodo utilizado como inóculo de los reactores SBR (Figura 24a), mostraron que a los 10 días de cultivo se obtuvo una eficiencia 
de consumo de $\mathrm{N}-\mathrm{NH}_{4}{ }^{+}$de $99.3 \pm 0.1 \%$ y un rendimiento de producción de nitrato de $0.96 \pm 0.01$, indicando que el proceso nitrificante se llevó a cabo adecuadamente, puesto que todo el amonio se consumió y oxidó a nitrato. Bajo estas condiciones, las qN-NH${ }_{4}^{+}$y qN-NO${ }_{3}^{-}$fueron $402.9 \pm 0.1$ mg de $\mathrm{N}$ consumido/g proteína d y $154.9 \pm 4.6 \mathrm{mg}$ de $\mathrm{N}$ producido/g proteína $\mathrm{d}$ respectivamente (Tabla 11). En el ensayo nitrificante en presencia de ATU (Figura 24b), no se observó consumo de amonio ni producción de nitrito a lo largo de los 10 días de cultivo, lo cual corroboró la eficacia de la aliltiourea como compuesto inhibitorio de la enzima AMO (Ginestet y col., 1998; Silva y col., 2009).

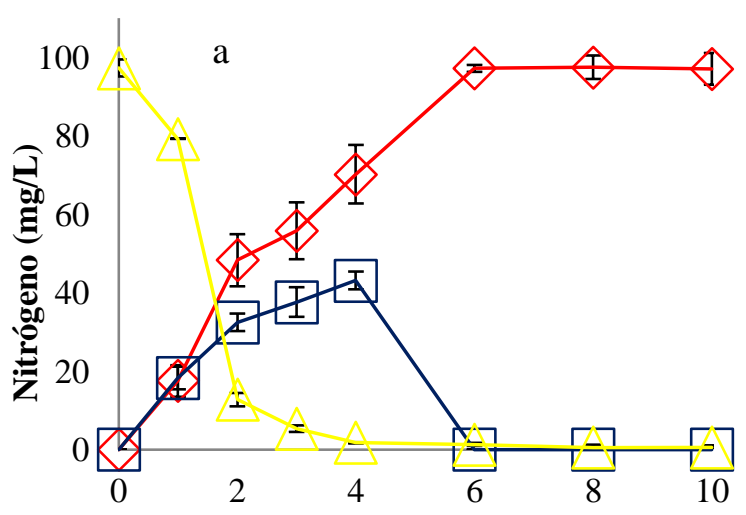

Tiempo (d)

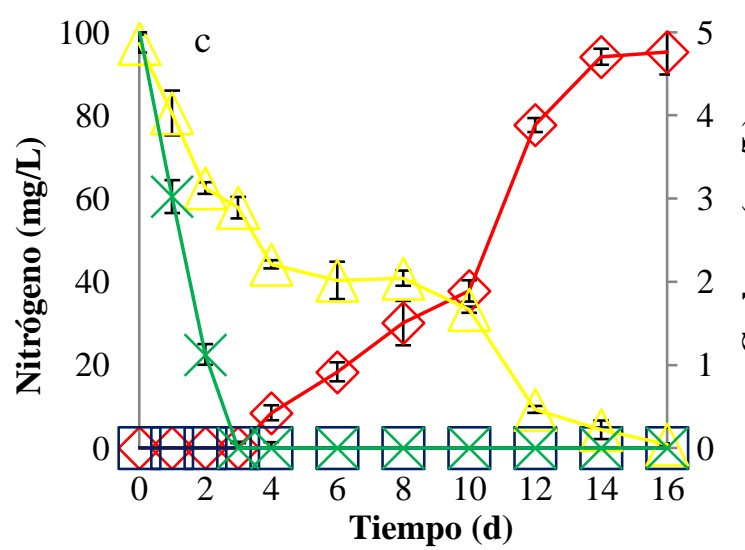

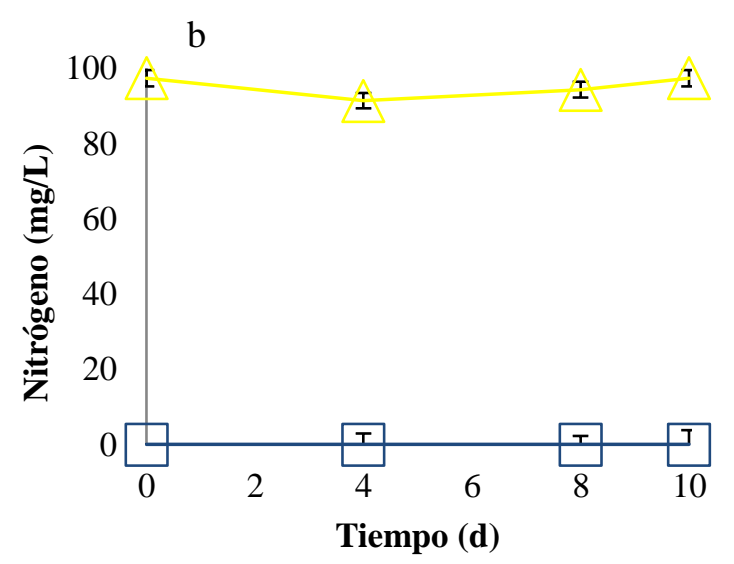

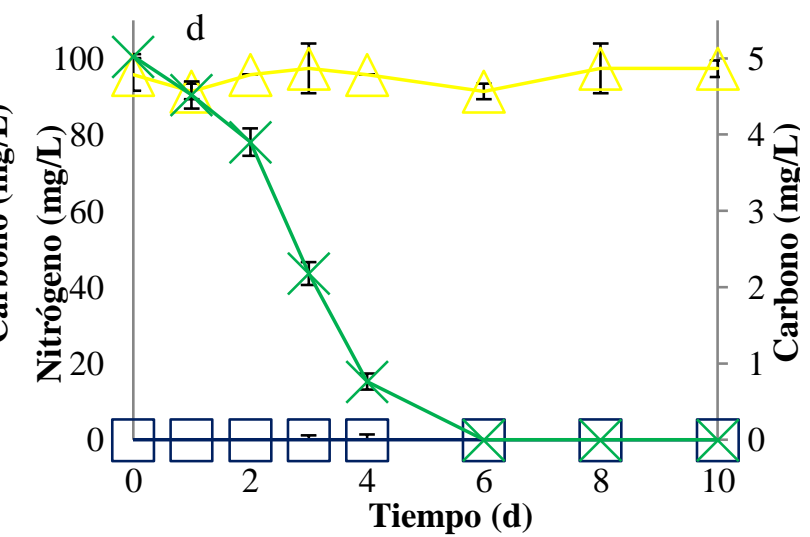

Figura 24. Perfiles de los ensayos en lote previos a la inoculación de los SBR: Nitrificación de referencia (a), Nitrificación con ATU (b), Nitrificación con 2-CF (c) y Nitrificación, 2-CF y ATU (d). Amonio ( $\triangle$ ), Nitrito ( $\square$ ), Nitrato $(\diamond)$ y 2 -CF $(\times)$. 
Tabla 11. Variables de respuesta en los ensayos en lote nitrificantes en presencia y ausencia de aliltiourea.

\begin{tabular}{|c|c|c|c|c|c|c|}
\hline Ensayo & EN-NH${ }_{4}^{+}$ & $\mathrm{YN}^{-\mathrm{NO}_{3}}{ }^{-}$ & $\mathrm{qN}^{-\mathrm{NH}_{4}}{ }^{+}$ & $\mathrm{qN}^{\mathrm{N} \mathrm{NO}_{3}}$ & $\mathrm{qC}-2-\mathrm{CF}$ & Biomasa \\
\hline \multicolumn{7}{|c|}{ Inicio } \\
\hline $\mathrm{NH}_{4}{ }^{+}$ & $99.3 \pm 0.1$ & $0.96 \pm 0.01$ & $402.9 \pm 0.1$ & $154.9 \pm 4.6$ & ND & $213.5 \pm 0.7$ \\
\hline $\mathrm{NH}_{4}^{+}+\mathrm{ATU}$ & 0 & 0 & 0 & 0 & ND & $203.0 \pm 4.2$ \\
\hline $\mathrm{NH}_{4}^{+}+2-\mathrm{CF}$ & $99.1 \pm 0.3$ & $0.98 \pm 0.10$ & $33.9 \pm 1.6$ & $49.27 \pm 2.0$ & $12.95 \pm 0.31$ & $209.1 \pm 5.6$ \\
\hline $\mathrm{NH}_{4}^{+}+2-\mathrm{CF}+\mathrm{ATU}$ & 0 & 0 & 0 & 0 & $8.51 \pm 0.40$ & $207.8 \pm 1.4$ \\
\hline \multicolumn{7}{|c|}{ Final } \\
\hline $\mathrm{NH}_{4}^{+}$ & $99.4 \pm 0.1$ & $1.00 \pm 0.02$ & $421.9 \pm 32.0$ & $103.2 \pm 8.0$ & ND & $208.5 \pm 2.2$ \\
\hline $\mathrm{NH}_{4}{ }^{+}+\mathrm{ATU}$ & 0 & 0 & 0 & 0 & ND & $205.5 \pm 3.5$ \\
\hline $\mathrm{NH}_{4}{ }^{+}+2-\mathrm{CF}$ & $99.6 \pm 0.1$ & $0.98 \pm 0.01$ & $166.5 \pm 3.1$ & $139.6 \pm 3.4$ & $13.69 \pm 1.81$ & $202.5 \pm 0.7$ \\
\hline $\mathrm{NH}_{4}{ }^{+}+2-\mathrm{CF}+\mathrm{ATU}$ & 0 & 0 & 0 & 0 & $6.45 \pm 0.17$ & $206.5 \pm 0.7$ \\
\hline \multicolumn{7}{|c|}{ 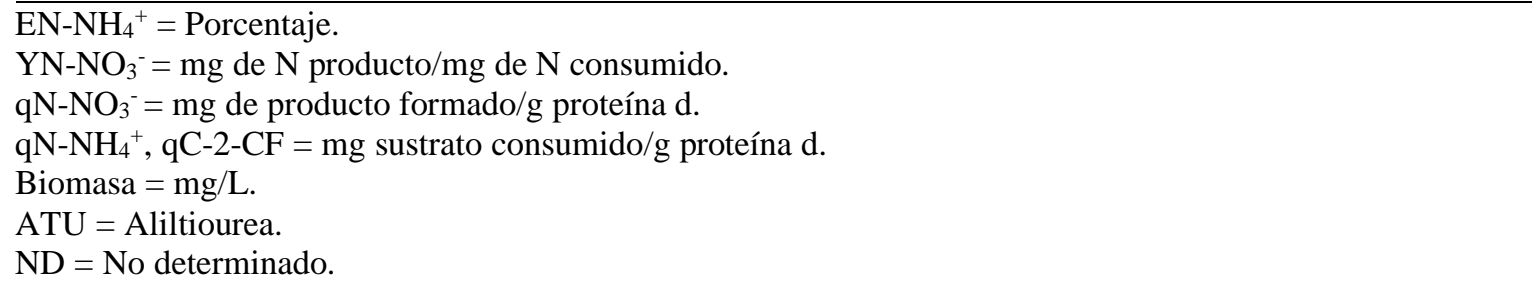 } \\
\hline
\end{tabular}

En el ensayo en lote con $100 \mathrm{mg}$ de $\mathrm{N}_{-} \mathrm{NH}_{4}{ }^{+} / \mathrm{L}$ y $5 \mathrm{mg} \mathrm{C}-2-\mathrm{CF} / \mathrm{L}$, el lodo con el que se inocularon los reactores mostró una nitrificación completa después de 16 días de cultivo y un consumo de 2-CF del 100\% en 3 días (Figura 24c), indicando la capacidad del lodo nitrificante para llevar a cabo el proceso nitrificante en presencia de 2-CF. En la Figura 24d, se presenta el ensayo nitrificante con $100 \mathrm{mg}$ de $\mathrm{N}_{-} \mathrm{NH}_{4}{ }^{+} / \mathrm{L}, 5 \mathrm{mg} \mathrm{C}-2-\mathrm{CF} / \mathrm{L}$ y adicionado con ATU, donde se observa claramente que por la acción del inhibidor sobre la actividad de la enzima AMO, no hay consumo de amonio ni presencia de nitrito. Asimismo, bajo estas condiciones se conserva el consumo total de 2-CF, sin embargo, se requiere de un tiempo mayor para lograrlo, aumentando de 3 a 6 días. En los ensayos adicionados con ATU, el incremento en el tiempo requerido para el consumo del 2-CF estuvo asociado con una disminución en su velocidad de consumo (Tabla 11). De hecho, cuando la actividad de la enzima AMO fue inhibida por la ATU,

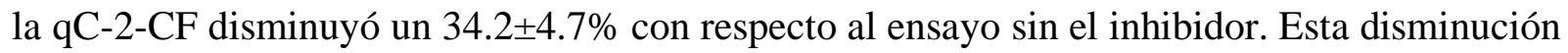
en la velocidad específica indica la participación de la AMO en el consumo de 2-CF. Las qC-2CF obtenidas en los ensayos nitrificantes en ausencia y presencia de ATU se compararon mediante un análisis estadístico de homogeneidad de coeficientes, el cual mostró una diferencia significativa entre ambas velocidades $(\alpha=0.025)$. Pérez-Alfaro (2015), encontró resultados 
similares en ensayos en lote con un lodo nitrificante sin previa exposición a compuestos fenólicos, al determinar que la AMO participa en el consumo de 2-CF.

Los ensayos nitrificantes realizados con el lodo obtenido al finalizar la experimentación en los reactores SBR (una vez transcurridos 13 ciclos de operación), mostraron una EN-NH${ }_{4}^{+}$ de $99.4 \pm 0.1 \%$ y un rendimiento de producción de nitrato de $1.00 \pm 0.02$ en 10 días de cultivo, mientras que las $\mathrm{qN}^{-\mathrm{NH}_{4}}{ }^{+}$y $\mathrm{qN}-\mathrm{NO}_{3}{ }^{-}$fueron $421.9 \pm 32.0$ y $103.2 \pm 8.0 \mathrm{mg} / \mathrm{g}$ proteína d respectivamente (Tabla 11, Figura 25a). Asimismo, en el ensayo nitrificante adicionado con ATU, tampoco se presentó consumo de amonio ni producción de nitrito o nitrato (Figura 25b). Cuando se adicionaron $100 \mathrm{mg}$ de $\mathrm{N}_{-} \mathrm{NH}_{4}{ }^{+} / \mathrm{L}$ y $5 \mathrm{mg} \mathrm{C}-2-\mathrm{CF} / \mathrm{L}$, se encontró que tanto el amonio como el 2-CF se consumieron total y simultáneamente entre 3 y 4 días, mientras que la completa formación de nitrato ocurrió en 6 días (Figura 25c), es decir, se requirió de un tiempo menor para llevar a cabo el proceso nitrificante. El menor tiempo requerido para realizar la nitrificación estuvo asociado con un aumento en las $\mathrm{qN}^{-\mathrm{NH}_{4}}{ }^{+}$y $\mathrm{qN}-\mathrm{NO}_{3}{ }^{-}$, las cuales bajo estas condiciones incrementaron 4.9 y 2.8 veces respectivamente. Este comportamiento se puede deber a la mejora en la actividad cinética y metabólica del lodo nitrificante adquirida durante los ensayos en el SBR al aumentar la concentración de amonio alimentado. Cuando a este lodo se le adicionó ATU, no se presentó consumo de amonio ni formación de nitrito, sin embargo, se siguió presentando el consumo total de 2-CF, aunque en un tiempo mayor al requerido en el ensayo sin inhibidor (Figura 25d). Igualmente, al comparar las velocidades obtenidas de consumo de 2CF en ausencia y presencia de ATU, el análisis estadístico de homogeneidad de coeficientes evidenció una diferencia significativa entre ambas $(\alpha=0.025)$. En estos ensayos, cuando la actividad de la enzima AMO fue inhibida por ATU, la q C-2-CF disminuyó un 52.3 $\pm 7.7 \%$ con respecto al ensayo sin el inhibidor. Esta disminución en la qC-2-CF fue mayor que la obtenida en los ensayos con el lodo utilizado como inóculo de los reactores SBR, donde la disminución en la qC-2-CF fue de un 34.2 $\pm 4.7 \%$. Esto evidencia claramente que después de exponer el lodo nitrificante a concentraciones crecientes de amonio, la participación de la AMO en el consumo

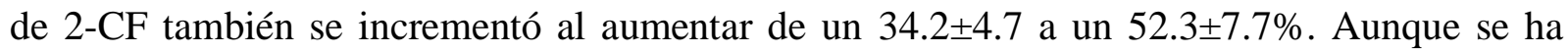
reportado que el proceso amonio oxidante es más sensible y se afecta por la presencia de compuestos orgánicos (Zepeda y col., 2003), o por la presencia de 2-CF (Martínez-Hernández 
y col., 2011; Pérez-Alfaro y col., 2013; Martínez-Jardines, 2015), en el presente trabajo el incremento en la participación de la enzima AMO para consumir 2-CF también es una evidencia de que el consumo de 2-CF por el lodo nitrificante ocurrió por cometabolismo.
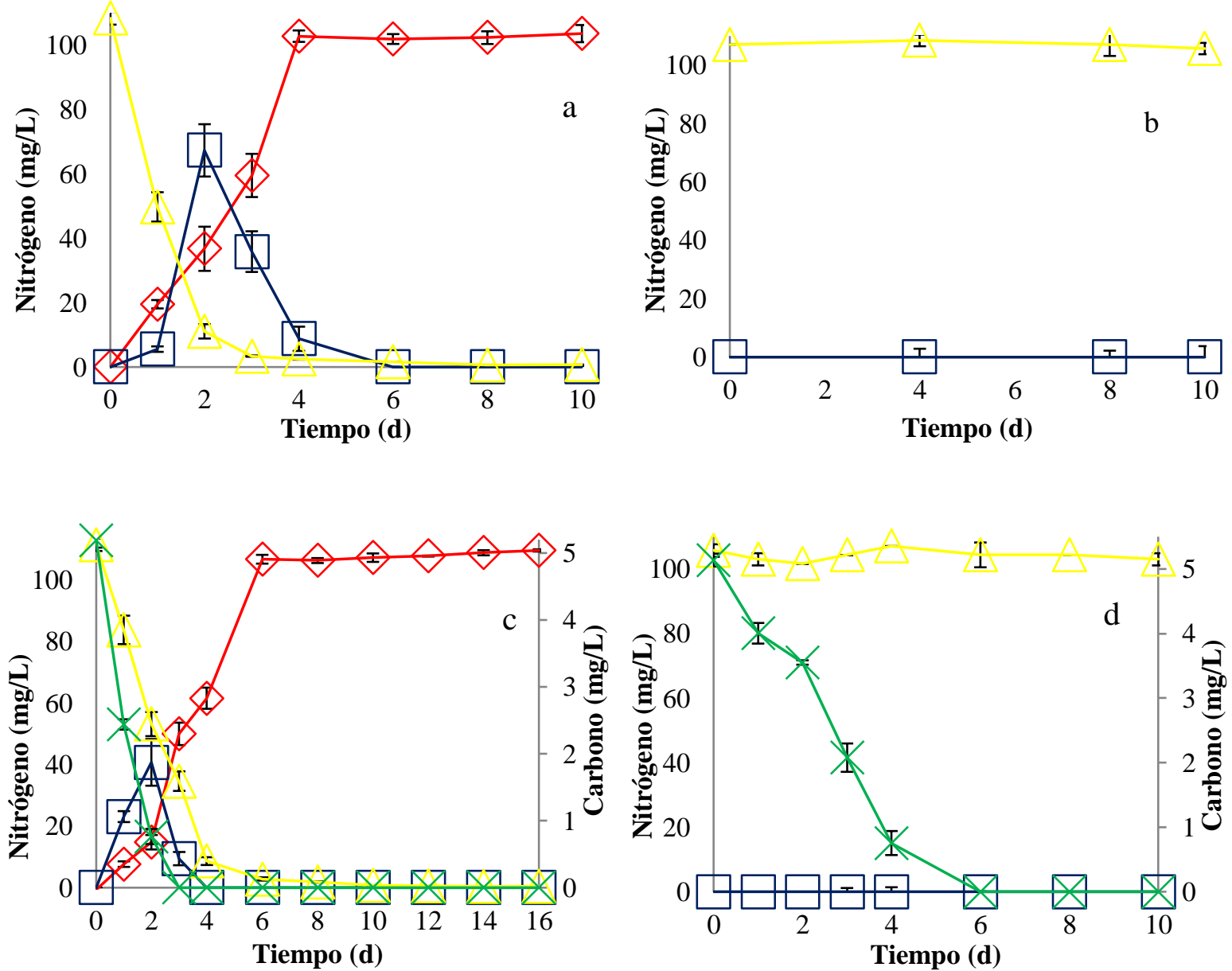

Figura 25. Perfiles de los ensayos en lote posteriores a la experimentación en los SBR: Nitrificación de referencia (a), Nitrificación con ATU (b), Nitrificación con 2-CF (c) y Nitrificación, 2-CF y ATU (d). Amonio ( $\triangle$ ), Nitrito $(\square)$, Nitrato $(\diamond)$ y $2-\mathrm{CF}(X)$.

En la literatura se ha reportado la relación entre la velocidad específica nitrificante y la velocidad específica de biodegradación de microcontaminantes de un lodo activado nitrificante alimentado con diferentes concentraciones de amonio (40-500 $\left.\mathrm{mg} \mathrm{N}^{-\mathrm{NH}_{4}}{ }^{+} / \mathrm{L}\right)$ y entre 10-20 ppb de microcontaminantes (ibuprofeno (IBP), naproxeno (NPX), trimetoprim (TMP), eritromicin (ERY), roxitromicin (ROX), fluoxetina (FLX), (galaxolida (HHCB) y tonalida (AHTN)), los cuales se degradaron cometabólicamente. Aunque los autores no determinaron la participación 
de la enzima $\mathrm{AMO}$ en el proceso, proponen que ésta podría ser la responsable del efecto cometabólico (Fernandez-Fontaina y col., 2012). Por otro lado, se ha reportado que la oxidación de disolventes clorados mediante la reacción con una oxigenasa, genera productos que pueden reaccionar con macromoléculas celulares o pueden hidrolizarse espontáneamente en dióxido de carbono, cloruro u otros productos no volátiles fácilmente mineralizables por microorganismos (Alvarez-Cohen y Spietel, 2001). Se sabe también que una amplia gama de microorganismos que expresan oxigenasas y utilizan al amonio como fuente de energía, pueden oxidar disolventes clorados (Arciero y col., 1989, Vannelli y col., 1990). En cultivos de Nitrosomonas europaea, la enzima AMO puede oxidar compuestos alifáticos y aromáticos halogenados y no halogenados, como metilbromuro, 1,2-dicloropropano, 1,2-dibromo-3cloropropano, tricloro etileno, etano, cloropropano, tolueno, benceno y fenol (Keener y Arp 1994; Hyman y col., 1995; Alvarez-Cohen y Spietel 2001). También ha sido observada la oxidación de fenol, benceno y 2CF por un lodo nitrificante asociada al consumo y oxidación de amonio (Zepeda y col., 2003; Silva y col., 2011; Martínez-Jardines y col., 2019). Sin embargo, en ninguno de estos trabajos fue evaluada la participación de la AMO en el consumo de estos compuestos. Asimismo, se ha sugerido que la enzima AMO de bacterias amonio oxidantes, juega un papel importante en la biodegradación cometabólica de diversos contaminantes orgánicos $(\mathrm{CO})$, puesto que bajo condiciones nitrificantes y en sistemas alimentados en continuo, se observa que, al aumentar la velocidad de carga de amonio, se consigue una mayor biodegradación de los contaminantes (Tran y col., 2013). Estos autores proponen que la presencia de un sustrato de crecimiento promueve la biodegradación cometabólica de los CO.

En todos estos trabajos se puede observar que aunque se ha reportado el consumo cometabólico de compuestos recalcitrantes por lodos nitrificantes, o el consumo de estos compuestos por la enzima AMO, en ninguno de ellos se ha evidenciado el consumo cometabólico de compuestos clorofenólicos por la enzima AMO, en específico del 2-CF. Recordando que en los ensayos realizados en el presente trabajo en los reactores SBR, al aumentar la concentración de amonio se favoreció el consumo de éste y que tanto las qN-NH${ }_{4}^{+}$ como las q C-2-CF aumentaron simultáneamente, el hecho de que en los lodos nitrificantes operados durante 13 ciclos en presencia de 2-CF, la participación de la AMO en el consumo del 
2-CF aumentó, indica que la enzima AMO está involucrada en el consumo cometabólico de 2CF. De esta forma, este trabajo aporta evidencias claras de que, en el consorcio nitrificante, la participación de la enzima AMO en el consumo cometabólico de 2-CF se incrementa al aumentar la concentración de amonio alimentado. Estos resultados pueden ser atribuidos al incremento de la concentración de amonio como sustrato de crecimiento en los ensayos SBR, que propició un aumento en la cantidad y/o actividad de las bacterias AOB y/o en la cantidad de enzima AMO producida por estas bacterias a lo largo de la operación de los reactores SBR.

\subsection{Extracción, amplificación y purificación de ADN de los lodos nitrificantes en presencia de 2-CF y diferentes concentraciones iniciales de amonio en el reactor $S B R$}

Para observar el efecto de la concentración inicial de amonio en presencia de 2-CF sobre la dinámica poblacional del lodo nitrificante se tomaron muestras de los lodos al final de cada uno de los 13 ciclos de operación en el reactor SBR. De cada una de ellas se realizó la extracción de ADN, amplificación de fragmentos del gen 16S ADNr usando cebadores bacterianos universales y posteriormente, se realizó la técnica de Electroforesis en Gel con Gradiente Desnaturalizante (DGGE). Consecutivamente se realizó la determinación de los cambios en las comunidades bacterianas mediante índices ecológicos y por último la identificación de especies bacterianas por medio de secuenciación.

En la Figura 26 se indican las muestras del lodo nitrificante $(0.27 \pm 0.03 \mathrm{~g})$ tomadas al final de cada ciclo de operación de los reactores SBR a fin de extraer el ADN. Se extrajo una concentración de ADN de 12.4 $\pm 5.4 \mathrm{ng} / \mu \mathrm{l}$, la cual fue evaluada mediante electroforesis (85 V, 45 min) en geles de agarosa al 1\%. La cuantificación del ADN extraído y la pureza del mismo se determinaron en un espectrofotómetro para micromuestras (NanoDrop 2000, Thermo Scientific) midiendo la absorbancia a $260 \mathrm{~nm}$ y la relación entre la absorbancia a 260 y a 280 nm, respectivamente. La relación 260/280 encontrada fue de 1.82 \pm 0.12 , indicando que las muestras obtenidas tuvieron una pureza adecuada. 


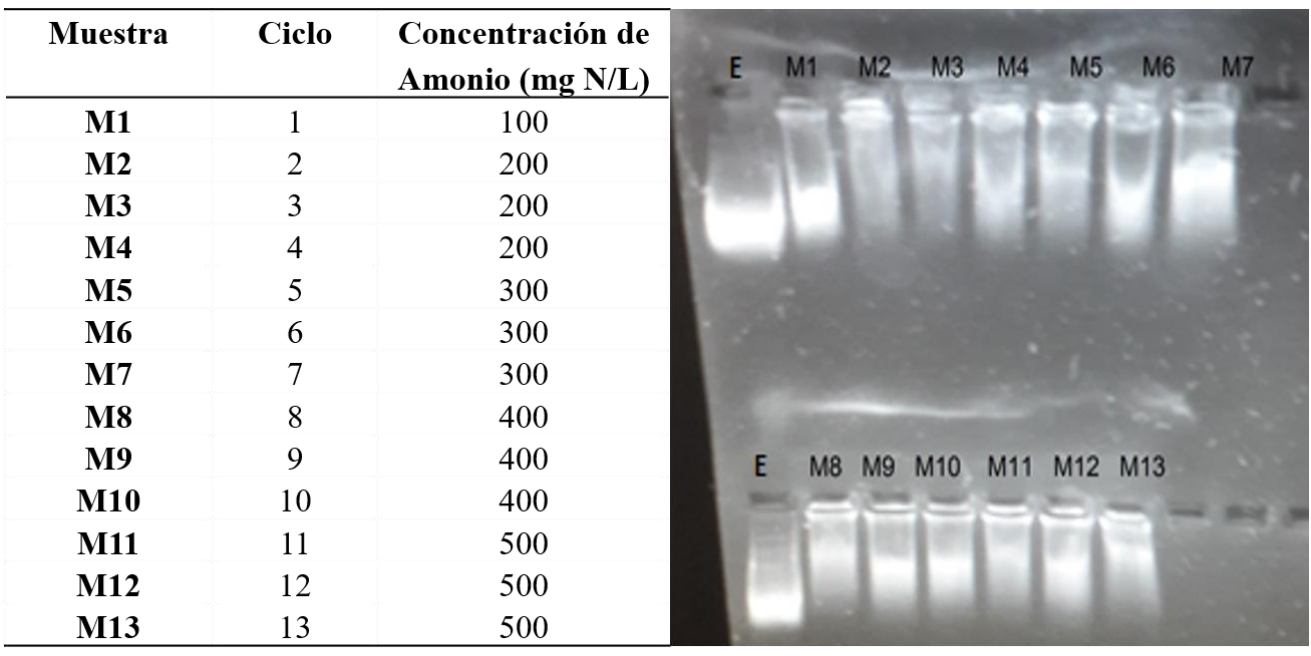

Figura 26. Extracción de ADN de los lodos nitrificantes a lo largo de los ciclos de operación con 60 mg de C-2$\mathrm{CF} / \mathrm{L}$ y con diferentes concentraciones iniciales de amonio. E: Escalera.

Posteriormente a la extracción de ADN se realizaron dos PCR y una purificación, obteniendo una concentración de $\mathrm{ADN}$ de $450.9 \pm 52.2 \mathrm{ng} / \mu \mathrm{l}$. Los resultados obtenidos de la electroforesis $(85 \mathrm{~V}, 45 \mathrm{~min})$ en geles de agarosa al 1\%, se observan en la Figura 27. Los resultados indican que todas las muestras se amplificaron y purificaron correctamente.

\begin{tabular}{|c|c|c|c|c|c|c|c|c|c|c|}
\hline Muestra & Ciclo & $\begin{array}{l}\text { Concentración de } \\
\text { Amonio (mg N/L) }\end{array}$ & E & M1 & M2 & M3 M4 & MS & M6 & M7 & E \\
\hline M1 & 1 & 100 & & & & & & & & \\
\hline M2 & 2 & 200 & & & & & & & & \\
\hline M3 & 3 & 200 & 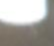 & & & & & & & \\
\hline M4 & 4 & 200 & & & & & & & & \\
\hline M5 & 5 & 300 & & & & & & & & \\
\hline M6 & 6 & 300 & & & & & & & & $\therefore$ \\
\hline M7 & 7 & 300 & & & & & & & & $\mathrm{E}$ \\
\hline M8 & 8 & 400 & $t$ & M8 & M9 & M10 & M12 & M13 & & \\
\hline M9 & 9 & 400 & & & & & 1 & & $2 x$ & \\
\hline M10 & 10 & 400 & & & & 8 & & & & \\
\hline M11 & 11 & 500 & & & & & & & & \\
\hline M12 & 12 & 500 & & & & & & & & \\
\hline M13 & 13 & 500 & & & & 1 & & & & . \\
\hline
\end{tabular}

Figura 27. Amplificación y purificación de ADN de los lodos nitrificantes a lo largo de los ciclos de operación con $60 \mathrm{mg}$ de C-2-CF/L y con diferentes concentraciones iniciales de amonio. E: escalera. 


\subsection{Dinámica poblacional del lodo nitrificante en presencia de 2-CF y diferentes concentraciones iniciales de amonio en el reactor SBR.}

El perfil de bandas de DGGE del lodo nitrificante obtenido a lo largo de los ciclos de operación se muestra en la Figura 28. Cabe recordar que, de acuerdo con la técnica de DGGE, cada una de las bandas encontradas en cada carril del gel se puede asociar a una especie bacteriana diferente entre sí y aquellas que se encuentran en la misma posición horizontalmente representan la misma especie.

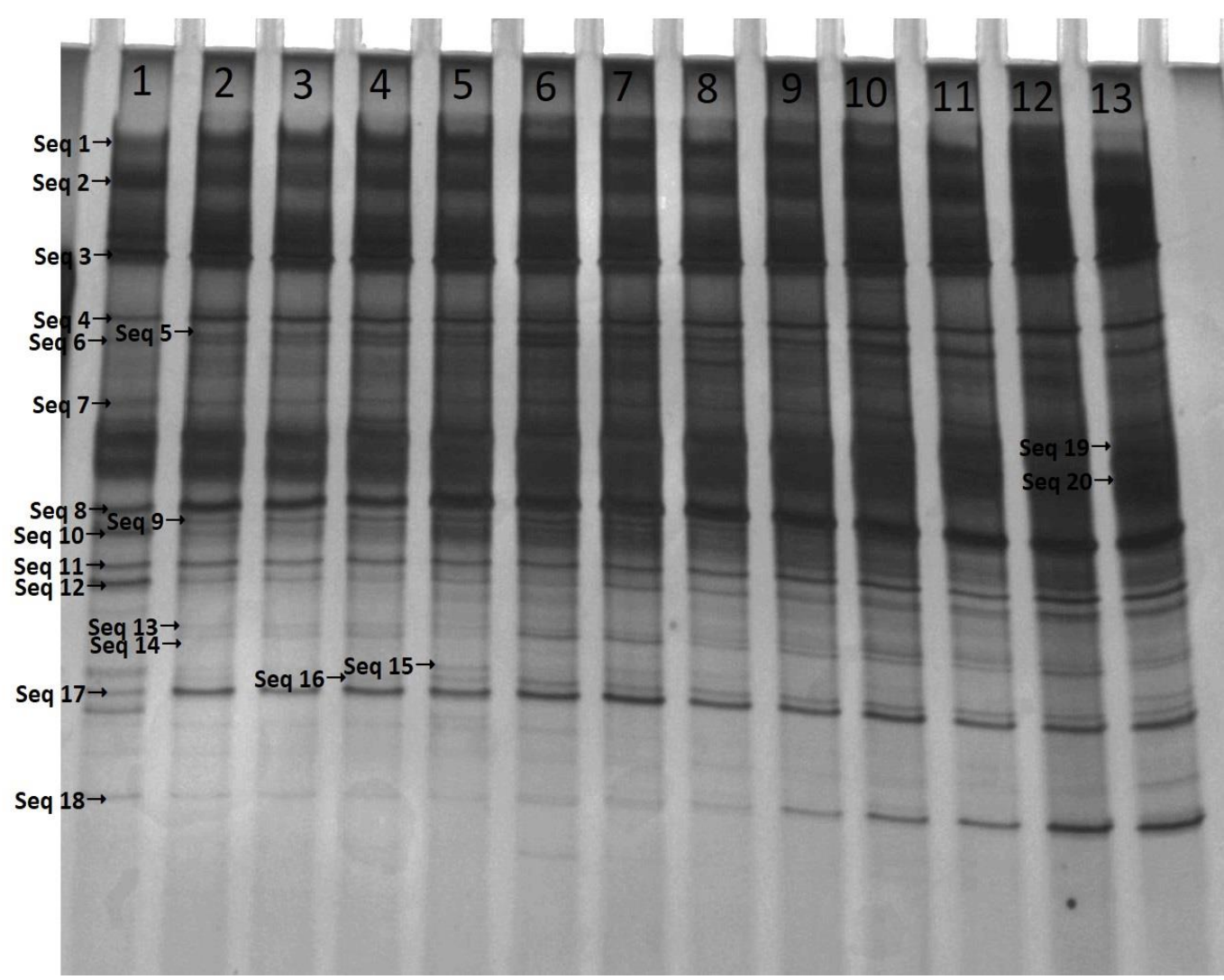

Figura 28. Análisis DGGE de las regiones V6 - V8 de 16S rDNA del lodo nitrificante a lo largo de los ciclos de operación con $60 \mathrm{mg}$ de C-2-CF/L y con diferentes concentraciones iniciales de amonio. Carril 1 con $100 \mathrm{mg}$ de $\mathrm{N}-\mathrm{NH}_{4}{ }^{+} / \mathrm{L}$ (ciclo 1 de operación), carril 2, 3 y 4 con $200 \mathrm{mg}$ de $\mathrm{N}-\mathrm{NH}_{4}+/ \mathrm{L}$ (ciclo 2, 3 y 4 de operación respectivamente), carril 5, 6 y 7 con $300 \mathrm{mg}$ de $\mathrm{N}^{-\mathrm{NH}_{4}}+\mathrm{L}$ (ciclo 5, 6 y 7 de operación respectivamente), carril 8, 9 y 10 con $400 \mathrm{mg}$ de N-NH${ }_{4}^{+} / \mathrm{L}$ (ciclo 8, 9 y 10 de operación respectivamente), carril 11, 12 y 13 con $500 \mathrm{mg}$ de N$\mathrm{NH}_{4}+/ \mathrm{L}$ (ciclo 11, 12 y 13 de operación respectivamente). Las bandas cortadas y secuenciadas se indican en el DGGE. 
Se ha reportado que la intensidad de las bandas se puede asociar a un cierto tamaño de población o bien a una cierta proporción de individuos (Nicolaisen y Ramsing, 2002; Liu y col., 2010). Por lo tanto, en un DGGE también se puede observar la dinámica poblacional en cuanto a la proporción de individuos. En la Figura 28 se pueden observar algunas diferencias en la posición e intensidad de las bandas en el gel de DGGE. A partir de esta Figura y con los datos obtenidos de las intensidades de banda mediante el programa image J se generó el Mapa de calor de la Figura 29. Durante el transcurso de los trece ciclos de operación en presencia de 2-CF y con el aumento en la concentración de amonio, se encontró un total de 276 bandas, de las cuales 39 especies fueron diferentes entre sí.

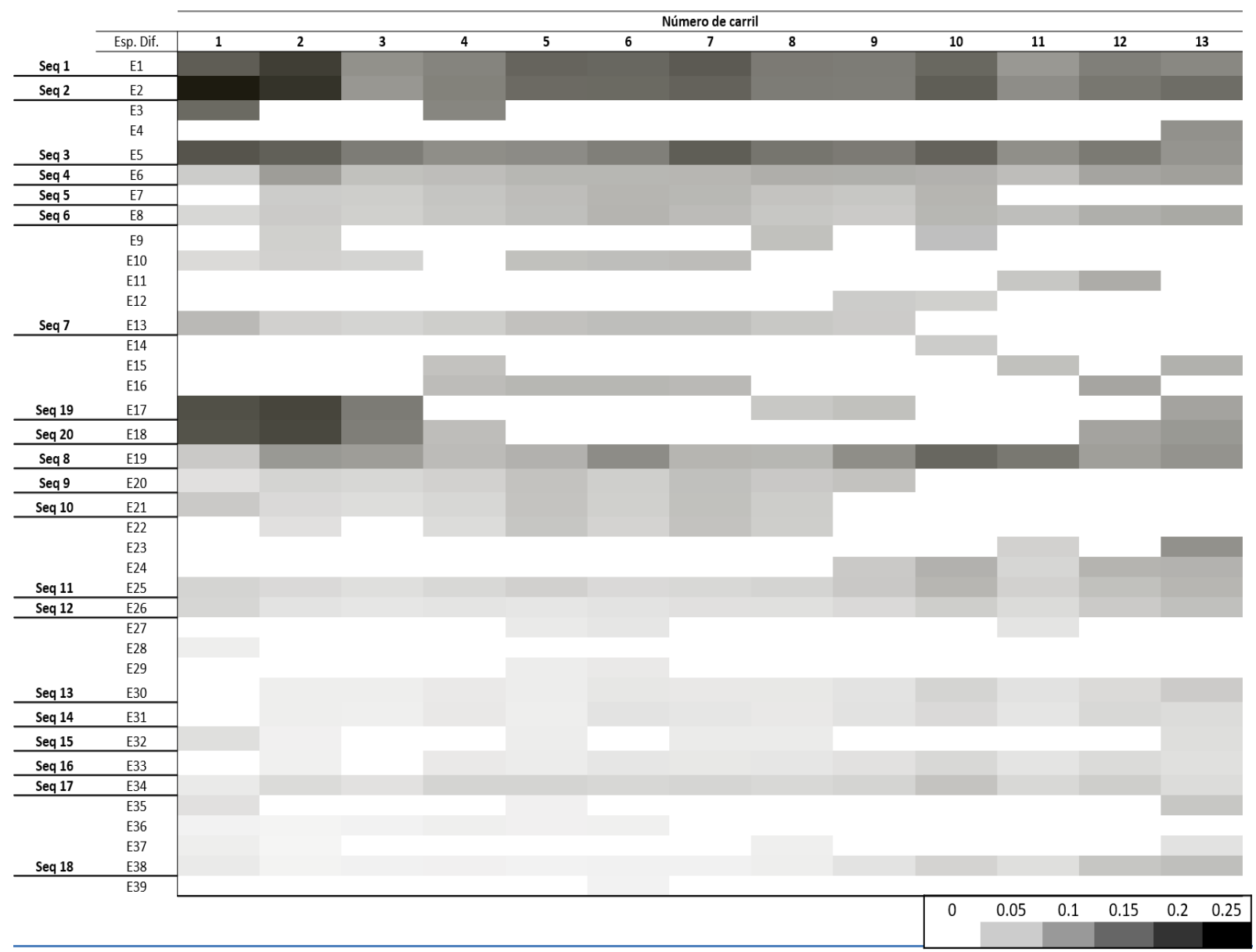

Figura 29. Mapa de calor generado a partir de las intensidades de banda del gel de DGGE del lodo nitrificante a lo largo de los ciclos de operación con $60 \mathrm{mg}$ de C-2-CF/L y con diferentes concentraciones iniciales de amonio. El color blanco indica ausencia o no detección de la especie y el color negro indica la mayor proporción de individuos encontrada. Las bandas secuenciadas se indican en la figura (primera columna). 
De acuerdo a la Figura 29 se pueden observar diferentes intensidades de banda con el aumento en la concentración de amonio y a lo largo de los ciclos de operación, en donde un color blanco indica ausencia o no detección de la especie correspondiente, un desplazamiento hacia colores más oscuros indica tanto la presencia de la especie como una mayor proporción de individuos encontrada. De acuerdo a lo anterior, la Figura 29 nos permite observar la dinámica poblacional del lodo nitrificante en términos de proporción de individuos presentes a lo largo de los ciclos de operación y asociados al aumento en la concentración de amonio. En la figura también se señalan las bandas que se cortaron y se secuenciaron.

Un análisis estadístico de frecuencia de aparición de especies en el lodo nitrificante, indicó que, a lo largo de la experimentación, de las 39 especies diferentes, 10 de ellas (Seq 1, 2, $3,4,6,8,11,12,17$ y 18.) siempre se mantuvieron presentes, 7 especies aparecieron con una frecuencia de 8 a 12 veces y 22 especies aparecieron con una frecuencia de 1 a 7 veces (Figura 30). De esta forma, el $25.6 \%$ de las especies encontradas en el DGGE se detectaron desde el inicio de la experimentación con $60 \mathrm{mg}$ de C-2-CF/L y $100 \mathrm{mg}$ de N-NH${ }_{4}{ }^{+} / \mathrm{L}$ y se mantuvieron aún con el aumento de hasta $500 \mathrm{mg}$ de $\mathrm{N}_{-} \mathrm{NH}_{4}{ }^{+} / \mathrm{L}$ y la presencia de $2-\mathrm{CF}$, lo que indica que estas especies fueron tolerantes y/o resistentes a los cambios e incrementos en la concentración de amonio y a la constante exposición al compuesto halogenado. El 74.4\% restante de las especies aparecieron y desaparecieron en diferentes ocasiones de la experimentación, indicando un cambio en la dinámica poblacional del lodo nitrificante, ocasionado por el incremento en la concentración de amonio y el transcurrir de los ciclos de operación. 


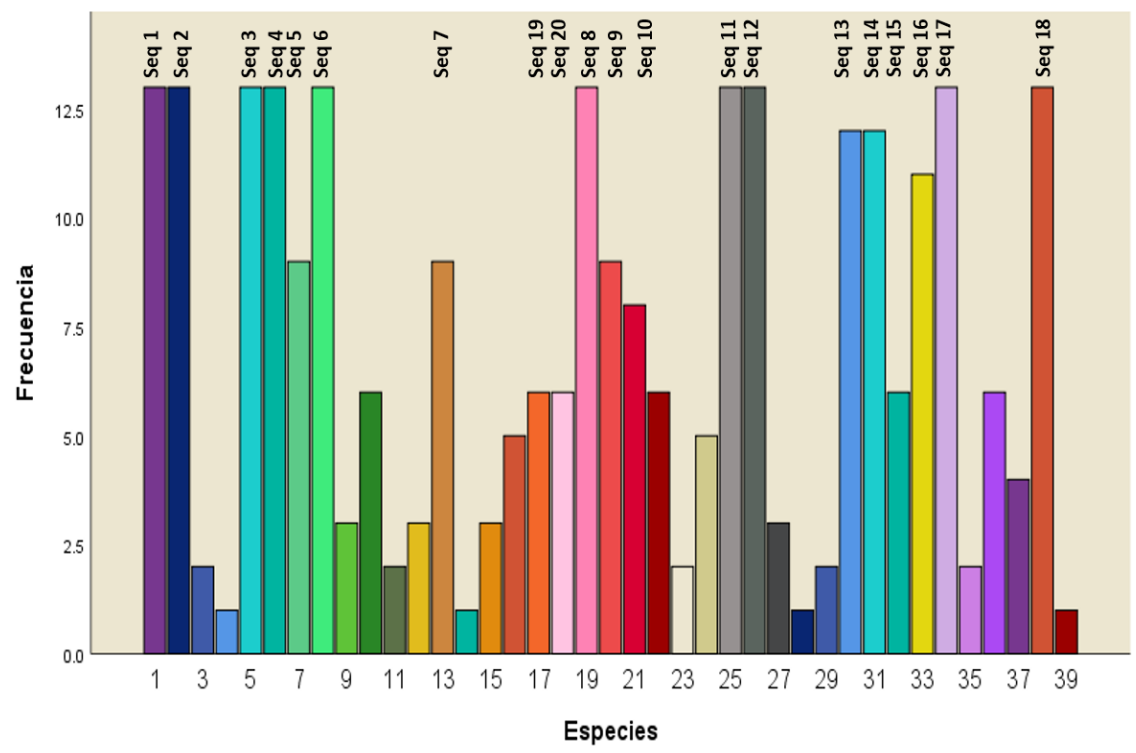

Figura 30. Análisis de frecuencia de aparición de las especies del lodo nitrificante a lo largo de los ciclos de operación con $60 \mathrm{mg}$ de C-2-CF/L y con diferentes concentraciones iniciales de amonio. Las bandas secuenciadas se indican en la figura.

Asimismo, el patrón de bandas del DGGE se analizó mediante los índices ecológicos S, H y J, cuyos cálculos se definieron en la Sección 5.7.3 de materiales y métodos. El índice $\mathrm{S}$ representa la riqueza de especies en la comunidad, el índice $\mathrm{H}$ refleja la diversidad mientras que el índice $\mathrm{J}$ (que varía entre 0 y 1 ) indica el predominio de especies en una comunidad microbiana, donde un valor de 0 representa el predominio de ciertas especies y 1 representa una población con una uniformidad perfecta en la comunidad. Todos estos índices se reportan en la Tabla 12. Al inicio de la experimentación con $100 \mathrm{mg}$ de $\mathrm{N}_{-} \mathrm{NH}_{4}{ }^{+} / \mathrm{L}$, el lodo nitrificante presentó un valor de $\mathrm{S}$ de 22 y con el incremento a $200 \mathrm{mg}$ de $\mathrm{N}_{-} \mathrm{NH}_{4}{ }^{+} / \mathrm{L}, \mathrm{S}$ aumentó hasta 25, sin embargo, después de dos ciclos con la misma concentración de amonio este índice disminuyó a 23. Un comportamiento similar se obtuvo con las concentraciones de 300 y $400 \mathrm{mg}$ de $\mathrm{N}_{-} \mathrm{NH}_{4}{ }^{+} / \mathrm{L}$, de forma que en el ciclo 10 de operación se obtuvo un índice $\mathrm{S}$ de 18. En el ciclo 11, con el último aumento a $500 \mathrm{mg}$ de $\mathrm{N}-\mathrm{NH}_{4}{ }^{+} / \mathrm{L}$, se obtuvo el mismo número de especies y en el ciclo 13 de operación se obtuvo una tendencia al incremento, puesto que se encontraron nuevamente 22 especies. Cabe destacar que de las 22 especies encontradas en el ciclo 1, 14 de ellas se mantuvieron hasta el final de la experimentación, es decir, aunque el número de especies al 
inicio y final de la experimentación fue el mismo (22 especies), solo el $63 \%$ de ellas fue el mismo (14 especies). El índice H se mantuvo entre 2.7 y 3.0 durante toda la experimentación.

Tabla 12. Índices ecológicos obtenidos a partir del gel de DGGE del lodo nitrificante a lo largo de los ciclos de operación con $60 \mathrm{mg}$ de C-2-CF/L y con diferentes concentraciones iniciales de amonio: Índices de riqueza de especies (S), diversidad estructural $(\mathrm{H})$ y equitatividad (J) de la comunidad microbiana nitrificante.

\begin{tabular}{|c|c|c|c|c|c|c|c|c|c|c|c|c|c|}
\hline \multicolumn{14}{|c|}{ Concentración de amonio (mg N/L) } \\
\hline \multirow[b]{2}{*}{ No. ciclo } & \multirow{2}{*}{$\begin{array}{c}100 \\
1 \\
\end{array}$} & \multicolumn{3}{|c|}{200} & \multicolumn{3}{|c|}{300} & \multicolumn{3}{|c|}{400} & \multicolumn{3}{|c|}{500} \\
\hline & & 2 & 3 & 4 & 5 & 6 & 7 & 8 & 9 & 10 & 11 & 12 & 13 \\
\hline $\mathbf{S}$ & 22 & 25 & 20 & 23 & 25 & 24 & 21 & 22 & 19 & 18 & 18 & 17 & 22 \\
\hline $\mathbf{H}$ & 2.75 & 2.83 & 2.76 & 2.97 & 2.98 & 2.95 & 2.85 & 2.91 & 2.81 & 2.76 & 2.75 & 2.75 & 3.07 \\
\hline $\mathbf{J}$ & 0.89 & 0.88 & 0.92 & 0.95 & 0.93 & 0.93 & 0.93 & 0.94 & 0.96 & 0.96 & 0.95 & 0.97 & 0.99 \\
\hline
\end{tabular}

Por otro lado, en el primer ciclo de operación el valor del índice J fue de 0.89 . Es notorio que a lo largo de los ciclos de operación y con el aumento en la concentración de amonio, el índice $\mathrm{J}$ tuvo una tendencia al incremento, de manera que en el último ciclo con $500 \mathrm{mg}$ de $\mathrm{N}$ $\mathrm{NH}_{4}{ }^{+} / \mathrm{L}$, alcanzó un valor de 0.99. Dado que este valor es muy cercano a uno y aunque se encontraron diferentes especies, puesto que las bandas no eran las mismas, las poblaciones microbianas fueron muy uniformes al final de la experimentación, es decir, no hubo predominio de especies dentro de la comunidad microbiana del lodo nitrificante. Cabe recordar que en el presente estudio se obtuvieron $\mathrm{EN}_{-} \mathrm{NH}_{4}{ }^{+}$cercanas al $100 \%,{\mathrm{YN}-\mathrm{NO}_{3}}^{-}$alrededor de 1 y EC-2-CP del $100 \%$. La eficiencia de consumo de compuestos, tanto nitrogenados como carbonados alta, así como una comunidad microbiana homogénea, coincide con lo reportado por Silva y col. (2014) quienes sugieren que el uso de sistemas SBR podría conducir a la obtención de una comunidad microbiana estable a lo largo de los ciclos de operación aun en la presencia de compuestos recalcitrantes como el $p$-cresol. Existen reportes en reactores SBR con lodos anaerobios que llevaron a cabo el consumo de mezclas de 2-CF y fenol, en los que se calcularon índices $\mathrm{J}$ mayores que 0.95 , indicando que a lo largo de los ciclos de operación las poblaciones microbianas fueron uniformes (Beristain-Montiel y col., 2015). Bajo estas condiciones los autores también reportaron eficiencias de consumo altas (91\%) y proponen que estos resultados podrían estar relacionados con la uniformidad de la comunidad microbiana. 
Del total de bandas registradas en el gel de DGGE, se secuenciaron veinte, correspondientes a las bandas DGGE que siempre estuvieron presentes y a las que aparecieron con mayor frecuencia (Figura 28). Con los resultados de la secuenciación, se realizó un primer BLAST utilizando la base de datos general del GenBank del NCBI, con el que se obtuvieron los parientes cercanos con su respectivo porcentaje de similitud (Tabla 13). Se puede observar que la mayoría de las secuencias se relacionan con aislados o clones de bacterias no cultivables y solo cuatro de las veinte secuencias se pueden relacionar con alguna especie representativa (Seq 6, 17, 18 y 20). Sin embargo, este primer BLAST proporciona información sobre el ambiente de dónde se obtuvieron la mayoría de las especies presentes en este trabajo. Por ejemplo, de lodos de agua potable (Ma y col., 2016), suelo geotérmico (Gomez-Alvarez, 2007), comunidades bacterianas de acuíferos (Handley y col., 2012), suelos de pasto, lixiviación séptica, reactores que realizan remoción de nitrógeno, comunidades metanotróficas y en la biodegradación de BTEX (Akmirza y col., 2017). Con la información de este BLAST, se realizó un primer árbol filogenético en el cual se encontró que el $45 \%$ de las bandas secuenciadas se agruparon como $\beta$-proteobacteria, el 30\% en el grupo de acidobacteria mientras que el 10 y $15 \%$ restantes en el de Deinococcus-thermus y $\gamma$-proteobacteria, respectivamente (Figura 31). 
Tabla 13. Identificación de secuencias de nucleótidos analizadas a partir de bandas DGGE del lodo nitrificante a lo largo de los ciclos de operación con $60 \mathrm{mg}$ de C-2-CF/L y con diferentes concentraciones iniciales de amonio utilizando la base de datos estándar del NCBI.

\begin{tabular}{cccc}
\hline $\begin{array}{c}\text { Banda cortada } \\
\text { del DGGE }\end{array}$ & Parientes cercanos & $\begin{array}{c}\text { \%de } \\
\text { Similitud }\end{array}$ & $\begin{array}{c}\text { \% de } \\
\text { Cobertura }\end{array}$ \\
\hline Seq1 & Uncultured Acidobacteria bacterium (GU046318.1) & 97.36 & 98 \\
Seq2 & Uncultured bacterium clone S-7 (KM243008.1) & 100 & 100 \\
Seq3 & Uncultured bacterium isolate DGGE (KU605593.1) & 88.71 & 100 \\
Seq4 & Uncultured bacterium clone (DQ791352.1) & 94.90 & 100 \\
Seq5 & Uncultured bacterium clone (HM277052.1) & 96.69 & 100 \\
Seq6 & Stenotrophobacter terrae (NR_146023.1) & 98.71 & 99 \\
Seq7 & Uncultured bacterium clone (JX222212.1) & 84.83 & 99 \\
Seq8 & Uncultured ammonia-oxidizing bacterium (MH359107.1) & 99.40 & 100 \\
Seq9 & Uncultured bacterium clone (KJ490001.1) & 97.42 & 100 \\
Seq10 & Bacterium enrichment culture (KM210547.1) & 100 & 100 \\
Seq11 & Uncultured ammonia-oxidizing bacterium (MH359104.1) & 97.10 & 100 \\
Seq12 & Uncultured proteobacterium clone (KJ081615.1) & 98.43 & 100 \\
Seq13 & Uncultured bacterium clone (KT798368.1) & 87.50 & 81 \\
Seq14 & Uncultured bacterium isolate (KR002619.1) & 98.88 & 100 \\
Seq15 & Uncultured bacterium isolate (KU605601.1) & 91.03 & 98 \\
Seq16 & Uncultured bacterium isolate (KY003178.1) & 99.40 & 100 \\
Seq17 & Truepera radiovictrix (NR_043482.1) & 97.70 & 99 \\
Seq18 & Nitrococcus mobilis (NR_104912.1) & 96.88 & 100 \\
Seq19 & Uncultured bacterium clone (MK066468.1) & 100 & 100 \\
Seq20 & Nitrosomonas communis (NR_104887.1) & 98.88 & 100 \\
\hline
\end{tabular}




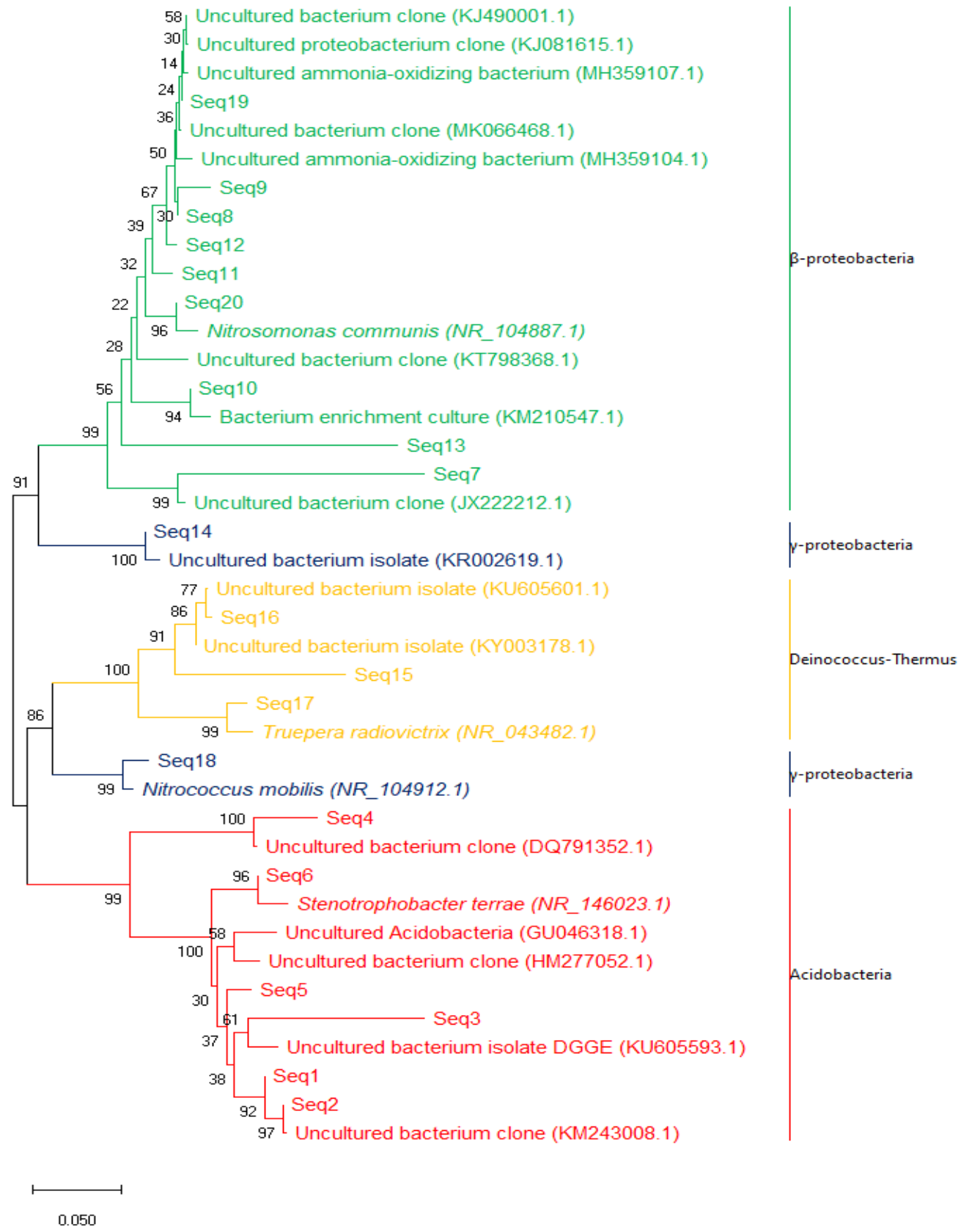

Figura 31. El árbol filogenético se generó con base en el método de neighbor-joining y modelo de sustitución Jukes-Cantor de las secuencias de 16s rARN-DGGE y secuencias relacionadas de la base de datos estándar del GenBank del NCBI de lodo nitrificante en el reactor SBR en presencia de 2-CF. La barra representa la sustitución de 5 nucleótidos por 100 nucleótidos. La robustez nodal del árbol se evaluó utilizando 1000 réplicas de arranque. El número de acceso de NCBI GenBank para cada bacteria se muestra entre paréntesis. 
A fin de conocer el parentesco de las bandas cortadas del gel de DGGE con alguna especie de bacterias, se realizó un segundo BLAST utilizando ahora la base de datos del 16s rRNA de bacterias del GenBank del NCBI, con la cual se obtuvieron los parientes cercanos con su respectivo porcentaje de similitud presentados en la Tabla 14.

Tabla 14. Identificación de secuencias de nucleótidos analizadas a partir de bandas DGGE del lodo nitrificante a lo largo de los ciclos de operación con $60 \mathrm{mg}$ de C-2-CF/L y con diferentes concentraciones iniciales de amonio, utilizando la base del 16s rRNA de bacterias del GenBank del NCBI.

\begin{tabular}{|c|c|c|c|}
\hline $\begin{array}{c}\text { Banda cortada } \\
\text { del DGGE }\end{array}$ & Parientes cercanos & $\begin{array}{c}\% \text { de } \\
\text { Similitud }\end{array}$ & $\begin{array}{c}\% \text { de } \\
\text { Cobertura }\end{array}$ \\
\hline Seq1 & Tellurimicrobium multivorans (NR_146026.1) & 92.43 & 98 \\
\hline Seq2 & Tellurimicrobium multivorans (NR_146026.1) & 91.59 & 100 \\
\hline Seq3 & Blastocatella fastidiosa (NR_118350.1) & 90.38 & 100 \\
\hline Seq4 & Pyrinomonas methylaliphatogenes (NR_133835.1) & 94.9 & 100 \\
\hline Seq5 & Stenotrophobacter roseus (NR_146022.1) & 95.87 & 100 \\
\hline Seq6 & Stenotrophobacter terrae (NR_146023.1) & 98.71 & 99 \\
\hline Seq7 & Sulfurirhabdus autotrophica (NR_147728.1) & 82.87 & 99 \\
\hline Seq8 & Nitrosospira multiformis (NR_074736.1) & 98.8 & 100 \\
\hline Seq9 & Nitrosomonas aestuarii (NR_104818.1) & 95.52 & 95 \\
\hline Seq10 & Nitrosomonas europaea (NR_117368.1) & 100 & 100 \\
\hline Seq11 & Nitrosomonas marina (NR_104815.1) & 96.13 & 100 \\
\hline Seq12 & Nitrosospira tenuis (NR_114773.1) & 97.64 & 100 \\
\hline Seq13 & Nitrosomonas oligotropha (NR_104820.1) & 87.8 & 81 \\
\hline Seq14 & Dokdonella ginsengisoli (NR_041369.1) & 97.2 & 100 \\
\hline Seq15 & Deinococcus phoenicis (NR_134016.1) & 82.87 & 96 \\
\hline Seq16 & Deinococcus peraridilitoris (NR_102475.1) & 91.32 & 100 \\
\hline Seq17 & Truepera radiovictrix (NR_043482.1) & 97.7 & 99 \\
\hline Seq18 & Nitrococcus mobilis (NR_104912.1) & 96.88 & 100 \\
\hline Seq19 & Nitrosospira multiformis (NR_115148.1) & 99.38 & 100 \\
\hline Seq20 & Nitrosomonas communis (NR_104887.1) & 98.88 & 100 \\
\hline
\end{tabular}

Con la información de la Tabla 14 se construyó un nuevo árbol filogenético (Figura 32) en el que las secuencias también se ubicaron en cuatro grupos bacterianos diferentes: $\beta$ proteobacteria, acidobacteria, Deinococcus-thermus y $\gamma$-proteobacteria. 


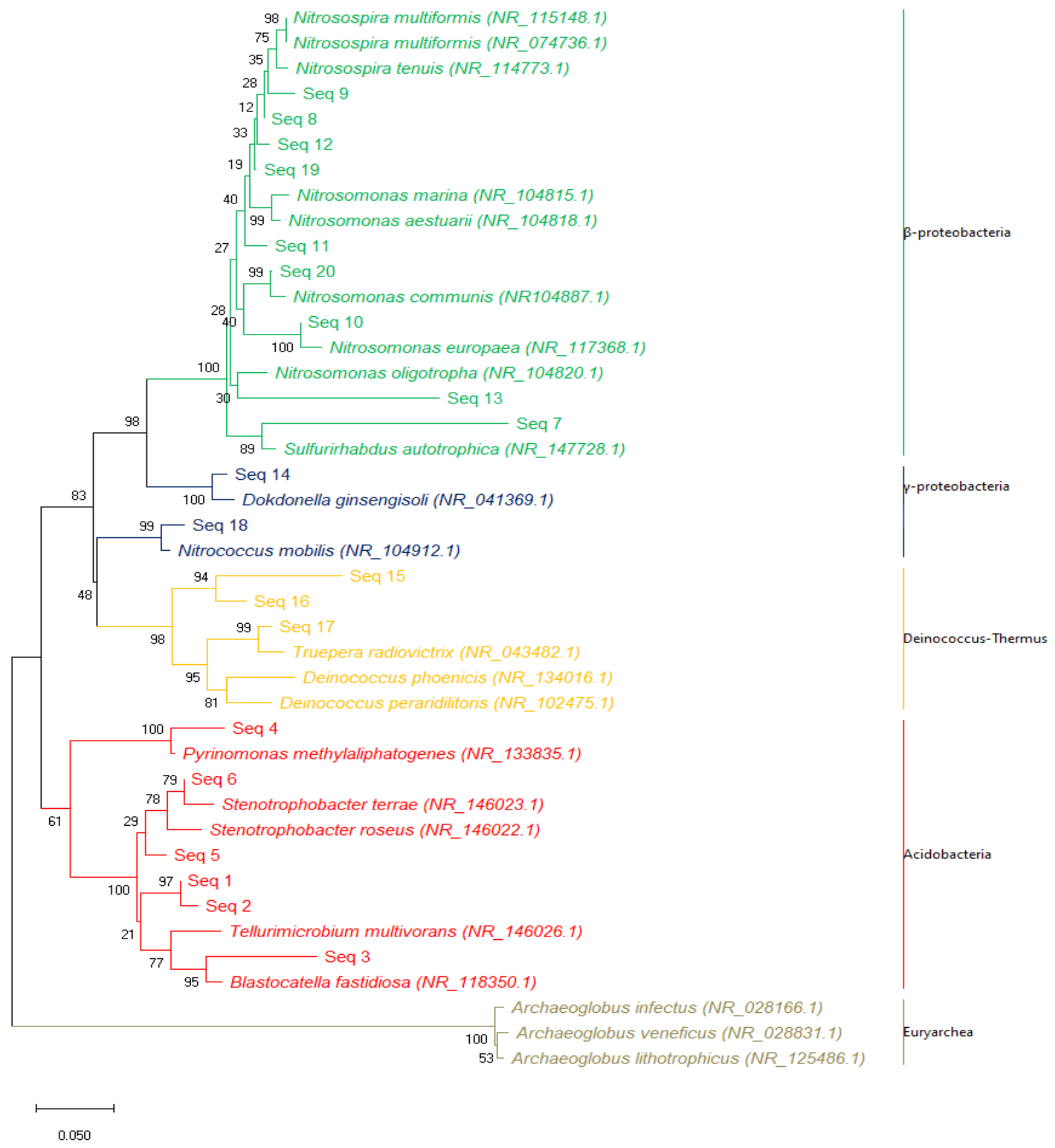

Figura 32. El árbol filogenético se generó con base en el método de neighbor-joining y modelo de sustitución Jukes-Cantor de las secuencias de 16S rARN-DGGE y secuencias relacionadas de la base de datos del 16s rRNA de bacterias del GenBank del NCBI de lodo nitrificante en el reactor SBR en presencia de 2-CF. La barra representa la sustitución de 5 nucleótidos por 100 nucleótidos. La robustez nodal del árbol se evaluó utilizando 1000 réplicas de arranque. El número de acceso de NCBI GenBank para cada bacteria se muestra entre paréntesis. 
Los microorganismos encontrados en el lodo nitrificante se identificaron por su relación con algunas bacterias (Tabla 14). El 40\% de las especies secuenciadas se asociaron con bacterias $\mathrm{AOB}$, de las cuales tres de ellas (Seq 8, Seq 11 y Seq 12) aparecieron en todos los ciclos de operación en los reactores SBR, lo que indica su tolerancia a la presencia de 2-CF, así como al incremento en la concentración de amonio desde 100 y hasta $500 \mathrm{mg}$ de $\mathrm{N}-\mathrm{NH}_{4}{ }^{+} / \mathrm{L}$. La Seq 8 se relaciona con Nitrosospira multiformis, la Seq 11 con Nitrosomonas marina y la Seq 12 con Nitrosospira tenuis. La presencia de Nitrosomonas marina se ha reportado en lodos nitrificantes de dos plantas de tratamiento de aguas residuales (PTAR) a gran escala, una PTAR municipal que trata $20 \mathrm{mg}$ de $\mathrm{N}-\mathrm{NH}_{4}{ }^{+} / \mathrm{L}$ y una PTAR porcina que trata $220 \mathrm{mg}$ de N-NH${ }^{+} / \mathrm{L}$ (Whang y col., 2009), mientras que especies de Nitrosospira tenuis y Nitrosospira multiformis se han encontrado en un reactor de lodo granular aerobio a escala de laboratorio (Winkler y col., 2013). Se ha encontrado una mayor proporción del género Nitrosospira en un SBR nitrificante aireado constantemente y alimentado con $62 \mathrm{mg}$ de $\mathrm{N}^{-\mathrm{NH}_{4}}{ }^{+} / \mathrm{L}$ en comparación con otros géneros de bacterias nitrificantes tales como Nitrosomonas, Nitrospira y Nitrobacter (Dytczak y col., 2008). La presencia de estas tres especies de AOB ha sido reportada en sistemas alimentados con concentraciones de amonio menores a las utilizadas en este estudio, por lo que su permanencia en ambos reactores SBR evidencia su capacidad para desarrollarse en diversas condiciones operacionales y ambientales, así como su tolerancia a concentraciones altas de amonio. Aunque la Seq 13, relacionada con Nitrosomonas oligotropha, es otra bacteria AOB que se ha encontrado en lodos activados de plantas de tratamiento de aguas residuales industriales y residenciales alimentadas con diferentes concentraciones de $\mathrm{NH}_{3}(21.1 \mathrm{a} 47.1 \mathrm{mg}$ de $\mathrm{N}_{-} \mathrm{NH}_{3} / \mathrm{L}$ ) (Siripong y Rittmann, 2007), no aparece en el ciclo 1 con $100 \mathrm{mg}$ de $\mathrm{N}_{-} \mathrm{NH}_{4}^{+} / \mathrm{L}$, su presencia se detectó al aumentar la concentración de amonio a $200 \mathrm{mg}$ de $\mathrm{N}-\mathrm{NH}_{4}{ }^{+} / \mathrm{L}$ y se mantuvo hasta el ciclo 13 de operación, por lo que esta secuencia también resultó tolerante a concentraciones altas de amonio y a la adición de 2-CF. Dentro del grupo de bacterias AOB, el género de las Nitrosomonas ha sido de los más estudiados (Koops y col., 1991). Su presencia se ha detectado en diferentes ambientes, por ejemplo, en lodos activados de 7 diferentes plantas de recuperación de agua que alcanzan porcentajes de remoción de amonio mayores que 90\% (Siripong y Rittmann, 2007); en plantas de tratamiento a gran escala de aguas residuales con lodos activados donde es posible remover hasta un $98 \%$ del amonio presente (Dionisi y col., 
2002); o bien en sistemas donde se lleva a cabo la biotransformación de compuestos aromáticos como el etilbenceno, tolueno, fenol, p-xyleno y anilina (Keener y Arp, 1994). En el presente estudio, especies como Nitrosomonas aestuarii y Nitrosomonas europaea, relacionadas con las secuencias 9 y 10 respectivamente, aparecen desde el ciclo 1 y hasta el ciclo 8 y 9 cuando se incrementó a $300 \mathrm{mg}$ de $\mathrm{N}-\mathrm{NH}_{4}{ }^{+} / \mathrm{L}$. Sin embargo, al incrementar la concentración de amonio a $400 \mathrm{mg}$ de $\mathrm{N}_{-} \mathrm{NH}_{4}{ }^{+} / \mathrm{L}$, no se detectó ninguna de ellas, lo que indica que no fueron tolerantes a concentraciones altas de amonio. Por otro lado, se detectaron algunas especies que, aunque aparecieron al inicio de los ensayos en los SBRs, no se detectó su presencia durante ciertos ciclos, pero vuelven a detectarse hasta el final de la experimentación. Tal es el caso de la Seq 19, relacionada con Nitrosospira multiformis, la cual solo se registra en los primeros tres ciclos de operación, en los primeros dos ciclos con $400 \mathrm{mg}$ de $\mathrm{N}-\mathrm{NH}_{4}{ }^{+} / \mathrm{L}$ y vuelve a observarse en el último ciclo de operación con $500 \mathrm{mg}$ de $\mathrm{N}-\mathrm{NH}_{4}{ }^{+} / \mathrm{L}$. Un comportamiento similar se observa con la Seq 20 que se relaciona con Nitrosomonas communis, la cual aparece desde el inicio de operación de los SBRs, en los tres ciclos siguientes con $200 \mathrm{mg}$ de $\mathrm{N}-\mathrm{NH}_{4}{ }^{+} / \mathrm{L}$ y vuelve a observarse hasta los últimos dos ciclos de operación con $500 \mathrm{mg}$ de $\mathrm{N}_{-} \mathrm{NH}_{4}{ }^{+} / \mathrm{L}$. La Seq 18 se relaciona con Nitrococcus mobilis, una bacteria NOB (Watson y Waterbury, 1971) y aparece en todos los ciclos de operación de los reactores SBR, independientemente del aumento en la concentración de amonio y la exposición constante a 2-CF. Es interesante resaltar que la presencia de esta especie solo se ha reportado en sistemas marinos (Füssel y col., 2017) y no en el tratamiento de aguas residuales o en procesos nitrificantes, de forma que esta es la primera vez que se observa en un reactor nitrificante alimentado con 2-CF y diversas concentraciones de amonio. Asimismo, dado que bajo las condiciones experimentales establecidas fue la única especie NOB que se detectó, se puede decir que es la responsable de que el proceso nitrito oxidante se llevara a cabo y se obtuviera una nitrificación completa.

La Seq 7 relacionada con Sulfurirhabdus autotrophica, es una bacteria oxidante de azufre que ha sido aislada de un sedimento de agua dulce (Watanabe y col., 2015), y a pesar de que no ha sido relacionada con el tratamiento de aguas residuales, con el proceso nitrificante o con el consumo de compuestos clorofenólicos, se pudo detectar en este estudio. Al igual que las bacterias AOB, Sulfurirhabdus autotrophica pertenece a la familia de las $\beta$-proteobacteria y 
mostró una resistencia a $400 \mathrm{mg}$ de $\mathrm{N}-\mathrm{NH}_{4}{ }^{+} / \mathrm{L}$, sin embargo, dos ciclos después de haber estado expuesta a esta concentración desapareció del gel. La presencia de esta especie en el consorcio nitrificante no está del todo clara, por lo que se podrían realizar más estudios a fin de entender su posible relación con el tratamiento de aguas residuales o el proceso nitrificante.

Seis de las bandas secuenciadas pertenecen al grupo de las acidobacterias (Seq 1, 2, 3, 4, 5 y 6), las cuales se relacionan con diferentes especies heterotróficas. Se encontró que las Seq 1 y 2 se relacionan con Tellurimicrobium multivorans reportada recientemente en suelos de sabana semiárida de Namibia (suroeste de África) por Pascual y col. (2015). Las Seq 3, Seq 4 y Seq 6 relacionadas respectivamente con Blastocatella fastidiosa, Pyrinomonas methylaliphatogenes y Stenotrophobacter terrae, al igual que algunas especies AOB, aparecen desde el ciclo 1 de operación con $60 \mathrm{mg}$ de C-2-CF/L y $100 \mathrm{mg}$ de $\mathrm{N}-\mathrm{NH}_{4}{ }^{+} / \mathrm{L}$, se mantienen durante el transcurso de los ciclos y hasta el final de la experimentación. Las especies de las Seq 3 y 4 se han reportado recientemente por primera vez en condiciones aerobias heterotróficas y en presencia de diferentes sustratos, por ejemplo, Blastocatella fastidiosa con medios suplementados con quitina, celulosa y almidón (Foesel y col., 2013) y Pyrinomonas methylaliphatogenes con urea, nitrato y amonio (Crowe y col., 2014). Sin embargo, ninguna de estas especies se ha reportado en condiciones similares a las de este estudio, por lo que es la primera vez que se reporta su tolerancia a concentraciones altas de amonio y hasta $60 \mathrm{mg}$ de C2-CF/L, lo que sugiere su participación en el consumo de ambos compuestos. La Seq 5, que se relaciona con Stenotrophobacter roseus no aparece en el ciclo 1 pero se puede detectar al aumentar a $200 \mathrm{mg}$ de $\mathrm{N}-\mathrm{NH}_{4}{ }^{+} / \mathrm{L}$ en el ciclo 2 y hasta el ciclo 10 con $400 \mathrm{mg}$ de $\mathrm{N}-\mathrm{NH}_{4}{ }^{+} / \mathrm{L}$, mientras que al incrementar a $500 \mathrm{mg}$ de $\mathrm{N}_{-} \mathrm{NH}_{4}+/ \mathrm{L}$ en el ciclo 11 , no fue posible detectar su presencia. La presencia del género Stenotrophobacter se ha reportado en un lodo activado dentro de un reactor SBR alimentado con aguas residuales sintéticas con $30.6 \pm 0.5 \mathrm{mg}$ de $\mathrm{N}-\mathrm{NH}_{4}{ }^{+} / \mathrm{L}$ (Li y col., 2019). A pesar de que el grupo de las acidobacterias se ha reportado en diferentes plantas de tratamiento de aguas residuales municipales (Zhang y col., 2019), de textiles (Meerbergen y col., 2017) y de petroquímicas (Yang y col., 2015), que pueden contener amonio y/o compuestos fenólicos, los resultados obtenidos sugieren que la mayoría de las especies encontradas en este estudio fueron tolerantes a concentraciones altas de amonio y a la presencia 
de 2-CF. Sin embargo, la bacteria relacionada con Stenotrophobacter roseus no fue tolerante a estas concentraciones, por lo que su participación en el consumo de amonio o del 2-CF no está del todo clara.

Se encontró una relación de las Seq 15, 16 y 17 con Deinococcus phoenicis, Deinococcus peraridilitoris y Truepera radiovictrix respectivamente, las cuales se agrupan en la familia de Deinococcus-thermus. La Seq 15 se detecta en los ciclos 1, 2, 5,7, 8 y 13, por lo que su aparición y detección ocurrió de forma independiente de la concentración de amonio alimentada. Por otro lado, la Seq 16 apareció en la mayoría de los ciclos de operación del reactor SBR a excepción del ciclo 1 y 3, donde la concentración de amonio estuvo entre 100 y $200 \mathrm{mg}$ de $\mathrm{N}-\mathrm{NH}_{4}{ }^{+} / \mathrm{L}$. En contraste, la Seq 17 se detectó en todas las concentraciones de amonio estudiadas. Hasta el momento, no se ha reportado en la literatura la participación y/o presencia de este grupo de bacterias en el tratamiento de aguas residuales o en la degradación de algún compuesto recalcitrante, por lo que se sugiere que podría estar asociada al consumo de amonio y 2-CF. En este sentido se requieren más estudios que permitan entender el comportamiento y contribución de este grupo bacteriano en los procesos nitrificantes. Finalmente, la Seq 14 relacionada con Dokdonella ginsengisoli y al igual que la Seq 18, pertenece a la familia de las $\gamma$-proteobacterias. Esta especie heterotrófica se detectó en todos los ciclos de operación con diferentes concentraciones iniciales de amonio excepto en el ciclo 1 de operación. La presencia de esta especie se ha reportado en una muestra de suelo de un campo de ginseng en la provincia de Pocheon, Corea del Sur (Ten y col., 2009) y es la primera vez que se reporta en condiciones similares a las establecidas en este trabajo. Por último, en la Figura 33 se observa el mapa de calor de las intensidades de banda de las 20 especies secuenciadas, y con qué especie se relaciona. En ella se observa que la proporción de cada especie fue cambiando a lo largo de los ciclos de operación en el reactor SBR adicionado con $60 \mathrm{mg}$ de $\mathrm{C}-2-\mathrm{CF} / \mathrm{L}$ y con diferentes concentraciones iniciales de amonio. Asimismo, se observa que las secuencias 1, 2, 3, 19 y 20 fueron las que presentaron el mayor número de individuos. Con esta información y mediante un análisis estadístico se podría asociar la proporción bacteriana de las especies presentes en el consorcio nitrificante con el comportamiento del proceso respiratorio nitrificante, es decir, con el consumo de amonio y de $2-\mathrm{CF}$. 


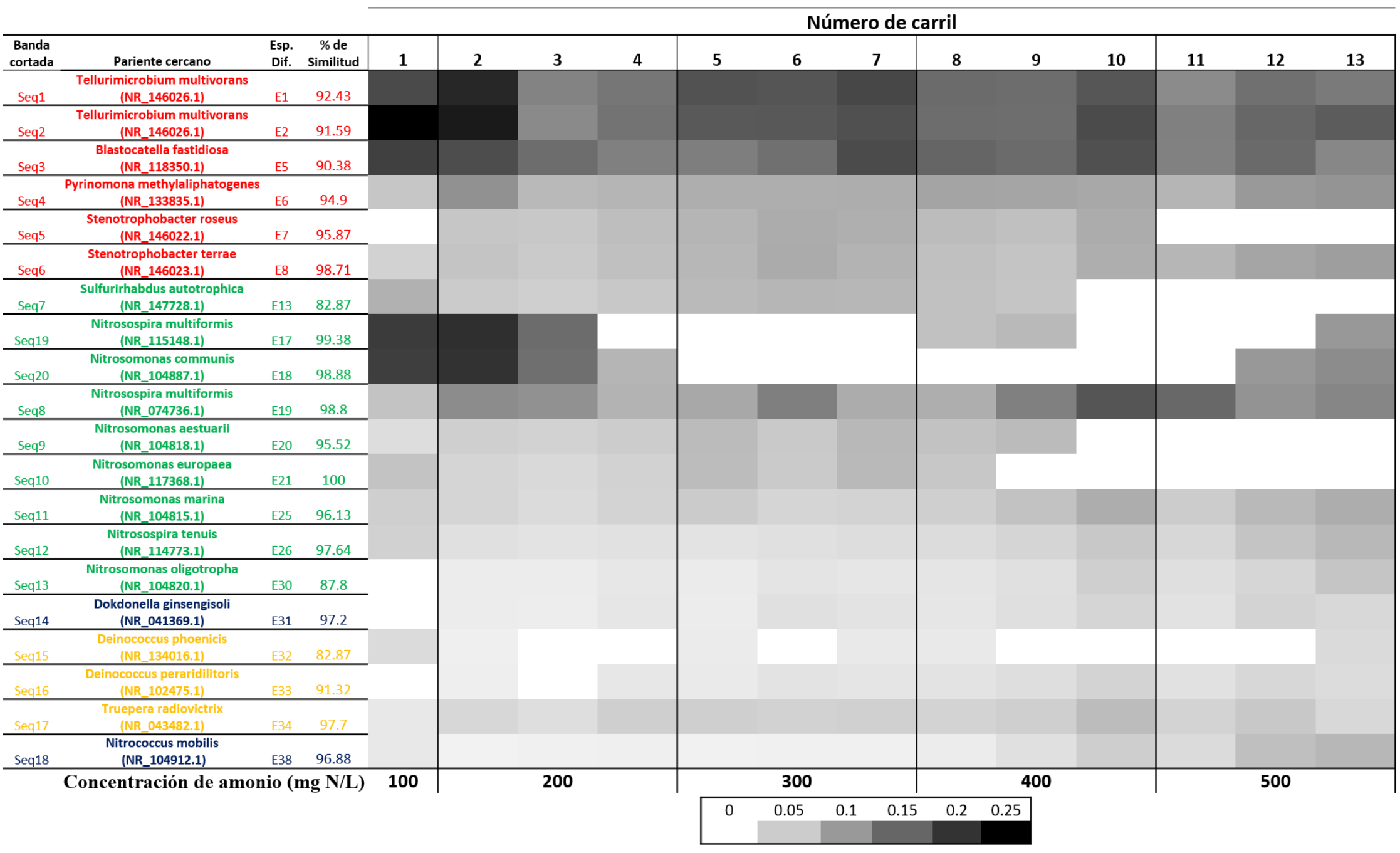

Figura 33. Mapa de calor de las intensidades de banda de las 20 secuencias obtenidas a partir del DGGE con su especie relacionada a lo largo de los ciclos de operación con $60 \mathrm{mg}$ de $\mathrm{C}-2-\mathrm{CF} / \mathrm{L}$ y con diferentes concentraciones iniciales de amonio del reactor SBR. 


\subsection{Relación de la respuesta fisiológica y cinética del lodo nitrificante con su dinámica poblacional.}

Uno de los objetivos de este trabajo fue estudiar la relación del proceso respiratorio nitrificante del lodo, utilizando las variables de respuesta del comportamiento fisiológico (EN$\mathrm{NH}_{4}{ }^{+}, \mathrm{YN}^{-\mathrm{NO}_{3}}{ }^{-}$y EC-2-CF) y cinético (qN-NH${ }_{4}{ }^{+}, \mathrm{qN}^{-} \mathrm{NO}_{3}{ }^{-}$y qC-2-CF), con el comportamiento de las variables de respuesta de su dinámica poblacional (índices ecológicos de riqueza de especies (S), de equitatividad (J) y la presencia de las especies identificadas). Los resultados de un análisis de correlación entre las variables de respuesta determinadas a las diferentes concentraciones de amonio y los ciclos de operación transcurridos, se muestran en la matriz de correlación de la Tabla 15. En ella, $\mathrm{N}$ es el número de datos que se utilizaron para el análisis y representa el número de ciclos de operación realizados en los reactores SBR. El coeficiente de correlación de Pearson (r), puede tomar valores entre -1 o 1 . Un asterisco junto al valor de $r$ indica que la correlación es significativa con un valor de $\alpha$ de $0.05 \mathrm{y}$ dos asteriscos con un valor de $\alpha$ de 0.01 . En color verde se indican las correlaciones significativas y en color rojo las que no lo son. Las correlaciones significativas indican que se pueden asociar los índices ecológicos con la respuesta fisiológica y cinética. Por ejemplo, el índice $\mathrm{S}$ solo se asocia con los ciclos de operación, la concentración de amonio y con la qC-2-CF, mientras que el índice J se asocia con la mayoría de las variables de respuesta nitrificante y solo no se asocia con la EC-2-CF. 
Tabla 15. Matriz de correlaciones de las variables de respuesta cinéticas y fisiológicas del proceso respiratorio nitrificante y los índices ecológicos del lodo. En color verde se indican las correlaciones significativas y en color rojo las que no lo son.

\begin{tabular}{|c|c|c|c|c|c|c|c|c|c|c|c|}
\hline \multirow{2}{*}{$\overline{\mathrm{qN}-\mathrm{NH}_{4}{ }^{+}}$} & \multirow{4}{*}{$\begin{array}{l}\text { Correlación } \\
\text { Sig. (bilateral) } \\
\text { N }\end{array}$} & \multirow{3}{*}{$\frac{\mathbf{q N}-\mathbf{N H}_{4}{ }^{+}}{1}$} & \multicolumn{2}{|c|}{$q \mathrm{~N}-\mathrm{NO}_{3}{ }^{-} \mathrm{qC}-2-\mathrm{CF}$} & \multirow[t]{2}{*}{$\mathbf{S}$} & \multirow[t]{2}{*}{$\mathbf{J}$} & \multirow[t]{2}{*}{$\mathrm{EN}-\mathrm{NH}_{4}{ }^{+}$} & \multirow[t]{2}{*}{$\mathrm{YN}^{-\mathrm{NO}_{3}}{ }^{-}$} & \multirow[t]{2}{*}{ EC-2-CF } & \multirow[t]{2}{*}{ Ciclos } & \multirow[t]{2}{*}{ [Amonio] } \\
\hline & & & & & & & & & & & \\
\hline & & & & & & & & & & & \\
\hline & & 13 & & & & & & & & & \\
\hline \multirow[t]{3}{*}{$\mathrm{qN}-\mathrm{NO}_{3}{ }^{-}$} & Correlación & 0.42 & 1 & & & & & & & & \\
\hline & Sig. (bilateral) & 0.15 & & & & & & & & & \\
\hline & $\mathrm{N}$ & 13 & 13 & & & & & & & & \\
\hline \multirow[t]{3}{*}{$\mathrm{qC}-2-\mathrm{CF}$} & Correlación & $0.834^{* *}$ & 0.50 & 1 & & & & & & & \\
\hline & Sig. (bilateral) & 0.00 & 0.08 & & & & & & & & \\
\hline & $\mathrm{N}$ & 13 & 13 & 13 & & & & & & & \\
\hline \multirow[t]{3}{*}{$\bar{S}$} & Correlación & -0.51 & -0.36 & $-.654^{*}$ & 1 & & & & & & \\
\hline & Sig. (bilateral) & 0.08 & 0.23 & 0.02 & & & & & & & \\
\hline & $\mathrm{N}$ & 13 & 13 & 13 & 13 & & & & & & \\
\hline \multirow[t]{3}{*}{$\mathbf{J}$} & Correlación & $0.816^{* * *}$ & $0.601^{*}$ & $0.855^{* * *}$ & -0.53 & 1 & & & & & \\
\hline & Sig. (bilateral) & 0.00 & 0.03 & 0.00 & 0.07 & & & & & & \\
\hline & $\mathrm{N}$ & 13 & 13 & 13 & 13 & 13 & & & & & \\
\hline \multirow[t]{3}{*}{ EN-NH4${ }_{4}^{+}$} & Correlación & $0.755^{* *}$ & $0.670^{*}$ & $0.788^{* *}$ & -0.41 & $0.641^{*}$ & 1 & & & & \\
\hline & Sig. (bilateral) & 0.00 & 0.01 & 0.00 & 0.17 & 0.02 & & & & & \\
\hline & $\mathrm{N}$ & 13 & 13 & 13 & 13 & 13 & 13 & & & & \\
\hline \multirow[t]{3}{*}{$\mathrm{YN}-\mathrm{NO}_{3}{ }^{-}$} & Correlación & 0.52 & 0.43 & 0.48 & -0.15 & $0.620^{*}$ & 0.53 & 1 & & & \\
\hline & Sig. (bilateral) & 0.07 & 0.15 & 0.09 & 0.63 & 0.02 & 0.07 & & & & \\
\hline & $\mathrm{N}$ & 13 & 13 & 13 & 13 & 13 & 13 & 13 & & & \\
\hline \multirow[t]{3}{*}{$\overline{\mathrm{EC}-2-\mathrm{CF}}$} & Correlación & 0.46 & 0.15 & 0.29 & -0.45 & 0.28 & 0.21 & 0.36 & 1 & & \\
\hline & Sig. (bilateral) & 0.11 & 0.62 & 0.35 & 0.13 & 0.35 & 0.49 & 0.23 & & & \\
\hline & $\mathrm{N}$ & 13 & 13 & 13 & 13 & 13 & 13 & 13 & 13 & & \\
\hline \multirow[t]{3}{*}{ Ciclos } & Correlación & $0.943^{* *}$ & 0.47 & $0.933^{* *}$ & $-.614^{*}$ & $0.891^{* * *}$ & $0.772^{* *}$ & 0.54 & 0.34 & 1 & \\
\hline & Sig. (bilateral) & 0.00 & 0.10 & 0.00 & 0.03 & 0.00 & 0.00 & 0.06 & 0.25 & & \\
\hline & $\mathrm{N}$ & 13 & 13 & 13 & 13 & 13 & 13 & 13 & 13 & 13 & \\
\hline \multirow[t]{3}{*}{ [Amonio] } & Correlación & $0.944^{* *}$ & 0.430 & $0.923^{* *}$ & $-.565^{*}$ & $0.823^{* * *}$ & $0.834^{* *}$ & 0.48 & 0.28 & $0.976^{* * *}$ & 1 \\
\hline & Sig. (bilateral) & 0.00 & 0.14 & 0.00 & 0.04 & 0.00 & 0.00 & 0.10 & 0.36 & 0.00 & \\
\hline & $\mathrm{N}$ & 13 & 13 & 13 & 13 & 13 & 13 & 13 & 13 & 13 & 13 \\
\hline
\end{tabular}

**. La correlación es significativa en el nivel 0.01 (bilateral).

*. La correlación es significativa en el nivel 0.05 (bilateral).

Para una mejor representación de los resultados obtenidos en el análisis de correlación, se presentan los perfiles del índice S (Figura 34a y 34b) así como del índice J (Figura 34c y 34d) con la concentración de amonio y el número de ciclos transcurridos. En cada figura se presenta el coeficiente de correlación de Pearson (r) encerrado en un rectángulo de color verde, indicando las correlaciones que tienen significancia.

El índice S mostró una correlación significativa entre la concentración de amonio y el número de ciclos con un valor de $\mathrm{r}$ de -0.56 y -0.61 respectivamente, describiendo una relación 
inversamente proporcional entre ellos (Figura 34a y 34b). Es decir, el aumento en la concentración de amonio y el transcurso de los ciclos de operación se asocia con la disminución en el número de especies del lodo nitrificante, de forma que la riqueza de especies del lodo disminuye a lo largo de la experimentación.
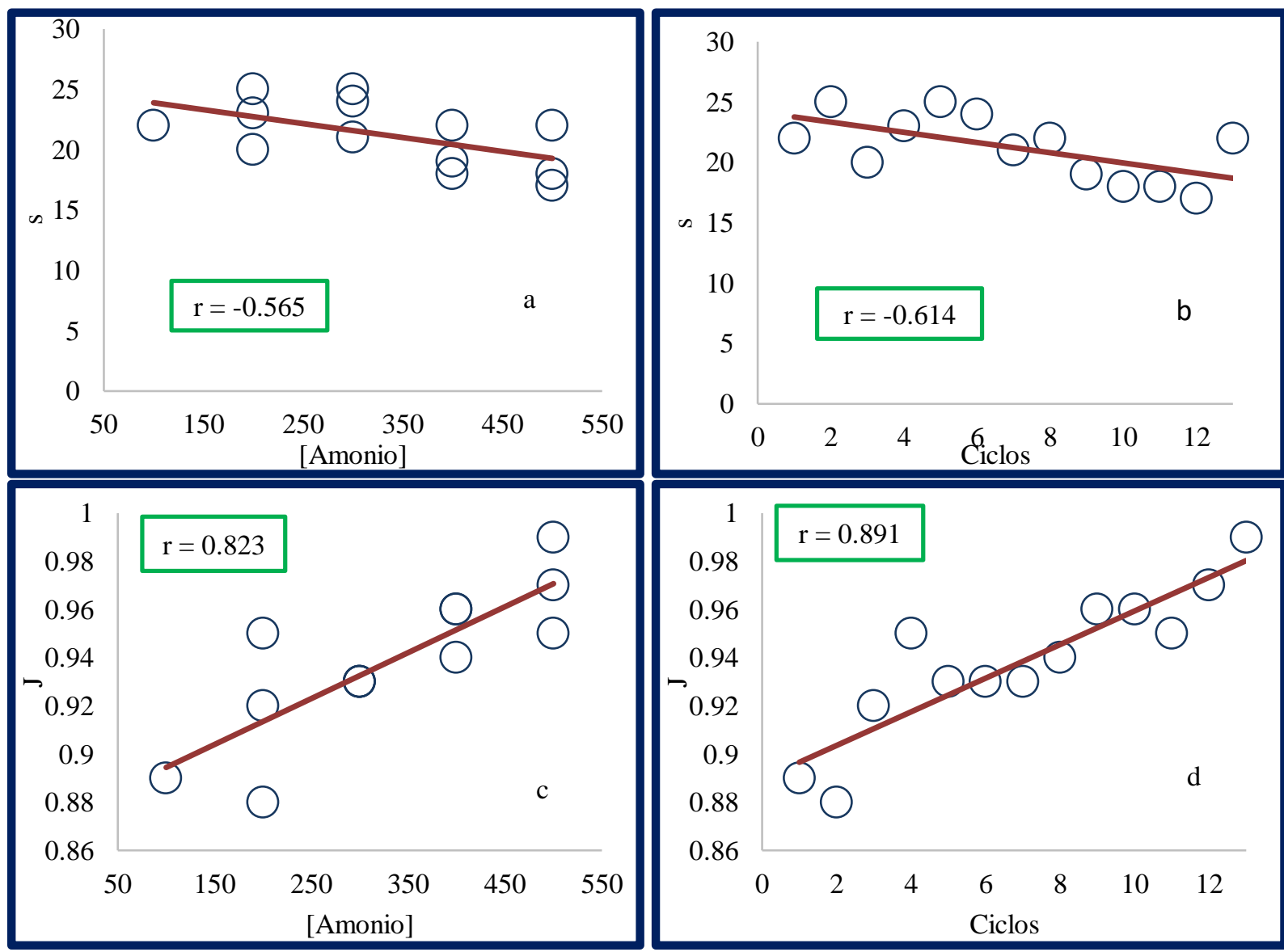

Figura 34. Perfiles de correlación de los índices ecológicos: S con la concentración de amonio (a) y los ciclos de operación (b). J con los ciclos de operación (c) y la concentración de amonio (d).

El índice J mostró una correlación significativa con la concentración de amonio y el número de ciclos ( $\mathrm{r}$ de 0.82 y 0.89 respectivamente, Figura 34 c y $34 \mathrm{~d}$ ), que para este caso fue directamente proporcional, indicando que conforme transcurren los ciclos de operación y la concentración de amonio va en aumento, la equitatividad del lodo nitrificante incrementa, es decir el lodo nitrificante tiende a la homogeneidad. Hasta el momento, no hay reportes en la literatura sobre la relación de la concentración de amonio con índices ecológicos, en específico 
con el $\mathrm{S}$ y $\mathrm{J}$ en procesos nitrificantes en presencia de 2-CF o de otros compuestos inhibitorios y/o recalcitrantes. Silva y col. (2015) han reportado en reactores SBR con un lodo nitrificante, que al aumentar la concentración alimentada de p-cresol hasta $200 \mathrm{mg} \mathrm{C} / \mathrm{L}$, a lo largo de los ciclos de operación los índices $\mathrm{J}$ y $\mathrm{S}$ disminuyeron con respecto a ciclos anteriores $\sin p$-cresol. Por otro lado, en un SBR con lodos anaerobios alimentados con concentraciones de hasta 140 $\mathrm{mg} / \mathrm{L}$ de C-2-CF, con respecto al inóculo el índice $\mathrm{S}$ aumentó de 7 a 12 a lo largo de los ciclos de operación mientras que el índice J se mantuvo cercano a 1 (Beristain-Montiel y col., 2015). Aunque estos trabajos no presentan un análisis estadístico, junto con los resultados obtenidos en el presente estudio, permiten observar que en reactores SBR el comportamiento de los índices S y J dependerán del lodo utilizado, de las condiciones ambientales y operacionales establecidas, así como del compuesto recalcitrante alimentado.

En la Figura 35 se presentan los perfiles de correlación de la riqueza de especies $(\mathrm{S})$ con las diferentes variables de respuesta fisiológicas y cinéticas del lodo nitrificante. En cada figura se presenta el coeficiente de correlación de Pearson (r), en este caso encerrado en un rectángulo de color rojo indicando que en ningún caso se estableció una correlación significativa, lo que indica que bajo las condiciones experimentales establecidas en el presente trabajo, no hay relación entre la disminución del número de especies en el lodo, la obtención de una nitrificación completa $\left(\mathrm{EN}^{-\mathrm{NH}_{4}}{ }^{+}\right.$y $\mathrm{YN}^{-\mathrm{NO}_{3}}{ }^{-}$altos$)$y la mejora en las velocidades específicas del consorcio nitrificante $\left(\mathrm{qN}-\mathrm{NH}_{4}{ }^{+}\right.$y qN$\left.-\mathrm{NO}_{3}{ }^{-}\right)$observadas al transcurrir los ciclos de operación. 

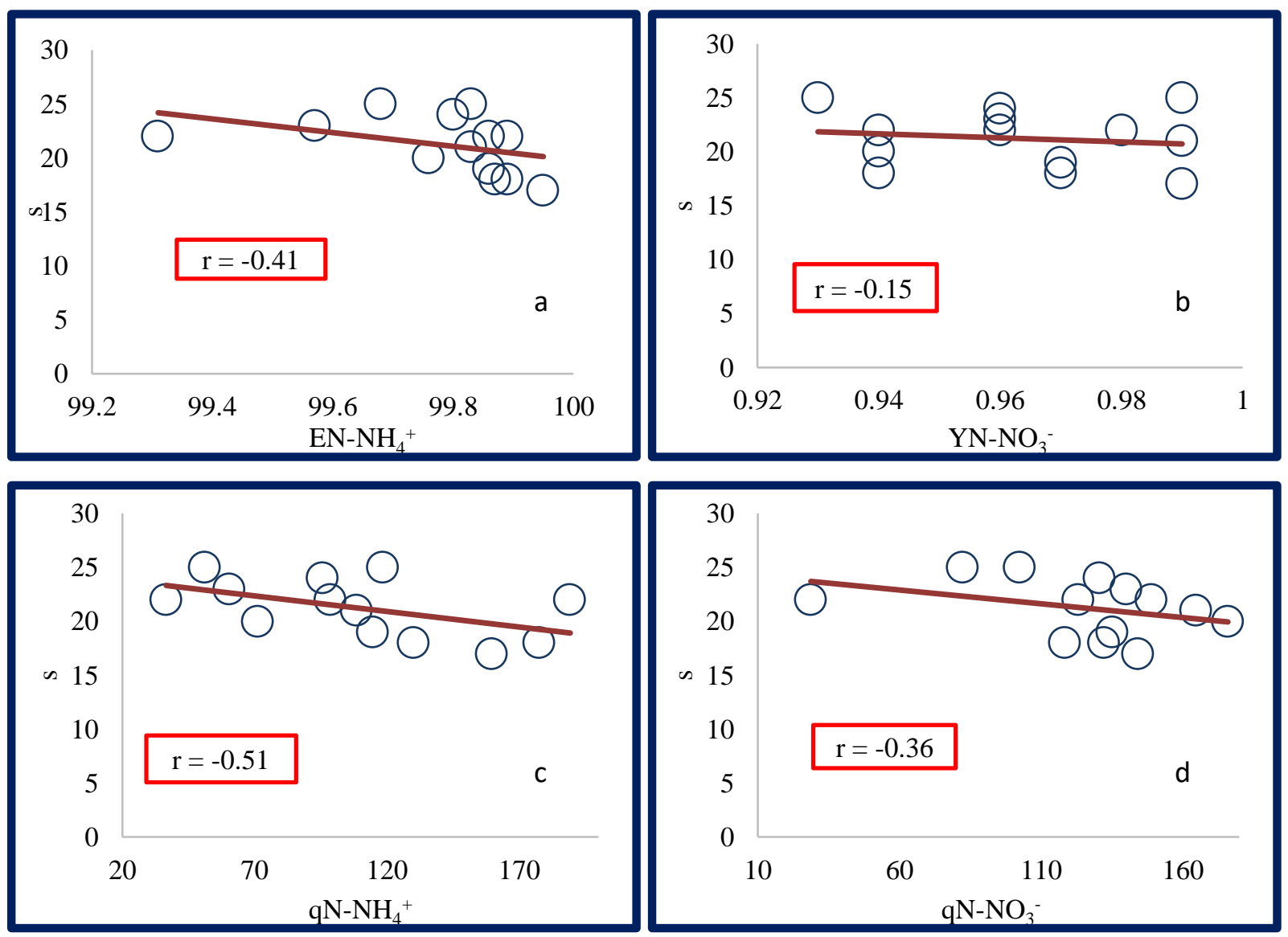

Figura 35. Perfiles de correlación del índice ecológico $\mathrm{S}$ con las variables de respuesta fisiológicas $\left(\mathrm{EN}^{-\mathrm{NH}_{4}}{ }^{+}(\mathrm{a})\right.$ y $\left.\mathrm{YN}_{-} \mathrm{NO}_{3}^{-}(\mathrm{b})\right)$ y cinéticas $\left(\mathrm{qN}-\mathrm{NH}_{4}{ }^{+}(\mathrm{c})\right.$ y $\left.\mathrm{qN}-\mathrm{NO}_{3}{ }^{-}(\mathrm{d})\right)$ del lodo nitrificante.

Por otra parte, la Figura 36 muestra los perfiles de correlación de la equitatividad (J) con las diferentes variables de respuesta fisiológicas y cinéticas del proceso respiratorio realizado por el lodo nitrificante. En contraste con la riqueza de especies, en todos los casos hay una relación directa, proporcional y significativa, con coeficientes de r entre 0.60 y 0.81 encerrados en un rectángulo de color verde (indicando que hay significancia), del índice $\mathrm{J}$ con el establecimiento de una nitrificación muy eficiente y completa, así como con la tendencia al incremento de 5.1 y 5.2 veces en las $\mathrm{qN}-\mathrm{NH}_{4}{ }^{+}$y q N-NO${ }_{3}^{-}$. De acuerdo a lo anterior se puede decir que junto con la mejora del proceso respiratorio se favorece la homogeneidad del consorcio nitrificante. Los resultados del presente trabajo contrastan con los reportados por Silva y col. (2015), donde se han reportado índices J de 0.68 \pm 0.03 en reactores SBR nitrificantes para el 
consumo de amonio y p-cresol. Los autores sugieren que al presentarse cambios mínimos o nulos en las bandas de DGGE el consorcio se mantuvo estable, también mencionan que de acuerdo al índice $\mathrm{J}$ existe la predominancia de algunas especies y que este comportamiento

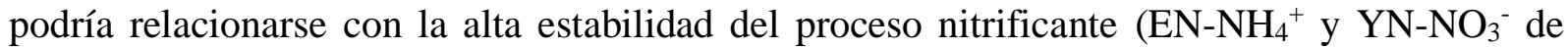
$99.0 \% \pm 0.5 \%$ y $0.98 \pm 0.07$ respectivamente). Por el contrario, en el presente estudio no se encontró predominancia de alguna especie, el consorcio nitrificante tuvo una tendencia a la homogeneidad y el proceso respiratorio se mantuvo completo y eficiente con una mejora en la actividad cinética en el consumo de amonio y producción de nitrato.
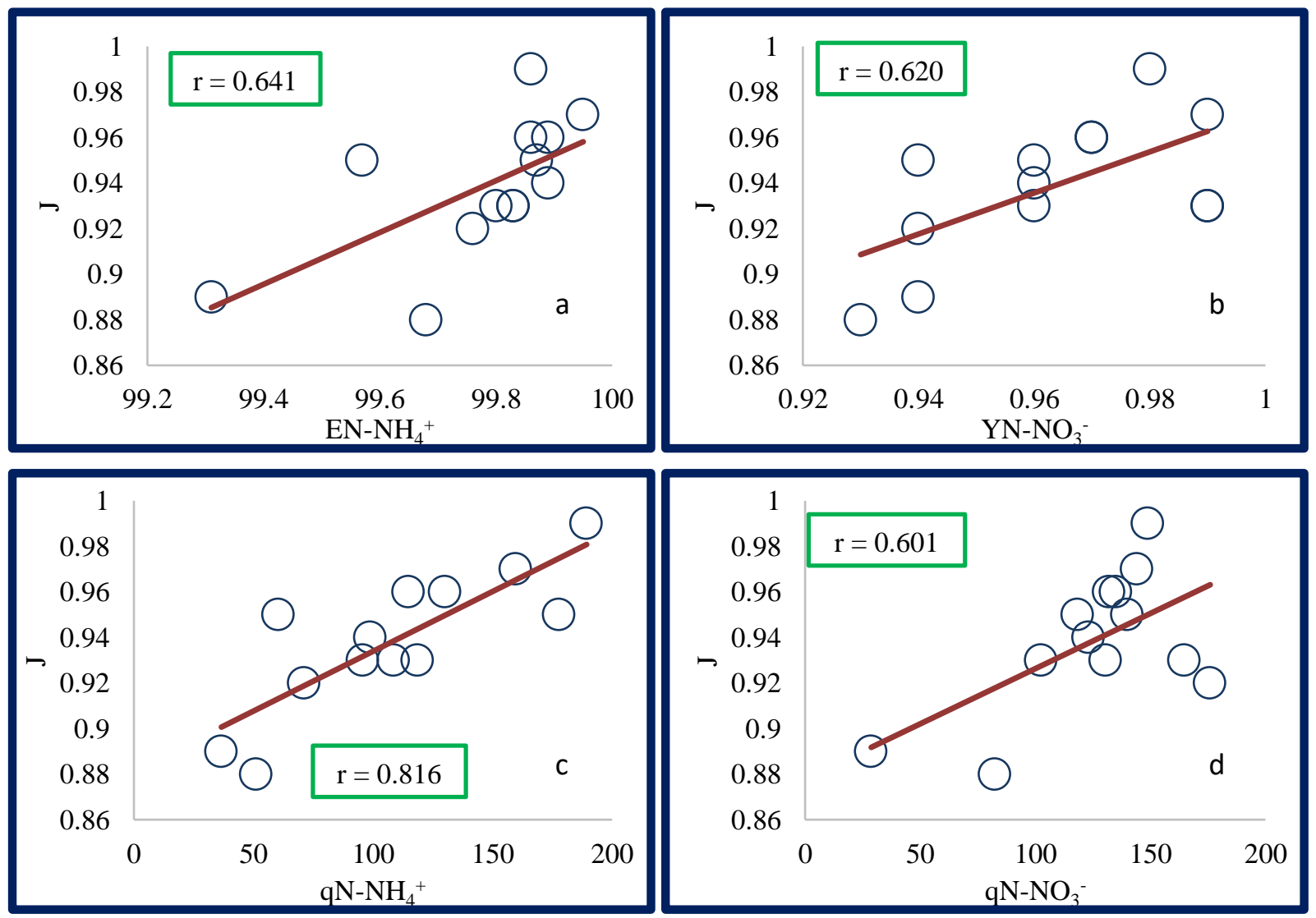

Figura 36. Perfiles de correlación del índice ecológico $\mathrm{J}$ con las variables de respuesta fisiológicas $\left(\mathrm{EN}^{-\mathrm{NH}_{4}}{ }^{+}\right.$(a) y $\mathrm{YN}^{-\mathrm{NO}_{3}}{ }^{-}$(b)) y cinéticas (qN-NH${ }_{4}^{+}$(c) y qN-NO${ }_{3}^{-}$(d)) del lodo nitrificante. 
El lodo nitrificante mantuvo una eficiencia de consumo de 2-CF cercana al $100 \%$ y una tendencia al incremento en la qC-2-CF en todos los ciclos de operación de los SBR. La Figura 37 a y 37 b muestra las correlaciones de $\mathrm{J}$ y S con la eficiencia de consumo de 2-CF respectivamente. Se observa que la correlación no es significativa, lo que indica que el consumo de 2-CF no tiene relación con el número de especies presentes en el lodo nitrificante ni con su equitatividad.

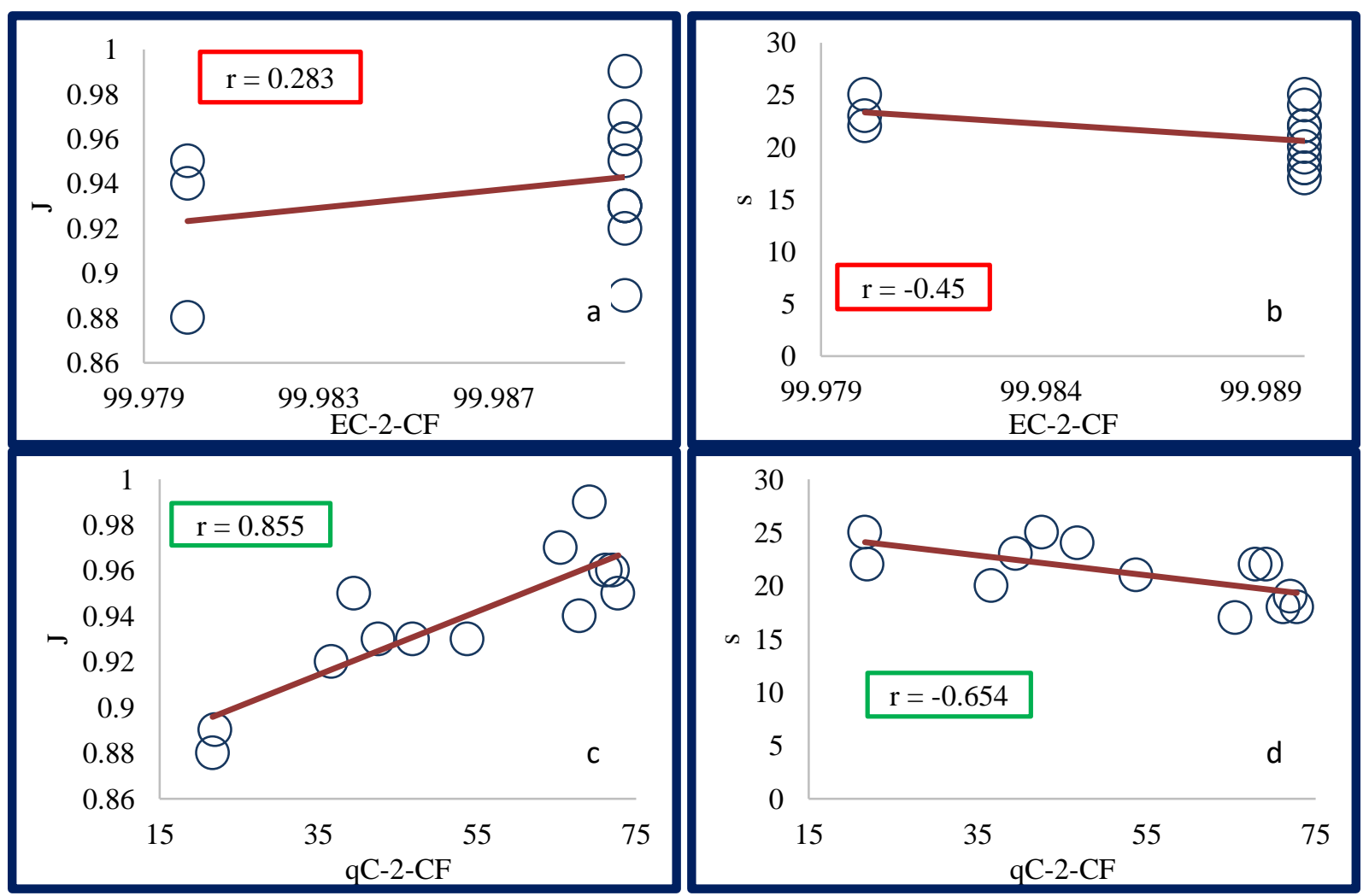

Figura 37. Perfiles de correlación de los índices ecológicos: J con el consumo de 2-CF (a) y la velocidad específica del consumo de 2-CF (c). S con el consumo de 2-CF (b) y la velocidad específica del consumo de 2-CF (d).

Un comportamiento diferente sucede con la correlación de los índices J y S con la qC2-CF, en donde se presentan valores de $r$ de 0.85 y -0.65 respectivamente (Figura 37c y 37d), indicando que hay una relación directa, proporcional y significativa con la tendencia a la homogeneidad del consorcio nitrificante y una relación inversamente proporcional y significativa con la riqueza de especies. Se ha reportado que en un SBR anaerobio alimentado 
con $140 \mathrm{mg} / \mathrm{L}$ de C-2-CF, la qC-2-CF se incrementó a lo largo de los ciclos de operación al igual que el índice $S$, mientras que J se mantuvo constante (Beristain-Montiel y col., 2015). En contraste, en este estudio el incremento de la qC-2-CF a lo largo de los ciclos de operación se relacionó con la tendencia a la disminución de la riqueza de especies $(\mathrm{S})$ y con la tendencia a la homogeneidad del consorcio nitrificante (J), sin embargo, ni el índice $\mathrm{S}$ ni el $\mathrm{J}$ se relacionaron con la EC-2-CF, que se mantuvo en $100 \%$.

Existen diferentes factores que afectan el comportamiento nitrificante, en este estudio se evaluó el efecto de la concentración inicial de amonio y el transcurso de los ciclos de operación en reactores SBR. Los microorganismos presentes en el consorcio microbiano también podrían ser un factor importante, por lo tanto, además de la relación del comportamiento nitrificante con los índices ecológicos, se buscó relacionar la respuesta fisiológica y cinética con las intensidades de banda de las especies obtenidas a partir de la secuenciación y del mapa de calor del DGGE de la Figura 33. Es importante recalcar que, para este análisis, solo se tomaron en cuenta las especies que estuvieron presentes en la mayoría de los ciclos de operación, ya que son las especies que podrían estar participando en el consumo de amonio y 2-CF a lo largo de todo el estudio. Esto no quiere decir que las demás especies encontradas no participen en el comportamiento del proceso respiratorio o en el consumo de 2-CF, sino que solo se buscó asociar el aumento de la intensidad de banda, interpretado como incremento en la proporción de individuos, con la respuesta nitrificante. Asimismo, solo se presentan los casos en que las correlaciones fueron significativas y positivas. La Tabla 16 muestra las correlaciones de las intensidades de banda de nueve de las veinte especies identificadas a partir de la secuenciación de las bandas de DGGE y que estuvieron presentes en la mayoría de los ciclos de operación, con la concentración de amonio y el transcurrir de los ciclos de operación. Estas especies pertenecen a alguno de los 4 grupos bacterianos mostrados en el árbol filogenético de la Figura 32: $\beta$-proteobacteria, acidobacteria, deinococcus-thermus y $\gamma$-proteobacteria. La mayoría de las intensidades de banda de las especies obtenidas tuvieron una correlación significativa y positiva con los ciclos de operación y/o con la concentración de amonio, con excepción de las bandas relacionadas con Nitrosospira multiformis y Truepera radiovictrix, que no correlacionaron con los ciclos de operación ni con la concentración de amonio respectivamente, indicando que la 
intensidad de banda de estas dos especies no se asocia con las variables de respuesta nitrificante. Además, se puede observar que en el grupo $\beta$-proteobacteria (al que pertenecen las bacterias AOB) existe mayor correlación con la concentración de amonio y los ciclos de operación, ya que cuatro ( $\mathrm{r}$ entre 0.56 y 0.83 ) y tres especies ( $\mathrm{r}$ entre 0.70 y 0.88 ) presentaron significancia respectivamente. Esto indica que el aumento en la concentración de amonio y el número de ciclos de operación tuvieron un efecto más notorio sobre las intensidades de banda de las especies de bacterias AOB y se reflejó en el aumento de la proporción de estos individuos.

Tabla 16. Matriz de correlaciones de las intensidades de banda de las especies de los 4 grupos bacterianos obtenidas a partir de la secuenciación del DGGE (acidobacteria-rojo, $\beta$-proteobacteria-verde, deinococcus-thermus-amarillo y $\gamma$-proteobacteria-azul) con la concentración de amonio y el número de ciclos de operación del lodo nitrificante.

\begin{tabular}{|c|c|c|c|}
\hline & & [Amonio] & Ciclos \\
\hline \multirow{3}{*}{$\begin{array}{c}\text { Stenotrophobacter } \\
\text { terrae } \\
\text { (NR_146023.1) }\end{array}$} & Correlación & $.739^{* *}$ & $.783^{* *}$ \\
\hline & Sig. (bilateral) & 0.004 & 0.002 \\
\hline & $\mathrm{N}$ & 13 & 13 \\
\hline \multirow{3}{*}{$\begin{array}{c}\text { Nitrosospira } \\
\text { multiformis } \\
\text { (NR_074736.1) }\end{array}$} & Correlación & $.566^{*}$ & 0.551 \\
\hline & Sig. (bilateral) & 0.044 & 0.051 \\
\hline & $\mathrm{N}$ & 13 & 13 \\
\hline \multirow{3}{*}{$\begin{array}{c}\text { Nitrosomonas } \\
\text { marina } \\
(\mathrm{NR} 104815.1)\end{array}$} & Correlación & $.680^{*}$ & $.763^{* *}$ \\
\hline & Sig. (bilateral) & 0.011 & 0.002 \\
\hline & $\mathrm{N}$ & 13 & 13 \\
\hline \multirow{3}{*}{$\begin{array}{c}\text { Nitrosospira } \\
\text { tenuis } \\
\text { (NR_114773.1) }\end{array}$} & Correlación & $.600^{*}$ & $.705^{* * *}$ \\
\hline & Sig. (bilateral) & 0.030 & 0.007 \\
\hline & $\mathrm{N}$ & 13 & 13 \\
\hline \multirow{3}{*}{$\begin{array}{l}\text { Nitrosomonas } \\
\text { oligotropha } \\
\text { (NR_104820.1) }\end{array}$} & Correlación & $.834^{* * *}$ & $.887^{* *}$ \\
\hline & Sig. (bilateral) & 0.000 & 0.000 \\
\hline & $\mathrm{N}$ & 13 & 13 \\
\hline \multirow{3}{*}{$\begin{array}{c}\text { Truepera } \\
\text { radiovictrix } \\
(\mathrm{NR} 043482.1)\end{array}$} & Correlación & 0.542 & $.556^{*}$ \\
\hline & Sig. (bilateral) & 0.056 & 0.048 \\
\hline & $\mathrm{N}$ & 13 & 13 \\
\hline \multirow{3}{*}{$\begin{array}{c}\text { Deinococcus } \\
\text { peraridilitoris } \\
\text { (NR_102475.1) }\end{array}$} & Correlación & $.824^{* *}$ & $.847^{* * *}$ \\
\hline & Sig. (bilateral) & 0.001 & 0.000 \\
\hline & $\mathrm{N}$ & 13 & 13 \\
\hline \multirow{3}{*}{$\begin{array}{c}\text { Dokdonella } \\
\text { ginsengisoli } \\
\text { (NR_041369.1) }\end{array}$} & Correlación & $.825^{* *}$ & $.862^{* * *}$ \\
\hline & Sig. (bilateral) & 0.001 & 0.000 \\
\hline & $\mathrm{N}$ & 13 & 13 \\
\hline \multirow{3}{*}{$\begin{array}{c}\text { Nitrococcus } \\
\text { mobilis } \\
\text { (NR_104912.1) }\end{array}$} & Correlación & $.738^{* * *}$ & $.815^{* * *}$ \\
\hline & Sig. (bilateral) & 0.004 & 0.001 \\
\hline & $\mathrm{N}$ & 13 & 13 \\
\hline
\end{tabular}

**. La correlación es significativa en el nivel 0,01 (bilateral).

*. La correlación es significativa en el nivel 0,05 (bilateral). 
En la Figura 38 se muestran algunos ejemplos de los perfiles de la correlación de Pearson (r) entre las intensidades de banda de algunas de las especies de los cuatro grupos bacterianos (acidobacteria-rojo, deinococcus-thermus-amarillo, $\beta$-proteobacteria-verde, y $\gamma$-proteobacteriaazul) con el aumento en la concentración de amonio y el transcurso de los ciclos de operación en los reactores SBR. En cada figura se presenta el coeficiente de correlación encerrado en un rectángulo de color verde, indicando que hubo una correlación significativa y en todos los casos mayor a 0.73 . En los cuatro casos, se estableció una relación directamente proporcional entre la intensidad de las bandas de las especies con respecto al aumento en la concentración de amonio y el transcurso en el número de ciclos. Es decir, que el aumento en la proporción de individuos se asocia con el aumento en la concentración de amonio y el transcurso de los ciclos en el reactor SBR. Estos resultados sugieren que dentro del reactor SBR ocurrió una selección de especies microbianas heterotróficas y nitrificantes capaces de adaptarse a los diferentes cambios en la concentración de amonio y que la proporción de sus individuos se incrementó a lo largo de los ciclos de operación. Al respecto se ha propuesto que al imponer ciertas condiciones operacionales en los sistemas SBR, se generan presiones selectivas que promueven el enriquecimiento de consorcios microbianos específicos, así como la inducción de vías metabólicas deseadas (Irvine y col., 1997; Ketchum, 1997). Un comportamiento similar pudo haber ocurrido en este estudio. En cuanto al ejemplo de las bacterias amonio-oxidantes, se sabe que su rendimiento celular es bajo y se ha reportado que en presencia de algún tipo de materia orgánica lo es aún más (Wiesmann,1994), por lo tanto, la presencia de 2-CF podría tener un efecto negativo en el crecimiento de bacterias AOB. Sin embargo, de acuerdo con los resultados obtenidos en este estudio, la concentración utilizada de hasta $500 \mathrm{mg}$ de $\mathrm{N}-\mathrm{NH}_{4}+/ \mathrm{L}$ pudo haber favorecido el aumento en la intensidad de banda de algunos individuos de especies AOB en el reactor SBR. Al respecto, algunos autores han reportado que al alimentar con concentraciones de amonio mayores a $100 \mathrm{mg}$ de $\mathrm{N}-\mathrm{NH}_{4}{ }^{+} / \mathrm{L}$, a lo largo de los ciclos de operación en reactores SBR se puede favorecer el crecimiento y selección de algunas especies de bacterias AOB como Nitrosomonas en un lodo nitrificante (Terada y col., 2013), aunque es importante mencionar que, a diferencia del presente estudio, los autores no realizaron análisis estadísticos para corroborar la relación entre la concentración de amonio, los ciclos de operación y el crecimiento de especies nitrificantes. 

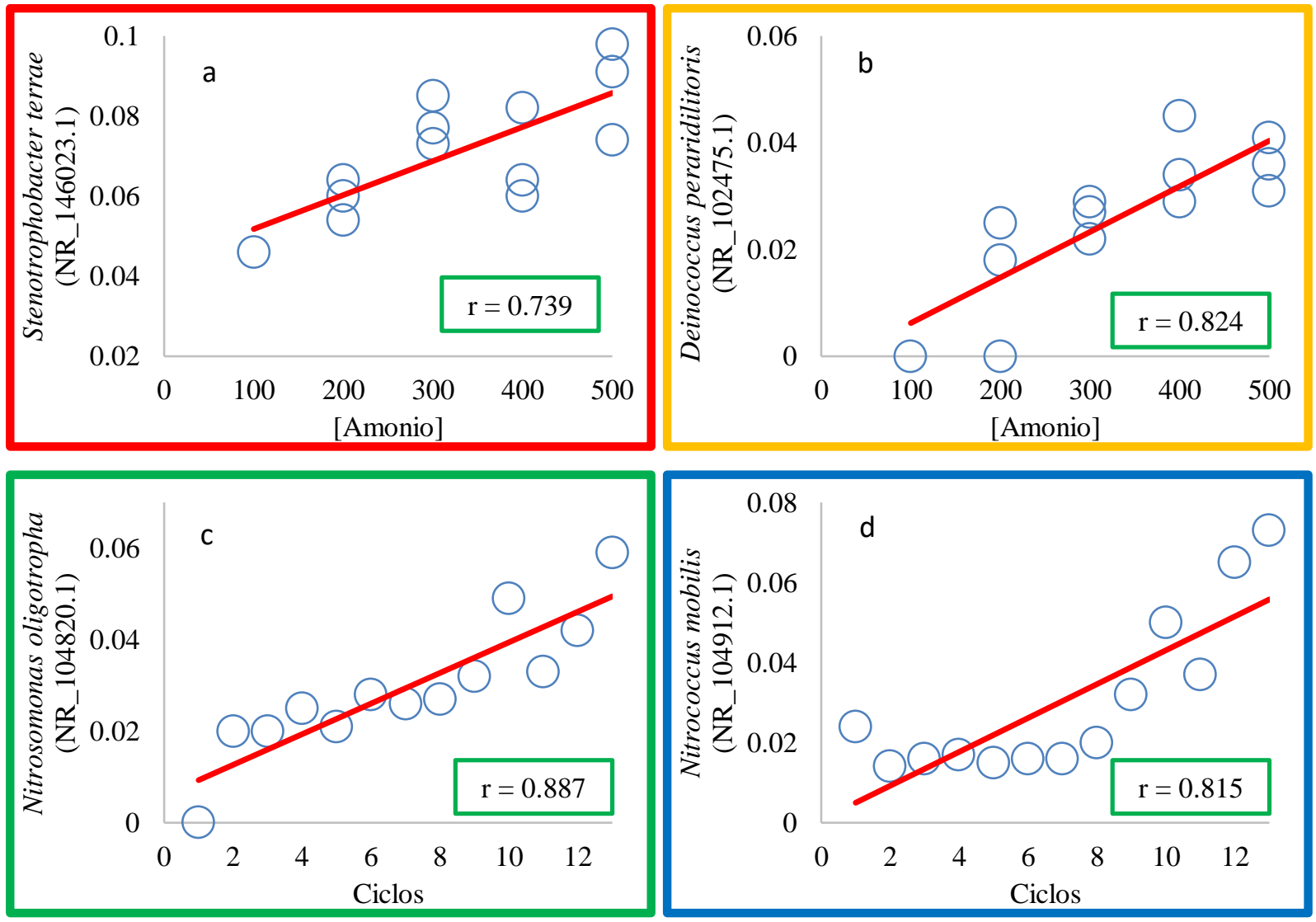

Figura 38. Perfiles de correlación de la intensidad de banda de las especies obtenidas a partir de la secuenciación del DGGE con el aumento en la concentración de amonio (a, acidobacteria y b, deinococcus-thermus) y los ciclos de operación (c, $\beta$-proteobacteria y d, $\gamma$-proteobacteria).

Para el caso particular de las especies AOB pertenecientes al grupo $\beta$-proteobacteria, se muestra en la Tabla 17, la correlación de las intensidades de banda de estas especies con la EN$\mathrm{NH}_{4}{ }^{+}$, la qN-NH${ }_{4}^{+}$y la qC-2-CF. Se puede observar que la relación entre las intensidades de banda de las especies relacionadas con Nitrosospira multiformis y Nitrosomonas oligotropha y la EN-NH${ }_{4}^{+}$; Nitrosomonas marina, Nitrosospira tenuis y Nitrosomonas oligotropha y la qN$\mathrm{NH}_{4}{ }^{+}$, así como Nitrosomonas marina y Nitrosomonas oligotropha con la qC-2-CF fueron en todos los casos significativas y positivas. Todas estas correlaciones presentaron valores de $r$ mayores de 0.57 . 
Tabla 17. Matriz de correlaciones de las intensidades de banda de las especies de bacterias AOB con las variables de respuesta del consumo de amonio y $2-\mathrm{CF}$.

\begin{tabular}{|c|c|c|c|c|c|c|c|c|}
\hline & & $\mathrm{EN}-\mathrm{NH}_{4}{ }^{+}$ & qN-NH${ }_{4}^{+}$ & $q C-2-C F$ & $\begin{array}{c}\text { Nitrosospira } \\
\text { multiformis } \\
\text { (NR_074736.1) }\end{array}$ & $\begin{array}{c}\text { Nitrosomonas } \\
\text { marina } \\
(\mathrm{NR} 104815.1)\end{array}$ & $\begin{array}{c}\text { Nitrosospira } \\
\text { tenuis } \\
\text { (NR_114773.1) }\end{array}$ & $\begin{array}{c}\text { Nitrosomonas } \\
\text { oligotropha } \\
\text { (NR_104820.1) }\end{array}$ \\
\hline \multirow{3}{*}{$\mathrm{EN}-\mathrm{NH}_{4}{ }^{+}$} & Correlación & 1 & & & & & & \\
\hline & Sig. (bilateral) & & & & & & & \\
\hline & $\mathrm{N}$ & 13 & & & & & & \\
\hline \multirow{3}{*}{$\mathrm{qN}-\mathrm{NH}_{4}{ }^{+}$} & Correlación & $.755^{* *}$ & 1 & & & & & \\
\hline & Sig. (bilateral) & 0.003 & & & & & & \\
\hline & $\mathrm{N}$ & 13 & 13 & & & & & \\
\hline \multirow{3}{*}{$\mathrm{qC}-2-\mathrm{CF}$} & Correlación & $.788^{* * *}$ & $.834^{* *}$ & 1 & & & & \\
\hline & Sig. (bilateral) & 0.001 & 0.000 & & & & & \\
\hline & $\mathrm{N}$ & 13 & 13 & 13 & & & & \\
\hline \multirow{3}{*}{$\begin{array}{c}\text { Nitrosospira } \\
\text { multiformis } \\
\text { (NR_074736.1) }\end{array}$} & Correlación & $.569^{*}$ & 0.548 & 0.550 & 1 & & & \\
\hline & Sig. (bilateral) & 0.042 & 0.053 & 0.052 & & & & \\
\hline & $\mathrm{N}$ & 13 & 13 & 13 & 13 & & & \\
\hline \multirow{3}{*}{$\begin{array}{c}\text { Nitrosomonas } \\
\text { marina } \\
(\mathrm{NR} 104815.1)\end{array}$} & Correlación & 0.425 & $.693^{* *}$ & $.647^{*}$ & 0.488 & 1 & & \\
\hline & Sig. (bilateral) & 0.148 & 0.009 & 0.017 & 0.090 & & & \\
\hline & $\mathrm{N}$ & 13 & 13 & 13 & 13 & 13 & & \\
\hline \multirow{3}{*}{$\begin{array}{c}\text { Nitrosospira } \\
\text { tenuis } \\
\text { (NR_114773.1) }\end{array}$} & Correlación & 0.227 & $.634^{*}$ & 0.518 & 0.325 & $.900^{* *}$ & 1 & \\
\hline & Sig. (bilateral) & 0.455 & 0.020 & 0.070 & 0.279 & 0.000 & & \\
\hline & $\mathrm{N}$ & 13 & 13 & 13 & 13 & 13 & 13 & \\
\hline \multirow{3}{*}{$\begin{array}{c}\text { Nitrosomonas } \\
\text { oligotropha } \\
\text { (NR_104820.1) }\end{array}$} & Correlación & $.732^{* * *}$ & $.826^{* *}$ & $.780^{* *}$ & $.644^{*}$ & $.811^{* *}$ & $.700^{* *}$ & 1 \\
\hline & Sig. (bilateral) & 0.004 & 0.001 & 0.002 & 0.018 & 0.001 & 0.008 & \\
\hline & $\mathrm{N}$ & 13 & 13 & 13 & 13 & 13 & 13 & 13 \\
\hline
\end{tabular}

**. La correlación es significativa en el nivel 0.01 (bilateral).

*. La correlación es significativa en el nivel 0.05 (bilateral).

Entre las bacterias AOB identificadas en los reactores SBR, se encontró que la intensidad de banda de Nitrosomonas oligotropha tiene una relación significativa y directamente proporcional con las variables de respuesta fisiológicas y cinéticas $\left(\mathrm{EN}-\mathrm{NH}_{4}{ }^{+}\right.$, la qN-NH${ }_{4}^{+}$y la qC-2-CF) como lo indica el valor de la $r$ encerrada en un cuadro de color verde (Figura 39). Estos resultados indican que al transcurrir los ciclos de operación el aumento en la proporción de individuos se asocia con el consumo de amonio alto y el incremento de las velocidades específicas de consumo de sustratos. El aumento en la proporción de individuos de las especies de AOB (Nitrosospira multiformis, Nitrosomonas marina, Nitrosospira tenuis y Nitrosomonas oligotropha) podría resultar en una mayor cantidad de enzima AMO, la cual podría contribuir tanto en el consumo de amonio y 2-CF, como en el mejoramiento de las velocidades específicas de consumo tanto de amonio como del compuesto aromático. Se ha reportado que al aumentar la concentración de amonio de 100 a $500 \mathrm{mg}$ de $\mathrm{N}_{-} \mathrm{NH}_{4}{ }^{+} / \mathrm{L}$ en cultivos de Nitrosomonas, las velocidades específicas de consumo de amonio y de compuestos recalcitrantes como 
tricloroetileno aumentan (Kocamemi y Çeçen, 2007; 2010). Los autores sugieren que este comportamiento se podría asociar con una cinética de primer orden en el consumo de sustratos, con la formación de oxigenasas que contribuye al aumento de estas velocidades, y con que se llevó a cabo un consumo cometabólico del tricloroetileno. Alvarez-Cohen y Spietel (2001), han sugerido que las oxigenasas de los microorganismos catalizan la oxidación de disolventes clorados y favorecen su conversión a productos fácilmente mineralizables. Con base en esto, se puede decir que las especies relacionadas con Nitrosomonas oligotropha y Nitrosomonas marina que en este estudio presentaron un aumento en la proporción de individuos, podrían haber sintetizado más oxigenasas, en este caso más enzima AMO que pudiera favorecer la oxidación de amonio y el consumo cometabólico de 2-CF y, por tanto, resultar en una correlación alta y significativa con la $\mathrm{qN}-\mathrm{NH}_{4}{ }^{+}$y la qC-2-CF.
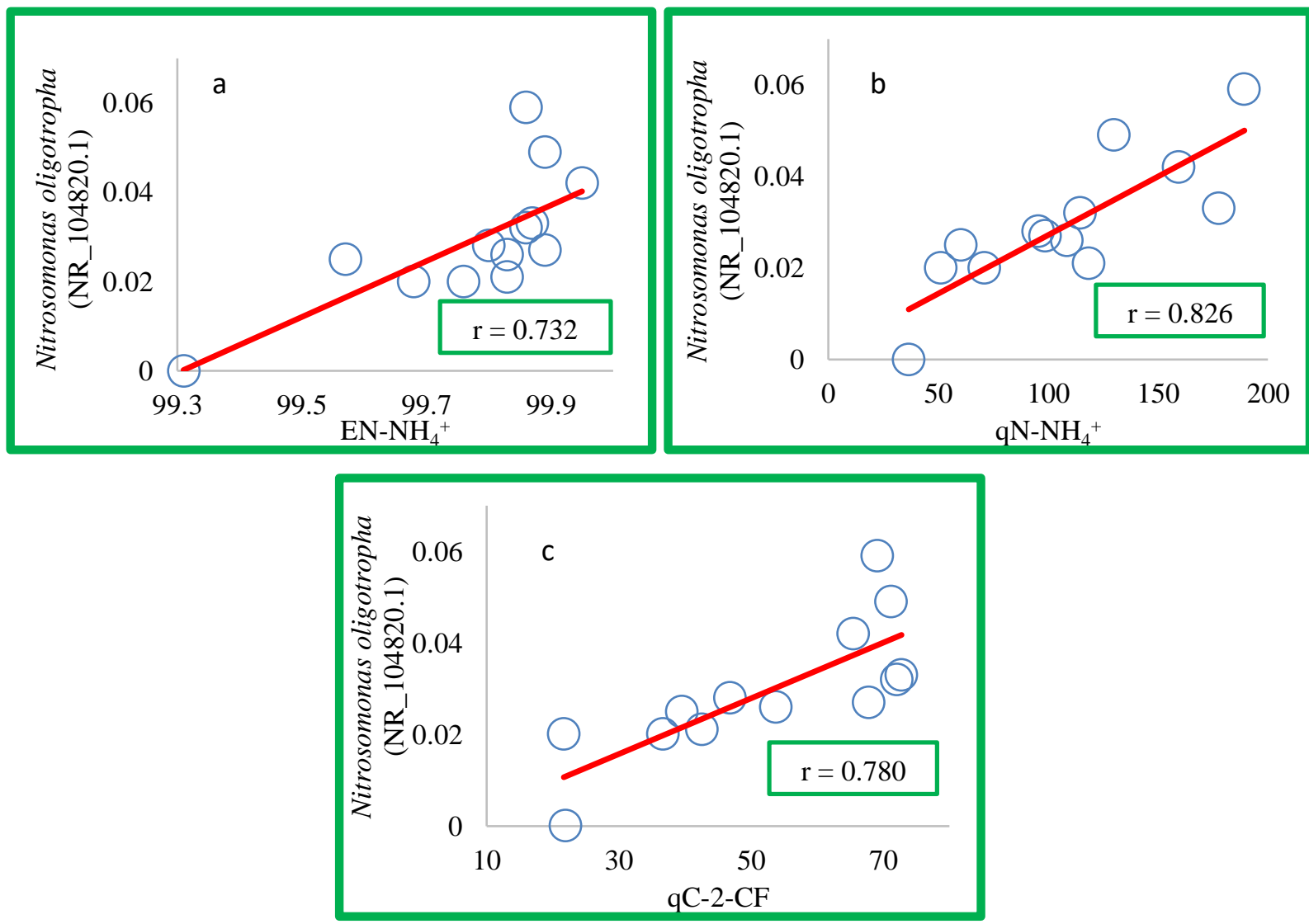

Figura 39. Perfiles de correlación de la intensidad de banda de Nitrosomonas oligotropha con el consumo de amonio (a), la velocidad específica del consumo de amonio (b) y la velocidad específica del consumo de 2-CF (c). 
Por último, la Tabla 18 presenta la matriz de correlaciones que fueron significativas y positivas de las especies heterotróficas (Dokdonella ginsengisoli del grupo $\gamma$-proteobacteria, Deinococcus peraridilitoris y Truepera radiovictrix del grupo Deinococcus-thermus y Stenotrophobacter terrae del grupo acidobacteria) con la qC-2-CF.

Tabla 18. Matriz de correlaciones de la velocidad específica de consumo de 2-CF y las intensidades de banda de diferentes especies heterotróficas obtenidas a partir de la secuenciación del DGGE (acidobacteria-rojo, Deinococcus-thermus-amarillo y $\gamma$-proteobacteria-azul).

\begin{tabular}{|c|c|c|c|c|c|c|}
\hline & & $\mathrm{qC}-2-\mathrm{CF}$ & $\begin{array}{c}\text { Dokdonella } \\
\text { ginsengisoli } \\
\text { (NR_041369.1) }\end{array}$ & $\begin{array}{c}\text { Deinococcus } \\
\text { peraridilitoris } \\
\text { (NR_102475.1) }\end{array}$ & $\begin{array}{c}\text { Truepera } \\
\text { radiovictrix } \\
(\mathrm{NR} 043482.1)\end{array}$ & $\begin{array}{c}\text { Stenotrophobacter } \\
\text { terrae } \\
(\mathrm{NR} \mathbf{1 4 6 0 2 3 . 1 )}\end{array}$ \\
\hline \multirow{2}{*}{$q C-2-C F$} & $\begin{array}{c}\text { Correlación } \\
\text { Sig (bilateral) }\end{array}$ & 1 & & & & \\
\hline & $\mathrm{N}$ & 13 & & & & \\
\hline \multirow{3}{*}{$\begin{array}{c}\text { Dokdonella } \\
\text { ginsengisoli } \\
\text { (NR_041369.1) }\end{array}$} & Correlación & $.793^{* *}$ & 1 & & & \\
\hline & Sig. (bilateral) & 0.001 & & & & \\
\hline & $\mathrm{N}$ & 13 & 13 & & & \\
\hline \multirow{3}{*}{$\begin{array}{c}\text { Deinococcus } \\
\text { peraridilitoris } \\
\text { (NR_102475.1) }\end{array}$} & Correlación & $.815^{* *}$ & $.912^{* *}$ & 1 & & \\
\hline & Sig. (bilateral) & 0.001 & 0.000 & & & \\
\hline & $\mathrm{N}$ & 13 & 13 & 13 & & \\
\hline \multirow{3}{*}{$\begin{array}{c}\text { Truepera } \\
\text { radiovictrix } \\
\text { (NR_043482.1) }\end{array}$} & Correlación & $.600^{*}$ & $.790^{* *}$ & $.842^{* *}$ & 1 & \\
\hline & Sig. (bilateral) & 0.030 & 0.001 & 0.000 & & \\
\hline & $\mathrm{N}$ & 13 & 13 & 13 & 13 & \\
\hline \multirow{3}{*}{$\begin{array}{c}\text { Stenotrophobacter } \\
\text { terrae } \\
\text { (NR_146023.1) }\end{array}$} & Correlación & $.592^{*}$ & $.830^{* *}$ & $.773^{* *}$ & $.559^{*}$ & 1 \\
\hline & Sig. (bilateral) & 0.033 & 0.000 & 0.002 & 0.047 & \\
\hline & $\mathrm{N}$ & 13 & 13 & 13 & 13 & 13 \\
\hline
\end{tabular}

En la Figura 40 se observan los perfiles de estas especies con la qC-2-CF, así como los valores de $\mathrm{r}$ en un rectángulo de color verde, que en todos los casos fueron mayores que 0.59. Los resultados indican que fue posible establecer una relación significativa directamente proporcional entre las especies heterotróficas y el incremento de la qC-2-CF. Al transcurrir los ciclos de operación, el aumento de individuos de las especies heterotróficas se asocia con el incremento de la qC-2-CF. Se ha reportado en la literatura tanto el consumo de hidrocarburos como de compuestos aromáticos, tales como fenoles y cresoles por bacterias heterotróficas aerobias (Becker y Dott, 1995). Por ejemplo, se ha visto que el consumo de clorofenoles como el 4-CF por cepas heterotróficas, se favorece al inocular estas cepas en el suelo, de forma que tanto el aumento de especies heterotróficas como el consumo de compuestos recalcitrantes se mejora (Nowak y Mrozik, 2018). Los autores sugieren que se puede llevar a cabo la inducción 
de las enzimas involucradas en la degradación de compuestos aromáticos en microorganismos que previamente existen en suelos contaminados. También se ha reportado que bacterias heterotróficas aerobias son menos sensibles a la toxicidad del 2-CF en comparación con bacterias nitrificantes como Nitrosomonas (Blum y Speece, 1991). Por lo tanto, la relación entre el aumento en la proporción de especies heterotróficas con el aumento en la qC-2-CF, podría atribuirse tanto a la tolerancia de estas especies al 2-CF, al incremento en su población y por tanto a la mayor formación de enzimas capaces de biotranformar al 2-CF.
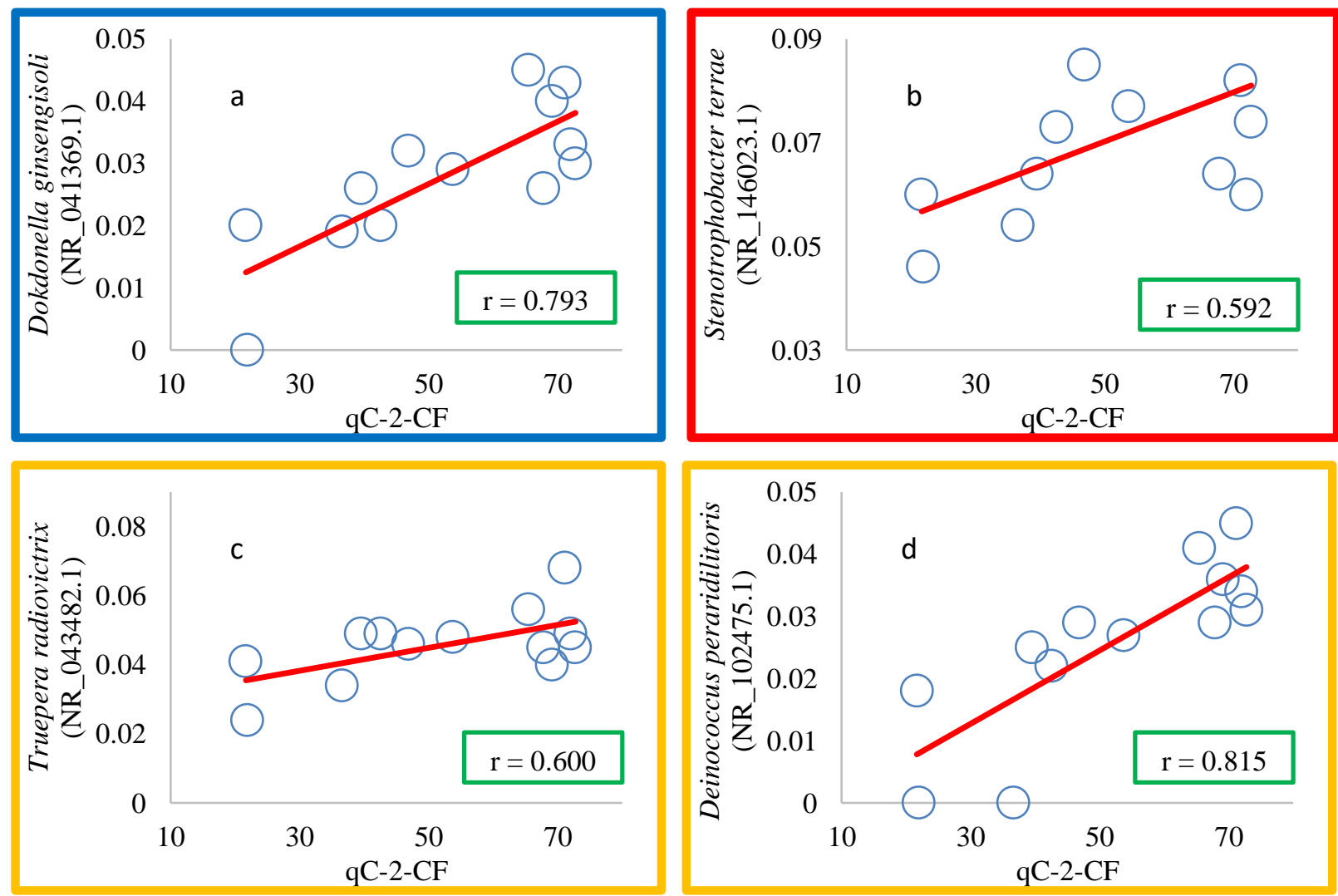

Figura 40. Perfiles de correlación de la intensidad de banda de diferentes especies heterotróficas ( $\gamma$-proteobacteriaazul, a, acidobacteria-rojo, b y deinococcus-thermus-amarillo, c y d) con la velocidad específica de consumo de 2$\mathrm{CF}$. 
En resumen, el lodo nitrificante tuvo la capacidad de consumir desde 100 y hasta 500 mg de $\mathrm{N}-\mathrm{NH}_{4}+/ \mathrm{L}$ al transcurso de 13 ciclos de operación, así como $60 \mathrm{mg}$ de C-2-CF/L. Al final de la experimentación la comunidad bacteriana tuvo una tendencia a la homogeneidad (con un índice $\mathrm{J}$ de 0.99 ), un comportamiento nitrificante completo y estable (con $\mathrm{EN}^{-\mathrm{NH}_{4}}{ }^{+}$arriba del 99\% y $\mathrm{YN}^{-\mathrm{NO}_{3}}{ }^{-}$entre el 0.93 y 0.99), así como velocidades específicas de consumo de amonio, producción de nitrato y consumo de 2-CF altas (con incrementos de 5.1, 5.2 y 3.1 veces al final del estudio respectivamente) y un consumo cometabólico de 2-CF. La capacidad del consorcio nitrificante para consumir de forma eficiente y completa al amonio y 2-CF, así como de realizar simultáneamente una nitrificación eficiente, completa y estable, podría asociarse con el incremento en la concentración de amonio, el transcurrir de los ciclos de operación y con el aumento en la proporción de individuos de las diferentes especies encontradas en el DGGE del lodo nitrificante. 
CONCLUSIONES 


\section{CONCLUSIONES}

$\mathrm{Al}$ incrementar la concentración de amonio desde 100 y hasta $500 \mathrm{mg} \mathrm{N}-\mathrm{NH}_{4}{ }^{+} / \mathrm{L}$ y en presencia de $60 \mathrm{mg} / \mathrm{L}$ de C-2-CF, se obtuvieron diferentes efectos fisiológicos, cinéticos y en la dinámica poblacional del lodo nitrificante. A continuación, se desglosan:

I. La evaluación del proceso nitrificante en presencia de 2-CF a lo largo de 13 ciclos de operación en los reactores SBR indicó que:

- Se llevó a cabo una nitrificación completa, se favoreció el proceso nitrificante y el consumo de 2-CF, puesto que se obtuvieron $\mathrm{EN}_{-} \mathrm{NH}_{4}{ }^{+}$mayores del $99 \%, \mathrm{YN}_{-} \mathrm{NO}_{3}{ }^{-}$ entre el 0.93 y 0.99 y EC-2-CF de $100 \%$.

- Se registró una mejora cinética del proceso nitrificante, las $\mathrm{qN}^{-\mathrm{NH}_{4}}{ }^{+}, \mathrm{qN}^{-\mathrm{NO}_{3}{ }^{-} \mathrm{y} \mathrm{qC}-}$ 2-CF aumentaron 5.1, 5.2 y 3.1 veces respectivamente.

- Existió una relación directa y significativa entre la $\mathrm{qN}^{-\mathrm{NH}_{4}}{ }^{+}$y la qC-2-CF con un coeficiente de correlación de 0.83 .

- Se estableció un consumo cometabólico de 2-CF por el lodo nitrificante.

II. El estudio de la participación de la enzima AMO en el consumo de 2-CF en los ensayos en lote mostró que:

- En el lodo nitrificante con el que se inició la experimentación, cuando la actividad de la enzima AMO del lodo nitrificante utilizado como inóculo fue inhibida por

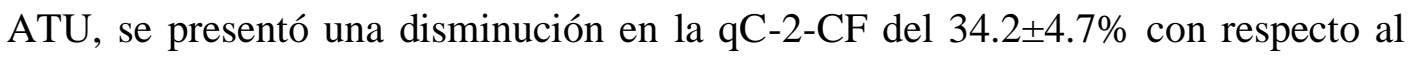
ensayo nitrificante sin ATU, indicando que la AMO participa en el consumo de 2CF.

- Después de 13 ciclos de operación al finalizar la experimentación en los reactores SBR, se encontró que, al inhibir la actividad de la enzima AMO por ATU, la disminución en la qC-2-CF fue del 552.3 $\pm 7.7 \%$ con respecto al ensayo nitrificante sin ATU, indicando una mayor participación de la enzima AMO en el consumo de 2-CF. 
III. En el estudio de la dinámica poblacional del lodo nitrificante en presencia de 2-CF se evidenció que a lo largo de 13 ciclos de operación en los reactores SBR:

- Se presentaron 39 especies diferentes, de las cuales 10 siempre estuvieron presentes.

- Se presentó una tendencia a la disminución en la riqueza de especies (S). Al final de la experimentación se encontraron 22 especies, de las cuales 14 se encontraron desde el inicio.

- La comunidad nitrificante tuvo una tendencia a la homogeneidad al iniciar con una equitatividad ( $\mathrm{J}$ ) de 0.89 y terminar en 0.99. Esta homogeneidad en la comunidad podría estar asociada a la estabilidad del proceso nitrificante.

- El $45 \%$ de las especies encontradas se agruparon como $\beta$-proteobacteria, el $30 \%$ en el grupo de acidobacteria, mientras que el 10 y $15 \%$ restantes en el de $\gamma$ proteobacteria y Deinococcus-thermus.

- El consumo simultáneo de amonio y 2-CF se podría atribuir a la presencia y permanencia de especies de AOB relacionadas con Nitrosomonas marina, Nitrosospira tenuis, Nitrosospira multiformis y Nitrosomonas oligotropha.

- La nitrito-oxidación se podría atribuir a la presencia y permanencia de especies de NOB relacionadas con Nitrococcus mobilis, las cuales junto con las AOB llevaron a cabo la nitrificación completa.

- El consumo de 2-CF se podría atribuir a la presencia de bacterias heterotróficas de los grupos Acidobacteria relacionados con Tellurimicrobium multivorans, Blastocatella fastidiosa, Pyrinomonas methylaliphatogenes y Stenotrophobacter terrae; $\gamma$-proteobacteria relacionadas con Dokdonella ginsengisoli; y deinococcusthermus relacionadas con Deinococcus peraridilitoris y Truepera radiovictrix.

IV. Mediante el análisis de correlación se llegó a lo siguiente:

- Se estableció una relación significativa entre la riqueza de especies (S) y la concentración de amonio y los ciclos de operación (con valores de r de -0.56 y -0.61 respectivamente). La disminución en $\mathrm{S}$ se asocia con el incremento en la concentración de amonio y el transcurso de los ciclos de operación. 
- No se estableció una relación significativa de $\mathrm{S}$ con la respuesta fisiológica (EN$\left.\mathrm{NH}_{4}{ }^{+}, \mathrm{YN}_{-} \mathrm{NO}_{3}{ }^{-}\right)$y cinética $\left(\mathrm{qN}-\mathrm{NH}_{4}{ }^{+}, \mathrm{qN}^{-\mathrm{NO}_{3}}{ }^{-}\right)$del proceso nitrificante ( $\mathrm{r}$ entre 0.15 y -0.51). Esto es, la disminución en la riqueza de especies no se asocia con la respuesta fisiológica y cinética del proceso nitrificante.

- Se mostró una relación significativa de S con la qC-2-CF (r de -0.65), pero no con la EC-2-CF ( $\mathrm{r}$ de -0.45). Es decir, la disminución en la riqueza de especies se asocia con el aumento en la qC-2-CF, pero no con la EC-2-CF.

- Se llevó a cabo una relación significativa entre la equitatividad (J) y la concentración de amonio y los ciclos de operación ( $\mathrm{r}$ de 0.82 y 0.89 respectivamente). La tendencia a la homogeneidad $(\mathrm{J}=0.99)$ se asocia con el incremento en la concentración de amonio y el transcurso de los ciclos de operación.

- Se decretó una relación significativa del índice J con la respuesta fisiológica (EN$\left.\mathrm{NH}_{4}{ }^{+}, \mathrm{YN}_{-} \mathrm{NO}_{3}{ }^{-}\right)$y cinética $\left(\mathrm{qN}-\mathrm{NH}_{4}{ }^{+}, \mathrm{qN}^{-\mathrm{NO}_{3}}{ }^{-}\right)$del proceso nitrificante. La comunidad homogénea $(\mathrm{J})$ se asocia con la respuesta fisiológica y cinética del proceso nitrificante $(r>0.60)$.

- Se presentó una relación significativa de $\mathrm{J}$ con la qC-2-CF ( $\mathrm{r}$ de 0.85 ), pero no con EC-2-CF ( $\mathrm{R}$ de 0.28). La tendencia a la homogeneidad se asocia con el aumento en la $\mathrm{qC}-2-\mathrm{CF}$, pero no con la EC-2-CF.

- Se estableció que el aumento en la proporción de individuos de las diferentes especies obtenidas del DGGE del lodo nitrificante (Dokdonella ginsengisoli, Deinococcus peraridilitoris, Truepera radiovictrix, Stenotrophobacter terrae, Nitrosomonas marina, Nitrosospira tenuis, Nitrosomonas oligotropha, Nitrococcus mobilis) se asocia con el incremento en la concentración de amonio y los ciclos de operación.

- Se señaló que el aumento en la proporción de individuos de especies de AOB como Nitrosospira multiformis y Nitrosomonas oligotropha se asocia con el consumo de amonio (EN-NH$\left.{ }_{4}^{+}>99 \%\right)$, Nitrosomonas marina, Nitrosospira tenuis, Nitrosomonas oligotropha con el incremento de la $\mathrm{qN}-\mathrm{NH}_{4}{ }^{+}$y Nitrosomonas marina, Nitrosomonas oligotropha con el incremento de la $\mathrm{qC}-2-\mathrm{CF}$. 
- Se determinó que el aumento en la proporción de individuos de especies heterotróficas como Dokdonella ginsengisoli, Deinococcus peraridilitoris, Truepera radiovictrix y Stenotrophobacter terrae se asocian con el incremento de la qC-2-CF.

Al final de la experimentación con $60 \mathrm{mg}$ C-2-CF/L y una concentración de 500 mg de $\mathrm{N}-\mathrm{NH}_{4}{ }^{+} / \mathrm{L}$, se obtuvo una comunidad bacteriana homogénea con el aumento en proporción de individuos de algunas especies, que contribuyeron a un proceso fisiológicamente estable con velocidades específicas altas y un consumo cometabólico de 2-CF por la enzima AMO. 


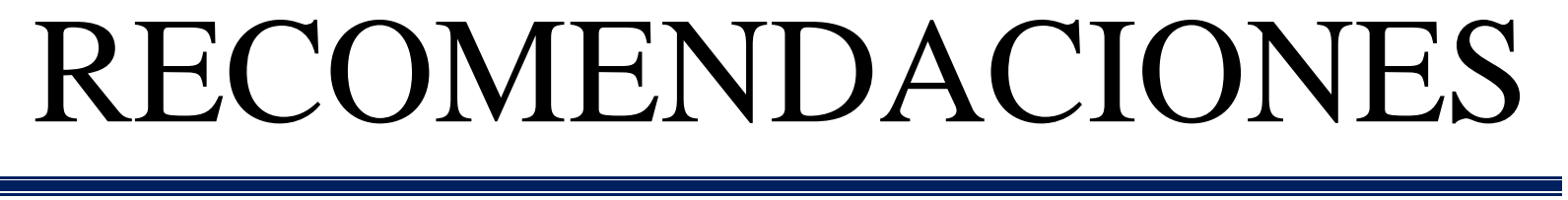




\section{RECOMENDACIONES}

De acuerdo al análisis de resultados y conclusiones de este estudio se recomienda incrementar la concentración inicial de amonio, así como utilizar reactores SBR para obtener una mejora en el proceso nitrificante y el consumo cometabólico de 2-CF.

Dado que es posible que las aguas residuales se encuentren contaminadas con compuestos fenólicos o recalcitrantes, ya sea individualmente o en una mezcla de ellos, y que podrían ocasionar efectos negativos en el proceso respiratorio nitrificante, sería recomendable investigar si un lodo nitrificante tiene la capacidad de consumir cometabólicamente otros compuestos, así como verificar que la enzima AMO participe en el consumo de los mismos.

Puesto que se sigue presentando un efecto inhibitorio del 2-CF sobre el proceso amonio oxidante, sería de gran interés determinar las diferentes constantes cinéticas como ks, km, Vmax, además de conocer el tipo de inhibición que ejerce el 2-CF sobre la amonio oxidación. Esto permitirá implementar modelos matemáticos que ayuden a predecir y simular los posibles efectos del 2-CF sobre el comportamiento amonio-oxidante y por consiguiente llevar a cabo un control del proceso y decisiones sobre los ensayos experimentales.

Por otra parte, en este estudio las técnicas de Biología Molecular permitieron relacionar la dinámica poblacional con las variables de respuesta del lodo nitrificante. Además de la técnica de DGGE, otras técnicas moleculares podrían dar información sobre el comportamiento del consorcio microbiano, tal es el caso de la secuenciación masiva que permite observar un panorama microbiológico de todas las especies presentes en el lodo nitrificante en los reactores SBR. También se podría dar seguimiento a algunos genes de interés, como el de la enzima AMO y conocer su aportación en el consumo de amonio y de 2-CF por medio de la técnica de PCR en tiempo real o PCR en tiempo real con transcriptasa reversa. Finalmente, estudios sobre proteómica permitirían conocer las rutas metabólicas y/o las enzimas involucradas por las cuales se lleva a cabo el consumo de 2-CF por bacterias nitrificantes o heterotróficas. 


\section{REFERENCIAS}

1 Akmirza, I., Pascual, C., Carvajal, A., Pérez, R., Muñoz, R., and Lebrero, R. (2017). Anoxic biodegradation of BTEX in a biotrickling filter. Science of the Total Environment, 587, 457-465.

2 Alvarez-Cohen, L. and Speitel, G. (2001). Kinetics of aerobic cometabolism of chlorinated solvents. Biodegradation. 12, 105-126.

3 Alvarez-Cohen, L. and Speitel, G. (2001). Kinetics of aerobic cometabolism of chlorinated solvents. Biodegradation. 12, 105-126.

4 Anthonisen, A.C., Loehr, R.C., Prakasom, T.B.S. and y Srinath E.G. (1976). Inhibition of nitrification by ammonia and nitrous acid. Journal of Water Pollution Control Federation. 48(5), 835-851.

5 Arciero, D., Vannelli, T., Logan, M. and Hoope,r A. B. (1989). Degradation of trichloroethylene by ammonia-oxidizing bacterium Nitrosomonas europaea. Biochemistry and Biophysical Research Communications. 159, 640-643.

6 Arp, D.J., Yeager, C.M. and Hyman, M.R. (2001). Molecular and cellular fundamentals of aerobic cometabolism of trichloroethylene. Biodegradation. 12, 81-103.

7 Bassin, J., Kleerebensemb, R., Muyzer, G., Soares R., Loosdrecht, M. and Dezotti, M. (2012). Effect of different salt adaptation strategies on the microbial diversity, activity, and settling of nitrifying sludge in sequencing batch reactors. Invironmental Biotechnology. 93, 1281-1294.

8 Becker, P. M. and Dott, W. (1995). Functional analysis of communities of aerobic heterotrophic bacteria from hydrocarbon-contaminated sites. Microbial ecology, 30(3), 285-296.

9 Bejarano-Ortiz, D., Thalasso, F., Cuervo-López, F. and Texier, A-C. (2013). Inhibitory effect of sulfide on the nitrifying respiratory process. Chemical Technology and Biotechnology. 88(7), 1344-1349.

10 Beristain-Montiel, L., Martínez-Hernández, S., Cuervo-López, F., Ramírez-Vives, F. (2015). Dynamics of a microbial community exposed to several concentrations of 2-chlorophenol in an anaerobic sequencing batch reactor. Environmental Technology. 36(14), 1776-1784.

11 Bernal, P., Segura, A. and Ramos, J. (2007). Compensatory role of the cis-trans-isomerase and cardiolipin synthase in the membrane fluidity of Pseudomonas putida DOT-T1E. Environmental Microbiology. 9(7), $1658-1664$.

12 Blum, D. J. and Speece, R. E. (1991). A database of chemical toxicity to environmental bacteria and its use in interspecies comparisons and correlations. Research Journal of the Water Pollution Control Federation, 198-207.

13 Carrera, J. (2004). Eliminación biológica de nitrógeno en un efluente con alta carga. Estudio de los parámetros del proceso y diseño de una depuradora industrial. Tesis Doctoral. Barcelona: Universidad Autónoma de Barcelona.

14 Cervantes, F.J., Cuervo-López, F. and Gómez, J. (2016). Fundamental aspects of biological processes involved in the removal of nitrogen from wastewaters. In: del Río, Angeles Val, Campos G_omez, Jos_e Luis, Mosquera Corral, Anuska (Eds.), Technologies for the Treatment and Recovery of Nutrients from Industrial Wastewater. IGI Global, pp. 112-146.

15 Chiavola, R., Baciocchi, R.L., Irvine, R., Gavasci, P. and Sirini. (2004). Aerobic biodegradation of 3chlorophenol in a sequencing batch reactor: effect of cometabolism. Water Science and Technology. 50 (10), 235-242.

16 Crowe, M., Power, J., Morgan, X., Dunfield, P., Lagutin, K., Rijpstra, W., Vyssotski, M., Damste J., Houghton, K., Ryan, J. and Stott, M. (2014). Pyrinomonas methylaliphatogenes gen. nov., sp. nov., a novel group 4 thermophilic member of the phylum Acidobacteria from geothermal soils. International Journal of Systematic and Evolutionary Microbiology. 64, 220-227. 
17 Cuervo-López, F., Martínez-Hernández, S., Texier, A.C. and Gómez, J., (2009). Denitrification for Wastewater Treatment in: Environmental Technologies to Treat Nitrogen Pollution. Principles and Engineering. International Water Association Publishing, ISBN 9781843392224, pp. 41-65.

18 Dalton, H. and Stirling, D.I. (1982). Co-metabolism. Biol. Sci. Phil. Trans. Roy. Soc. Lond. B 297, 481496.

19 Dionisi, H., Layton A., Harms, G., Gregory, I., Robinson, K. and Sayler G. (2002). Quantification of Nitrosomonas oligotropha-Like AmmoniaOxidizing Bacteria and Nitrospira spp. from Full-Scale Wastewater Treatment Plants by Competitive PCR. Applied and Environmental Microbiology. 68(1), 245-253.

20 Dytczak, M., Londry, K. and Oleszkiewicz, J. (2008). Activated sludge operational regime has significantimpact on the type of nitrifying communityand its nitrification rates. Water research. 42, 23202328.

21 Ely, R.L., Williamson, K.J., Hyman, M.R. and Arp, D.J., (1997). Cometabolism of chlorinated solvents by nitrifying bacteria: kinetics, substrate, interactions, toxicity effects, and bacterial response. Biotechnology Bioenginering. 54, 520-534.

22 Fernandes, H., Jungles, M., Hoffmann, H., Antonio, R. and Costa, R. (2013). Full-scale sequencing batch reactor (SBR) for domestic wastewater: Performance and diversity of microbial communities. Bioresource Technology. 132, 262-268.

23 Fernandez-Fontaina, E., Omil, F., Lema, J. M. and Carballa, M. (2012). Influence of nitrifying conditions on the biodegradation and sorption of emerging micropollutants. Water Research. 46, 5434-5444.

24 Foesel, B., Rohde, M. and Overmann, J. (2013). Blastocatella fastidiosa gen. nov., sp. nov., isolated from semiarid savanna soil - The first described species of Acidobacteria subdivision 4. Systematic and Applied Microbiology. 36(2), 82-89.

25 Füssel, J., Lücker, S., Yilmaz, P., Nowka, B., van Kessel, M. A., Bourceau, P. and Daims, H. (2017). Adaptability as the key to success for the ubiquitous marine nitrite oxidizer Nitrococcus. Science advances. 3(11), e1700807.

26 García-Rivero, M. and Peralta-Pérez, M. (2008). Cometabolism in the biodegradation of hydrocarbons. Revista mexicana de ingeniería química. 7(1), 1-12.

27 Ginestet, P., Audic, J.M., Urbain, V. and Block, J.-C. (1998). Estimation of nitrifying bacterial activities by measuring oxygen uptake in the presence of the metabolic inhibitors allylthiourea and azide Appl. Environmental Microbiology. 64, 2266-2268.

28 Gomez-Alvarez, V., King, G. M. and Nüsslein, K. (2007). Comparative bacterial diversity in recent Hawaiian volcanic deposits of different ages. FEMS microbiology ecology. 60(1), 60-73.

29 Handley, K.M., Wrighton, K.C., Piceno, Y.M., Andersen, G.L., DeSantis, T.Z., Williams, K.H. and Long, P.E. (2012). High-density PhyloChip profiling of stimulated aquifer microbial communities reveals a complex response to acetate amendment. FEMS microbiology ecology, 81(1), 188-204.

30 Hyman, M.R., Russell, S.A., Ely, R.L., Williamson, K.J. and Arp, D.J., (1995). Inhibition,inactivation, and recovery of ammonia-oxidizing activity in cometabolism oftrichloroethylene by Nitrosomonas europaea. Applied and Environmental Microbiology. 61(4), 1480-1487.

31 Irvine, R., Wilderer, P. and Flemming, H. (1997). Controlled unsteady state processes and technologies an overview. Water Science and technology. 35(1), 1-10.

32 Jesus, J., Frascari, D., Pozdniakovac, T. and Dankoa A. (2016). Kinetics of aerobic cometabolic biodegradation of chlorinated and brominated aliphatic hydrocarbons: A review. Journal of Hazardous Materials. 309, 37-52. 
33 Keener, W. and Arp, D.J. (1994). Transformation of aromatics compouns by Nitrosomonas europaea. Applied and Environmental Microbiology. 60, 1914-1920.

34 Ketchum, J. (1997). Design and Physical Features of Sequencing Batch Reactors. Water Science and technology. 35(1), 11-18.

35 Khademi, S., O'Connell, J., Remis, J., Robles-Colmenares, Y., Miercke, L.J. and Stroud, R.M. (2004). Mechanism of ammonia transport by Amt/MEP/Rh: structure of AmtB at $1.35 \AA$ Acience. 305(5690), $1587-1594$.

36 Kocamemi, B. and Çeçen, A. F. (2010). Biological removal of the xenobiotic trichloroethylene (TCE) through cometabolism in nitrifying systems. Bioresource Technology.101, 430-433.

37 Kocamemi, B. and Çeçen, A. F. (2010). Biological removal of the xenobiotic trichloroethylene (TCE) through cometabolism in nitrifying systems. Bioresource Technology.101, 430-433.

38 Kocamemi, B. and Çeçen, A.F. (2007). Kinetic analysis of the inhibitory effect of trichloroethylene (TCE) on nitrification in cometabolic degradation. Biodegradation. 18(1), 71-81.

39 Kocamemi, B. and Çeçen, A.F. (2007). Kinetic analysis of the inhibitory effect of trichloroethylene (TCE) on nitrification in cometabolic degradation. Biodegradation. 18(1), 71-81.

40 Koops, Bottcheru, B., Mollera, C., Pommerening-roser, A. and Stehr, G. (1991). Classification of eight new species of ammonia-oxidizing bacteria: Nitrosomonas communis sp. nov., Nitrosomonas ureae sp. nov., Nitrosomonas aestuarii sp. nov., Nitrosomonas marina sp. nova, Nitrosomonas nitrosa sp. nov., Nitrosomonas eutropha sp. nov., Nitrosomonas oligotropha sp. nov. and Nitrosomonas halophila sp. nov. Journal of General Microbiology. 137, 1689-1699.

41 Li, S., Ma, B., Zhao, C., She, Z., Yu, N., Pan, Y., Gao, M., Guo, L., Jin, C. and Zhao Y. (2019). Longterm effect of different $\mathrm{Cu}$ (II) concentrations on the performance, microbial enzymatic activity and microbial community of sequencing batch reactor. Environmental Pollution. 255, 113-216.

42 Lin, Y., Zexing, C. and Yirong, M. (2006). Molecular Dynamic simulations on the Escherichia coli ammonia channel protein AmtB: mechanism of ammonia/ ammonium transport. J. Am. Chem. Soc. 128 (33), 10876-10884.

43 Liu, C., Yang, J., Wu G. Zhang, S. Li, Z.X. and Guo, J.B. (2010). Estimation of dominant microbial population sizes in the anaerobic granular sludge of a full-scale UASB treating streptomycin wastewater by PCR-DGGE. World J Microbiol Biotechnol. 26, 375-379.

44 Liu, D., Maguire, R.J., Pacepavicius, G., and Dutka, B.J. (1991). Biodegradation of Recalcitrant Chlorophenols by Cometabolism. Environmental Toxicology and Water Quality: An International Journal. 6, 85-95. 29.

45 Ma, G., Pei, H., Hu, W., Xu, X., Ma, C. and Pei, R. (2016). Effects of glucose on microcystin-LR removal and the bacterial community composition through anoxic biodegradation in drinking water sludge. Environmental technology. 37(1), 64-73.

46 Martínez-Hernández, S., Texier, A-C., Cuervo-López, F. and Gómez, J. (2011). 2-Chlorophenol and its effect on the nitrifying sludge. Journal Hazardous Materials.185, 1592-1595.

47 Martínez-Jardines, M. (2015). Evaluación de la inhibición de la nitrificación en presencia de 2-clorofenol y la dinámica poblacional del consorcio nitrificante. Tesis de maestría. Universidad Autónoma Metropolitana Iztapalapa.

48 Martínez-Jardines, M., Perez-Alfaro, E., Gonzalez-Robles, R.O., Texier, A.-C. and Cuervo-López, F., (2019). Decrease of inhibitory effect of 2-chlorophenol on nitrification in sequencing batch reactors. Environmental Technology. 40(26), 3422-3433. 
49 Meerbergen, K., Van Geel, M., Waud, M., Willems, K. A., Dewil, R., Van Impe, J., Appels, L. and Lievens, B. (2017). Assessing the composition of microbial communities in textile wastewater treatment plants in comparison with municipal wastewater treatment plants. Microbiology Open. 6, e00413.

50 Monsalvo, V.M., Mohedano, A.F., Casas, J.A. and Rodríguez, J.J. (2009). Cometabolic biodegradation of 4-chlorophenol by sequencing batch reactors at different temperatures. Bioresource Technology. 100(20), $4572-4578$.

51 Nicolaisen, M. and Ramsing, N. (2002). Denaturing gradient gel electrophoresis (DGGE) approaches to study the diversity of ammonia-oxidizing bacteria. Journal of Microbiological Methods. 50, 189-203.

52 Nowak, A. and Mrozik, A. (2018). Degradation of 4-chlorophenol and microbial diversity in soil inoculated with single Pseudomonas sp. CF600 and Stenotrophomonas maltophilia KB2. Journal of environmental management, 215, 216-229.

53 Pascual, J., Wüsta, P., Gepperta, A., Foesela, B., Hubera, K. and Overmann, J. (2015). Novel isolates double the number of chemotrophic species and allowthe first description of higher taxa in Acidobacteria subdivision 4. Systematic and Applied Microbiology 38, 534-544.

54 Peng, Y. and Zhu G. (2006). Biological nitrogen removal with nitrification and denitrification via nitrite pathway. Applied Microbiology and Biotechnology. 75, 15-26.

55 Pérez-Alfaro, E. (2015). Efecto del 2-clorofenol sobre la nitrificación. Tesis de doctorado. Universidad Autónoma Metropolitana Iztapalapa.

56 Pérez-Alfaro, J.E., Buitrón, G., Gómez, J., Texier, A-C. and Cuervo-López, F. M. (2013). Kinetic and Physiological Evaluation of Ammonium and Nitrite Oxidation Processes in Presence of 2-Chlorophenol. Applied Biochemistry and Biotechnology. 169(3), 990-1000.

57 Salas-Cortés, J., Cuervo-López, F. and Texier, A.-C.. (2017). Simultaneous oxidation of ammonium and cresol isomers in a sequencing batch reactor: physiological and kinetic study. Environ. Sci. Pollut. Res. 24(33), 25667-25675.

58 Segura, A., Duque, E., Rojas, A., Godoy, P., Delgado, A., Hurtado, A., Cronan, J. and Ramos, J. (2004). Fatty acid biosynthesis is involved in solvent tolerance in Pseudomonas putida DOT-T1E. Environmental Microbiology. 6(4), 416-423.

59 Sikkema, J., Bont, J. and Poolman, B. (1995). Mechanisms of membrane toxicity of hydrocarbons. Microbiology and Molecular Biology Reviews. 59(2), 201-222.

60 Silva, C.D., Beristain-Montiel, L., Cuervo-López, F. and Texier, A-C. (2014). p-cresol mineralization and bacterial population dynamics in a nitrifying sequential batch reactor. Journal of Environmental Sciences. 26, 1885-1893.

61 Silva, C.D., Gómez, J, Beristain-Cardoso, R. Cuervo-López, F. and Texier, A-C. (2009). p-cresol biotransformation by a nitrifying consortium. Chemosphere. 75, 1387-1391

62 Silva, C.D., Gómez, J. and Beristain-Cardoso, R. (2011). Simultaneous removal of 2-chlorophenol, phenol, p-cresol and p-hydroxybenzaldehyde under nitrifying conditions: Kinetic study. Bioresource Technology. 102, 6464-6468.

63 Siripong, S. and Rittmann, B. (2007). Diversity study of nitrifying bacteria in full-scale municipal wastewater treatment plants. Water research. 41, 1110-1120.

64 Téllez-Pérez, S., Silva, D. and Texier, A-C. (2013). Simultaneous ammonium and $p$-hydroxybenzaldehyde oxidationin a sequencing batch reactor. Revista Mexicana de Ingeniería. 12(1), 97-104.

65 Ten, L.N., Jung, H.M., Im, W.T., Oh, H.W., Yang, D.C., Yoo, S.A. and Lee, S.T. (2009). Dokdonella ginsengisoli sp. nov., isolated from soil from a ginseng field, and emended description of the genus Dokdonella. International journal of systematic and evolutionary microbiology. 59(8), 1947-1952. 
Terada, A., Sugawara, S., Yamamoto, T., Zhou, S., Koba, K. and Hosomi, M. (2013). Physiological characteristics of predominant ammonia-oxidizing bacteria enriched from bioreactors with different influent supply regimes. Biochemical engineering journal, 79, 153-161.

67 Texier, A-C. and Gómez, J. (2004). Settleability and kinetics of a nitrifying sludge in a sequencing batch reactor. Canadian Journal of Microbiology. 50, 943-949.

68 Texier, A-C. and Gómez, J. (2007). Simultaneous nitrification and p-cresol oxidation in anitrifying sequencing batch reactor. Water research. 41, 315-322.

69 Tran, N., Urase, T., Ngo, H., Hu, J. and Ong, S. (2013). Insight into metabolic and cometabolic activities of autotrophic and heterotrophic microorganisms in the biodegradation of emerging trace organic contaminants. Bioresource Technology. 146, 721-731.

70 Vannelli, T., Logan, M., Arciero, D.M. and Hooper, A.B. (1990). Degradation of halogenatedaliphatic compounds by the ammonia-oxidizing bacterium Nitrosomonaseuropaea. Appl. Environ. Microbiol. 56 (4), 1169-1171.

71 Watanabe, T., Hisaya Kojima, H., Fukui, M. (2016). Sulfuriferula thiophila sp. nov., a chemolithoautotrophic sulfur-oxidizing bacterium, and correction of the name Sulfuriferula plumbophilus Watanabe, Kojima and Fukui 2015 to Sulfuriferula plumbiphila corrig. International Journal of Systematic and Evolutionary Microbiology. 66, 2041-2045.

72 Watson, S.W. and Waterbury, J.B. (1971). Characteristics of two marine nitrite oxidizing bacteria, Nitrospina gracilis nov. gen. nov. sp. and Nitrococcus mobilis nov. gen. nov. sp. Archiv für Mikrobiologie. 77(3), 203-230.

73 Whang, L.M., Chien, I.C., Yuan, S.L. and Wu, Y.J. (2009). Nitrifying community structures and nitrification performance of full-scale municipal and swine wastewater treatment plants. Chemosphere. 75(2), 234-242.

74 Wiesmann, U. (1994). Biological nitrogen removal from wastewater. In: Advances in biochemical engineering/biotechnology, A. Fiechter, (Ed.), 113-154, Springer, Verlag, Berlin

75 Winkler, M-K.H., Kleerebezem, R. Bruin, L., Abbas, B., Habermacher, J.M. and van Loosdrecht, C.M. (2013). Microbial diversity differences within aerobic granular sludge and activated sludge flocs. Appl Microbiol Biotechnol. 97, 7447-7458.

76 Yang, Q., Xiong, P., Ding P., Chu L. and Wang, J. (2015). Treatment of petrochemical wastewater by microaerobic hydrolysis and anoxic/oxic processes and analysis of bacterial diversity. Bioresource Technology. 196, 169-175.

77 Zepeda, A., Ben-Youssef, C., Rincon, S., Cuervo-López, F. and Gómez, J. (2012). Complete and simultaneous removal of ammonium and $m$-cresol in a nitrifying sequencing batch reactor. Biodegradation. 24(3), 377-385.

78 Zepeda, A., Texier, A-C., Razo-Flores, E. and Gómez, J. (2003). Benzene Transformation in Nitrifying Batch Cultures. Biotecnologia Progress. 19, 789-793

79 Zhang, L., Shen, Z., Fang, W. and Gao, G. (2019). Composition of bacterial communities in municipal wastewater treatment plant. Science of The Total Environment. 689, 1181-1191.

80 Zheng, L., Kostrewa, D., Bernèche, S., Winkler, F.K. and Li, X.D. (2004). The mechanism of ammonia transport based on the crystal structure of AmtB of Escherichia coli. Proceedings of the National Academy of Sciences. 101(49), 17090-17095. 


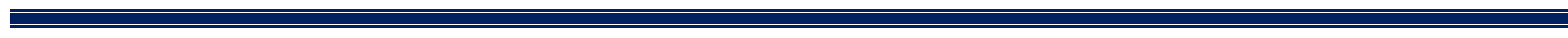

ANEXOS 


\section{ANEXOS}

\subsection{Artículo publicado}

Chemosphere $2 \mathrm{I2}$ (2018) 41-49

\section{2-Chlorophenol consumption by cometabolism in nitrifying SBR reactors}

Miguel Martínez-Jardines ${ }^{a}$, Sergio Martínez-Hemández ${ }^{\mathrm{b}}$, Anne-Claire Texier ${ }^{\mathrm{a}}$, Flor Cuervo-López ${ }^{\text {a, * }}$

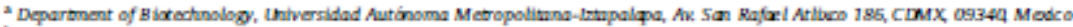

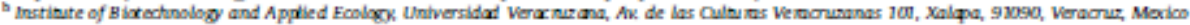

H I G H L I G H T S

- Complete and simultaneous nitrification and 2-CP consumption in SBR systems

- Increase of 2- $\alpha$ consumption spe cific rate due to increasing NHt concentrations

- Positive carrelation between specific rates of $2-\alpha$ consumption and $\mathrm{NH}_{4}^{+}$ oxidation.

- Cometabolic consumption of 2-CP by the AMO enzyme by a ritrifying sludge

- Increase of AMO participation in $2 \mathrm{CP}$ consumption along the operation cycles.

A R T I CLE I N F O

Article hestory:

Recelved 14 May 2018

Received in revised form

25 July 2018

Accepted 14 August 2013

Avallable online 15 August 2018

Handl ing editor. $Y . \mathrm{Lu}$

Neywords

2-Ch lomp henol

Ammonium monocangenase

Ammonium m

Cometabolis

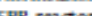

G R A P H I C A L A B S T R C T

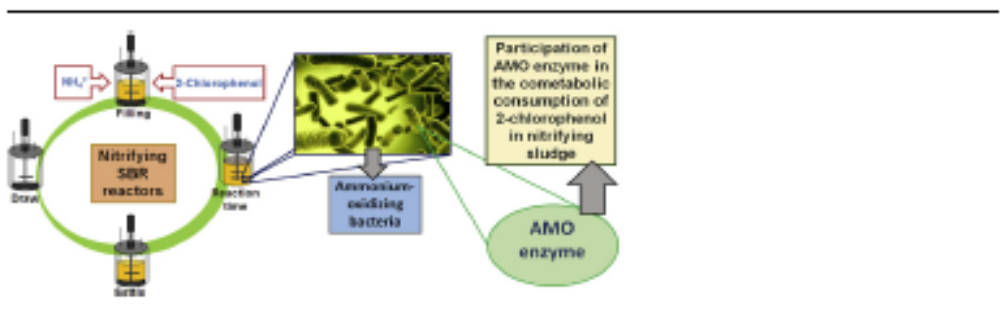

A B S T R A C T

Cometabolic consumptian of 2 -chlorophenol (2-CP) by a nitrifying sludge was evaluated in two SBR reactors fed with $60 \mathrm{mg} 2-C P-C /$ and different initial ammonium concentrations (100, 200, 300, 400, and $500 \mathrm{mg}$ $\mathrm{NH}+-\mathrm{N} / \mathrm{L}$, lrrespectively to the increase in ammanium cance ntration and throughout the operational cycles theslud ge adtieved a complete nitrification in 14 drys, accounting for ammonium consumption efficiencies clase to $99 \%$ and nitrate production yields between 0.93 and 0.99 . The sludge was able to completely cansume 2 CP within 7 days. The increase in ammonium concentration provoked an increment in the specific rates of both ammonium ( $\left(\mathrm{N} N \mathrm{H}_{4}-\mathrm{N}\right)$ and $2-\mathrm{QP}(\mathrm{q} 2-\mathrm{CP}-\mathrm{C})$ cansumption up to 52 and 3.1 times, respectively. The cometabolic effect of the increase in ammonium conoentration on 2 -CP consumption was supported by a direct and significant relations hip between the qNH $4-\mathrm{N}$ and q2.CP.C $(\mathrm{r}-0.83)$. Moreovet bach assays conduxted with ammonium 2-CP, allylthioure a as specific inhibitor of the ammonium monooxygenase (AMO) enzyme, and the sluxl ge inoculated into the reactors, resulted in a decrease of $34 x$ in $\mathrm{q}_{2}$. CP.C, evidencing the participation of the AMO in the consumption of 2 CP. When the same assays were $C P C$, evidencing the par tidpation of the $A M O$ in the consumption of 2 CP. When the same assiys were the AMO in 2-CP consumptian was noticed with adecrease of $53 \%$ in $Q 2-C P$ - C.According to these results, the use of nitrifying sluxlge and high ammonium conce ntrations in SBR systems can be a suitable alternative for increasing the cometabolic consumption of recald trant compounds like 2 -CP.

Q 2018 Elsevier ltd. All rights reserved.

\footnotetext{
Corresponding author.

E-mal aldres: fmdaxanum.uam.mx (F. Cuervo-lópez)
}

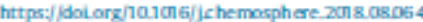
00456535102018 Floewer Ltal. All rights reserved 


\section{Introduction}

The widespread use of 2-chlorophenol (2-CP) as a structural part of pesticides and preservers in the wood industry; in petrochemical, textile, and paper industries as well as its solubility $(2.8 \mathrm{~g} /$ $100 \mathrm{~mL}$ of $\mathrm{H}_{2} \mathrm{O}$ ) has become in soils and diverse aquifers pollution (Czaplicka, 2004; Pera-Titus et al., 2004; Puhakka and Melin, 1996). Like other chlorophenols, 2-CP could become toxic, mutagenic, and carcinogenic and its environmental impact on air, water, and soil is significant (Majumder and Gupta, 2007). The Agency for toxic substances and disease registry has considered 2-CP removal as a priority concern (ATSDR, 2015).

It has been reported that several microorganisms are able to degrade by cometabolism different recalcitrant organic compounds, as aromatic and halogenated compounds (Hao et al., 2002; Liu et al., 1991). Cometabolism has been defined as the capacity of microorganisms to transform a substrate that is not used as growth support in the obligatory presence of a growth substrate or easily transformable or biodegradable compound in aerobic or anaerobic conditions (Arp et al., 2001; Dalton and Stirling, 1982; Jesus et al,, 2016). Under aerobic conditions, some strains of Pseudomonas putida have the capacity to biodegrade chlorinated phenolic compounds such as 2-CP and 4-chlorophenol (4-CP) in the presence of phenol as growth substrate (Kai-Chee and Tingting, 2006). Ammonium-oxidizing bacteria such as Nitrosomonas europaea are capable of cometabolically biodegrade different chlorinated organic compounds such as dichloroethylene (DCE), trichloroethylene (TCE), chloroform (CF), and dichloroethane (DE) in the presence of ammonium (Ely et al., 1997). There is also information indicating that nitrifying consortia are candidates for conducting the biological consumption of recalcitrant organic compounds throughout cometabolism (Tran et al., 2013). Kocamemi and Çeçen 2010) reported results on the cometabolic removal of TCE with a nitrifying consortium when an increase in ammonium concentration resulted in a higher specific consumption rate of TCE. Likewise, it has been reported the cometabolic biodegradation of 3chlorophenol (3-CP) (Chiavola et al., 2004) and 4-CP (Monsalvo et al., 2009) in sequencing batch reactor (SBR) systems inoculated with activated sludge where phenol was added as growth substrate. Nevertheless, more information on cometabolic consumption of chlorophenols by nitrifying consortia where ammonium could be acting as primary substrate is required.

In nature, nitrification is carried out altogether with denitrification, maintaining an efficient recirculation of nitrogen. However, the huge generation of ammonium is much higher than its recirculation rate, provoking foremost environmental problems (Cervantes et al., 2016). Nitrification is carried out in two successive metabolic stages. The first stage consists of two reactions performed by ammonium-oxidizing bacteria (AOB), starting with the oxidation of ammonium to hydroxylamine through the activity of ammonium monooxygenase (AMO) enzyme and ending with the oxidation of hydroxylamine to nitrite, which is catalyzed by hydroxylamine oxide reductase enzyme. Subsequently, in the second stage of nitrification, the nitrite-oxidizing bacteria (NOB) oxidize nitrite to nitrate by the action of nitrite oxide reductase (NOR) enzyme (Bock et al., 1991). In each stage, the nitrifying bacteria use ammonium or nitrite as energy source, molecular oxygen as the final electron acceptor and $\mathrm{CO}_{2}$ as carbon source. Nitrification is one of the main microbial processes used in wastewater treatment for biological nitrogen removal. The high sensitivity of the nitrifying processes to the toxic or inhibitory effects of various organic compounds is well documented in literature (Schweighofer et al., 1996; Texier et al., 2012). It has been reported that 2-CP is a potent inhibitor of nitrification (Pérez-Alfaro et al., 2013).
Nonetheless, time of 3 days to begin the consumption of $5 \mathrm{mg} 2-\mathrm{CP}-$ $\mathrm{C} / \mathrm{L}$ by a sludge acclimated to 4-methylphenol in nitrifying batch assays has been reported (Pérez-Alfaro et al., 2015) and 14 days for the consumption of up to $20 \mathrm{mg} 2-\mathrm{CP}-\mathrm{C} / \mathrm{L}$ by nitrifying sludge acclimated to phenolic compounds in SBR systems (MartínezJardines et al., 2018). In these works, the time to carry out the oxidation of $100 \mathrm{mg} \mathrm{NH}_{4}^{-}-\mathrm{N} / \mathrm{L}$ to nitrate was comprised between 7 and 21 days as 2-CP kept presenting a negative effect on the nitrifying process. The use of SBR has been implemented as strategy for promoting the biodegradation of a wide range of toxic or inhibitory organic compounds, such as 4-CP, 2,4-dichlorophenol, 2,4,6-trichlorophenol (Buitron et al., 2001), phenol (Yoong et al., 2000), and 2-CP (Basu and Oleszkiewicz, 1995) under aerobic conditions. However, there is a lack of studies that address the use of nitrifying SBR systems amended with ammonium and 2-CP to evaluate the biodegradation processes along the cycles. In spite of the inhibitory effects of organic matter on AOB activity, it is known that these microorganisms have the capacity to oxidize diverse organic compounds, which has been associated with the AMO enzyme affinity for organic compounds, including chlorinated aliphatic compounds such as DCE, TCE, and even CF (Ely et al., 1997); as well as aromatic compounds, such as benzene, ethylbenzene, chlorobenzene, toluene, $p$-cresol, and p-xylene (Keener and Arp, 1994; McCarty, 1999). It has been also reported that many of the cometabolic reactions are carried out by oxygenase enzymes, such as methane monooxygenase, toluene mono and dioxygenase, biphenyloxygenase and AMO enzyme (Furukawa, 2000; Hazen, 2010).

It has been reported that in a nitrifying consortium, the specific consumption rate of TCE or DE increased with the increase in ammonium concentration (Kocamemi and Çeçen, 2007a,b). Under these conditions, ammonium consumption rate was also increased. Information on the enhancement of cometabolic consumption of chlorophenols by nitrifying consortia through the addition of increasing ammonium concentrations is missing in literature and more research is needed in this topic. Regarding this, the cometabolic consumption of 2-CP under nitrifying conditions could be sustained by the increasing presence in both industrial and municipal effluents of ammonium, which could be acting as a primary or growth substrate. Therefore, further work is necessary for generating more information about the kinetic and physiological behavior of nitrifying consortia in SBR reactors conducing cometabolic degradation of 2-CP. Thus, the aim of this work was to evaluate in nitrifying SBR reactors the cometabolic consumption of 2 -CP, when ammonium was added as growth substrate at increasing initial concentrations. Special emphasis was paid on evaluating in nitrifying batch assays, the participation of AMO enzyme in 2-CP consumption. Physiologic and kinetic evaluation of the nitrifying process throughout operation cycles and in batch assays was done by means of ammonium consumption efficiencies, nitrate production yields and specific rates of substrates (ammonium and 2-CP) consumption and nitrate generation.

\section{Materials and methods}

2.1. Nitrifying assays in sequencing batch reactors: effect of initial ammonium concentration on 2-CP consumption

Two nitrifying sequencing batch reactors (Applikon ADI 1012, Holland) of $2 \mathrm{~L}$ capacity and $1.2 \mathrm{~L}$ of operation volume (SBR1 and SBR2) were set up for evaluating the effect of different initial concentrations of ammonium (mg N/L): 100, 200, 300, 400 and 500 on the nitrifying process and consumption of $60 \mathrm{mg}$ of $2-\mathrm{CP}-\mathrm{C} / \mathrm{L}$ throughout the operation cycles. One cycle with $100 \mathrm{mg} \mathrm{NH}_{4}^{+}-\mathrm{N} / \mathrm{L}$ 
and three cycles with the other concentrations were assayed resulting in 13 cycles of total experimentation. The SBRs were inoculated with nitrifying sludge $(354.7 \pm 9.9 \mathrm{mg} / \mathrm{L}$ of microbial protein as biomass) obtained from a SBR reactor fed with ammonium (100 $\left.\mathrm{mg} \mathrm{NH}_{4}-\mathrm{N} / \mathrm{L}\right)$ and $2-\mathrm{CP}(60 \mathrm{mg} 2-\mathrm{CP}-\mathrm{C} / \mathrm{L})$ for 11 months. The reactors were fed with a mineral medium consisting of nitrogen (medium A) and carbon (medium B) source. The chemical composition of medium A was ( $\mathrm{g} / \mathrm{L}): \mathrm{NH}_{4} \mathrm{Cl} 0.385,\left(\mathrm{NH}_{4}\right)_{2} \mathrm{SO}_{4} 0.47$, $\mathrm{KH}_{2} \mathrm{PO}_{4} 0.56, \mathrm{MgSO}_{4} 0.4$ and $\mathrm{NaCl} 0.4$. Medium B consisted (g/L) of: $\mathrm{NaHCO}_{3} 3.5, \mathrm{CaCl}_{2} 0.02$ and $1 \mathrm{~mL}$ of a solution of $\mathrm{FeSO}_{4} \cdot 7 \mathrm{H}_{2} \mathrm{O}(5 \% \mathrm{v} /$ v). Depending on the concentration of ammonium $\left(\mathrm{NH}_{4} \mathrm{Cl}\right.$ and $\left.\left(\mathrm{NH}_{4}\right)_{2} \mathrm{SO}_{4}\right)$ fed, the respective bicarbonate concentration was added to maintain a $\mathrm{C} / \mathrm{N}$ ratio of 2.5. The addition of $60 \mathrm{mg} 2-\mathrm{CP}-\mathrm{C} / \mathrm{L}$ was not considered in the $\mathrm{C} / \mathrm{N}$ ratio and no other additional source of organic carbon was added. Reactors remained sealed to avoid 2CP losses and were intermittently aerated twice a day with $\mathrm{O}_{2}(99 \%$ purity) for maintaining a dissolved oxygen (DO) concentration of $4.1 \pm 1.7 \mathrm{mg} / \mathrm{L}$. Initial medium $\mathrm{pH}$ was $8.1 \pm 1.3$, room temperature and stirred at $250 \mathrm{rpm}$. Operation cycles were divided into the following periods: filling $=0.02 \mathrm{~d}$; reaction time $=14-21 \mathrm{~d}$; settle $=0.02 \mathrm{~d}$ and draw $=0.083 \mathrm{~d}$. Samples from each SBR culture were withdrawn at different times over the reaction phase of cycles, filtered $(0.45 \mu \mathrm{m})$ and analyzed for ammonium, nitrite, nitrate, and 2-CP, for obtaining nitrifying and 2-CP consumption profiles and kinetic studies at different operation cycles. Control abiotic assays with mineral medium supplemented with $20 \mathrm{mg} 2-\mathrm{CP}-\mathrm{C} / \mathrm{L}$ in absence of nitrifying sludge were also conducted in both SBR systems during a period of 6 days to measure the loss of 2-CP by volatilization or chemical reaction.

\subsection{Nitrifying batch assays: participation of AMO enzyme in 2-CP} consumption

In batch assays, participation of AMO enzyme in 2-CP consumption was determined with the sludge inoculated into SBR systems at the beginning of the experimentation and with the sludge obtained at the end of experimentation in SBR reactors after 13 operation cycles. Batch assays were performed in serological bottles of $160 \mathrm{~mL}$ with an operation volume of $100 \mathrm{~mL}$ and inoculated with $207.1 \pm 3.5 \mathrm{mg}$ of microbial protein/L as biomass. Medium composition was (g/L): $\mathrm{NH}_{4} \mathrm{Cl} 0.193,\left(\mathrm{NH}_{4}\right)_{2} \mathrm{SO}_{4} 0.24, \mathrm{KH}_{2} \mathrm{PO}_{4}$ $0.28, \mathrm{MgSO}_{4} 0.2, \mathrm{NaCl} 0.2, \mathrm{NaHCO}_{3} 1.75, \mathrm{CaCl}_{2} 0.01$ and $0.5 \mathrm{~mL}$ of a solution of $\mathrm{FeSO}_{4} \cdot 7 \mathrm{H}_{2} \mathrm{O}(5 \% \mathrm{v} / \mathrm{v})$. Four assays with $100 \mathrm{mg} \mathrm{NH} \mathrm{H}_{4}^{-\mathrm{N}} / \mathrm{L}$ and $\mathrm{C} / \mathrm{N}$ ratio of 2.5 were carried out (the addition of $5 \mathrm{mg} \mathrm{2-CP-C/L}$ was not considered in the $\mathrm{C} / \mathrm{N}$ ratio): 1 ) Reference nitrification; 2) Nitrification in presence of $40 \mathrm{mg}$ allylthiourea/L (ATU) as a specific inhibitor for AMO enzyme activity (Silva et al., 2009); 3) Nitrification in presence of $5 \mathrm{mg} \mathrm{2-CP-C/L}$ and 4) Nitrification in presence of $40 \mathrm{mg}$ ATU/L and $5 \mathrm{mg}$ 2-CP-C/L. The medium was bubbled for 2 min with oxygen (99\% purity). Bottles were inoculated, added with 2-CP and/or ATU according to each test, hermetically sealed with a rubber stopper and an aluminum ring and finally, the headspace was saturated for 2 min with oxygen (99\% purity). Initial $\mathrm{pH}$ value of the medium was $8.0 \pm 0.9$. Bottles were incubated at $28^{\circ} \mathrm{C}$ and stirred at $200 \mathrm{rpm}$. The assays were performed in duplicate and independent samples were withdrawn at various times during 15 days of culture and filtered $(0.45 \mu \mathrm{m})$ for analyzing ammonium, nitrite, nitrate, and 2-CP. Abiotic control assays with mineral medium $(50 \mathrm{~mL}), 40 \mathrm{mg}$ ATU/L and $20 \mathrm{mg} 2-\mathrm{CP}-\mathrm{C} / \mathrm{L}$, without oxygen in absence of biomass were conducted in serologic bottles of $100 \mathrm{~mL}$ capacity. Finally, 2-CP adsorption on the nitrifying sludge was assessed. In doing so, mineral medium $(70 \mathrm{~mL})$ supplemented with $20 \mathrm{mg} 2-\mathrm{CP}-\mathrm{C} / \mathrm{L}$ and $204 \pm 16 \mathrm{mg}$ microbial protein/L of sterilized nitrifying sludge $\left(120^{\circ} \mathrm{C}\right.$ for $\left.15 \mathrm{~min}\right)$ were placed in serologic bottles of $100 \mathrm{~mL}$ capacity without oxygen. The bottles were incubated at $28^{\circ} \mathrm{C}$ during 6 days by duplicate to measure the loss of 2-CP. Loss of 2-CP was established as the difference between initial and final concentrations of 2-CP detected in the liquid phase.

\subsection{Analytical methods}

Ammonium concentration was analyzed by a selective electrode (Phoenix Electrode Company, USA). Nitrite and nitrate concentrations were determined by capillary electrophoresis (Beckman Coulter, USA) according to Martínez-Hernández et al. (2011). Concentration of 2-chlorophenol was determined by HPLC (Perkin Elmer, series 200, USA) using a reverse phase column C-18 (Bondclone, Phenomenex, $300 \times 3.9 \mathrm{~mm}$, USA) and a UV detector at $274 \mathrm{~nm}$. The mobile phase was acetonitrile/water $(60 / 40, \mathrm{v} / \mathrm{v})$ at a flow of $1.5 \mathrm{~mL} / \mathrm{min}$ as reported by Martínez-Hernández et al. (2011). Modified Lowry's method was used for measuring microbial protein concentration (Lowry et al., 1951; Martínez et al., 2004). DO concentration and $\mathrm{pH}$ were measured by selective electrodes (DO HI98186 Hanna, Romania and Digi-Sense digital pH, USA, respectively). Standard curves for each analytical method were performed resulting in variation coefficients of the slope lower than $6 \%$ and determination coefficients $\left(\mathrm{r}^{2}\right)$ higher than 0.98 .

2.4. Evaluation of the nitrifying process, 2-CP consumption and statistical analysis

In both SBR reactors and batch assays, the nitrifying activity and 2-CP consumption were evaluated by the following response variables: ammonium $\left(\mathrm{ENH}_{4}^{+}-\mathrm{N}\right)$ and 2-CP (E2-CP-C) consumption efficiency ([mg $\mathrm{N}$ or $\mathrm{C}$ consumed/mg $\mathrm{N}$ or $\mathrm{C}$ fed] $\times 100$ ), nitrate production yield $\left(\mathrm{YNO}_{3}^{-}-\mathrm{N}\right.$, [mg $\mathrm{NO}_{3}^{-}-\mathrm{N}$ produced/mg $\mathrm{NH}_{4}^{-}-\mathrm{N}$ consumed $]$ ), biomass yield production ( $\mathrm{YBM}=\mathrm{mg}$ biomass- $\mathrm{N}$ produced/mg $\mathrm{NH}_{4}-\mathrm{N}$ consumed or $\mathrm{mg}$ biomass-C/mg 2-CP-C consumed) and specific rates of substrates $\left(\mathrm{NH}_{4}^{-}-\mathrm{N}, 2-\mathrm{CP}-\mathrm{C}\right)$ consumption and product $\left(\mathrm{NO}_{3}^{-}-\mathrm{N}\right)$ generation ( $\mathrm{q}$, [mg Nor $\mathrm{C} / \mathrm{g}$ protein d]).

Specific rates for substrates consumption or product generation were calculated using the adjusted Gompertz model (Zwietering et al., 1990) according to equation (1) where concentration of ammonium or 2-CP consumed, nitrate produced $Y(\mathrm{t})[\mathrm{mg} / \mathrm{L}]$, at time $t[\mathrm{~d}]$, can be expressed as a function of time. Increments in the amount of ammonium and 2-CP consumed $[\mathrm{mg} / \mathrm{L}]$ were calculated along experimental time regarding the respectively initial $\mathrm{NH}_{4}^{-}-\mathrm{N}$ or 2-CP-C concentrations. In this sense and according to Gompertz model, $Y(\mathrm{t})$ represents the increment of $\mathrm{NH}_{4}^{-}-\mathrm{N}$ or $2-\mathrm{CP}-\mathrm{C}$ consumed $[\mathrm{mg} / \mathrm{L}], A$ is the maximum concentration of $\mathrm{NH}_{4}^{-}-\mathrm{N}$ or 2$\mathrm{CP}-\mathrm{C}$ consumed $[\mathrm{mg} / \mathrm{L}]$ when time tends to infinity, $\mathrm{C}$ is the inflection time [d], while $B$ is the ammonium or 2-CP volumetric consumption rate $[\mathrm{mg} / \mathrm{Ld}]$ and $t$ is time $[\mathrm{d}]$. When adjusting nitrate production performance over experimental time, $Y(\mathrm{t})$ represents the concentration of $\mathrm{NO}_{3}-\mathrm{N}$ produced $[\mathrm{mg} / \mathrm{L}], A$ is the maximum concentration of $\mathrm{NO}_{3}-\mathrm{N}$ produced $[\mathrm{mg} / \mathrm{L}]$ when time tends to infinity, $C$ is the inflection time [d], while $B$ is the nitrate volumetric production rate $[\mathrm{mg} / \mathrm{L} \mathrm{d}]$ and $t$ is time [d]. The three $A, B$, and $C$ regression coefficients were calculated by NCSS program by adjusting the Gompertz model (Hintze, 2001)

$Y(t)=A \exp (-\exp (-B((t)-C)))$

The maximum volumetric rates (Vmax) of nitrate production and ammonium or 2-CP consumption were calculated according to equation (2). In biological terms, it is usual that bacterial activity shows a period of time where the specific rate begins at a value of zero and then increases to a maximal. This time can be represented by the lag time or lag phase $(\lambda)$. The $\lambda$ required for the ammonium 
and 2-CP consumption was calculated according to equation (3). Subsequently, the respective specific rate $\left(\mathrm{qNH}_{4}{ }_{4}-\mathrm{N}, \mathrm{q} 2-\mathrm{CP}-\mathrm{C}, \mathrm{qNO}_{3}^{-}\right.$ $\mathrm{N}$ ) was calculated by dividing $V \max$ between the protein concentration determined in the SBR or batch assays (equation (4)). Significance of the model and $r^{2}$ levels $\left(r^{2}>0.98\right)$ were used as adjusting criterion.

Finally, the q2-CP-C obtained in batch assays in the presence or absence of the ATU, were compared with each other using the statistical tests of homogeneity of coefficients in regression models (Martínez and Castillo, 1987).

$V \max =\frac{A B}{\exp }$

$\lambda=\frac{\mathrm{BC}-1}{\mathrm{~B}}$

$q=\frac{V \max }{\text { Protein concentration }}$

\section{Results and discussion}

3.1. Evaluation in the $S B R$ reactors of the nitrifying process and 2-CP consumption at different initial ammonium concentrations

Control abiotic assays showed that after 6 days of experimentation, $96.7 \pm 3.2 \%$ of 2 -CP was maintained in SBR systems; hence, the loss of 2-CP by volatilization or chemical reaction was negligible.
Fig. 1 shows the nitrifying profiles at different initial ammonium concentrations $\left(100,200,300,400\right.$, and $\left.500 \mathrm{mg} \mathrm{NH}_{4}^{-}-\mathrm{N} / \mathrm{L}\right)$ and $60 \mathrm{mg}$ of $2-\mathrm{CP}-\mathrm{C} / \mathrm{L}$ at different operation cycles. Total ammonium consumption was observed between 10 and $14 \mathrm{~d}$ of culture (Fig. 1a). In all cases, an accumulation of nitrite was observed (Fig. 1b), which was oxidized in a longer time with the increase in ammonium concentration and the course of the operation cycles. A lag phase of 4 days was observed for starting both nitrite and nitrate production (Fig. 1b). This behavior might be related to the effect of $60 \mathrm{mg} \mathrm{2-CP-}$ $\mathrm{C} / \mathrm{L}$ on nitrification performance, due to a significant affectation on the processes of hydroxylamine formation/oxidation or nitrite consumption and its oxidation into nitrate, as has been previously proposed (Martínez-Jardines et al., 2018). The maximum production of nitrate and complete nitrification was obtained in $18 \mathrm{~d}$ with $100 \mathrm{mg} \mathrm{NH}_{4}^{+}-\mathrm{N} / \mathrm{L}$, however, by increasing the ammonium concentration, a complete nitrification was achieved in only 14 and $15 \mathrm{~d}$ throughout the operation cycles (Fig. 1c). 2-CP was completely consumed within $15 \mathrm{~d}$ with $100 \mathrm{mg} \mathrm{NH}_{4}^{-}-\mathrm{N} / \mathrm{L}$ whereas a decrease in the time required $(8 \mathrm{~d})$ to carry out the complete 2 -CP consumption in all subsequent operation cycles was registered (Fig. 1d). In all cases, ammonium consumption efficiencies $\left(\mathrm{ENH}_{4}^{-}-\mathrm{N}\right)$ above $99 \%$, nitrate production yields $\left(\mathrm{YNO}_{3}^{-}-\mathrm{N}\right)$ between 0.93 and 0.99 and 2chlorophenol consumption efficiencies (E2-CP-C) of $100 \%$ were achieved along the operational cycles elapsed. Moreover, according to a mass balance, small amount of biomass was generated in both SBRs accounting for a dissimilative process (YBM ranging between $0.01+0.002$ and $0.06+0.006 \mathrm{mg}$ biomass $-\mathrm{N} / \mathrm{mg} \mathrm{NH}_{4}^{-}-\mathrm{N}$ consumed and $0.07 \pm 0.005$ and $0.27 \pm 0.08 \mathrm{mg}$ biomass-C/mg $2-\mathrm{CP}-\mathrm{C}$ consumed). An unidentified intermediary of 2-CP was detected by HPLC along the operating cycles in the SBR reactors. According to its retention time $(1.58 \mathrm{~min})$ this intermediary might be the same
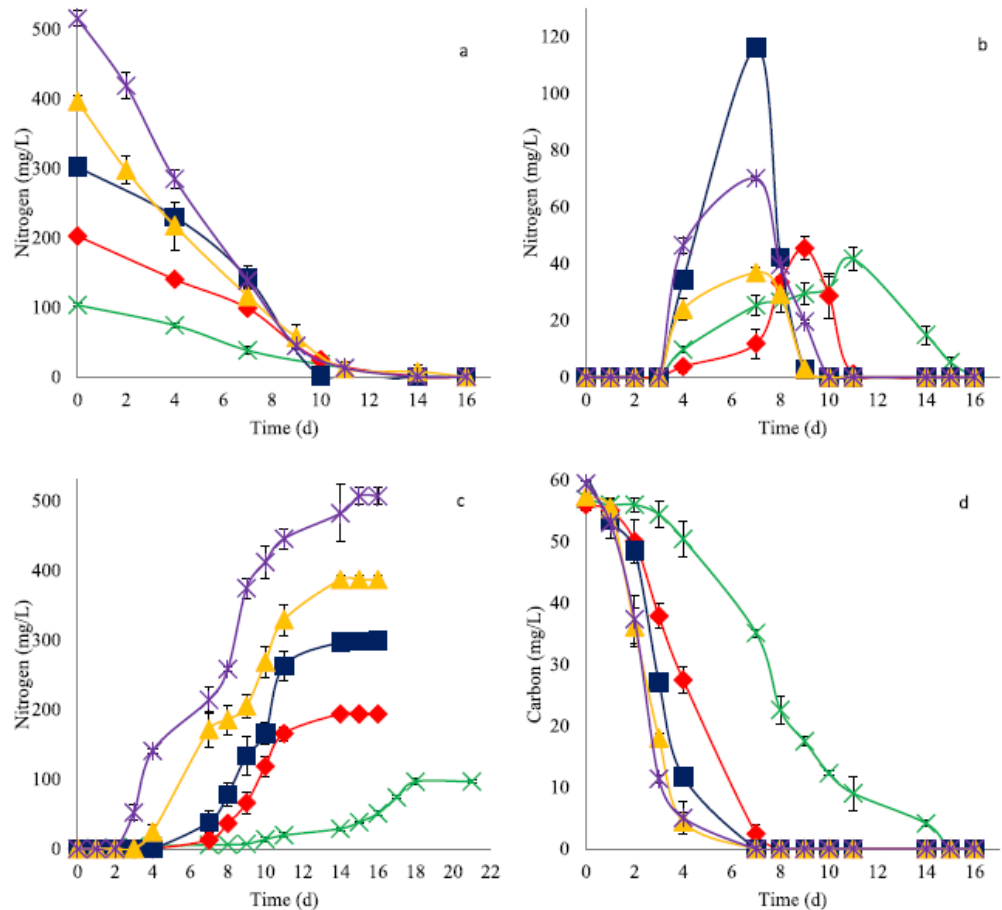

Fig. 1. Profile of the nitrifying process in the SBR reactors in presence of $2-\mathrm{CP}(60 \mathrm{mg} \mathrm{C} / \mathrm{L})$ and different ammonium concentrations $\left(\mathrm{mg} \mathrm{NH}{ }_{4}-\mathrm{N} / \mathrm{L}\right): 100(\mathrm{cycle} 1)(\mathrm{X}) ; 200$ (cycle 4$)$

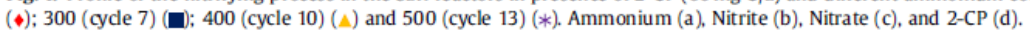


reported by Pérez-Alfaro et al. (2013) as a similar retention time was reported by these authors $(1.6 \mathrm{~min})$. Nevertheless, no more analyses were conducted in our study. Therefore, these results indicate that regardless the presence of $60 \mathrm{mg} 2-\mathrm{CP}-\mathrm{C} / \mathrm{L}$ and the increase in ammonium concentration up to $500 \mathrm{mg} \mathrm{NH}_{4}^{+}-\mathrm{N} / \mathrm{L}$; the sludge maintained a stable nitrifying activity. It has been previously reported in SBR reactors the ability of nitrifying sludge for consuming several recalcitrant compounds such as m-cresol (Zepeda et al., 2013) and mixtures of cresol isomers (Salas-Cortés et al., 2017) in presence of $50 \mathrm{mg} \mathrm{NH}_{4}^{-}-\mathrm{N} / \mathrm{L}$, as well as $p$-hydroxybenzaldehyde (Téllez-Pérez et al., 2013) and p-cresol (Silva et al, 2014) with $100 \mathrm{mg} \mathrm{NH}_{4}^{-}-\mathrm{N} / \mathrm{L}$ To our knowledge, this is the first report where the nitrification process is kinetically and physiologically evaluated throughout the cycles of SBRs fed with increasing ammonium concentrations $(100-500 \mathrm{mg} \mathrm{N} / \mathrm{L}$ ) and a recalcitrant compound like 2-CP.

It has been reported in batch assays using nitrifying sludge without previous exposition to phenolic compounds, $\lambda$ values from 15 to $30 \mathrm{~d}$ for initiating the consumption of $100 \mathrm{mg} \mathrm{NH}_{4}-\mathrm{N} / \mathrm{L}$ and $10-30 \mathrm{~d}$ for initiating the consumption of $5-10 \mathrm{mg} 2-\mathrm{CP}-\mathrm{C} / \mathrm{L}$ respectively (Martínez-Hernández et al., 2011; Pérez-Alfaro et al., 2013). In the present work, according to the data generated with the Gompertz model, the nitrifying sludge required a lag phase for ammonium and 2-CP consumption below of $3.7 \mathrm{~d}$ in all cycles despite the increase in ammonium concentration up to $500 \mathrm{mg} / \mathrm{L}$ and $60 \mathrm{mg} \mathrm{2-CP-C/L}$ (Fig. 2a). The lower $\lambda$ values obtained in the present work might be associated to the previous sludge acclimation to 2-CP and to the use of SBR systems which favors the ammonium and 2-CP consumption and the formation of nitrate. The $\lambda$ values for beginning ammonium and 2-CP consumption decreased respectively by $54 \%$ and $65 \%$ from cycle 1 to cycle 13 , showing that in spite of the increase in ammonium concentration, the lag phases tended to diminish throughout the cycles. A similar behavior was registered in $\lambda$ for starting nitrate production with $\lambda$ of $2.50 \pm 0.02 \mathrm{~d}$ in the last operating cycle with $500 \mathrm{mg} \mathrm{NH}_{4}-\mathrm{N} / \mathrm{L}$, representing a $76 \%$ decrease respect to the $\lambda$ obtained in cycle 1 with $100 \mathrm{mg} \mathrm{NH}_{4}^{-}-\mathrm{N} / \mathrm{L}$ (Fig. 2b). Therefore, additionally to the stable nitrifying process obtained in the SBRs fed with 2-CP, an improvement in nitrification and 2-CP consumption processes was achieved as operating cycles elapsed through a decrease in lag phases.

In addition to the decrease in $\lambda$ for nitrification and 2-CP consumption, the increase in ammonium concentration along the cycles resulted in a beneficial effect on the kinetic sludge behavior, since increases in specific consumption and production rates were determined (Fig. 3). It is important to mention that biomass concentration remained constant at $365.8 \pm 10.9 \mathrm{mg} / \mathrm{L}$ in the SBR reactors. Therefore, the changes observed in specific rates were not related to changes in biomass concentration but in physiologic activity of the nitrifying sludge. Fig. 3a illustrates $\mathrm{qNH}_{4}^{-}-\mathrm{N}$ profiles along experimentation. With the first increase to $200 \mathrm{mg} \mathrm{NH}_{4}{ }_{-}-\mathrm{N} / \mathrm{L}$ in cycle 2 , the $\mathrm{qNH}_{4}-\mathrm{N}$ increased by $40 \%$ respect to cycle 1 operated

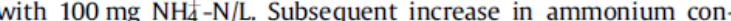
centration provoked increases in $\mathrm{qNH}_{4}^{+}-\mathrm{N}$. Hence, in the last operating cycle with $500 \mathrm{mg} \mathrm{NH}_{4}^{-}-\mathrm{N} / \mathrm{L}$, a 5.2 -fold increase in $\mathrm{qNH}_{4}^{-}-\mathrm{N}$ was achieved regarding to cycle 1 . A similar behavior in $\mathrm{q} 2-\mathrm{CP}-\mathrm{C}$ was noticeable throughout the operation cycles in the SBRs (Fig. 3b). It was found that three cycles later of the increase to $200 \mathrm{mg} \mathrm{NH}{ }_{4}-\mathrm{N} / \mathrm{L}$, an increment of $82 \%$ in $\mathrm{q} 2-\mathrm{CP}-\mathrm{C}$ was accomplished. The highest increment in $\mathrm{Q} 2-\mathrm{CP}-\mathrm{C}$ was achieved when $500 \mathrm{mg} \mathrm{N} / \mathrm{L}$ of ammonium were amended to the SBRs as a 3.1-fold increase in $\mathrm{q} 2-\mathrm{CP}-\mathrm{C}$ regarding to cycle 1 was determined. On the other hand, the greatest increase in specific rate of nitrate pro-

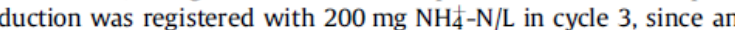
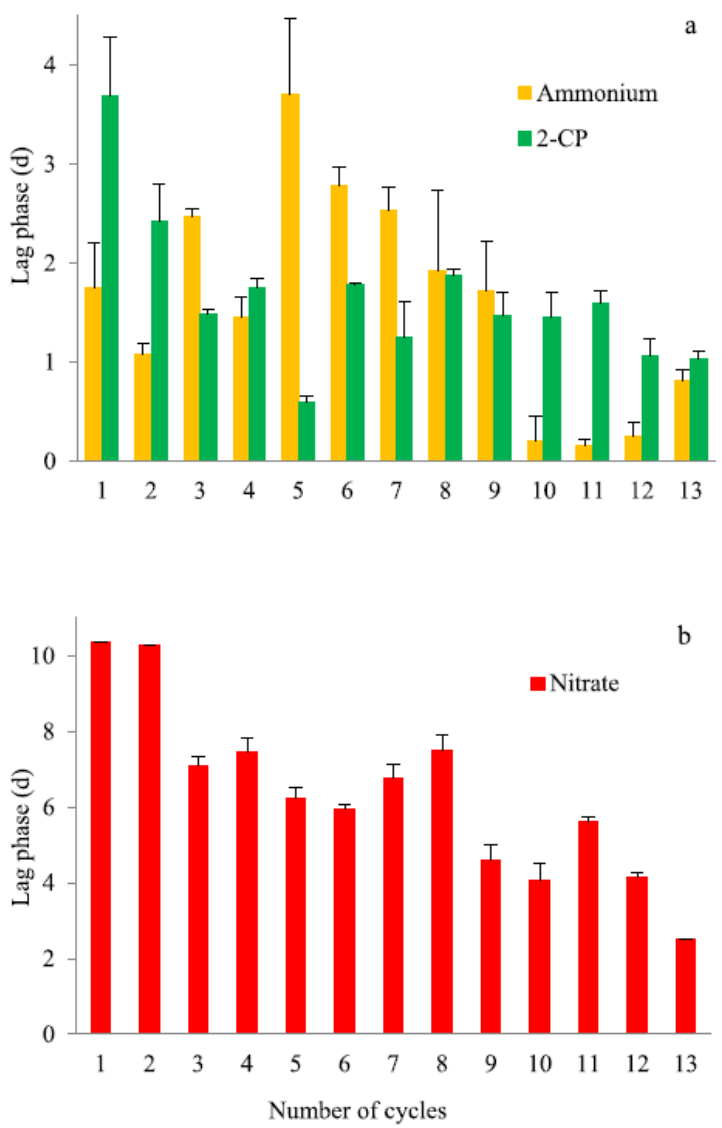

Fig. 2. Lag phases for initiating ammonium or 2-CP consumption (a) and nitrate production (b) obtained in the nitrifying SBR reactors amended with $60 \mathrm{mg} 2-\mathrm{CP}-\mathrm{C} / \mathrm{L}$. and different ammonium concentrations $\left(\mathrm{mg} \mathrm{NH}_{4}^{-}-\mathrm{N} / \mathrm{L}\right.$ ) along operation cycles: 100 (cycle 1), 200 (cycles 2, 3, and 4), 300 (cycles 5, 6, and 7), 400 (cycles 8, 9, and 10) and 500 (cycles 11, 12, and 13).

increment of 6.1-fold was recorded at this step whereas 5.2 -fold increment in $\mathrm{qNO}_{3}^{-}-\mathrm{N}$ was quantified at cycle 13 (Fig. 3c). In summary, increases of 5.2, 3.1, and 5.2-fold in the $\mathrm{qNH}_{4}-\mathrm{N}, \mathrm{q} 2-\mathrm{CP}-\mathrm{C}$, and $\mathrm{qNO}_{3}-\mathrm{N}$, were respectively found because of the increase in the ammonium concentration fed and the course of the operation cycles in the SBR reactors.

It has been previously reported that the use of SBR systems results in improvements in the kinetics of nitrifying process throughout operation cycles as increments in specific ammonium consumption and nitrate production rates have been documented (Texier and Gómez, 2004). Specific rate of substrate consumption is a variable of first order which is dependent on the environmental culture conditions (Cuervo-López et al., 2009). In the present work; higher ammonium concentrations provoked increases in $\mathrm{qNH}_{4}-\mathrm{N}$ values. Likewise, at high ammonium concentrations, passive transport of $\mathrm{NH}_{4}^{+}$could be favored due to the concentration gradient and the ammonium transport enhanced into the cell (Lin et al., 2006), being a key factor for improving $\mathrm{qNH}_{4}{ }_{4}-\mathrm{N}$. Another possible effect of the increase in ammonium concentration would be related to the activity of AMO enzyme, which also would be reflected in major $\mathrm{qNH}_{4}-\mathrm{N}$ values. 

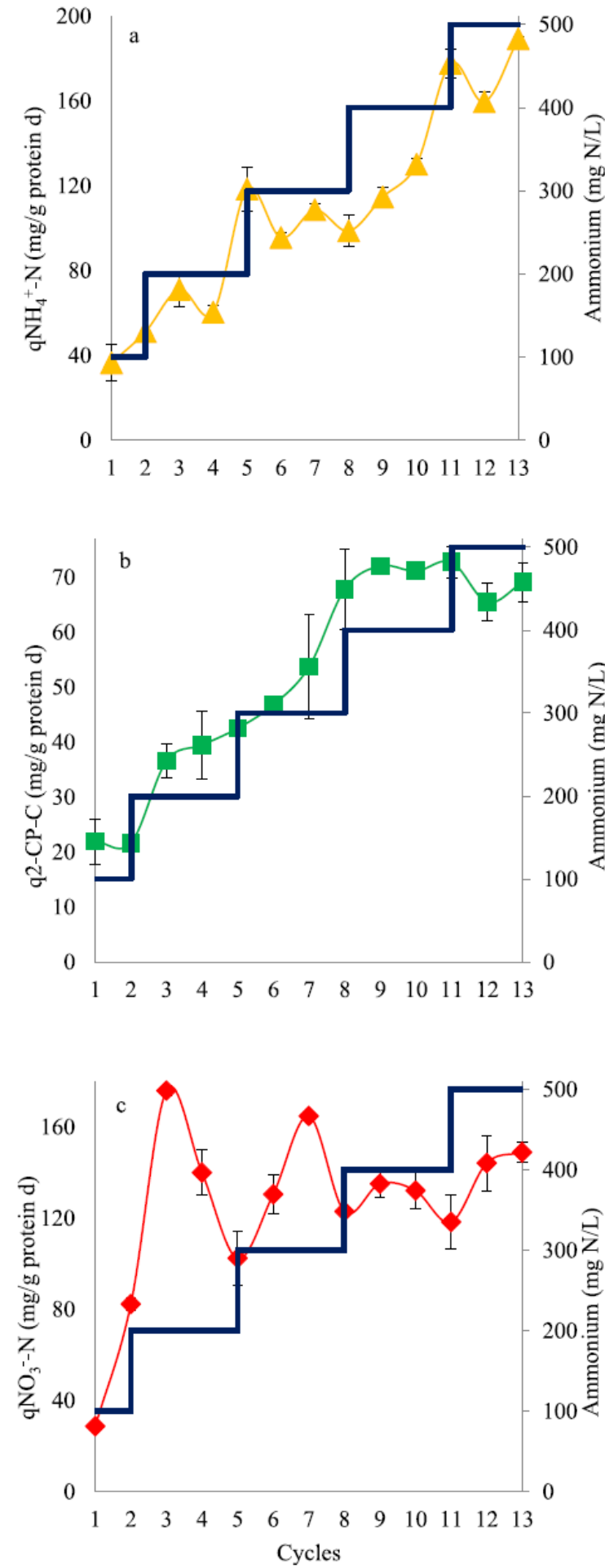

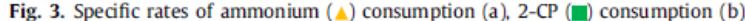
and nitrate $(\uparrow)$ production $(\mathrm{c})$. Initial ammonium concentration $(-)$.

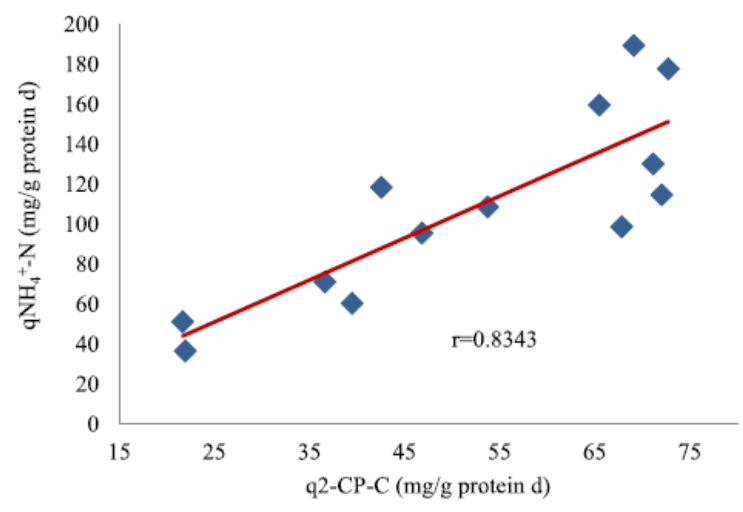

Fig 4. Correlation between $\mathrm{qNH}_{4}^{+}-\mathrm{N}$ and $\mathrm{q} 2-\mathrm{CP}-\mathrm{C}$.

A direct and significant relationship between specific consumption rate of ammonium and 2-CP was observed (Fig. 4). In fact, a positive correlation of 0.83 between both specific rates was determined, indicating the cometabolic 2-CP consumption in the presence of ammonium that might be acting as primary substrate for growth and cell maintenance. The cometabolic degradation of recalcitrant compounds such as 3,5-dichlorophenol (DCP), 3,4,5trichlorophenol (TCP), and 2,3,5,6-tetrachlorophenol (TRCP) when pentachlorophenol was used as growth substrate has been previously reported (Liu et al., 1991). Likewise, cometabolic biotransformation of 3-CP (Chiavola et al., 2004) and 4-CP (Monsalvo et al., 2009) has been reported in SBR systems with activated sludge and phenol as growth substrate. Nevertheless, no mention about kinetic sludge behavior was made in these works as only substrate consumption efficiencies were calculated. Degradation of a wide range of recalcitrant compounds such as DCE, TCE, DE, CF, trichloroethane and chloroethane by cometabolism under aerobic conditions with ammonium as growth substrate has been previously reported (Arp et al., 2001; Jesus et al., 2016). Cometabolism under nitrifying conditions has been also reported by using axenic Nitrosomonas europaea cultures and ammonium as primary substrate for TCE, DE, and CF elimination (Alvarez-Cohen and Speitel, 2001; Arciero et al., 1989; Ely et al., 1997). As obtained in the present study for 2-CP and ammonium, kinetic results have been reported by Kocamemi and Çeçen (2010) for TCE and ammonium, where the $\mathrm{qNH}_{4}^{+}-\mathrm{N}$ and qTCE increased with the increment in the initial concentration of both substrates. The authors concluded that the correlated increments of the specific rates were indicative that cometabolic events occur. Fernandez-Fontaina et al. (2012) have reported a relationship between specific nitrification rate with $40-500 \mathrm{mg}$ $\mathrm{NH}_{4}^{+}-\mathrm{N} / \mathrm{L}$ and specific biodegradation rate during the cometabolic degradation of different micropollutants such as ibuprofen, naproxen, trimethoprim, erythromycin, roxithromycin, fluoxetine, galaxolide and tonalide. These authors indicated that as the higher the consumption rate of the primary substrate by bacteria, the higher the rate for micropollutants consumption. They also proposed the involvement of AMO enzyme not only for ammonium oxidation, but also for the cometabolic degradation of micropollutants. However, authors did not determine the AMO enzyme participation in the process.

\subsection{Nitrifying batch assays: $2-C P$ consumption by the AMO enzyme}

Abiotic control and adsorption assays showed that after 6 days of experimentation, $99 \pm 0.5 \%$ and $95.5 \pm 4.5 \%$ of $2-\mathrm{CP}$ was 
Table 1

Response variables determined in nitrifying batch assays: efficiencies, yields, and specific rates determined with the sludge used for inoculating SBR systems (a) and with the sludge obtained at the end of cycle 13 (b).

\begin{tabular}{|c|c|c|c|c|c|}
\hline Assay & $\mathrm{ENH}_{4}^{+}-\mathrm{N}$ & $\mathrm{YNO}_{3}^{-}-\mathrm{N}$ & $\mathrm{qNH}_{4}^{+}-\mathrm{N}$ & $\mathrm{qNO}_{3}^{-}-\mathrm{N}$ & q2-CP-C \\
\hline a) Reference $\left(\mathrm{NH}_{4}^{+}\right)$ & $99.3 \pm 0.1$ & $0.96 \pm 0.01$ & $402.9 \pm 0.1$ & $154.9 \pm 4.6$ & - \\
\hline a) $\mathrm{NH}_{4}^{+}+$ATU & 0 & 0 & 0 & 0 & - \\
\hline a) $\mathrm{NH}_{4}^{-}+2-\mathrm{CP}$ & $99.1 \pm 0.3$ & $0.98 \pm 0.10$ & $33.9 \pm 1.6$ & $49.3 \pm 2.0$ & $12.95 \pm 0.3$ \\
\hline a) $\mathrm{NH}_{4}^{+}+2-\mathrm{CP}+\mathrm{ATU}$ & 0 & 0 & 0 & 0 & $8.51 \pm 0.4$ \\
\hline b) Reference $\left(\mathrm{NH}_{4}^{+}\right)$ & $99.4 \pm 0.1$ & $1.00 \pm 0.02$ & $421.9 \pm 32$ & $103.2 \pm 8.0$ & - \\
\hline b) $\mathrm{NH}_{4}^{+}+\mathrm{ATU}$ & 0 & 0 & 0 & 0 & - \\
\hline b) $\mathrm{NH}_{4}^{-}+2-\mathrm{CP}$ & $99.6 \pm 0.1$ & $0.98 \pm 0.01$ & $166.5 \pm 3.1$ & $139.6 \pm 3.4$ & $13.69 \pm 1.8$ \\
\hline b) $\mathrm{NH}_{4}^{+}+2-\mathrm{CP}+\mathrm{ATU}$ & 0 & 0 & 0 & 0 & $6.45 \pm 0.2$ \\
\hline
\end{tabular}

$\mathrm{ENH}_{4}^{+}-\mathrm{N}=\mathrm{mg}$ of $\mathrm{N}$ consumed $/ \mathrm{mg} \mathrm{N}$ fed $) \times 100$.

$\mathrm{YNO}_{3}^{-} \mathrm{N}=\mathrm{mg}$ of $\mathrm{N}$ produced $/ \mathrm{mg}$ of $\mathrm{N}$ consumed

$\mathrm{qNO}_{3}^{-}-\mathrm{N}=\mathrm{mg}$ of product generation $/ \mathrm{g}$ protein $\mathrm{d}$.

$\mathrm{qNH}_{4}^{-}-\mathrm{N}, \mathrm{q} 2-\mathrm{CP}-\mathrm{C}=\mathrm{mg}$ substrate consumption/g protein $\mathrm{d}$.

ATU $=$ Allylthiourea.

maintained in the culture respectively; therefore, the loss of this compound by chemical reaction, volatilization or adsorption was negligible.

Participation of AMO enzyme in 2-CP consumption was assessed in batch assays with the nitrifying sludge used for inoculating the SBR reactors and the sludge obtained at the end of the 13 operating cycles. In each case, four assays were conducted: i) Reference nitrification; ii) Nitrification in presence of ATU; iii) Nitrification in presence of 2-CP, and iv) Nitrification in presence of 2-CP and ATU. In nitrifying reference assays conducted with both nitrifying inoculum and sludge obtained at cycle 13, high $\mathrm{ENH}_{4}^{-}-\mathrm{N}$ and $\mathrm{YNO}_{3}^{-}-$ $\mathrm{N}$ values were obtained within 10 days of culture (Table 1 ) indicating a successful nitrifying process under the batch experimental conditions established. In all cases, nitrifying assays in presence of ATU evidenced neither ammonium consumption nor nitrite or nitrate production within the culture time because of the ATU inhibitory effect on the AMO enzyme (Table 1). Assays with $100 \mathrm{mg}$ $\mathrm{NH}_{4}^{+}-\mathrm{N} / \mathrm{L}$ and $5 \mathrm{mg} 2-\mathrm{CP}-\mathrm{C} / \mathrm{L}$ with the nitrifying sludge used as inoculum (Fig. 5a), resulted in complete nitrification and total 2-CP consumption within 16 and 3 days of culture. Under the same
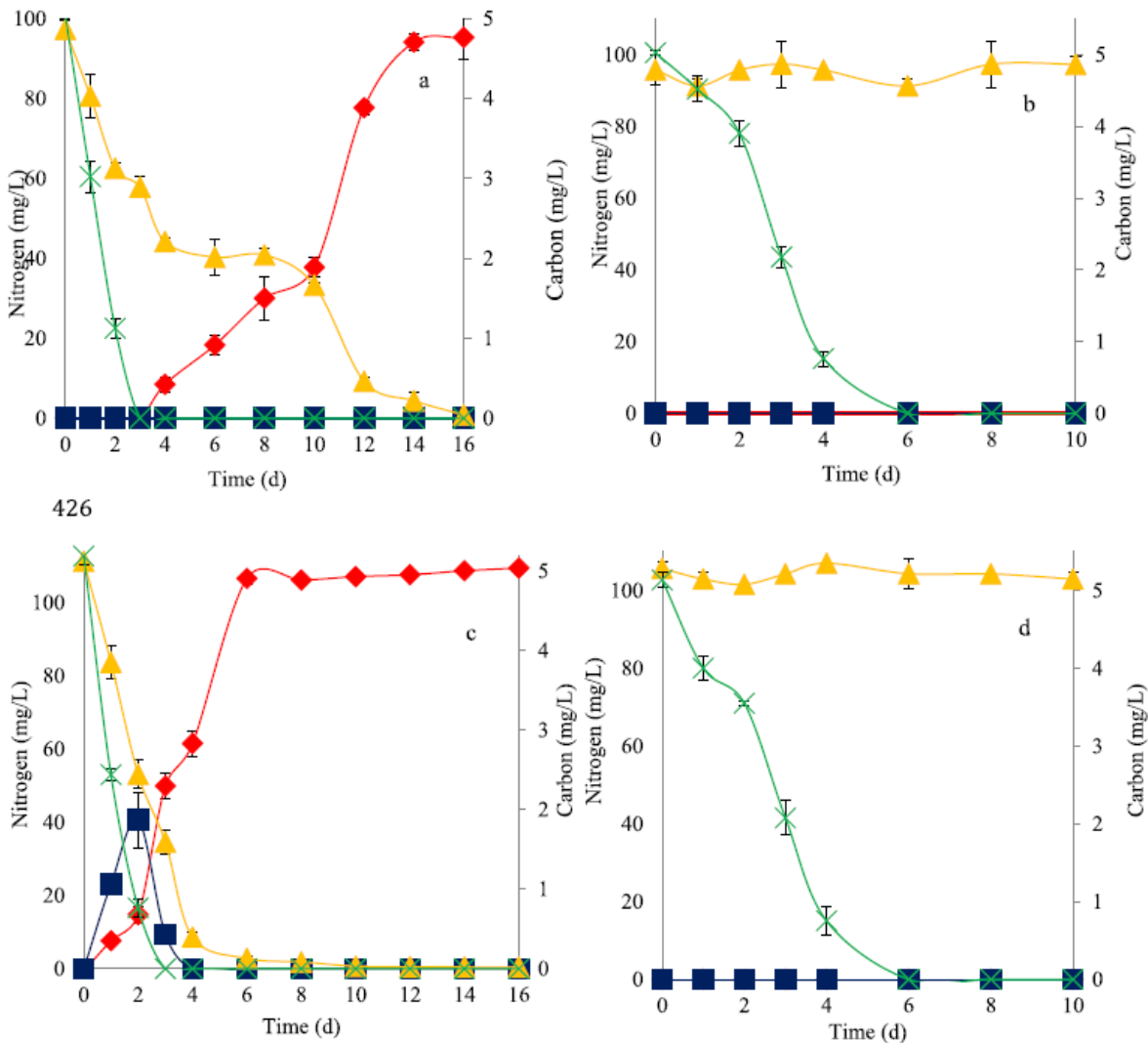

Fig. 5. Nitrifying profiles obtained in batch assays with the sludge used for inoculating SBR systems: a) Nitrification with 2-CP, b) Nitrification with 2-CP, and ATU. Nitrifying profiles obtained in batch assays at the end of cycle 13: c) Nitrification with 2-CP, d) Nitrification with 2-CP, and ATU. Ammonium ( $\triangle$ ), Nitrite $(\mathbf{\square})$, Nitrate ( $\bullet)$, and 2-CP (X). 
conditions but in presence of ATU, the time required for total 2-CP consumption increased from 3 to 6 days (Fig. 5b). When the AMO enzyme activity was inhibited by ATU, q2-CP-C decreased by $34 \%$ with respect to the assay without the inhibitor (Table 1). In fact, a significant difference $(\alpha=0.025)$ between the q2-CP-C obtained in the assays in absence and presence of ATU was evidenced by statistical analysis of coefficients homogeneity (Martínez and Castillo, 1987). These results indicate the participation of AMO enzyme in 2CP consumption.

Kinetic sludge behavior with $100 \mathrm{mg} \mathrm{NH}_{4}^{+}-\mathrm{N} / \mathrm{L}$ and $5 \mathrm{mg} 2-\mathrm{CP}-\mathrm{C} /$ $\mathrm{L}$ evaluated at the end of the 13 operation cycles in the SBRs, evidenced total and simultaneous ammonium oxidation to nitrate and 2-CP consumption within 6 and 3 days, respectively (Fig. 5c). When ATU was added to this sludge, total 2-CP consumption was measured but a longer time of $6 \mathrm{~d}$ was required regarding to noninhibited assay (Fig. 5d). Likewise, when comparing q2-CP-C obtained in absence and presence of ATU, a significant difference between these rate values was evidenced $(\alpha=0.025)$ (Table 1 ). It is noteworthy that the decrease in $\mathrm{q} 2-\mathrm{CP}-\mathrm{C}$ in the assays where AMO enzyme was inhibited corresponded to $53 \%$ regarding to the assay without the inhibitor. It is remarkable that the decrease in q2-CP-C was greater than that obtained in the assays with the sludge used for inoculating SBR reactors, as in this case q2-CP-C only decreased $34 \%$. This shows that the nitrifying sludge exposure to increasing ammonium concentrations in the SBR reactors was reflected in the higher participation of AMO in 2-CP consumption.

It is known that oxygenase enzymes are capable to oxidize a substrate that does not provide carbon nor energy source during aerobic cometabolism (Jesus et al., 2016). A wide range of microorganisms which express oxygenase activity and use ammonium as energy source can oxidize chlorinated solvents (Arciero et al., 1989; Vannelli et al., 1990). It has been suggested that the AMO enzyme of AOB can play an important role in the cometabolic biodegradation of various organic pollutants, since under nitrifying conditions and high ammonium loading rates, significant organic compounds biodegradation was observed (Tran et al., 2013). Nevertheless, the participation of AMO enzyme was not always elucidated. AMO enzyme ability for oxidizing halogenated and non-halogenated aliphatic and aromatic compounds, such as methylbromide, 1,2dichloropropane, 1,2-dibromo-3-chloropropane, trichloroethylene, ethane, chloropropane, toluene, benzene, and phenol, has been shown in Nitrosomonas europaea cultures (Alvarez-Cohen and Speitel, 2001; Hyman et al., 1995; Keener and Arp, 1994). Oxidation of phenol, benzene, and 2-CP associated with the oxidation of ammonium by nitrifying sludge has been also reported (MartínezJardines et al., 2018; Silva et al., 2011; Zepeda et al., 2003), although participation of AMO enzyme in the consumption of these compounds was not confirmed by the authors. Results obtained in this work indicate that the continue exposition of the sludge to high ammonium concentrations in the SBRs might favored the higher participation of AMO enzyme in the cometabolic 2-CP consumption.

\section{Conclusions}

Results obtained in the present work evidenced that by increasing the ammonium concentration from 100 to $500 \mathrm{mg} \mathrm{NH}_{4}-$ $\mathrm{N} / \mathrm{L}$ and throughout the operating cycles of the SBR reactors, both the nitrifying process and the cometabolic $2-\mathrm{CP}$ consumption were enhanced, as significant improvements in $\mathrm{qNH}_{4}-\mathrm{N}, \mathrm{q} 2-\mathrm{CP}-\mathrm{C}$, and $\mathrm{qNO}_{3}^{-}-\mathrm{N}$ were achieved along the cycles. A direct and significant relationship with a correlation coefficient of 0.83 between $\mathrm{qNH}_{4}^{+}-\mathrm{N}$ and $\mathrm{q} 2-\mathrm{CP}-\mathrm{C}$ was established. It was evidenced that the participation of AMO enzyme in the cometabolic 2-CP consumption increased from 34 to $53 \%$ throughout the SBR cycles, showing a major participation of $\mathrm{AOB}$ in 2-CP consumption. These results suggest the use of nitrifying SBR systems as a suitable alternative for increasing the cometabolic consumption of recalcitrant compounds such as 2-CP besides treating effluents highly contaminated with ammonium.

\section{Acknowledgments}

This work was supported by the Council of Science and Technology of Mexico (grant no. CONACYT-CB-2015-01 255740) and Divisional Council of Universidad Autónoma MetropolitanaIztapalapa, CBS, Mexico. M.A. Martínez-Jardines received a Ph.D. fellowship from Council of Science and Technology of Mexico.

\section{References}

Agency for toxic substances and disease registry (ATSDR) (2015). www.atsdr.cdc gov/spl/resources/2015_atsdr_substance_priority_list.html.

Alvarez-Cohen, L., Speitel, G.E., 2001. Kinetics of aerobic cometabolism of chlorinated solvents. Biodegradation 12, 105-126. https://doi.org/10.1023/A: 1012075322466.

Arciero, D., Vannelli, T., Logan, M., Hooper, A.B., 1989. Degradation of trichloroethylene by ammonia-oxidizing bacterium Nitrosomonas europaea. Biochem. Biophys. Res. Commun. 159, 640-643. https://doi.org/10.1016/0006-291X(89) 90042-9.

Arp, D.J., Yeager, C.M., Hyman, M.R, 2001. Molecular and cellular fundamentals of aerobic cometabolism of trichloroethylene. Biodegradation 12,81-103. https:// doi.org/10.1023/A:1012089908518.

Basu, S.K., Oleszkiewicz, J.A., 1995. Factors affecting aerobic biodegradation of 2chlorophenol in sequencing batch reactors. Environ. Technol. 16, 1135-1143. https://doi.org/10.1080/09593331608616349.

Bock, E., Koops, H.P., Harms, H., Ahlers, B., 1991. The biochemistry of nitrifying microorganism. In: Bock, E. (Ed.), Variations in Autotrophic Life. Academic Press London, pp. $171-200$.

Buitron, G., Soto, G., Vite, G., Moreno, J., 2001. Strategies to enhance the biodegradation of toxic compounds using discontinuous processes. Water Sci. Technol. 43 (3), 283-290.

Cervantes, F.J., Cuervo-López, F, Gómez, J., 2016. Fundamental aspects of biological processes involved in the removal of nitrogen from wastewaters. In: de Río, Angeles Val, Campos Gómez, José Luis, Mosquera Corral, Anuska (Eds.) Technologies for the Treatment and Recovery of Nutrients from Industrial Wastewater. IGI Global, pp. 112-146. https://doi.org/10.4018/978-1-5225-10375.ch005.

Chiavola, A., Baciocchi, R, Irvine, RL, Gavasci, R., Sirini, P., 2004. Aerobic biodegradation of 3-chlorophenol in a sequencing batch reactor: effect of cometabolism. Water Sci. Technol. 50 (10), 235-242.

Cuervo-López, F., Martínez-Hernández, S. Texier, A.C., Gómez, J., 2009. Denitrification for Wastewater Treatment in: Environmental Technologies to Treat $\mathrm{Ni}$ trogen Pollution. Principles and Engineering. International Water Association Publishing, ISBN 9781843392224, pp. 41-65.

Czaplicka, M., 2004. Sources and transformations of chlorophenols in the natura environment. Sci. Total Environ. 322, 21 -39. https://doi.org/10.1016/j.scitotenv. 2003.09.015.

Dalton, H., Stirling, D.L, 1982. Co-metabolism. Biol. Sci. Phil. Trans. Roy. Soc. Lond. B 297, 481-496. https://doi.org/10.1098/rstb.1982.0056.

Ely, R.L, Williamson, K.J., Hyman, M.R., Arp, D.J., 1997. Cometabolism of chlorinated solvents by nitrifying bacteria: kinetics, substrate, interactions, toxicity effects, and bacterial response. Biotechnol. Bioeng. 54, 520-534. https://doi.org/10 1002/(SIC) 1097-0290(19970620)54:6<520::AID-BIT3>3.0.CO;2-L.

Fernandez-Fontaina, E., Omil, F, Lema, J.M., Carballa, M., 2012. Influence of nitrifying conditions on the biodegradation and sorption of emerging micropollutants. Water Res. 46 (16), 5434-5444. https://doi.org/10.1016/j.watres. 2012.07.037.

Furukawa, K., 2000. Engineering dioxygenases for efficient degradation of environmental pollutants. Curr. Opin. Biotechnol. 11 (3), 244-249. https://doi.org 10.1016/S0958-1669(00)00091-4.

Hao, O.J., Kim, H.M., Seagren, A.E., Kim, H., 2002. Kinetics of phenol and chlorophenol utilization by Acinetobacter species. Chemosphere 46 (6), 797-807. ophenol utilization by Acinetobacter species. Chem
https://doi.org/10.1016/S0045-6535(01)00182-5.

Hazen, T.C., 2010. Cometabolic bioremediation. In: Timmis, K.N. (Ed.), Handbook of Hydrocarbon and Lipid Microbiology. Springer-Verlag Berlin Heidelberg. pp. 2505-2514.

Hintze, J., 2001. Number Cruncher Statistical System (NCSS).

Hyman, M.R., Russell, S.A., Ely, R.L, Williamson, K.J., Arp, D.J., 1995. Inhibition, inactivation, and recovery of ammonia-oxidizing activity in cometabolism of trichloroethylene by Nitrosomonas europaea. Appl. Environ. Microbiol. 61 (4), $1480-1487$.

Jesus, J., Frascari, D., Pozdniakovac, T., Dankoa, A., 2016. Kinetics of aerobic cometabolic biodegradation of chlorinated and brominated aliphatic hydrocarbons: a review. J. Hazard. Mater. 309, 37-52. https://doi.org/10.1016/j.jhazmat.2016. 
01.065 .

Kai-Chee, L., Tingting, W., 2006. Cometabolic transformation of 2-chlorophenol and 4-chlorophenol in the presence of phenol by Pseudomonas putida. Can. J. Chem. Eng. 84 (3), 356-367. https://doi.org/10.1002/cjee.5450840312.

Keener, W., Arp, D.J., 1994. Transformation of aromatics compounds by Nitrosomonas europaea. Appl. Environ. Microbiol. 60, 1914-1920.

Kocamemi, B., Cecen, F., 2007a. Kinetic analysis of the inhibitory effect of trichloroethylene (TCE) on nitrification in cometabolic degradation. Biodegradation 18 (1), 71-81. https://doi.org/10.1007/s10532-005-9037-3.

Kocamemi, B., Cecen, F, 2007b. Inhibitory effect of the xenobiotic 1.2 dichloroethane in a nitrifying biofilm reactor. Water Sci. Technol. 55 (8-9), 67-73. https://doi.org/10.2166/wst.2007.243.

Kocamemi, B., Çeçen, F., 2010. Biological removal of the xenobiotic trichloroethylene (TCE) through cometabolism in nitrifying systems. Bioresour. Technol. 101, 430-433. https://doi.org/10.1016/j.biortech.2009.07.079.

Lin, Y., Zexing, C., Yirong, M., 2006. Molecular Dynamic simulations on the Escherichia coli ammonia channel protein AmtB: mechanism of ammonia/ ammonium transport. J. Am. Chem. Soc. 128 (33), 10876-10884. https://doi.org/ 10.1021/ja0631549.

Liu, D., Maguire, R.J., Pacepavicius, G., Dutka, B..., 1991. Biodegradation of recalcitrant chlorophenols by cometabolism. Environ. Toximl 6, 85-95. https://doi trant chlorophenols by come

Lowry, O.H., Rosebrough, N.J., Farr, A.L., Randall, R.J., 1951. Protein measurement with the folin phenol reagent. J. Biol. Chem. 193, 265-275.

Majumder, P.S., Gupta, S.K., 2007. Removal of chlorophenols in sequential anaerobic-aerobic reactors. Bioresour. Technol. 98, 118-129. https://do i.org/10. 1016/j.biortech.2005.11.009.

Martínez, F, Lema, J., Méndez, R., Cuervo-Lopez, F., Gomez, J., 2004. Role of exopolymeric protein on the settleability of nitrifying sludges. Bioresour. Technol, 94, 43-48. https://doi.org/10.1016/j.biortech.2003.11.010.

Martínez, G.A. Castillo, M.A, 1987. In: Teoría de la Regresión con aplicación agronómica. Colegio de Posgraduados, México, p. 490.

Martínez-Hernández, S., Texier, A.-C., Cuervo-López, F., Gomez, J., 2011. 2Chlorophenol and its effect on the nitrifying sludge. J. Hazard. Mater. 185, 1592-1595. https://doi.org/10.1016/j.jhazmat.2010.09.100.

Martínez-Jardines, M., Pérez-Alfaro, E., González-Robles, R.O., Texier, A.-C., CuervoLópez, F., 2018. Decrease of inhibitory effect of 2-chlorophenol on nitrification in sequencing batch reactors. Environ. Technol. https://doi.org/10.1080/ 09593330.2018.1476594.

McCarty, G., 1999. Modes of action of nitrification inhibitors. Biol. Fertil. Soils. 29, 1-9. https://doi.org/10.1007/s003740050518.

Monsalvo, V.M., Mohedano, A.F., Casas, J.A., Rodríguez, J.J. 2009. Cometabolic biodegradation of 4-chlorophenol by sequencing batch reactors at different temperatures. Bioresour. Technol. 100 (20), 4572-4578. https://doi.org/10.1016/ temperatures. Bioresou

Pera-Titus, M., García-Molina, V., Baños, M., Giménez, J., Esplugas, S., 2004. Degradation of chlorophenols by means of advanced oxidation processes: a general review. Appl. Catal. B Environ. 47 (4), 219-256. https://doi.org/10.1016/j.apcatb. 2003.09.010.

Pérez-Alfaro, J.E., Buitrón, G., Gomez, J., Texier, A.-C., Cuervo-López, F., 2013. Kinetic and physiological evaluation of ammonium and nitrite oxidation processes in presence of 2-chlorophenol. Appl. Biochem. Biotechnol. 169 (3), 990-1000. https://doi.org/10.1007/s12010-012-0065-2.
Pérez-Alfaro, E., González-Blanco, G., Sierra-Palacios, E., Marcial-Quino, J., BeristainCardoso, R, 2015. Acclimation of nitrifying biomass and its effect on 2 chlorophenol removal. Water Sci. Technol. 71 (2), 277-282. https://doi.org/10. 2166/wst.2014.508.

Puhakka, J.A., Melin, E.S., 1996. Bioremediation of chlorinated phenols. In: Crawford, R.L, Crawford, D.. (Eds.), Bioremediation: Principles and Applications. Cambridge Univ Pr, New York, pp. 254-297.

Salas-Cortés, J. Cuervo-López, F., Texier, A.-C., 2017. Simultaneous oxidation of ammonium and cresol isomers in a sequencing batch reactor: physiological and kinetic study. Environ. Sci. Pollut. Res. 24 (33), 25667-25675, https://doi.org/10. 1007/s11356-016-6293-1.

Schweighofer, P., Nowak, O., Svardal, K., Kroiss, H., 1996. Steps towards the upgrading of a municipal WWTP affected by nitrification inhibiting compounds-a case study. Water Sci. Technol. 33 (12), 39-46.

Silva, C.D., Beristain-Montiel, L, Cuervo-López, F., Texier, A.-C., 2014. p-Cresol mineralization and bacterial population dynamics in a nitrifying sequential batch reactor. J. Environ. Sci. 26 (9) 1885-1893. https://doi.org/10.1016/j.jes. 2014.06.033.

Silva, C.D. Gómez, J., Beristain-Cardoso, R., 2011. Simultaneous removal of 2 chlorophenol, phenol, $p$-cresol and $p$-hydroxybenzaldehyde under nitrifying conditions: kinetic study. Bioresour. Technol. 102 (11), 6464-6468. https://doi. conditions: kinetic study. Bioresour.
org/10.1016/j.biortech.2011.03.105.

Silva, C.D., Gómez, J., Houbron, E., Cuervo-López, F., Texier, A.-C., 2009. p-creso biotransformation by a nitrifying consortium. Chemosphere 75 (10) 1387-1391. https://doi.org/10.1016/j.chemosphere.2009.02.059.

Téllez-Pérez, S., Silva, D, Texier, A.-C., 2013. Simultaneous ammonium and phydroxybenzaldehyde oxidation in a sequencing batch reactor. Rev. Mex. Ing. Quim. 12 (1), 97-104.

Texier, A.-C., Gómez, J., 2004. Settleability and kinetics of a nitrifying sludge in a sequencing batch reactor. Can. J. Microbiol. 50 (11), 943-949. https://doi.org/10. 1139/w04-078.

Texier, A.-C.,Zepeda, A., Gómez, J., Cuervo-López, F., 2012. Simultaneous elimination of carbon and nitrogen compounds of petrochemical effluents by nitrification and denitrification. In: Patel, Vivek (Ed.), Petrochemicals. InTech, pp. 106-108.

Tran, N., Urase, T., Ngo, H., Hu, J., Ong, S., 2013. Insight into metabolic and cometabolic activities of autotrophic and heterotrophic microorganisms in the biodegradation of emerging trace organic contaminants. Bioresour. Technol. 146, 721-731. https://doi.org/10.1016/j.biortech.2013.07.083.

Vannelli, T., Logan, M., Arciero, D.M., Hooper, A.B., 1990. Degradation of halogenated aliphatic compounds by the ammonia-oxidizing bacterium Nitrosomonos europaea. Appl. Environ. Microbiol, 56 (4), 1169-1171.

Yoong, E.T., Lant, P.A., Greenfield, P.F., 2000. In situ respirometry in an SBR treating wastewater with high phenol concentrations. Water Res. 34 (1), 239-245. https://doi.org/10.1016/S0043-1354(99)00142-6.

Zepeda, A., Ben-Youssef, C., Rincon, S., Cuervo-López, F., Gómez, J., 2013. Complete and simultaneous removal of ammonium and $m$-cresol in a nitrifying sequencing batch reactor. Biodegradation 24 (3), 377-385. https://doi.org/10. 1007/s10532-012-9595-0.

Zepeda, A., Texier, A.-C., Gomez, J., 2003. Benzene transformation in nitrifying batch cultures. Biotechnol. Prog. 19 (3), 789-793. https://doi.org/10.1021/bp0201408

Zwietering, M.H., Jongenburger, I., Rombouts, F.M., Van't Riet, K., 1990. Modeling of the bacterial growth aurve, Appl, Environ, Microbiol, 56 (6), 1875-1881. 


\subsection{Trabajos presentados en eventos nacionales e internacionales}

- Martínez-Jardines M., Martínez-Hernández S., Texier A.C., Cuervo-López F. Participación de la Enzima Amonio Monooxigenasa en el Consumo de 2-Clorofenol. Presentación oral en el 5th IWA México Young Water Professionals Conference. Morelia, México. Mayo, 2017.

- Martínez-Jardines M., Martínez-Hernández S., Texier A.C., Cuervo-López F. 2017. Consumo de amonio y 2-clorofenol por cometabolismo en un reactor SBR nitrificante. Presentación cartel en el XVII Congreso Nacional de Biotecnología y Bioingeniería de la SMBB. Puerto Vallarta, Jalisco. México. Junio, 2017

- Martínez-Jardines M., Martínez-Hernández S., Texier A.C., Cuervo-López F. 2Chlorophenol consumption by cometabolism in nitrifying SBR reactors. Presentación cartel en The Sixth International Symposium on Environmental Biotechnology and Engineering. Ciudad Obregón, Sonora, México. Noviembre, 2018

- Martínez-Jardines M., Martínez-Hernández S., Texier A.C., Cuervo-López F. Dinámica poblacional de un lodo nitrificante durante el consumo cometabólico de amonio y 2clorofenol en un SBR. Presentación oral en el XVIII Congreso Nacional de Biotecnología y Bioingeniería de la SMBB. León, Guanajuato, México. Junio, 2019. 
$\Delta$ a1

UNIVERSIDAD AUTONOMA METROPOLITANA

\section{ACTA DE DISERTACIÓN PÚBLICA}

Matricula

ELIMINACION 5IMULTKMEA DE AMONID Y 2-CLDROEENOT:

ANALISTS CTMETTCO

MOLSCULAR.

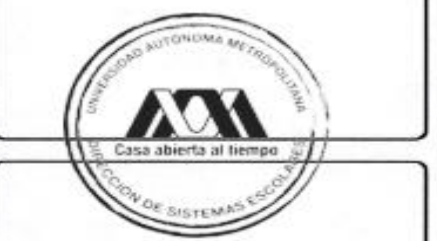

Eajo la presidencla de la primera y con carácter de

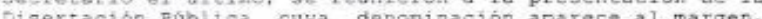

DOCTOR EN BIOTECHOLOGIA

DE: MIGUEL AHGEL MAFZIMEZ JARDTMES

$y$ de acuerdo con $=1$ artieulo 7 d fraceión IV del Reglamento Metropolitara, los miembeos del jurado resolvierons

MIGUEL ANGÉL MARTINEZ JARDINES ALUMNO

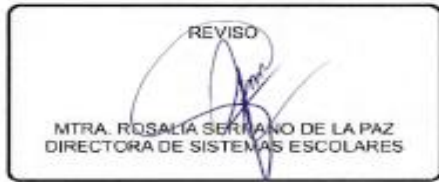

Aprobar

Acto continuo, la presidenta del jurado comunfeo al en caso

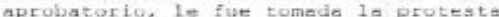

E presente documento cuenta con la firma -autbornfa, escaneada o digital, según corresponda- del funcionario universitario competente, que certifica que las firmas que aparecen en esta acta - Temporal, digital o dictamen- son auténticas y las mismas que usan los c.c. profesores mencionados en ella 